

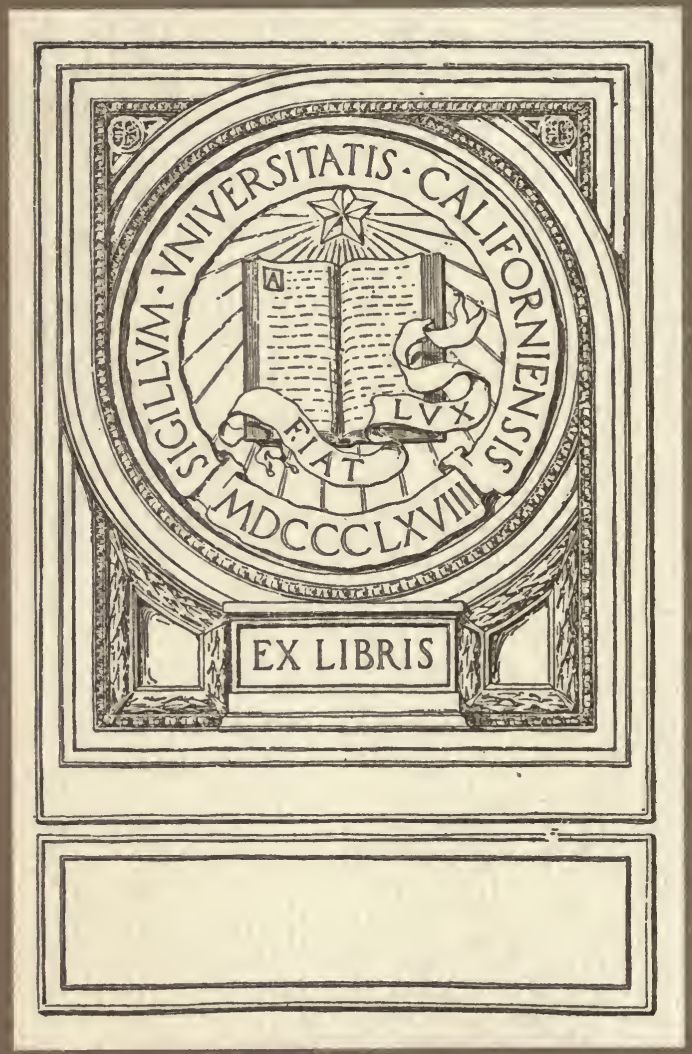



4

$1=$

1
$=1$
$=5=$
$=5$

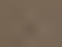

ifitis

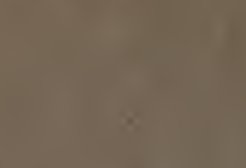

(1)

1. 1

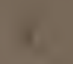

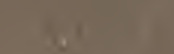

11

1.

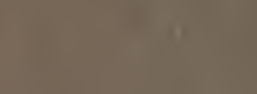

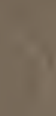
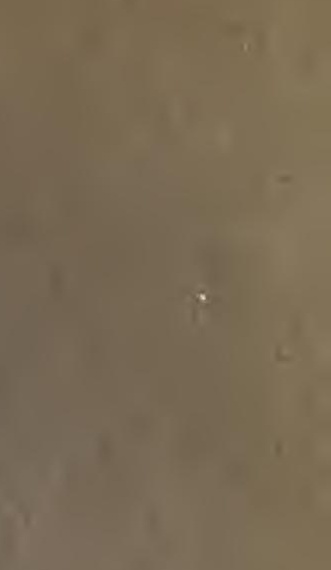

(1)

$*$

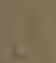
(1)

$-$ 1

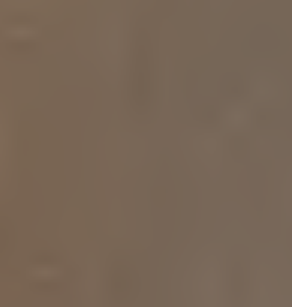

wa

atin
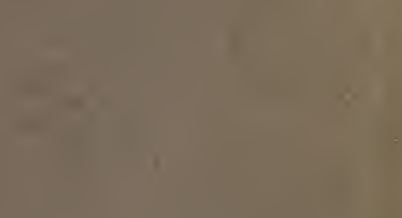

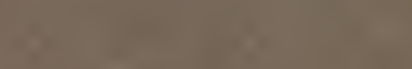

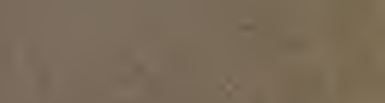

$+2$
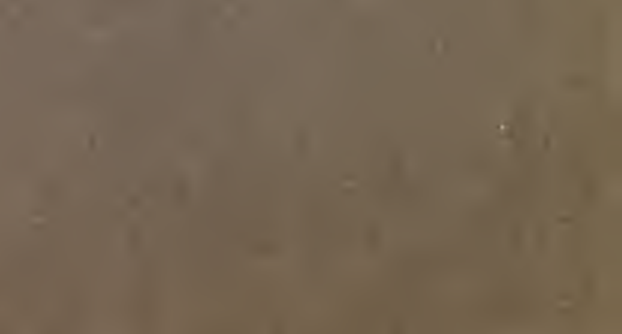



\section{THE WORLD MACHINE}

THE FIRST PHASE

THE COSMIC MECHANISM 
IN PREPARATION

THE MECHANISM OF LIFE

THE SOCIAL MECHANISM 


\title{
THE
}

\section{${ }^{\circ}$ WORLD MACHINE}

THE FIRST PHASE

\section{THE COSMIC MECHANISM}

\author{
BY \\ CARL S N P ER
}

"Vicisti, Galileo!"

\section{SECOND IMPRESSION}

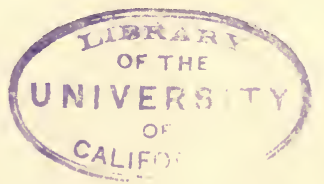

LONGMANS, GREEN, AND CO. 39 PATERNOSTER ROW, LONDON

NEW YORK, BOMBAY, AND CALCUTTA

$$
1907
$$


GEREKAL

179769 
TO

THE ALL BUT FORGOTTEN MEMORY

OF

\section{DEMOCRITUS OF ABDERA}

(ca. $460-360$ B.c. $)$.:

Justly esteemed by Bacon as the weightiest of the ancients ;

Forerunner by a century of Aristotle and Euclid;

Geometer and traveller, physiologist and polyhistor, path-hewer and sage.

He wrote illuminatively upon almost every branch of natural knowledge, in an Attic praised by Cicero as rivalling Plato's ;

Founder of the Atomic Theory, and first of whom we know, historically to conceive this world and all it contains as a mechanism.

To his ideas, 2000 years of invention, discovery, and research have added much but changed little. 

WHEN now I had for a long time reflected upon the uncertainty that pervaded all the mathematical results then existing as to the motions of the planets, it began to be repellent to me that the philosophers who would investigate with such extraordinary care the most insignificant details of the course of the heavenly bodies, should yet find no certain ground for the movement of the World Machine.

Coppernicus, De Revolutionibus: Introd. (1543). 
Since Coppernicus, Man seems as if thrown upon an inclined plane, down which he is rolling, rolling, faster and ever faster-away from his central place in creation-Whither? Into Nothingness? Into a deep-penetrating sense of nothingness?

FRIEDRICH NIETZSCHE, Zur Genealogie der Moral. 


\title{
CONTENTS
}

\author{
CHAPTER I
}

\section{IMAGO MUNDI}

The world-old effort of the race to construct a world image, a picture of the universe-Its history-It is scattered through a variety of works, most of which had appeared before the idea of evolution had taken hold-The permanence of our presentday conceptions .

\section{CHAPTER II \\ THE OVERCOMING OF APPEARANCES}

The whole intellectual and scientific advance has been characterised by the overturning of primitive impressions and beliefs-A survey of the wondrous change in our ideas which this process has wrought-The implication $\quad . \quad$. $\quad$.

\section{CHAPTER III}

\section{MICRO-MAN : THE BACILLUS ON THE WHEEL}

Endeavouring to portray the extraordinary difficulties with which man has had to contend in his struggle for knowledge-His helplessness and his ignorance-His littleness compared with the cosmos he has learned to know . . . .

\section{CHAPTER IV}

\section{THE BEGINNINGS OF CERTITUDE}

Primitive man and his world-His earliest ideas of fixity and law must have come from the development of mathematics and its applications-How he first learned "to count, to measure, to time, and to weigh" . . . . . . 


\section{CHAPTER V}

BION AND THE DOCTRINE OF A ROUND EARTH

The earliest recorded geometrical demonstration of the earth's shape PAGE

- How he proved it-The mechanism of night and day . $6 r$

\section{CHAPTER VI}

\section{ERATOSTHENES AND THE EARLIEST MEASURES OF THE EARTH}

The earliest accurate measure of the circumference of the earth in Alexandria, B.c. 275-The simplicity of his method-Subsequent confirmation

\section{CHAPTER VII}

\section{ARISTARCHUS AND THE DISTANCE AND GRANDEUR OF THE SUN}

The simple method by which he calculated that the sun was 300 times the volume of the earth-Other calculations of the ancients-The littleness of the earth was early recognised .

\section{CHAPTER VIII}

THE TURNING OF THE EARTH : THE FIXITY OF THE SKY

The teachings of Pythagoras, Philolaus, and others, as to the motion of the earth on its axis-Their mode of proof .

\section{CHAPTER IX}

THE FLYING EARTH : THE FIXITY OF THE SUN

The Coppernican system 2000 years before Coppernicus-It is in reality the system of Aristarchus of Alexandria-How he reached it-Why it failed of acceptance 


\section{CONTENTS}

\section{CHAPTER $\mathrm{X}$}

\section{ARCHIMEDES AND THE FIRST IDEAS OF GFAVITATION}

The ancients just failed of attaining to Newton's discovery-The PAGE conditions which hindered them

\section{CHAPTER XI}

DEMOCRITUS AND THE CONCEPT OF AN ATOMIC UNIVERSE

His mode of reasoning-The grandeur of his conceptions-In their larger outlines they have been but little modified since . . I29

\section{CHAPTER XII}

THE LEGACY OF THE GREEKS: THE REBIRTH OF TIME

The ideas of Lucretius, Cicero, Cleomedes-It was all a heritage from Greek science-The utter intellectual aridity of Roman culture-The submergence of Hellenic civilisation-Greek traditions kept alive by the Arabs-Their original contributions were slight-The cause of the Renaissance-The discovery of America

\section{CHAPTER XIII}

\section{COPPERNICUS; THE TRUE SYSTEM OF THE WORLD}

His work was thoroughly in the modern spirit; it was inspired undoubtedly by the discovery of America-What there was in it that was new-Its confirmation due to chance . . I6I

\section{CHAPTER XIV}

BRUNO AND THE RECEPTION OF THE COPPERNICAN IDEAS

Bruno was the first to spread the Coppernican doctrine over Europe - His grandiose extensions of the doctrine-His tragic death 


\section{CHAPTER XV}

KEPLER : PIONEER OF THE MODERN IDEAS OF NATURAL LAW

PAGE

He was the first to undertake to reduce natural phenomena to mathematical formulæ- $-\mathrm{He}$ was the forerunner of Newton in the ideas of gravitation

\section{CHAPTER XVI \\ GALILEO AND THE OPTIC TUBE}

$\mathrm{He}$ was the true inventor of the telescope-His discoveries as contrasted with the meagreness of his resources-His greatest work was his investigation of the laws of motion and his foundation of dynamics

\section{CHAPTER XVII}

THE ADVANCE TOWARD A RATIONAL WORLD CONCEPTION

Ideas and contributions of Bacon, Descartes, Gassendi, and Hobbes - Descartes was the first distinctly to picture the world as a mechanism

\section{CHAPTER XVIII}

THE TRUE GRANDEUR OF THE SUN

The first accurate measures of the sun's distance and size by Domenico Cassini-The amazing change which had already come over European thought.

\section{CHAPTER XIX}

THE DEVELOPMENT OF MECHANICS : THE FORERUNNERS OF NEWTON

Rise of the great mathematical school of the seventeenth century -Doctrine of inertia-The discoveries of Torricelli-Many minds on the edge of the law of gravitation 


\section{CHAPTER XX}

NEWTON AND THE MOTOR FORCE OF THE WORLD MACHINE

The precise nature of his discovery-Its history-Just what it meant

PAGE

\section{CHAPTER XXI}

HALLEY AND THE MESSENGERS OF THE GODS

The terror formerly inspired by the appearance of comets-Its powerful influence towards superstition-Computation of the first cometary orbit-The first prediction and its realisation .

\section{CHAPTER XXII}

ROEMER AND THE PROOF OF THE EARTH'S MOTION

How he came to his discovery-Its general rejection-Confirmed by Bradley's discovery of aberration

\section{CHAPTER XXIII}

LAPLACE AND THE STABILITY OF THE SOLAR SYSTEM

The work of Newton taken up by the French mathematiciansLaplace and Lagrange determine that the planets constitute a stable system

\section{CHAPTER XXIV}

FIXING THE BOUNDARIES OF OUR SOLAR WORLD

The ancient ideas of the world enlarged by the discovery of Uranus and Neptune-The triumph of the theory of gravitation through the calculations of Adams and Leverrier. 


\section{CHAPTER XXV}

\section{HERSCHEL AND THE HELTER-SKELTER FLIGHT OF THE STARS}

He demonstrates stellar motion, and with it the motion of the whole solar system-The grandeur of his ideas-The wonderful advance from the time of Galileo to the death of Herschel

\section{CHAPTER XXVI}

\section{THE MEASURE OF STELLAR SPACES}

The first successful measures of stellar parallax-The final proofIt supplies the absolute proof of the Coppernican theory-The size of the stars-The grandeur of Canopus-It may be a million times our sun . . . . . .

\section{CHAPTER XXVII}

THE SPECTROSCOPE AND THE STUFF OF COSMOS

The proof that the material of the universe is all the same-Other revelations-A second method of deriving stellar motion

\section{CHAPTER XXVIII}

\section{OUR PLACE IN SPACE : THE PLURALITY OF WORLDS}

The endeavour to fix the number of the stars-The difficultyProbability of thousands of worlds in parallel development to our own

\section{CHAPTER XXIX}

\section{THE ASTRONOMY OF THE INVISIBLE}

Discovery of dark suns-Probability that their number vastly exceeds that of luminous stars-Binary or twin suns-The spectroscope and stellar collisions 


\section{CHAPTER XXX}

\section{THE STRUCTURE OF THE UNIVERSE}

Lambert's vast reveries-The evidence for the grindstone theoryThe question of a central sun-Probability that the structure of the universe corresponds more to the modern kinetic theory of gases-Analogies . $\quad . \quad$. $\quad . \quad$.

\section{CHAPTER XXXI}

\section{THE BIRTH AND DEATH OF WORLDS}

The increasing evidence for the nebular hypothesis-Ideas of Buffon, Kant, Laplace, and their successors-Evidence from the theory of solar heat-Evidence from photographs of the nebulæ-They are sketches of worlds in the process of creation .

\section{CHAPTER XXXII}

\section{THE COSMIC EXCHANGE OF MATTER AND LIFE}

Worlds and systems are not isolated as was formerly supposed -The incessant exchange of matter and energy implies a more or less homogeneous universe-Possible means of a cosmic propagation of life-Ideas of Kelvin, Helmholtz, and Arrhenius .

\section{CHAPTER XXXIII}

\section{THE LAST RIDDIE}

The problem of gravitation and the force or forces which hold the universe together-Gravitation seems insufficient-The mystery of an apparently inexhaustible outpour of attractive energy -Speculations of Newton-Modern attempts at a solution . 


\section{CHAPTER XXXIV}

\section{THE END OF THE MACHINE}

The apparently increasing aggregation of matter-Evidence for the Spencerian formula-The existence of vast bodies like Canopus, a million times or more the bulk of our sun, seems to indicate the final congregation of the material of cosmos into a single inert body-The doctrine of energy likewise presents the simile of a clock that is running down-Résumé and conclusions-This volume to be followed by another on the mechanism of life and of human society.

BiBLIOGRAPHY .

INDEX . 
CHA PTER I IMAGO MUNDI 
Critias, long since, I know

(For Fate decreed it so),

Long since the world hath set its heart to live ;

Long since, with credulous zeal

It turns life's mighty wheel,

Still doth for labourers send

Who still their labour give,

And still expects an end.

Yet, as the wheel flies round, With no ungrateful sound

Do adverse voices fall on the world's ear.

Deafen'd by his own stir

The rugged labourer

Caught not till then a sense

So glowing and so near

Of his omnipotence.

Matthew ARNold, The World and the Quietist.

For the purged ear apprehends

Earth's import, not the eye late dazed:

The Voice said, "Call my works thy friends!

At Nature dost thou shrink amazed ?"

BRowning, Asolando. 


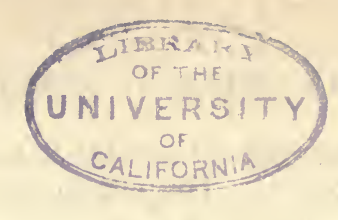

\section{THE WORLD MACHINE}

\section{CHAPTER I}

\section{(A toi)}

\section{M A O MUND I}

Some morning afield, when you seem peculiarly alive, a mind all open to the clamour of sensations, impressions, ideas, let your eye range the sky-it is taciturn; the hills-they are cryptic; the sea, if it be there-its murmuring voice is confused. $\mathrm{Re}$ flect then a little on what could be our ideas of creation, what sort of a "world image" we could form, if we had found no supplements or aids to the primitive senses with which we are born, if we had no miracle-working lenses and prisms, no angle measures, no strange magnetic needles, no Euclid, no long line before us of explorers and discoverers to write that ample page of knowledge which the pressed types make now the universal heritage of the race. As it would be to us, so it was to men and minds like yours and mine, ten, twenty thousand years ago.

In ten or twenty thousand years, we may imagine, the face of the earth has changed but little. The sky, the monotonous wash of the sea, the hills, the plains, the yellow wastes of the desert, must have looked very much to the cave-dwellers as they do to us. The human animal, too, has not varied greatly -his dress, his speech, his social relations, a little; the main activities of his daily life, his pleasures, his moral and economic problems, the struggle for existence, the ceaseless round of birth and death, remain much the same. What has so wonderfully changed in these ten or twenty thousand years is the human mind and its outlook on the world.

The transformation has been immense-how immense we have learned but recently, through the larger development of anthropology, to know. The earlier ideas of mankind were almost pure fancy. The earth rested serenely upon the back of 
a turtle, and the sun with Chesterfieldian urbanity stood still at the voice of the prophet. The imagination was unfettered and untrained. The coming of the spring, the yield of the harvest, the fate of battles, were conceived as in control of the gods. In the storm there were demons, in the fields there were fairies, in the woods the hamadryads played. There were omens and signs; the conditions of a chicken's entrails might forecast the destiny of empires. In the antique world there was a universal belief in the intervention of the preternatural in the affairs of men.

Little by little these beliefs fell away. In apparent chaos was found an order, and instead of caprice a scheme of nature in some sense understandable and in some sense predictable.

The change was slow, the path obscure and difficult. Probably the hardest thing the human race has had put before it to learn was the idea of fixity and consequence; the certitude that one event follows inevitably from another-the notion, as we say, of cause and effect; in Hume's phrase, of invariable sequence; what we have come in latter days to style the reign of law.

Even now it has penetrated but a very little way. It is the keynote of every rational work now written; it adorns the pages of amiable efforts at the conciliation of science and religion. The phrase has a sort of literary vogue. Yet, at each new extension of this idea of fixity and law into our daily lives and thoughts, the generality cries out, just as it did at the motion of the earth, at the law of gravitation, at the scheme of evolution, and all the rest.

The emotional side of the race has not changed. Law and fixity it will recognise now, after a painful effort, in the march of the heavens, in the course of the seasons, in the succession of geological epochs, of genera and species; even in a vague way, in human development. But find this same fixity and law in the rise and fall of nations, of human institutions, of human beliefs, its creeds, its political doctrines; to find this in the present primacy of America and the decadence of Spain; to view history as a tableau of destiny; our daily lives, down to the minutest detail of actions "good" or "evil," of thoughts "noble" or "vile," as the necessary and unescapable consequence of our surroundings which were created for us, our characters and bodily constitutions which were given to us: 
to view the world so-no, we are as yet very far from that ; for all practical consequences, scarce nearer than the barbarians who trembled before the thunder and offered human sacrifices to calm an infuriate Being above.

It seems a formidable theorem to grasp. It might be called the pons asinorum of intellectual development, alike of the individual and of the race.

But, if yet far from spiritual clarity, we have come some way. We no longer think the earth is flat, as was probably true, for example, of Socrates or of Solomon. We no longer believe that the sun is a god; nor do we regard it as an object two feet in width, as Epicurus taught. Nowadays frogs are not born from the mud, as Aristotle believed. The alchemist who offers us a receipt for transmuting base metal into noble gold we receive with a benevolent smile; the man with a new scheme for perpetual motion we know to be a crook or a fool; and if a priestess of spooks may still befuddle many seeming sane and clever men, at least presidents and premiers no longer consult an oracle before they go to war. How has all this come about ?

In a way we may answer: Through the growth of calculation and experiment, and the invention of mechanical devices which have almost infinitely widened, corrected, and supplemented our primitive five senses; in a larger way, we may say: From an inherent impulse to know-the effort of' "the restless cause-seeking animal " to probe the eternal riddle that surrounds and envelops him. Born into a world the mystery of whose phenomena fascinates even as it baffles, he has sought, undaunted by failure, undismayed by time, to find the elusive thread which binds events. It is the working of that instinct, not wholly absent in animals, which Renan calls the noblest craving of our nature: curiosity. It is the instinct of the child, whose incessant question is "Why ?-Why?" It is the interrogation which must have troubled the childhood of the world: "What am I ?" "Where am I ?" "Whence? and O heavens, whither?"

From the infancy of the race there have been minds which, turning aside from the ordinary pursuits and passions of men, from the prizes of trade, from the clamour of war, from the pluckings of fame, have given over their lives to the search. Argonauts in quest of the golden fleece of knowledge and of 
truth, their voyages have penetrated to the remotest corners of the earth and reached out among the stars. Magicians and sorcerers to tribal man; philosophers, the lovers of wisdom, when Hellenism rose ; discoverers and men of science-Galileos, Newtons now-civilisation is their work; the modern world is in some sense their creation. Amid the destruction and decay that attends all else from human hands, their achievements remain. The fabrics of the kingdoms melt away; where Accad and where Carthage stood, no broken pillar lifts its lonely form to mark the spot amid the desert silences. The dust and dreams of Cæsar mingle with the forgotten ashes of his slaves. But Archimedes' lever and Thales' magic stone, the theorems of Euclid and Hipparchus' starry sphere, the magnetic compass of the dynasty of Tsin, and the black powder of Berthold Schwartz and his forerunners, the pendulum of Ibn-Junis and Hans Lippershey's far-reaching, near-drawing tubes, the presses of Gutenberg and Coster, the balance and retorts of Lavoisier, James Watt's labouring giants of steam, Volta's pile, and Faraday's whirling magnets, are possessions imperishable while civilisation, their fruit, survives.

Thanks to five or ten thousand years, perhaps a still greater period, of tolerably connected and consecutive effort, there has been built up a considerable stock of knowledge which, deftly fitted together in an orderly way, has become our one sure guide in this weird journey through the wilderness. Supported by this slowly wrought fabric of fact and logical theory, it is possible now to give at least a partial answer to some of the primitive human problems. Relative to the rest of the cosmos, we know to some extent what we are, we know to some extent where we are, we have some slight idea as to whence we have come, we are beginning to perceive dimly whither we are going.

Much of this is very new. In nature there is a certain tendency to the dramatic, some little also in the progress of knowledge. In some sense, it seems as if we had attained to a sort of climax. This may be but an illusion, born of the natural inability of the mind to see beyond its own day and time. It may be that the astonishing advance of the last three hundred years will continue without check, and perhaps with accelerated pace. Yet we know that such a dramatic moment came at the opening of the seventeenth century, with the establishment of our ideas of the solar system. So it may 
be that some future historian, chronicling the stages of human development, will write :-

"It was at about the beginning of the twentieth century that man attained at last a true picture of the world-came to know, in brief, the cosmos as it is. It was at about this time that he came to perceive the eternal round of matter in the universe-the coalescence of vague and formless nebular masses into suns and satellites, their slow refrigeration into dark bodies, with the transient appearance of life, their dissipation again into primitive nebula through the incessant collisions to which they are subject.

"It was then that he came definitely to conceive the whole scheme of world formation as a mechanical process, following simple and well-understood laws; likewise that the incessant destruction of worlds is the result of a larger but still purely mechanical process.

"It was at about the same time that he came to recognise that the germs of life are being driven each whither from one planet and one world system to another, under the pressure of light-that it is in this manner that sterile planets are fertilised; that the varied life of these vast globes springs up under appropriate material conditions and in response to simple physical or chemical stimuli ; that the races of intelligent beings, with all their attendant creations of civilisation, their art, literatures, sciences, institutions, are part and parcel of this same mechanical or physical process, and like the hills or the suns, like worlds or atoms, are the fleeting and mysterious manifestations of that eternal we-know-not-what, that underlying reality which is back of all phenomena, whose nature it is not given to the conscious intelligence, part and product of it like the rest, to know.

"In larger phrase, it was at this period that the more instructed among men came definitively to regard the universe as a cyclic process-that is to say, as an unceasing machine, with no beginning and without an end.

"This result came as the culmination of a period of unparalleled intellectual activity, dating from the discovery of the New World and the appearance of a work by a Polish astronomer, wherein the true character of our immediate solar system was first adequately set forth. The accidental discovery of the telescope following shortly after placed in the hands of the 


\section{THE WORLD MACHINE}

investigator an implement of extraordinary utility. In a few years the central force of the mechanism had been revealed by Newton. An immense development in the domains of physics and chemistry found a climax in the almost magical revelations of the spectroscope, which filled as it were the last gap in the circle of cosmic knowledge. So it was that in the brief space of three or four centuries, and after an incalculable period of blind groping, man was able at last to work out a rational theory of the world, complete in all its essential details."

It may well be, let it be said again, that our present ideas of the cosmos, even in their larger outlines, are not yet final. They may be infinitely expanded with the years and the knowledge to come. Yet in many considerable items of this knowledge we may be certain that finality and completeness have been attained. Not so long as an intelligent race of beings survives its precarious existence upon this globe shall we ever cease to believe that the earth is a ball eight thousand miles in diameter. We shall never cease to believe that it turns upon its own axis, or that it booms through an orbit about the sun. It is for ever inconceivable that we should ever change our belief that the sun is a million times the bulk of the earth and four hundred times further than the moon. It is inconceivable that any subsequent knowledge will ever change our ideas of the distance of the nearest visible stars.

This much we know.

In a way this makes up, for us, three-quarters or four-fifths of the cosmic landscape. It will abide. For when we speak of this knowledge as being so very new, at the utmost three hundred years old, in some sense we err. In some sense it is as old as the race itself. Our ideas of the earth upon which we dwell, of the orb of fire whose children, literally, we arein a word, the whole world-picture, spacially at least, is the result of geometrical methods of reasoning and measurement. And geometry is old. It was old to the Greeks, who had it from the Egyptians, and we gather that the Egyptians had attained to a considerable stage of culture, intellectual and otherwise, certainly seven thousand years ago.

And again, what is all our geometry and mathematics, what are all our inductions and deductions, our inferences and demonstrations, but the codified experience, not merely of the human 
race but of all conscious intelligence. A careful observer of nature's plan has very cleverly remarked that the deer, scenting danger in the wind, and gauging the direction, turns to flee oppositely, reasons no less scientifically, builds up the same complex inference from previous experience as does the man of science. ${ }^{1}$ The fox, eluding his pursuers by doubling upon his tracks, the hound in following the scent, and when it is lost beating about the bush in the expectation that it will be caught again, follows out a train of reasoning differing neither in degree nor kind, and probably but little less conscious, than Newton inferring the law of gravitation from the falling of the apple.

With due deference to the piquant reveries of the geometers of multi-dimensional space, it is in little that we may conceive the main conclusions of Euclid vitiated through another two thousand or twenty thousand years. His axioms and his conclusions rest upon a registered racial experience-an experience that, as Spencer was perhaps the first to point out, is now a part, an anatomical part, of the physical constitution of our minds. It seems a little lost to view that our ideas of space, our conceptions of three dimensions and no more, are the physical product of a physical process that began with the appearance of life upon the earth. If the fourth dimension existed, it would to-day be as distinctly a part of our current beliefs, as distinctly a factor of our modes of daily thought, as are the primal three.

The foundations of science are firm. Its conclusions are not chimeras, unless indeed we are to accept the monstrous idea that the mind is so capable of turning round upon itself as to believe it has no individual existence. Like Kapila, in the early dawn of speculative philosophy, we may dream that " Neither I am, nor is aught mine, nor is there any I." It seems to the present writer there is no middle ground; it is an absolute nihilism that must outdo the Fichtean akosmism as does the latter a Berkeleyan idealism, or the acceptance of the conclusions of experimental science for what they seem.

For sane folk with a work to do in the world there will be little hesitation, and for them and all of those whose endeavour it is to follow in the pathways of the light, the horizons have of late been considerably enlarged. I doubt not that a future age will accord to our own something like a clear and somewhat 
detailed conception of the cosmic Reality. In any event, whether this prove true or no, this surely is certain, that our present-day ideas of creation represent the highest flight, or in varied metaphor, the loftiest monument of the human mind which we possess.

I wish to trace out the path and the method by which these ideas, these results, have been reached. Hereafter I shall present an argument, describe a doctrine, point out, as it were, the moral of the tale. But first of all there is need of a connected presentation of the facts. From age to age there have been various attempts towards such a complete world-picture. Their value naturally beccmes impaired with the advance of knowledge. Such an idea was more or less the basis of the Hebraic Pentateuch, and indeed the fundament of almost all religious systems has been an attempt towards an intelligible cosmogony. Such a work too, we may conjecture, was the Diakosmos of Democritus, written in the fourth century B.C., but now lost to us. A similar attempt is seen in Pliny's Natural History, in the first century A.D. ; in the works of Roger Bacon, the Admirable Doctor, in the thirteenth century ; in the Imago Mundi of Cardinal d'Ailly, which was the inspiration of Columbus; in the Natural History of Buffon and in many another.

In our own day the most noteworthy endeavour towards a complete physical description of cosmos was that made more than half a century ago by Humboldt. It was begun long after that splendid mind had passed the customary limits of productivity, before the doctrine of the conservation of energy had been established, and before it came to be understood that the sun is a cooling body whose light and life may one day die out-with it the light and life of the tiny bits of worlds which flutter in circles about him. In no later single work has Humboldt's vast design been realised. Such a work would be a summation, and more, of the physical sciences in their present state ; the task is probably beyond the powers of any single pen.

The same is true of the historical side. The full story of the slow growth of this body of knowledge, of theory, and of ideas, is to be found only in pages the most diverse. It has been dealt with in a variety of works, rather drearily by Whewell, rather dreamily by Apelt, with a good deal of bias by Draper, 
in graceful account by Williams, more technically by Bailly and Delambre, by Montucla and Libri ; various phases of it by countless others. The volumes of Bailly comprise an exquisitely conceived work of high philosophic interest; but it stops short even of Herschel and Laplace. There are some inspiring pages in Buckle, some instructive chapters in Lecky. But the work of Lecky begins in the Middle Ages, while the spirit of rationalism and inquiry, whose history he designed to trace, had flourished throughout Greater Greece through a longer period than in our modern world. The two volumes of Buckle are but a fragment, and in any event his work would have been a history of civilisation in England only in the older and more restricted sense of the word; it would have had nothing to do with the growth of English culture from its aboriginal elements. Draper treats of the intellectual development of Europe more as if it were the history of philosophies and religions and their political influence among one people and another.

The history of materialism-that is to say, the endeavour to describe the world in terms of matter and force-has been very brilliantly set forth by Lange, from whom Tyndall drew the inspiration for his ever memorable Belfast Address. But the pages of Lange deal less with the acquisitions of positive knowledge than with the endless "systems" or poetical concepts of the philosophers. A valuable attempt to forefigure both the solid results and the speculative inferences of the last century is now in course of publication by Merz. Interesting memoirs and sketches of the more important protagonists of the great drama have been offered by various pens-to note but a few, of Aristotle by Lewes, of Newton by Brewster and Rosenberger, of the Alexandrian school by Matter, of the later conquests of astronomy by Bertrand, Lodge, and Clerke. The development of mechanics has been admirably portrayed by Mach, among others; of physical theories by Duhem; of cosmical theory by Wolf. The original contributions of von Helmholtz, Kelvin, and others, are to be found in their own works. There is a wealth of excellent monographs, dealing, either in detail or in a clear and popular way, with especial questions, from Sir Robert Ball, Simon Newcomb, Whetham, not to speak of many other volumes informing and valuable. ${ }^{1}$

The ramifications of the inquiry have to-day become so

1 A bibliographical note will be found at the end of the volume. 
vast that there is scarce any branch of physical science into which it has not reached, and from which it has not drawn facts of greater or less import in the make-up of the composite sketch. Of any recent volume dealing at once broadly and in detail with the materials for a cosmical theory, beyond doubt the most notable is the text-book of cosmical physics from the pen of Arrhenius. It may be that in this original and stimulative work we see for the first time in its entirety the cycle of the cosmic machine.

In a larger sense we may now perceive that the development of a science of the earth and sun and stars, like human development in general, is an integral part of that vast scheme of evolution, of unfolding and becoming, which pervades the world. If life be universal, and of this we may little doubt, this growth of the race mind is a constant incident of the cosmic process. Doubtless in æons past other races upon infinitely distant planets have pursued the same difficult and devious way towards the light; doubtless in æons to come, when by the chance collision with some dark sun or huge swarm of meteorites our little earth and the system of which it is a part has been resolved again into chaos, the same process will be endlessly repeated within other systems possibly yet unborn.

But for the here and now this development has been a human process, and in some sense forms the fairest possession of stumbling, groping humanity. It has been in especial the work of a small number of singularly gifted, intensely curious minds. Each of these facts had to be thought out, intently and sometimes painfully, by some particular brain or group. "Behind the fossil shell," says Taine, "there was an animal, and behind the library document there was a man." No part of our human growth is of profounder interest or of larger import for the future.

In this it presents an inspiring contrast to the empty babble of wars and dynasties, of conquests and crusades, that passes ordinarily for history. The reading of the accustomed tales as a boyish pursuit is affected with an undivided charm. But he who in after years, when the boyish love of stirring tales of war and conquest and the pictured deeds of heroism has somewhat passed, dips again into these predilections of his youth, turns the chequered pages with other feelings. Let him lose 
himself through an idle evening in a volume wherein the whole world-tale is spread; his reverie, when the attention flags and the book is laid down, is one of mingled sadness and disgust; of revolt at the spectacle of carnage and rapacity; whole armies of men flung into a field to butcher each other for an envied province or an imagined slight; arson and thievery, pillage and atrocious crimes applauded under the sounding name of conquest; great cities sacked, the populations sold in degrading slavery, the women to shameful lives; until a scant century ago, the lower classes lost in barbarism and ignorance, a prey to the wildest superstitions; the upper class, a privileged few, despising work, despoiling the poor, licensed to pleasure, and often sunk in the grossest bestiality; human beings tossed to lions to glut the savage lusts of a Nero; heroes fed to slow fires for the preservation of the religion of God; low intrigues and court scandal, and women parading their harlotry, because they are the prostitutes of an individual called king ; nations and peoples rising to the splendour of an Athens and then swept away; mouldering stones where temples and palaces reared their graceful forms; world capitals the haunts of jackals and the lizard blinking in the sun; grandeur come to dust, and enterprises of great pith and moment all turned awry.

A story of disillusionment, a theatre of riot and ruin; a retrospect of what we commonly accept for history brings a weird and depressing feeling of its emptiness, its little importance, its pointlessness, its unworth. It summons the oppressed spirit of the melancholy Dane when he reflected on how

"Imperious Cæsar, dead and turned to clay, Might stop a hole to keep the wind away."

Set over against this tale full of sound and fury is the steady advance of civilisation, often slow, often halted, but ever renewed; the progress of invention, the amelioration of savage and brutal customs, the abolition of slavery, the wide diffusion of material comforts, of justice and of peace-in larger phrase, the broadening of the human mind, the heightening of the human consciousness. Instead of the mood of Volney's Ruins, we have that of Macaulay's pæan upon the Baconian philosophy; instead of disheartenment, a buoyant and invigorating sense of things done, of progress and of attainment. 
Look round upon the modern world, with its wealth, its broadened humanism, its beautiful cities, the ease of displacement, its universal culture, its patronage of science, the arts, the ennoblement of labour, and consider, then, that a few centuries ago our immediate forbears, the inhabitants of Great Britain and of the German forests, were painted and tattooed savages, who dwelt in huts of wattle and lived largely by the chase. The Britons who met the invasion of Roman arms dyed their bodies with blue woad; the Scots who resisted Agricola "fought naked and with short spears." Consider that so late as the Norman Conquest, in the eleventh century, the selling of men and women into slavery was a general custom in all parts of England. "You might have seen with sorrow long files of young people of both sexes and of the greatest beauty, bound with ropes and daily exposed for sale." So runs the word of a contemporary chronicler $;^{1}$ and these were not captives of another race, not blacks nor prisoners of war, but " their nearest relatives and even their own children."

Consider, again, that not its Parthenon, its Phidias, its Pericles, its serene and beautiful religion, could save the Athenian civilisation from decay, which came doubtless through the ravages of disease, the exhaustion of the soil, and ineffective resistance to the inroads of the barbarian. Consider that the dominion of the Romans, and again of the Arabians, each insuring over wide areas the peaceful and pleasurable pursuit of life, were to be almost utterly swept away; and reflect that our modern civilisation is secure. It fears no barbarian hordes; it may fight disease. The plague will never again sweep away half the population of London. No fanatical sect will ever burn the library of the British Museum. The hundred universities of Europe and America, after a lapse of six or eight centuries, will not, we may believe, be the haunts of bats and owls as a hundred universities of the Saracens became.

For all practical affairs, the theological, the ecclesiastical, the persecuting spirit, is all but dead; it will pass, and it will never return. In the political world there is a new order, an industrial order, and in the intellectual world there is a new method, the method of science. It is unbelievable that the mind of man will ever again spend itself for centuries over the arid and senseless disputes of scholasticism. It will not again

1 Life of Bishop Wolstan, quoted by Taine, History of English Literature. 
gravely debate the number of the band of angels able to maintain its balance upon the needle's point. It will find scant leisure, we may imagine, for that barren and fruitless philosophy which in all ages has sought to penetrate the mystery of things by fixing its intent gaze, as it were, upon the navel of the mind.

In the experimental investigation of the scheme of nature, the mind of man has a work to do ; but with the outer mystery it has nothing to do. We may conceive that in the times to come it will wholly give over the search for final causes or first causes, will recognise its vanity and its absurdity. What we call philosophy will be transformed or forgotten. After three or four thousand years man is no forwarder in his search for the meaning of things than when he began. Save in its content of positive knowledge, it is not clear that the philosophy of Spencer represents any considerable advance upon that of Democritus, who antedates him by twenty-three centuries. Alike they recognised the impercipience of the unknowable, which apparently the most of minds that betake themselves to metaphysics never can. The philosophers are like imprisoned birds within a glass-house, beating their ineffectual wings against the panes, for ever drawn on by the illusion of apparent freedom and the seemingly illimitable expanse of attainable knowledge. For that matter the whole of the race is a good deal the same.

But it is clear enough now that in some ways we shall never be any further advanced than we are. The simplest physical problem followed far enough, and usually it needs but a brief pursuit, lands the mind in the bogs of metaphysic. The ancient paradox as to the impossibility of contact between any two material bodies is but an instance among a multitude.

It is with the same sense of impotence that we recoil from an endeavour to read any purpose or plan into the scheme of nature. The thoughts of men widen with the suns; but " the increasing purpose" tends rather to disappear. The expansion of knowledge within the last few hundred years has been immense. Yet so far from bringing a real illumination of the larger problems of existence the mystery has been immeasurably deepened.

Not upon Pisgah's heights nor in Patmian visions, nor among the fisher-folk of Galilee, we may imagine, has the riddle of the world been most deeply felt, but rather by Weimar's high- 
ways or in the garden at Down. When with open mind we regard the cosmos, alike the infinitely little and the infinitely vast, there comes inevitably a sense of bewilderment and a perplexity that seems hopeless. The universe seems in travail of some vast work whose purport or moral or object utterly escapes us. It is in vain that we seek for evidence of any purpose when we survey the heavens and contemplate the probability that therein is an endless welter of dead suns, perhaps hundreds or thousands of millions of them, incapable of bearing life, and so far as we may perceive, mindless and dumb. Their life is spent. Their sole use, so far as we may surmise, is simply to pursue an empty track through the wilds of space until, in a colossal catastrophe, they are dissipated again into the formless nebula from which they sprang, to become the spawn of newer worlds.

It is in vain that we find any evidence of purpose or design in the appearance of the vast and uncouth lizards of the reptilian epoch-the gigantic brontosaurs that paddled about in the marshes, the fantastic pterodactyls who spread their darkening wings upon the heavy and mephitic air of that ancient time. Difficultly do we find a purpose in the tactics of a huge shoal of salmon entering a narrow pocket to destroy itself by the inrush of its own numbers. We fail to see the import or consequence that lies in the prodigious effort of the toiling millions of worker-ants that rear a million ant-hills, or of the myriads of coral polyps that weave the graceful atolls of the sea.

It is equally in vain that we contemplate the scum upon a duck-pond. This scum is the product of life, is teeming with life. Yet the highest intelligence fails to discover for it the slightest utility; and the instance is but one among thousands. It is with a perplexity bordering upon revolt that we consider the myriads of insects and of bacterial swarms which plague our human kind, breeding suffering and disease, and serving, so far as we may see, only to thwart the development of individuals and hence of the race. If mere bulk or numbers were a measure of importance, in totality of bulk and numbers they must vastly outclass all the higher forms of life.

We cannot recognise infinite goodness or intelligence in the avalanche, the cyclone, the lightning's bolt, the eruptions of Mont Pelée, the earthquake of Lisbon, the burning drouths 
of India, the famines of Ireland, the tidal-wave that flings up fifty thousand folk like so many drowned rats upon the coasts of Japan. We do not see the purport of an arrangement which covers the fertile lands of Europe and America with a sheet of ice once in a hundred thousand years or so, blotting out all life or banning it for an age.

Not less vain is our endeavour to find in the cosmic order those qualities which we regard as the highest and noblest among men. Nature is not "wise," it is not "loving," it is not "economical," it is not "moral." It is flaunting in its unchastity, shameless in its impudicity; its prodigality is not so much reckless as it is riotous. Its cruelty is savage, and

"Red in tooth and claw,

With ravine shrieks against his creed."

Plundering and murdering at every step, it knows no justice. Fecund as an ale-wife, it abandons its children to every danger and to every ill, careless alike of those who survive or fall. Highly ingenious in some ways, its constructive intelligence is infinitely surpassed by its human progeny. King Alphonso of Castile was not the first to suggest that he would find no difficulty in devising a more perfect world than that in which he found himself. In the larger scheme as in the least, nature seems but a

"Blind Cyclops, hurling stones of destiny And not in fury."

The observation is banal; in the pages of Stuart Mill and Spencer, of Renan, of Huxley, of Tennyson and Leconte de Lisle, of Mathilde Blind and Emily Pfeiffer, and many another, it has found ample expression. After them we may hope to have done with the frivolous and puerile phrases in which the attributes of creation were wont to be dressed.

A religion of nature is a chimera, an antithesis of terms. The aims of Nature seem as various as its phenomena, and in the future the hallucinated mind which professes to surprise its secret will be regarded as the proper subject of the alienist.

But if we may not explain, we may at least, in Schopenhauerian phrase, describe. No untoward visit of some vagrant sun to our system interrupting, we shall in time complete the description of cosmos and of its contents; but the "why" of 
things will remain as obscure as now. So far as we can perceive, the evolution of worlds, of life and of societies, of art and the sciences, is a pervasive phenomenon of the universe, ceaselessly interrupted, incessantly destroyed, ceaselessly begun again, like the spider with its web, the beaver with its dam, the bee with its comb, man with his works. A little while ago it seemed as if we might perceive the obscure workings of a Constructive Impulse in the scheme of the world. Its limitations eluding us, it seemed to promise much. But unless our present conceptions are radically changed, the idea of unending growth and expansion is an illusion, as if in entering a car of some gigantic Ferris wheel, and slowly lifted from the earth, we should believe that we should go on rising to the utmost reaches of the sky. The complement of evolution is devolution, and in the unfolding of worlds from a primal nebula, their slow decay and final resolution into nebula again, we can at present perceive but the ceaseless turning of a mighty wheel.

From this primal nebula, this diffused chaos, this formless fire-mist, this aimless welter of the atoms, to the green and peaceful plains, where under a smiling sky the work of man is done, is a far cry. Not stranger nor more weird has been the intellectual journey of the race from its rude fancies, its fantastic imaginings, to its present godlike outlook on the universe. We may regard the one, like the other, as a process. Examined a little nearer, in what does this process consist? 


\section{CHAPTER II}

\section{THE OVERCOMING OF APPEARANCES}


The lords of life, the lords of life, -

I saw them pass,

In their own guise,

Like and Unlike,

Portly and Grim,

Use and Surprise,

Surface and Dream,

Succession swift, and spectral Wrong.

Temperament without a tongue,

And the inventor of the game

Omnipresent without name :-

Some to see, some to be guessed,

They marched from east to west :

Little man, least of all,

Among the legs of his guardians tall,

Walked about with puzzled look:

Him by the hand dear nature took ;

Dearest nature, strong and kind,

Whispered, " Darling, never mind!

To-morrow they will wear another face, The founder thou I these are thy race !"

EMERSON. 


\section{CHAPTER II}

\section{THE OVERCOMING OF APPEARANCES}

IT was by an extraordinary mental effort that man came to know anything of the world wherein he lives. It was in the main a disillusionment, a struggle against and an overcoming of primitive impressions-that is to say, of appearances. There was, there is, little enough in his surroundings, in his daily life and experiences, to suggest to primitive man that the firm earth he treads is like the periphery of a wheel that is whirling him and all the things he looks upon-his habitations and his temples, the mountains and the seas-round and round with the velocity of a rifle bullet. No distance-posts flash by to tell him, or us, that between two beats of his pulse he has been shot through a space of I500 feet, a quarter of a mile. The farthest stretch of level plain or even the boundless expanse of the ocean but dimly suggest, if at all, that his earth is round like a melon or a pumpkin. As we journey from Liverpool to New York we have no sense to make us realise that the engines below are driving 30,000 tons over a mountain 350 miles high, but with no more effort than as though the Atlantic were as level as a floor.

If the earth be curved like a ball, are there, then, folk like us on the other side of it, straight beneath us, at the antipodes as we say - their feet to our feet, and hanging head downward ? And if there are, what is there to hinder them from dropping headlong into space? So men reasoned once. And if this ball is revolving like the fly-wheel of an engine, at an incredible speed of rooo miles an hour, I7 miles a minute, for any given point near the equator, how can anything be held to its surface; why do not we and the oxen of the field, and all other things, go flying off at a tangent? How does the atmosphere stay on ; why are the clouds not brushed away?

Again, as the thoughtful shepherds of Minor Asia, guarding their flocks, looked up into the sky, what could tell them that 
the glowing ball which made their day was three-score million times the bulk of the silver disk which companioned their nights, and four hundred times as far away? To the eye their diameters are equal; looked at between thumb and forefinger, held at arm's length, or through a pair of sights set on a board, the angle they subtend is the same. There is nothing to make one think they are so very large, save perchance that they at times seem a good way back of the highest clouds, which in turn may lie far back of towering mountain-tops. Objects at that distance are often larger than they seem; so Anaxagoras, friend of Pericles, Socrates, Euripides, conjectured that the sun is a body of red-hot iron, and may be as large as the whole of the Peloponnesus - that is, half as large as Greece.

But it is a puzzle-to these ancient eyes-how these bodies get back again, after setting in the west, to rise once more with the dawn. They must have got round or under in some way; it is very hard to say. Sometimes they are quite blotted out; probably the gods are angry or evil spirits are at work, so the multitude will go out from the city and drum valiantly and shout, and drive the spirits away. But when the sun or moon appear again are they the same, or have the gods made new ones ? Even so wise a man as Lucretius, living in the same city beside Cæsar and Cicero, is indifferent to which you answer make, if only you leave out the gods and put in their stead Nature, the fecund mother of all, who should be quite equal to the facture of a new luminary once in a while.

By-and-by, when the shadow cast on the moon by the earth, the slow sinking of the ships below the horizon, the changing elevation of the pole-star as the traveller goes northward or southward, and the arching vault of the heavens have suggested the sphericity of the earth, it seems plausible to suppose that the sun revolves about it, and thus makes night and day.

Aristarchus of Alexandria, pondering and measuring, concludes, eighteen centuries in advance of Coppernicus, that the opposite is true, that the earth sweeps round the sun. But who will believe it, who can imagine it now ? This solid earth, so vast that its curve cannot be measured by the eye, swung free in space, resting on nothing, and booming through the void at the speed of a million and a half miles a day, who can think it? That is, 66,000 miles an hour, or from Land's End to the Orkneys while the second hand of a watch turns once. A 
modern I6-inch gun hurls a projectile weighing a ton, with a muzzle velocity of 2000 feet per second; yet so swift is its flight that in its transit even this great mass is invisible to an observer standing by. The earth, could it be weighed at its own surface, would equal somewhat more than six thousand million billions $(6,000,000,000,000,000,000,000)$ of these ton projectiles, and it flashes through space at the rate of roo,00o feet, or I9 miles per second. An express train at 70 miles an hour does about roo feet per second.

If there were but stations along this circular railway round the sun-such, say, as the ancients imagined in the twelve signs of the zodiac-and we could take our stand upon a platform, we should see this solitary occupant of the track pass in 40 seconds; yet its greatest diameter would represent a train 8000 miles long. In a day its huge bulk would have dwindled to the size of the moon; in a week it would have disappeared among the trackless stars. And it would not return for a year.

This strange, lone voyager of space, this planet, whirling so violently upon its own axis and plunging through the sky like a meteor, nothing above it, nothing below, runs its round of the sun all as if it were fixed to a track, or were skimming the surface of a sea. Yet as there is no track, no surface whereon to run, a looker-on might think of the earth as fixed to the end of an invisible arm 93,000,000 miles long, or held in leash like a stone in a sling.

Some such fanciful mechanism is just what has been imagined and named Gravitation. Once it signified nothing more than the primitive impression of heaviness; it was thought of, in Aristotle's time, as something real, just as was its opposite, Levitation, the tendency to lightness. It is not difficult to measure its effect, the force of its pull, and we know, since old Sir Isaac's day, the simple formula which describes its action. But when we try to conceive how across a hundred million miles of seeming empty space it can hold a colossal body like the earth to a rigid path, throughout long ranges of cosmic time, we are baffled still. It is a world riddle.

Seventy times round the track and the little whirl of life is done. Of the first five one can remember nothing at all ; the next fifteen or twenty are passed in getting accustomed to one's 
surroundings; in the last ten the burden of the journey has begun to be felt. Of the forty remaining, one-third a man passes in an unconscious state he calls sleep. Finding his food and eating it, begetting, reproducing his kind, and hurrying about here and there like the restless ant, consumes the greater part of what is left. Scant wonder if, thus hobbled by the brevity of life, he should advance so little from one generation to the next, or that he should dream of another existence unruffled by the urgency of time.

Seventy times round the track, but the great world runs on -how long? Has it always been whirling along that selfsame groove at the selfsame speed? When did it begin-will it ever end? Bodies so large, traversing intervals of space so fathomless, require obviously for their formation, for their disintegration, corresponding intervals of time, not thousands or millions but rather thousands of millions of years. The flywheel of a very ordinary engine will do a thousand revolutions per minute; it makes its seventy turns in a few seconds, and a good engine may last for years. Whirling around a million or two million times a day, it is easy to see that the number of revolutions it will accomplish in its lifetime mounts into the billions.

There seems no reason to believe that our heliocentric engine is less stable. It has no valves to clog, no journals to wear; apparently space offers no resistance to its flight. It is noiseless, it seems to need no oiling, no care-no engineer. When was it built?

So long as the world seemed not so very big, our earth its centre and its grandest thing the sun, the stars revolving round it in some sort of way; the simplest explanation of how they all came to be was that they were conjured into existence from the void by an arch-magician, as a spectacle for the gods. And unbiassed by disturbing considerations, it was not deemed presumptuous to assign a date when the performance began. Thus Archbishop Usher; the good man lived in the brilliant days of Shakespeare and Bacon; he was fabulously learned in an age of scholars, and spent from the twentieth to the thirty-eighth year of his life reading the entire literature of ecclesiastical antiquity. Somewhat to the neglect of his slightly elder contemporaries, Galileo and Kepler, he succeeded in fixing the creation of the world in the first week of January, 4004 B.C. 
The date may still be found on the margins of practically every Bible printed in the English language.

The recent excavations of the tombs of the Nile kings, and of the great cities of the Syrian plains, reveal a people at a high stage of civilisation five and perhaps seven or ten thousand years before our era. Their temples, their palaces, their libraries, their sculpture, their jewellery, their sanitary and plumbing arrangements even, tell that even this remote day must have been but as yesterday compared with the distant time when troglodyte man left his bones, his weapons and instruments of flint, by the side of the remains of animals now in part extinct, in the caves wherein he dwelt.

And this Stone Age is but at the surface of the series of superimposed strata of stone which must have required for their deposition, and alternate elevation and depression above and below the level of the sea, uncounted æons.

Yet again, it was hard to imagine that before the age of man strange races of animals prowled the earth-vast and uncouth saurians and pterodactyls, which would dwarf even the mammoth; how much harder to think that more than half of Europe and North America were once covered with ice; to believe that Broadway and the crowded Strand, Himalayan and Cordilleran summits even, were once the floor of the ocean. It was long before there were any so to believe. Yet such is the unescapable testimony of the rocks, whose weird and ancient rime has never been more felicitously retold than in the haunting lines of Tennyson :-

"There rolls the deep where grew the tree.

$\mathrm{O}$ earth, what changes thou hast seen!

There where the long street roars has been

The stillness of the central sea.

The hills are shadows and they flow

From form to form, and nothing stands ;

They melt like mists, the solid lands,

Like clouds they shape themselves and go."

Projected into this "dark Backward and abysm of time," the mind soars in a chilling and lonesome grandeur, and fain would go back to the lost gardens of Elysium, amid whose enchanted spaces its childhood was spent. But the gates of toyland once passed are closed for ever; and in the intellectual 
life of the world it is the same. What the revelations of the telescope had implied, the advance of geognosy, of earth-knowledge, has confirmed; and to the conception of a universe immeasurably vast, we add at length that of an earth immeasurably old.

But if the calculations of the good Archbishop slightly erred, still did it never have a beginning at all ? By an instinct born of familiar associations the mind refuses to accept such a conclusion, and stirred by its restless fancy, will voyage where charts fail. It was from inquiry in another field that a clue came.

If the earth is a ball and we live at the surface, what is inside the drum? Is it hollow, and at the poles are there openings to an interior world-a fascinating world, perhaps, of gnomes and genii and dragons and elves and all the wonderful menagerie that was banished from the world of men? The fire-spouting cones of the volcanoes scattered here and there over the earth suggest that it might be rather too warm. The eruptions of Ætna and Vesuvius, Krakatoa and Mont Pelée, seem to indicate that the inside is filled with molten rock. This appears to be confirmed when men mine into the ground and find the temperature increases as they go deeper and deeper.

We live, then, on a crust that spans a glowing lake of fire, and on a crust that is very thin. If we took a sheet of paper and pasted it over the surface of a good-sized melon, we should have the relative proportions.

All this is strangely different from the early ideas of the race. This crust must have been formed by the cooling of this fiery mass. In cooling the mass would shrink. The earth may have once been a far larger body than now. Reasoning from the known effects of radiation and of attraction, we prolong the vision backward and see in a diffused fire-mist the beginning of the world! A time was, perhaps, when the earth was part of the sun, when the sun indeed stretched out beyond the present confines of the solar system. Through the ages it has been shrinking, throwing off planets by times, and by its shrinkage flooding the world with warmth and light. So in its turn the earth parted with the moon, and in that cold and lifeless orb we have a presentment of what must one day be the fate of our globe as well. 
Such is the grandiose perspective spread before our view. We may not greatly wonder that when it came to the mind of him who imagined it first, Immanuel Kant, he should exclaim, in an intoxication of the imagination such as possessed Archimedes of old :-

"Give me matter and I will build the world!"

If from out this fire-mist the earth, the moon, the sun have come, were these alone? Holds space no others? And if from chaos other worlds were born, where are they now ?

When on the plains of Mesopotamia, or by the turbid current of the Nile, priests and herdsmen lifted their eyes to the firmament of stars, circling through the serene sky above them, and, as it were, striking the hours of the night, there was little enough to suggest to them that amid these points of light were other planets like unto our own. There is little enough now. But watching their course night after night as they wheel the heavens, the shepherds noted that there were some which failed to keep an even course. From night to night their pathway in the sky changed subtly. There seemed a place where these errant stars would pause and go back again. So they were named planets - the wanderers. Now and then the moon hid them from view. Now and then a dark spot was seen to march across the face of the sun.

After a thousand years the course of these wanderers had been mapped. After a thousand vague conjectures, the idea began to grow up that they moved in circles, one behind the other, some between the moon and sun and some beyond. There came at last great organising minds like Aristarchus and Coppernicus to set these puzzling motions in order, to conceive this earth as a "wanderer" like the rest, and to picture them all as whirling round the sun.

If from somewhere in the zenith of the system, and dowered with telescopic eyes, we might watch them, what a curious picture they would present!- nine spheres, if we count the four hundred asteroids of "the shattered planet" as one, racing round and round ever so like the petites cheveaux of the spas and fairs with which Continental travellers are so familiar. Indeed we might conceive the huge Sirian of Voltaire's fanciful tale, off on a vacation from his native dog-star, mistaking these 
flashing, whirling planets for just such a machine, and, ignorant of Kepler's laws, backing little Mars for a winner against big Jupiter or the earth ! Surely a marvellous flight of the imagination, thus to reduce the whole solar system to the workings of a wheel, not of chance but of fate; and yet that is what the mighty intellect of Archimedes achieved. His planetarium, so admiringly and accurately described by Cicero, ${ }^{1}$ was mistaken only in placing the earth at the centre. Its construction was the feat of an intellectual giant whose mental level has been attained but rarely in the history of the race.

Thirty times distant from the sun as the earth, and so faint among the crowd of stars that its character as a "wanderer" was not detected until sixty years ago, the planet Neptune lies at the outer rim of this solar wheel. The expanse of its orbit is unthinkably vast; the earth, 90 millions of miles from the sun; Neptune thirty times 90 millions. Already the earth has been lost in immensity; viewed from the sun it would appear scarcely larger than does Mercury to us at its brightest, and far surpassed by Venus or Mars; viewed from Neptune it would be invisible to the naked eye, as Neptune is to us.

But the human mind, having reached such heights and depths, will not leave off. What lies beyond? In what unimaginable abyss of space is fixed the crystal sphere of the stars? The objection urged by Tycho against the ideas of Coppernicus was that if the earth spins about the sun, the fixed stars would appear to occupy a different position according as they were viewed from one side of the sun or the other-say, at the spring and autumn equinoctials. There would be a certain displacement; they would have an appreciable "parallax." And Tycho, observing genius as he was, could find none.

But what Tycho, and Galileo as well, thus vainly sought has been found. Marvellous instruments, devised since their day, have detected the parallax of a considerable number of stars, and we know now that the distance of the farthest planet is to that of the nearest star as an hour to a year. The flight of light from the sun to Neptune, speeding at I86 thousands of miles per second, requires four hours, to the earth eight minutes, to the nearest star four and a half years. Try to comprehend it who can! The moon is distant from us by ten circumferences 
of the earth; the sun is four hundred times the distance of the moon; Neptune, thirty times the distance of the sun; the nearest of the stars, nine thousand times the distance of Neptune.

Viewed from the rim of the solar machine the sun has shrunk to a body no larger than Venus at its brightest. And outside this outer planet is a sphere 800,000 million times more vast than our whole solar system, within whose black and desert emptiness there swims no star, no sun, to light the soul upon its journey to a fairer world.

Still undaunted, the mind of man, rising to horizons yet more vast, questions still: What lies beyond?

We may, if we like, picture the emptiness which lies outside our little solar world as a colossal hollow shell, enveloping it as one sphere may be made to fit over another. We may more than double the diameter of this shell, conceiving its outer surface at half again the distance of Alpha Centauri, and still, so far as present measures of parallax go, Alpha Centauri will be the only other occupant of the void. Light travelling at 660,000 millions of miles per hour will be ten or twelve years in crossing such a space from one boundary to the opposite. It follows, therefore, that if we could suddenly materialise this shell, so as to cut off the light of all the stars of heaven, it would be at least three years and a half before we should become aware that it had been done.

The number of the stars, we know, is as the sands upon the shores of the sea; not, there is some reason to think, infinite, but perhaps even now, in a vague way, estimable. And if in truth their number be finite and knowable, so then is the universe not boundless, but its extent and its shape may one day be known. We are here upon the edge of the future.

Some tentative calculations have already been made, exquisite in their simplicity, confounding in their results. They are as yet new ; they will doubtless be revised. Not improbably there are stars a thousand times more distant than our nearest neighbour stars; remote from us thirty thousand years of speeding light. The mind gropes in vain for units, mile-posts, to fathom such immensity of space. To vary a simile now grown a trifle antique, had these distant suns been extinguished in those remote and charming days when the moon paused in 
its peristaltic way, to sojourn in the valley of Ajalon, and the sun, not then grown to its vast proportions, and more attentive to the admonitions of the prophets, rested for a space upon Gibeon, these stars would still be shining for us in the sky. Or, in another way, though in a crash of colliding systems, some mightier Sirius might have blazed out in the heavens thirty centuries ago, its light would not yet have reached this earth to tell us of the fact.

A little dulled to wonder, the fabulous in science grow a little stale, these disclosures we read with the nonchalance that we skim the morning paper. They bring no stirring of the ancient awe. But when two centuries ago the curtain was first drawn aside, we shall not greatly wonder that the imaginative and trembling soul of a Pascal, before such a vision of the infinite, should recoil in fright.

So with the conception of a plurality of worlds. It was hard to think of, once. In the solitude of the cloister a Bruno hears the message of Coppernicus, reflects, and flinging aside his monkish robe, shouts across Europe: "The stars are suns." For his crime the blazing faggots roast his quivering flesh. To-day it is a commonplace of astronomy, and with it the belief that round these suns swing myriads of planets like our own. And if life is merely a stage of planetary evolution, then we must conceive that in the desert distant ways there are countless earths like unto our own, and undergoing the same strange, uncertain, fumbling, stumbling development of which this globe is the theatre.

Shrinking suns, dead moons, and dying worlds-is cosmos a clock that is running down? May we look forward to a day when, moons and meteors having fallen back into the planets which gave them birth, the planets in turn into the suns of which they were once a part; the suns drawn inward into a central mass, coalesced with the billions of other suns; the last star having shed its smokeless glow and gone out; the last particle of matter quivered with the last vibration of heat; the universe, a lifeless inert clod, sunk to the coldest cold of space, shall be at rest-at last? Is such the prospect ?

It may be; there is no certainty. Spacing the starry ways we find here and there a formless luminescence, faintly glowing like a wisp of cloud that sometimes floats across a summer's 
afternoon. These are the nebulæ, the fire-mists, from which new worlds are born-the spawn of cosmos! Could we stand by, and time for us stand still awhile, then here within these primal wombs we might watch the slow gestation and parturition of a race of Suns and Saturns, Neptunes, Jupiters, Mars, and earths-perchance the next cosmic generation to our own.

We reach here the astronomer's last word; the Book of Revelation, for the moment, ends. But what visions it conjures-what a distance from Chaldea we have come! Weird welter of worlds and races and terms and times, could we conceive of some vast being to whom our globe would appear but a mote floating in the air, and seen only in the pathway of a sunbeam, what a curious spectacle the universe would offer to his view! A chaotic, whirling, wildly dancing swarm of fire-flies the suns would seem, each glowing its little turn and dropping away, while another lights its lamp; swarms and swarms and never an end; no heaven above, no solid earth below, no foothold in infinitude.

So in the world of thought the soul of man. Visions of science ?-'tis a nightmare rather, like that vertigo of dreams wherein we seem falling through some vast abyss, and pale and trembling wake to find our horror but a figment of the mind. So we may wake.

Led thus by slow and stumbling steps to the summit at last, whereon he looked out, as it were, upon a universe of unceasing motion, without apparent bounds in space or time, man could but feel as we feel still, a profound and depressing sense of his littleness, his nothingness. Yet may he still reflect, with Pascal, that it is he who sees, he who is conscious of the wonder, and not the wonder itself; that the universe seems mindless, blind, and dumb; in a way this world about him, so illimitably vast, is but the creation of his own senses. If he like, he may dream with good Bishop Berkeley that it is all a dream.

Yet comforting as may be the legerdemain of an idealised idealism, there are still few among us who, whatever they may think regarding the problem of the external world, doubt that they themselves exist; and it needs no long pursuit of the will-o'-the-wisps of the Ich and non-Ich to assure oneself that in the unguarded moment we assume that we ourselves have a personality and a being, we let in the whole procession of appearances which come of the six gates of the senses. The 
nebular hypothesis, the light-bearing ether, the atomic theory, and all their like, may be but convenient "working hypotheses," but it is well to remember that, in the absence of negative proof, they stand on more or less the same footing as the hypothesis that a being you call you, O Indulgent Reader, scans these lines.

The phantoms of Idealism were born in Greece ; and though many have embraced, they have proven as barren as the vestal virgins of final causes. Stimulated by the amazing results of his endeavour to learn something of the world about him, man sometime since turned from inquiries into the nature of being to an examination of the parts of which his own being was composed.

If in his discovery of the revolutions of the earth he had bagged an engaging paradox, in his anatomical studies he captured a troop. For he was not long in perceiving that the various parts of himself bore a singular resemblance to the implements and contrivances of his workaday life. Little by little he came to see that the heart is a pump and the bloodvessels an intricate system of irrigation. The lungs are bellows, worked automatically from a centre at the base of the brain. The muscles are pulleys and the bones are cranes. The eye is a telescope, the ear an inverted megaphone. The kidneys are filters, the liver is a sugar factory, the stomach a vat for fermenting food, the thirty feet of coiled piping of the intestines the vital still where strength, warmth, courage, good feelings and bad, and all our outlook upon life are brewed.

Even the process of reproduction he came to realise was much like planting corn in the field; and if the growth of the corn was mysterious, hardly less so was the working of yeast in a lump of dough, or that a mixture of charcoal, nitre, and sulphur, properly pent up and set fire to, should throw a cannonball some miles.

Moreover, the chemical ingredients making up this strange being, capable at once of the sublimity of astronomical discoveries, and of burning old women, maidens, and men for witches or heretics-sometimes so near a god, sometimes a ravening savage-were found to be simple in the extreme. Water is the most important by nine-tenths. We know how water, skilfully mixed with a little glue or gelatine, makes a 
viscous mass much like the slime of life we call protoplasm. Add some charcoal from the hearth, some nitrogen and oxygen from the air, mix in a little sulphur, take some phosphorus for the brain, a trace of arsenic and some of the mineral salts, and the analysis, alike for a Shakespeare, a Newton, or a witchburner, is complete.

True, we may not as yet take carbon, water, ammonia, and a few salts and produce living matter; but I think the day when we shall is less distant than the end of the world.

If the telescope, reaching into the depths of stellar space, has seemed to reduce not merely man on his earth, but the whole solar realm to an atom of the cosmos, he has found in the microscope and in the test-tube of the chemist the salvation of his pride. But the revelations of the latter have not been less destructive to his primitive ways of thought.

Thus as he has found the heavens stretching away in a seeming unending welter of suns, so, floating invisible in the air about him, in the very air he breathes, he has learned to know that there are organisms so minute that, compared to them, he is a greater figure than the earth to him. They may and do infest the body in multitudinous hordes, and he be never aware of the fact. These are living beings, for they grow and reproduce as do other living things, and yet their organisation is so relatively simple that already the chemist, entrenching upon the domain of the physiologist, has caught a glimpse of their physical structure. It was, in truth, from their action upon different substances, that Pasteur, a chemist, was led to their discovery. And just as to-day the organic chemist takes apart the molecules of one kind of sugar to put them together again in another way to form forty other kinds, so the amazing achievements of Emil Fischer and his fellowworkers point to the day when they will do the same with the molecules of living matter which make up a microscopic bacterium.

Indeed, even if such a result had not been predicted by the recent attainments of biological chemistry, it would have been foreshadowed by the equally astonishing advance of histology, or micro-anatomy. It is a commonplace of these latter days that alike the oak and the turtle, man and all things living, are made up of bacteria-like units, the cells. By processes hardly 
less ingenious than those which have enabled the astronomer to divine and weigh dark suns, for ever invisible to the human eye, so the present-day anatomist, with his refined objectives and staining reagents, has penetrated the inner structure of the cell itself, watched it enveloping, digesting, and ejecting its food, joining in marriage with another, and then forming the beautiful astral figures, so suggestive of a magnetic field, which are preliminary to the birth of a new generation.

Thus pressed, on the one side by the chemist, on the other by the anatomist, we attend as it were the approaching juncture of two armies, whose coalition will mean the explanation of life in terms of valencies and atoms.

"In the beginning was chaos," the tutor of Epicurus explained. "And where did chaos come from ?" the young man asked. Following out the previsions of Democritus, advancing knowledge has seen all existing things, the living and the lifeless, the sentient and the inert, reduced to the invisible, and in the older view, indivisible atoms- "the foundation-stones of the universe." But what are the atoms? What are these seventy odd elementary substances which can no longer be resolved ? Are they the " massy, hard, impenetrable particles" that Newton fancied, " even so very hard as never to wear' or break in pieces; no ordinary power being able to divide what God made one in the first creation "?

We must wait for the answer. We seem to hover on the brink of a new revelation, the explanation of matter itself-of matter and of the other great mystery, of electricity, as well. A something smaller than the atom, the cathode "rays," the electron or "corpuscle," seems to have been found. We live in days of wonder, still.

Meanwhile, however the newest discoveries may turn, we know that in the spectra of the suns and stars the lines of many of our so-called elements do not appear. Conceivably in the fiercer heat of these blazing worlds some of the elements have been resolved; perchance, somewhere, all. They may be the result of condensation and cooling from temperatures which man has not yet been able to attain. Perchance in the primal fire-mist there was but one, the urstof, the protyl, of the cosmic mind.

We here reach bounds. Further the mind cannot go. Or 
rather, starting thus in either direction, and covering in its stupendous flight the ineluctably vast, the inconceivably small, it gains at least a common goal. Here pausing, it endeavours to bind the retrospect in a single principle, to link macrocosm and microcosm in a single enveloping conception. Rising from the analogy of the growing tree or the unfolding petals of a flower to see a kindred process in the whole spectacle of nature, it sums the course of universal development in a wordEvolution.

It is to be noted that we have here an analogy, a description, and not an explanation. It is expressly unconcerned with any thoughts of Cause. It was simply that with his ever-widening vistas of space and time man had found the more primitive simile of the potter and the clay had ceased to be adequate. Advancing knowledge had revealed a world awhirl-a whirling earth, a whirling sun, whirling planets, whirling atoms, and whirling stars. If the idea of an intervening artificer was to be retained, it would needfully have been under the altered guise of a maker and spinner of tops ; and the notion seemed a little bizarre. So from the symbol of the architect the mind of man broadened to conceive the whole of nature as an organism, subject to universal laws of growth and decay. For the old anthropomorphising theognosy it substituted a process, an unfolding, a becoming.

The idea of evolution, not less than the picturesque demons and deities of the antique world, was essentially a poetical conception-the effort of the mind toward a world-image. It seems to be a little lost to view that all world-pictures, all cosmogonies, are that, and no more than that. Herbert Spencer and Darwin, no less than the Pentateuchian theorisers and all their forerunners, were essentially poets, only dowered with a more highly developed imagination and a loftier range of thought than usually accompanies the merely rhyming brain.

And again, the idea of evolution was a stage, a step higher, in the unfolding of the world mind. Advancing knowledge is building yet a higher stage, approaching a yet wider view. It was more especially with the phenomena of life, the unfolding of new species, new races, new institutions, that the idea of evolution was concerned; and as the processes of life, growth, birth, and death are brought more and more within the domain of chemistry and physics, the evolutionary imagery must give 
way to a generalisation more definite and more precise, and less a poetical simile than a statement of fact.

With biology lifted to the rank of a physical science, and, in the phrase of Huxley, become a problem in molecular mechanics, we shall turn, I think, from the analogy of the flower and the tree to that of a world machine.

A doctrine as old as philosophy itself, refurbished by Descartes, and though he himself did not see it, inexpugnably fortified by Newton and by his discoveries, the idea of the universe as a mechanism is as yet very far from prevalence among the minds of men.

In the pages that follow I purpose to go back to the simplest beginnings of things - to the days when primitive man first learned to count, to measure, to time, and to weigh, and to mark out how his every step toward positive knowledge has been an advance toward mechanical conceptions of phenomena which must one day end in a mechanical conception of the whole. In a word, since strict logic has been of no avail to convince, I purpose to offer the induction of history, to endeavour to construct, as it were, the curve of the development of our knowledge of this world, and by the logic of its continuity, bridge certain obvious gaps which as yet remain to be filled in.

There are types of minds to which the idea of Necessity brings a vague shudder, as at the closing of iron gates. At each great step in the development of our world conceptions these emotional natures are stirred to revolt, or fright. But if the larger knowledge seems to subtract alike from the individual and the race something of their old importance, we need not forget that this knowledge is ours, and has been dug out by the race itself. Perhaps this is the true wonder. In any event, let us not lose sight of the grandeur of the achievement; for in it the intellect of man has in some sense turned round upon its antecedents and the universe of which it is corporeally so infinitely slight a part.

The theme is epic; but the bards are voiceless, the tale untold. We shall scarce lose ground if we consider for a moment what manner of being it was that could unclasp and read the book of the seven seals. 


\section{CHAPTER III}

MICRO-MAN : THE BACILLUS ON THE WHEEL 
Und schnell und unbegreiflich schnelle Dreht sich umher der Erde Pracht ; Es wechselt Paradieseshelle Mit tiefer schauervoller Nacht ;

Es schäumt das Meer in breiten Flüssen

Am tiefen Grund der Felsen auf, Und Fels und Meer wird fortgerissen In ewig schnellem Sphärenlauf.

Faust.

What peculiar privilege has this little agitation which we call thought that we must thus make it the model of the universe ?

Hume, Dialogues Concerning Natural Religion. 


\section{CHAPTER III}

\section{MICRO-MAN: THE BACILLUS ON THE WHEEL}

OUR human pride is great; and the love of vain boasting does not end. Yet in one noble regard it has ofttimes seemed to the present writer that scant justice, scant appreciation, has been done to the deeds of our human kind.

"Zwei Dingen erfüllen das Gemuth mit immer neuer und zunehmender Bewunderung," wrote the son of the saddler; and Tyndall repeats after him in a memorable address. Yet the "two things" were not the same with Tyndall as with Kant. For the prophet of the Scientific Imagination they were neither " the starry heavens " nor the "moral sense of man," rather - the littleness of man, set over against the grandeur of the cosmos he has learned to know. But to how many of us has ever come any vivid realisation of the struggle and the odds; man's extraordinary physical insignificance in the face of the world in which he lives, the seemingly insurmountable difficulties which have impeded his amazing explorations of the unimagined and unknown.

The littleness of the earth as compared with the sun is a commonplace. Consider the littleness of the human biped as compared with the globe of the earth. The diameter of the sun is but one hundred and nine times that of the earth; the diameter of the earth is not hundreds, or thousands, but millions of times the height of the tallest man.

Consider what a pigmy he is compared with the bulk and height of a soaring mountain peak, and yet that the greatest of these in no wise disturb what to an extra-mundane observer would seem the exceeding smoothness and polish of the surface of this sphere. Alike peak and sphere micro-man has learned to explore, to measure, to weigh-moon, sun, and hidden stars as well. Yet the wonder of it all seems dead. No poets sing the majesty of the mind; prattling apes chatter of "the bankruptcy of science"; we learn as children the results of 
this long and wondrous march of the intellect, with no hint of the difficulty, no inspiring presentation of the struggle, no awakening to the splendour of the conquest.

It is perhaps that we lack an adequate measure of the feat. But as the astronomer, unable like the surveyor to carry his chain to the moon, may yet calculate its distance from measures of its parallax, so perhaps by recourse to analogy, the parallax of the mind, we may find a help.

Swift, in his classical tale, imagines a race of elfish men so small that hundreds of them may climb about over his body. Let us try to conceive of a race somewhat ten thousand times smaller-that is, a race which has the same relation in stature to us as the diameter of the earth to an average man. It chances that within the last forty years we have come to know that beings of these ultra-microscopic dimensions actually exist : the minute fungi which, for good and evil, play so overshadowing a part in our daily lives-the bacteria. It is a somewhat curious fact that, with the perfection of oil-immersions, anastigmatics and their like, the eye is now able to perceive and study microbian races of just the proportion we seek. It would require about eight million men of average height, one standing on another's head, to equal a diameter of the earth. On the outermost fringe of visibility a modern microscope shows objects which stand in the same proportion to man.

It is a little difficult to form a vivid mental presentation of just what this relationship means. The naked eye is puzzled to detect points set much closer than a hundred to the inch; two or three hundred dots to the inch is for most eyes a continuous line. This is about a fine hair's-breadth. The unit of microscopic measures is the micron, marked with the Greek letter $\mu$, and these run 25,000 to the inch. The lower limits of visibility of present-day microscopes is from a quarter to a seventh of a micron. Doubtless there are living beings somewhat smaller; but a bacillus whose body is of these dimensions -that is, about the hundred thousandth part of an inch-is the smallest thing we know of alive, and it is the smallest thing that the human eye has ever seen. An average human being is very closely eight million times this in height.

Bacilli are, as we are learning slowly to know, organisms of an unsuspected complexity. They vary too in size, in shape, 
in function and activity, almost as much, one might say, as our gross animal world. Among them, if we may give fancy a rein, we might imagine elephants and dogs, horses and hippopotami, and all sorts of others. And we now know that they are numbered like the leaves of the forest. The large intestine of a man, for example, contains, normally, a bacterial population perhaps a hundred thousand times the human population of the earth-say a hundred to one hundred and fifty billions.

For the moment we will endow this microbe with a brain, though doubtless he possesses none; such vague sensations as he has he experiences, probably, with his whole being. We will give him hands to grasp with, feet to travel on; imagine him like a man, infinitely curious, but soon tired; able to go but a very little way when he must lay his head against the earth and sleep.

This being I will conceive in precisely the same habitat as that of man, as that of our own: I mean upon the fly-wheel of an engine-upon the surface of a very smooth and polished fly-wheel, turning at 4000 or 5000 revolutions per minute. It is little that we commonly think of our earth in such a guise; but equally little that we ever think of ourselves as one eightmillionth part of the diameter of the earth. We are insensible to the prodigious spin of the globe; equally so, let us say, is a bacillus upon a top. A wheel corresponding in size to this microbe as the earth to man would be of course about five or six feet in diameter; but there is no fly-wheel as large as this which turns at such a speed. The fly-wheel of a motor-carthe most familiar example one may choose nowadays-makes from 500 to 1500 revolutions; and it is quite impossible to see anything on its surface even at the slower speed.

Whirling at such a velocity, the first thought of course is that this microbe would be instantly swept off the wheel. There is no need of alarm; he is peacefully roaming about in the plains and the valleys that extend all over the wheel, for looked at under the microscope the surface of the wheel, polish it as highly as we may, is still mountainously "scarred and thunder-riven."

And does any one conceive that the smooth surface of the fly-wheel does not answer to the rugged face of the earth ? Let him then compute our highest Alpine or Himalayan 
rugosities; he will find that, reduced to an object he may hold in his hand, the earth would be smoother than any billiard ball can be made. But the atmosphere, the air which this bacillus must have to breathe ?-for breathe like us he must. The layer of atmosphere in which man may exist bears the same relation to the earth as a thin sheet of paper would, pasted down upon such a wheel. Probably every fly-wheel carries on its surface a very thin layer of air roughly, though very much thinner, corresponding to the earth's atmosphere.

What now might be the thoughts and sensations of this micro-man, this bacillus on the wheel ? What idea may he gain of his world?

Of course he has not the slightest idea that the wheel moves. It is to him very solid and very vast. He can gain little idea of its extent. It will take thousands of generations of bacilli even to venture on a guess as to its shape. Perhaps no thought can come to him more absurd than the idea that it is round, that the great plains and regions of high mountains which he traverses with infinite difficulty are the surface of a curve. Until he learns to lift a sail before the winds, he can get such a little way, anywhere. For aught he can see the thing has no end.

$\mathrm{He}$ is inquisitive, this micro-man, curious to the last degree; he loves to explore. But it is all so difficult, and he has so little time.

A single electric globe gives him all the light he has, and for some curious reason it goes curving around the walls of the room, then disappears, to come back on the other side, leaving him half the time in the dark. Moreover, it does not describe the same circle across the ceiling all the time, but its path moves up and down, with the apparent effect of his being most uncomfortably cold when it is down and beastly hot when it is high.

Puzzling over this foolish arrangement, he notes that this wobble has a seeming regularity; and using the alternate appearances and disappearances of his luminary as a unit to count with, finds that through about two hundred light and dark times he is warm and things will grow, and then for about two hundred more life is rather dull. Finally, observing the thing carefully through a great many wobbles, he concludes that there are very close to 365 alternations from the lowest 
point the lamp touches in its circle to the highest and back again. It is a stupid number, and it doesn't much matter any way; it is enough to know roughly, so he can plant his crops.

For the rest food is hard to get, and there are great famines and terrible plagues, when the microbes die like sheep-among them the microbes he most cared for ; and the newer generation does not seem the same. Then, too, other and more powerful microbes make war on his little tribe, slaughter his friends, carry off the maiden microbes to be harlots and the fine strong youths to be slaves. His home is pillaged, and it takes a long and painful effort to get on his feet again. The burden of taxation imposed by the imperial microbes who govern seems to grow heavier year by year; he borrows, the money-lender besieges him, his goods and chattels are sold to satisfy his debts, and aweary of the game, and taking consolation of his poets, he reflects on the vanity of existence. Sixty or seventy wobbles of his lamp through the sky and he is old, and though the time seems long, and he is weary, weary, what has it profited, what has he learned?

What could he learn ? What could he know? Three hundred and sixty-five turns of a wheel going at 5000 revolutions per minute-that is, about four seconds of our reckoning; and seventy times four seconds-that is, nearly five minutes. Not very long to learn what is this lamp that circles the ceiling and makes his nights and days; not very long to discover that he is on the periphery of a wheel-or, if you prefer, of a top that spins carelessly; not very long to figure out that the curious up-and-down wobble of the lamp is the effect of the whole wheel he is spinning on being in its turn spun round the lamp (how incredible!); not very long to come at last to believe that not only this swiftly turning wheel, but even the lamp round which it revolves, and all the objects of the room, are being rushed along as in an express train, where, were he big enough, he might look out of the window and see the landscape flying by.

Not very long! How difficult to imagine that man is no better placed; that he is a being as microscopic to the world into which he is born as this fanciful bacillus-man to us!

There is here a point of view worth the effort to attain. Let us take the matter in another way; let us turn the illustration quite about, just as Swift in Gulliver has done. But 
instead of his Brobdingnagian giants, let the imagination soar a little.

In his rather imitative tale of Micromegas, the nimble pen of Voltaire has sketched a traveller from a vast planet which is satellite to Sirius, and who on our dwarfish world skips lightly over the mountains and across the seas, as a goat from crag to crag. We may take a yet wider range.

Upon some clear moonless night, scintillant with the crowd of flaming stars, let your vagrant fancy roam the ways of space, there to picture, if you will, some gigantesque voyager from another realm than our own, distantly watching from the rail of his uncharted vessel the ceaseless turning of the silent earth. Directing his helmsman to parallel its course, he notes, as it turns and turns, here and there upon wide wastes which, from the brilliant reflection of their surface, he may conjecture to be oceans, faint specks. These, as he directs his glass to study them, seem to trail a thin blackish ribbon behind them. As with each successive turn of the earth they come again in view, he perceives that they have advanced a little toward one side or another of the mirror-like surfaces, finally to merge themselves in the dark patches which he may take to be land.

Puzzled at the capricious course of these moving specks, which, though regular in their motion, seem governed by no law, he signals the man at the wheel to draw nearer. Again searching with his glass, these specks take on the appearance of drawn-out egg-shells, and he finds that the trailing ribbon is a band of smoke. Though swiftly whirled from his view, he can yet determine that whichever way they go they pursue a fixed direction; failing to observe any means of propulsion, he must nevertheless infer that they have inside some propelling mechanism, and are in some way steered.

Curious and delighted at the thought of an intricate mechanism so marvellously small, he approaches his vessel as nearly as he dares to this rapidly turning ball, to follow whose flight through space he finds it needful to stoke his own engines smartly to keep up. With what excited pulses, with what genuine awe, does he perceive, in the brief moments that he can hold them in sight, that the decks of these trailing eggshells are covered with other moving specks; gradually he makes out that they are slender midgets, scarce larger to his eyes than the harvest mites that we may feel, but hardly see, 
chasing over the back of our hands; he smiles as he sees them dexterously balancing themselves on but two legs, instead of six or eight as other insects have.

Scanning closely, he beholds some of these microscopic beings lift their arms in the air and apparently point some object at the stars. Are they observing ? Are these telescopes ? Can these animalcules, then, reckon their way thus across the seas? How curiously he will think of them; what enchanted little eyes they must have; and in their microscopic brains what thrills must run! Upon the decks they go about in pairs; when the egg-shells have reached the shore he cannot follow them upon the dark land; they disappear, and yet he may not doubt that there they draw out the accustomed course of life -mate and have their homes, beget their kind and die.

As he steers away, to voyage on past Neptune and the dark, I imagine him inscribing in his notebook: "Travelled some time to-day alongside a considerable-sized globe, largely covered with water, and revolving at a high rate of speed. Was able to note upon its surface with the aid of my powerful new telemagnafecit an extraordinarily minute two-legged ant, certainly able to build and scientifically to navigate vessels at least a hundred and forty times his length, and therefore more than three million times his bulk, and probable weight. I seemed to go from wonder to wonder. How strange and fascinating this cosmos grows to me as I journey and learn!"

There are heavy types of minds to whom lively illustrations of this sort are repellent. Yet, thought of thus wise-these mating, building, navigating ants, able to strut about on two pipe-stems and not fall-is it not, after all, a marvel of marvels what they have done? Shall we not wake to a new sense of his achievement: this bacillus man, so infinitely little, set against the universe he is learning to map; so slight a thing, the ephemeron of a moment on the dial face of time, a butterfly fluttering through an unheeded hour of the cosmic day; so slight and weak a thing, cringing with terror before a storm, beset with ills, the prey of fear, strange and hapless estray of fate's designs! Do we not grow to a deepened respect for what his reasoning brain has forged-for that long-drawn-out chain of observation and inference, of comparing, combining, of measuring, imagining, of theorising and trying out, which link 
by link builds up that corselet of ordered knowledge we call science? Consider his lowly beginnings; think how handicapped man has been, how he has gone wrong, lost the way, stumbled, been led astray, in his long endeavour " to strike out a pathway toward the light" !

Think of his tools; he has eyes to see with, hands to feel; sound, taste, and smell are of little use. Measures of the eye do not turn out well, so he learns to mark off his fields in lengths of his feet or his stride; distances are a day's march. His eyes will see but a little way, and will show only objects comparatively immense; it is centuries before he hits on spectacles, and with these contrives the fernrohre, the "distance-tubes" of Hans Lippershey, of Zacharias Jensen, and the microscope as well.

His two hands are clumsy, and do not readily distinguish between two weights of silver or gold-he devises the balance; his sense of time is vague-he invents a time-machine, and the Roman slaves who run to the Forum to learn the noon hour give way to the clock. Patiently he ekes out the meagre endowments of nature, until at last amid the wilderness he has a workshop. And all the while he reflects, compares, "intends his mind." He ponders the changing length of nights and days, the order of the seasons, the position of the sun, the growth of the crops; he notes the course of the planets, of the moon, the nightly wheeling of the firmament round its central pivot star; through the whole concourse and spectacle subtly he begins to trace a connection, a binding chain; he perceives that in one way or another they are all linked together; he rises at last to the vast conception which embraces all phenomena in that unvarying sequence which he will come to call law. $\mathrm{He}$ attains at last to a perception of causal relations, within whose unbroken series the whole order of events is enchained. $\mathrm{He}$ pictures the universe as a mechanism; for chance he substitutes fate.

This is achievement sublime ; how did it come? 


\section{CHAPTER IV}

THE BEGINNINGS OF CERTITUDE 
UnTo the angel of the church of Ephesus write; These things saith he that holdeth the seven stars in his right hand, who walketh in the midst of the seven golden candlesticks.

And unto the angel of the church in Sardis write; These things saith he that hath the seven Spirits of God, and the seven stars.

And I saw in the right hand of him that sat on the throne a book written within and on the back side, sealed with seven seals.

And I stood upon the sand of the sea, and saw a beast rise up out of the sea, having seven heads and ten horns, and upon his horns ten crowns, and upon his heads the name of blasphemy.

Revelation ii. I ; iii. I; v. I ; xiii. I. 


\section{CHAPTER IV}

\section{THE BEGINNINGS OF CERTITUDE}

Primitrve man, we have learned to know, differed but slightly from the primitive man of now-that is to say, he was in little distinguished from an animal. Perhaps in a way the difference, even now, is not large. If in the course of fifty or a hundred thousand years he has become the "good gorilla" of Buffon, we may imagine in the beginning he was the gorilla without being good. He answered to the crazy ideal of Nietzsche; he was simply the "blonde beast," save that primitively, perchance, he was not blonde.

We have his portrait in the famous painting of Gabriel Max. The likeness is idealised, no doubt; the reality would have shown less of the age-old pathos that shines in the eyes of these our brute forbears; there would have been more of ferocity. He was a savage, with a savage's joy in killing things; he was a thief, a glutton, and a cannibal. To him nothing was forbidden, nothing was criminal. The idea of murder, rapine, pillage, torture, or incest brought no feeling of revolt, of disgust, or of injustice. They were the simple, natural instincts of the blonde beast. He was brutal, he was treacherous, sensual, lawless.

As he multiplied he split in roving bands; these grew into tribes, the tribes into nations. Association brought organisation. As food grew scarce, harder to get, he learned to herd, then to plant. With his flocks of animals, with his rude fields, came ideas of property. To preserve his own he united to stop thievery and plunder. This property right, at first tribal, became individual. Along with this had grown the idea of family. The woman was associated as part of his property; she was his chattel. He was primitively polygamous, no doubt gregarious. Eventually, individualising instincts, the sense of personal possession, brought a rude morality. He began to 
develop ideas of right and wrong. These, established by custom, finally became law. He had organised the primitive state.

Long before this he had learned to cook. The chance discovery that in cocoa-nuts, cracked and exposed to the air, the milk became bitter and produced a singular feeling of exhilaration, made him a brewer. He became a worker in mud and clay. In due time he learned to chip flints, to fashion weapons, then implements.

The discovery of fire was the most momentous event of his early history. By this means he became a chemist, a potter, a worker in glass, a metallurgist, eventually a mechanic. In the beginning these were doubtless the occupations of the slave. Nature's nobleman, the blonde beast, despised work. It was easier to steal, more exciting to hunt. His natural instincts of cruelty and lust were glutted by the rape and slaughter of other tribes; the portions that remained were made menials and serfs. Slavery was the universal characteristic of primitive brute society; it survived throughout antiquity. All the socalled civilisations of the Mediterranean basin, from the earliest of the Egyptians to the latest of the Romans, were founded upon slavery.

It was doubtless a world-wide characteristic. To work was ignoble, and it is curious to see how this primitive idea of nobility has survived among the property-holding classes of all times. The British land-holder despising "trade," the dilettanti and drones of all classes deploring the invasions of " commercialism," are a late survival of a society that was archetypal to Plato and his kind. From the beginning, human associations seem to have been made up of an aristocracy of spoliation and a proletariat of service. It was only with the invention of the steam-engine, the introduction of machinery, the enhancement in value of labour, the cheapening of its products, that the mass of humankind was manumitted from its world-old condition of essential serfdom.

It is easy to see that it was the slave, the worker, who, to lighten the burden of his lot, was the inventor, the improver, and out of this the observer and the experimenter. The hands which fashioned the primitive grist-mills and water-wheels, that lifted the first sails, that devised the rudder, that learned. to hitch a forked stick to an ox and with it to stir up the ground, were the hands of the serf. The occupations of the strong, 


\section{THE BEGINNINGS OF CERTITUDE}

the rich, the noble, were to hunt, to fight, to win more property by pillage, to make more slaves by conquest.

It is to the slave, then, in all likelihood, that we owe the beginnings of experimental knowledge. His simple inventions and contrivances would have sharpened his wits, trained his mind, taught him a rude cunning, developed him intellectually beyond the brute brain of his brute lord. In due time he would have acquired a knowledge of herbs and simples, and become something of a physician. His dexterity in cutting up the prizes of the chase would have made him the first surgeon. His knowledge of cooking and the effect of fire would have made him the first metallurgist. Out of this sprung the beginnings of alchemy. The natural lust of wonder, of mystery, would have early converted these into a primitive diabolism. To the heavy brain of his overlord, sodden with gluttony and strong drink, it would have readily seemed a black art. The slave would not have been long in discovering that in his weakness he had found strength, and that his intelligence had given him power.

From this would have come the medicine-man, the soothsayer, the mage, the priest. A portion of the social fund would have been set aside for their support ; they would have become teachers and prophets, workers of miracles, diviners of omens ; they would have been the interveners between the tribe and the evil spirits which populated the air, the nooks of the forest, the running streams, which came in the tempest, the thunder, the flash of the heavenly fires, and the shakings of the earth. The stages of this evolution are all to be traced in that convenient image of past days which we call anthropology. There is scarce any phase which may not be illustrated from living tribes.

It is easy to see that this slave element, become priest element, would have laid hold of every available means for the furtherance of its power. Foreseeing in a dim way that the origin of this lay in a knowledge of phenomena and, in a slender way, in devices for the control of phenomena, the more prescient among them would have observed attentively the varied processes at work about them.

This is not saying that the higher knowledge was wholly of slave origin. Obviously a large part of the human experience upon which it is based was a racial experience, with which the immediate occupations of the social units had no concern. 
Long centuries, millenniums even, doubtless elapsed between what we may term the tame gorilla stage and that in which the wonder-working slave had become augur, astrologer, alchemist, and austromant. It was long ages later still when from these rude beginnings, more than half mysterious, we may imagine, even to their practisers, that anything like a rational world conception, to say nothing of a mechanical world conception, could arise. Let us look about for the first steps.

Sometimes in the history of ideas the history of a word may shed a deal of light. It is of some curious interest to know that once learning, knowledge, and mathematics were one. This indeed was the meaning of the Greek verb mathemata, "to know." For the rest, one of the most primitive of human needs was a method of counting. If we look about a little we shall perceive that the earliest idea of fixity, of certainty, of inevitable sequence, must have arisen from the sense of fixity of numbers.

When man had learned to put together 2 and 2, to subtract, to multiply, and divide, he must have seemed face to face with a great light. Mere numbers now seem to us such lifeless abstractions, that the idea they could have once been almost the basis of a religion seems absurd. We know, however, that this was true. No doubt a curious sense of coincidence-that is, of mystery-must have come to the first man who noted that the first four figures of the counting scale, put together, sum up ten. Remember that all systems of notation were decimal systems, arising from the chance number of fingers upon the two hands. The Pythagoreans named the first four figures the "grand tetrad." There was a similar mystery about the number "seven," the number of planets or "wanderers" observed in the sky. The perfect number was twelve, doubtless because to them there were twelve lunations in the year, and because it divided into so many even parts. Even to Plato, numbers seemed the basis of all things.

Long before this a system of notation had been devised; its beginnings were crude enough. A single stroke counted for one, two strokes set side by side for two, and so on. This grew very clumsy before many digits had been told off, so various combinations were tried. The Babylonian character for ten, Grotefend believes to have been a rude picture of the two hands 
as they are held in prayer. Little by little, in what manner is hidden from our view, grew up the complicated systems which appear in the earliest of the clay tablets which have been unearthed.

It must have all been very old. Some of the Sumerian inscriptions, forerunners of the Babylonian, reveal the existence of a sexagesimal system-that is to say, in which the count extended up to sixty and there begins over again. It was long, probably, before the count extended up to a hundred and began again there. But why was this especial number of sixty chosen ? We can only conclude that by this time something of the properties of circles and radii had already become known. This in turn had obviously come from their endeavour to forefigure the year, the path of the moon, and all the like.

Doubtless the earliest of external phenomena which ancient man came to study with attention was the changing length of nights and days, the succession of heat and cold, the return of the seasons. When he had begun to seek a more stable foodsupply than from the precarious providence of nature, he needed a sign for the time to plant his crops. When he had organised into tribes and perhaps begun to barter his labour for produce, there came the need of a means of reckoning time. The going and coming of the moon gave him a unit for a bundle of days. He needed a larger, which should fix the return of spring.

As he watched the heavens he saw that the position of the stars at nightfall and at dawn, with reference to the sun, appears to change. It was a generalisation of a high order when he had reached the conception that the stars are stable, and that it is the sun, the bringer of the day, which in reality changes its place. Attentively observing the changing rising point and setting point of the sun, the primitive astronomers saw that it swept through a seeming circle in the air. From this perhaps came the Latin word for the year, annus, whence our word " annual," meaning a " ring" ; it appears primitively to have signified simply a "bending." The sun in his shift of position seemed to describe a continuous bending, which in the end brought it back to the same point.

The reckoning doubtless was not very close; there was a convenience in round numbers. In the beginning they appear to have fixed the number of days within this period at three hundred and sixty. Doubtless from this the study of the circle began. When they had found that a regular figure of 
six sides, each equal to the radius, could be described within every circle, it was natural that they should make such a division. Doubtless the earlier division had been into the twelve periods corresponding to the twelve lunations which their crude observations taught them to believe made up the year. The change of division marked the separation of the theoretical from the practical.

The three hundred and sixty divisions of the circle were named steps, or degrees. As their observations grew more accurate they split each of these into sixty parts, partes minuta, whence our minutes; these into sixty more, partes minuta secunda, whence our seconds. The day and the night they divided each into twelve parts, corresponding doubtless to the twelve divisions of the year. The first time-keeper was the sundial; its face was half a circle. It was natural that they should have employed these minor divisions of the circle to mark the subdivisions of the hour.

Along with this application of numbers to time came a parallel application to weights. Primitive man had made another prodigious step when he had discovered the principle of the balance. Our word "pound" comes from the same root as "pendant," meaning "to hang," that is, "to weigh." The ounce was the twelfth part of this, and meant simply the twelfth part; it is the same word as inch.

Even earlier must have been the application of numbers to measures. There was need first of all to define the exploits of the chase or of the march; this would evidently be in units of the distance an ordinary man might cover, travelling steadily through the day. With fixed habitations and the subdivisions of fertile areas into definite plots came corresponding subdivisions of the day's march. It is evident that the handiest units were the average length of feet and hands. It is a rather curious reflection of our Saxon civilisation that alone among the nations of the earth we should still be employing as our unit of a length the human foot, just as did the primitive folk of twenty or thirty thousand years ago. Up to within a recent time the French measure of an inch was the pousse, the thickness of a thumb. Fractions of this were expressed in lengths like our English barley-corn, just as a single grain formed a subdivision of the ounce in weight.

A pace was simply a step, a yard was a club or stick, doubt- 
less of the same length. A stadium was simply a "stage"that is, about the distance that one man could readily shout to another and be understood. When they had need of news more swiftly than it might be carried by horse or man, a line of shouters were stationed at intervals, sometimes over long distances. It was thus that word of the disaster at Thermopylæ was brought to the Persian king.

When these units of measure had been grouped up into a rude system, it is obvious that through a growing proclivity to barter must have come a growing sense of the fact of proportion. When for so many horses or slaves or wives a man traded so many skins or sacks of wheat, or weights of meat or roods of land, there came insensibly a sense of abstract values-that is, the relations of units of one kind to units of another. There would be an inevitable comparison of signs and symbols representing like quantities of different things. From this would have come an intimate sense of the fixity of numbers, and likewise of their inter-relations.

It was a far higher step when he had come to perceive that one number might bear the same relation to a second as a third to a fourth-our familiar rule of three. The utilisation of this method must have been among the earliest instances of that method of prevision and subsequent verification which is in a sense the foundation of exact knowledge.

The application of the method must have been very slow. There is a legend preserved by Diogenes of how Thales, the wise man, when he went among the Egyptians, showed them a simple means of measuring the height of the Pyramids. This was by measuring the length of the pyramid's shadow at the moment that the shadow cast by a staff equalled in length the height of the staff. Doubtless the story was a fable; it may have been merely Thales' own boastfulness; the boasting trait is strong in primitive man. The Pyramids are still a marvel of constructive accuracy. The base of the Great Pyramid is 756 feet on each side, and so near to a perfect square that the mean error of the four sides is only six-tenths of an inch. The height is to the total length of the sides as the quantity symbolised by $\pi$ to the circumference of a circle ; and there are other indications in the interior that the ratio of $\pi$ was accurately known. The Pyramids were built several thousand years before Thales was born. 
We have in the fable, then, either an evidence of the extreme slowness of mental development, or else an indication of the stage attained by the Greeks of Thales' time.

The construction of the Pyramids indicated a very considerable knowledge of geometry. Its birth must have been far back. Herodotus would have it that it was the invention of the Egyptian king who wished to give an equal measure of land to each of his subjects. Those who dwelt along the Nile suffered from the erosions of the river's annual flood, but in unequal degree. There was need, therefore, of an annual equalisation. This was the work of the harpedonapice or "ropestretchers." These may have been the first surveyors. Probably their art had existed in a rude form for many thousands of years. There is in the British Museum a hieratic papyrus dating from before I700 B.C., and founded upon an older work, believed to date from before 3400 B.c. This manuscript treatise of old Ahmes implies a rudimentary knowledge of proportion, squares the circle with very fair approximation, and contains many rules of much practical value. It contains no theorems.

Apparently, then, we might believe that, among the Egyptians at least, abstract reasoning-that is, mathematical generalisations-did not exist at this period; and we know of no other people then flourishing who were further advanced. The fact, however, is by no means certain. We know that among the ancient Egyptians learning was confined very largely to the priesthood. They guarded their treasure jealously. Knowledge did not ope her ample page to the vulgar. So it was even among the earlier Greeks. The Pythagoreans constituted a sort of secret society, and in times. of distress or disorder they were mobbed and their homes burned.

It may very well be, then, that the manuscript of Ahmes does not represent the intelligence of the time any more, let us say, than Mr. Gladstone's theories of creation and allied subjects represented the intelligence of his day. The mode of tradition may have been almost exclusively, as we know it was largely, oral. When the curtain lifts upon Greek geometry, we find it far advanced. Euclid is its culmination. Behind him we know of a long line of geometers. They in turn may have been the successors of a still longer line, reaching far into the mists of antiquity. The fact may always be that there came at this period a sudden flowering of the human intellect, like 
unto that of Europe after the long sleep of Christendom. The more clearly we are able to trace any especial development, however, the more we discover it to be genetic and even, rather than saltatory or precipitate.

Be this as it may, we know that by the time of Thales and Pythagoras methods of geometrical reasoning had taken deep hold. They stirred to a singular enthusiasm as well. Professor Benn remarks illuminatively upon the lively emotions that must have been excited among an intelligent people when squaring and cubing, the construction and equivalence of figures and the like, was just as strange and wonderful, and in another way much more rare, than the electric light dynamos and their kindred, a generation ago. There is a story of how Pythagoras sacrificed a hecatomb, a hundred oxen, in honour of his discovery of the theorem of three squares-that is, as to the equivalence of a square on the hypothenuse of a rightangled triangle. It is a little doubtful, for Pythagoras was a vegetarian and opposed to the shedding of blood; but the same story is told of Thales-so we may take our choice. A mathematical training came to be considered a mark and even necessity of culture.

We do not ordinarily think of Plato as a careful reasoner, and the puerile phantasies with which his pages are strewn do not give us a very high idea of his powers of mind. Nevertheless, his contributions to geometry were not few, and when he set up his academy at Athens, it will be remembered that he wrote over the door :-

"Let no one enter here who knows not geometry."

By the time the Ptolemies had set up their line of Greek kings in Egypt, the science had attained a high dignity. We may recall the rebuke of Euclid when the king asked for an easier path to learning than through mastery of his everlasting theorems :-

"There is no royal road to mathematics." .

The power of the new weapons found its highest exemplar in Archimedes, greatest mathematician of antiquity. It was while solving a geometrical problem, at past seventy, that he was struck down by a Roman soldier. Spite of all the mechanical marvels which he devised, we know that he selected 
as his chief title to fame the inscription of the cylinder within a sphere, and it was this figure which in after years made known his tomb to Cicero.

The development which the science has taken, especially since the introduction of the decimal system, the discovery of logarithms, and the like has been extensive. Beside it the mathematics of the ancients seem in many ways crude enough. The management of their systems of notation, in multiplication, in division, to say nothing of their struggles with fractions, would be to us simply distracting. To-day the schoolboy solves countless problems with an ease which would have filled Archimedes with breathless admiration. The mere introduction of the zero must have simplified operations, as measured by their rapidity, at least a dozen times. It seems incredible now that its advantages should not have been earlier perceived. There is some evidence that the Indian or decimal system was known in Europe before the rise of the Arabs; but it found no general introduction until it was borrowed from the Arabs at about the beginning of the thirteenth century. It does not appear to have been in use among the Hindus earlier than perhaps the fifth or sixth century. It was certainly not known either to the Greek or Latin mathematicians.

We gain a glimpse of the time from the fact that the clumsy abacus was then in universal use, as it is among the Chinese still. It consisted simply of beads or pebbles strung on parallel rods. Our word " calculate" from calx, " a stone," is a survival from this rude counting-machine. They had no algebra even; although Aristotle and even old Ahmes employed letters to represent indeterminate quantities, the swifter use of algebraic equations did not come in until some centuries later. Here, as elsewhere, we perceive the exceeding slowness with which new methods and new devices make their way.

Despite the crudity of their devices, our respect for the ancient mind is heightened rather than dulled by the applications which they made of the means at hand. In this later time we have come to perceive that the knowledge of antiquity, the range of its ideas, was far more extensive than had long been supposed. The high development of Greek philosophy, itself no doubt more or less a rescript of a yet more ancient time, is sufficient evidence of the ancient's capacity for abstract reasoning. In the pages that follow we shall find many acute 
and astonishing examples of their powers in the far more diffcult analysis of phenomena. Their employment of mathematical methods was constant, its applications were wide.

One of the earliest was the geometry of light. It must have been recognised far back that light travels in straight lines, and that its reflection has a sharp angle, equal in value to the angle of incidence. These facts were very early utilised in fixing the positions of the heavenly bodies and in effecting the beginnings of our cosmic knowledge. They are still the source of by far the larger part of our information as to the world in which we live.

By means of the eclipses men were able to understand that the sun lies back of the moon, and to unravel the mystery that lay in the puzzling and apparently inexplicable motions of the planets. It was by means of the eclipses, as we shall see, that a little later the Greeks were able to gather some idea of the relative distances of the moon and sun, some idea of their respective grandeurs as well.

It must have been very early that attentive minds observed that the light of the sun comes to us in practically parallel lines. On the day of the solstice when the sun seemed to stand still in the heavens, then began its winter retreat, there was a belt of considerable extent, several hundred stadia in width, in which perpendicular objects cast no shadow. This zone lay across the middle reaches of the Nile, just where Egyptian civilisation attained its highest efflorescence. The fact must have been deeply pondered by the observing priests. Its implications could hardly have escaped their wondering minds. A few hundred years later it seems to have been employed by Poseidonius to compute the distance of the sun, with an approximate success that is still amazing.

When we trace out the history of ideas we find as a rule that their lineage is long. In some of the earliest of Greek manuscripts that have come down, and again in the pages of Cicero, of Cleomedes, and a dozen others of that later day, we find perfectly correct notions of the earth and its immediate surroundings. These conceptions, analogy leads us to believe, must have been very old.

Inferences of such moment, deductions of such power, imply that far in the ancient time the idea of fixity in phenomena had been deeply impressed upon at least a slender body of 
minds. This was largely fruit from the application of exact, that is to say mathematical, methods of reasoning. To it, one set of phenomena in especial must have powerfully contributed. This was the regularity of recurrence in eclipses. When our knowledge of a given set of phenomena is so certain that we may rise to the prediction of future events, there comes a consciousness of certitude which can be inspired in no other way. The art of eclipse predictions was known among the earliest of the Greek philosophers of whom we have authentic report. The successful issue of a venture of this sort made Thales seem to the simple mortals about him a god-like intelligence. In a larger sense than that in which it was conceived by the marvelling Ionians this expressed a literal truth; for among the attributes which we may conceive of divinity surely a knowledge of the past and of the future must be one. The same story is told of Democritus of Abdera. Both of them had dwelt long in Egypt. Doubtless it was from the Egyptian priesthood that both of them had borrowed their art. It was certainly known among the Chaldeans hundreds of years before.

We know, too, that mathematical methods were very early applied in physical investigations, notably to that of sound. Whewell gives high credit to Plato as having been among the first to teach that phenomena were capable of numerical treatment, as opposed to the empty definitions of philosophers like Aristotle. In this he was but a disciple of Pythagoras, and Pythagoras in turn had drunk of the founts of ancient knowledge, that is to say, of Egypt.

Of far greater moment was the application of geometry to the determination of the figure, and eventually the measure of the earth. It was the first step in a true knowledge of the cosmos-that is to say, towards a rational conception of the world. It carried the mind into regions the feet of man could never traverse, that his eyes might never see.

How, thus hobbled, could he attain to a certainty that all the after flood of years would not disturb? 


\section{CHAPTER V}

BION AND THE DOCTRINE OF A ROUND EARTH 
Is it possible that men can be so absurd as to believe that there are crops and the trees on the other side of the earth that hang downward, and that men have their feet higher than their heads ? If you ask them how they defend these monstrosities? how things do not fall away from the earth on that side ? they reply that the nature of things is such, that heavy bodies tend toward the centre like the spokes of a wheel, while light bodies, as clouds, smoke, fire, tend from the centre to the heavens on all sides. Now I am really at a loss what to say of those who, when they have once gone wrong steadily persevere in their folly, and defend one absurd opinion by another.

Lactantius (fourth century, A.D.), On the Heretical Doctrine of the Globular Form of the Earth. Quoted by Draper, History of Intellectual Development. 


\section{CHAPTER V}

\section{BION AND THE DOCTRINE OF A ROUND EARTH}

THE parentage of ideas is as a rule obscure. Rarely may we trace their primigenial forms; they grow rather than are born. Empedocles seems vaguely to have antedated the especial ideas of Mr. Darwin by a matter of twenty-five centuries. This is more or less true of almost all our larger world conceptions.

In the fifteenth century the generality of men, in Europe at least, still believed that the earth is flat. Some doubted; they were few. It was the old question: Who was there fool enough to dream that there could be a race of men on the other side of the earth, with their heads pointing downward into the sky ? What would keep them from falling off ? So to the court of Ferdinand and Isabella, doubtless the most enlightened then in Europe, for to it Columbus of preference appealed, the arguments of the Genoese navigator seemed novel enough. They had been current among the more enlightened people of Greece at least four centuries before Christ.

Indeed for six hundred years after the time of Plato and Aristotle, it would probably be difficult to find a single instructed writer teaching any other doctrine. The beliefs of Alexander or of Cæsar, of Demosthenes or of Cicero, in this differed in no material way from those of Napoleon or $\mathrm{Mr}$. Gladstone. Whence did the idea come?

It seems older than history; older, no doubt, than the Pyramids. To the very earliest of Chaldean and Egyptian observers it was clear enough that the earth did not extend endlessly in space, for the sun, the moon, the stars revolve about it. And if the earth is not infinite in extent, then it must have some shape. But what? The simplest notion undoubtedly was to think of it as flat, perhaps as a flat disk, resting on the water. That was the belief of the Chinese, the Hebrews, and other primitive people, just as it is the belief of such savage tribes as have reached a similar stage of culture 
now. And this idea held the field for a long time. Much that is among the highest in human development had been attained before men ceased so to believe-the Parthenon had been built, the songs of Homer sung, the tragedies of Euripides enacted; Socrates had drunk of the hemlock.

But to men habituated, like the early shepherds, to watch the heavens night by night came suggestions of another sort. The vault of the sky seems a sphere. The stars seem to revolve in circles, the horizon is always round, the shadow cast by the earth in eclipse is round; it is a little strange that the early astronomers should ever have had any other idea than that the earth is a sphere as well.

This was certainly the teaching of Thales, one of the seven wise men; he had it undoubtedly from the Nile priests, among whom he had dwelt; they, we may surmise, may have been teaching it to the initiate for ten or twenty centuries before; perhaps for a period more distant from Thales than Thales from us. And the astronomy of the Chaldeans was not less ancient. Nevertheless their doctrines were not held by the generality of men.

We may fix with a fair degree of certainty when they came in, at least to European thought. They were not known or not accepted at the time of Athens in her glory, the Athens of Pericles and Phidias. They were accepted as a matter of fact by Aristotle a century later. Whatever their force, they did not prevail in the all-embracing mind of Democritus of Abdera-he who, save Archimedes, was perhaps the greatest intellect of antiquity. They had certainly been worked out in full detail by Bion, his pupil, if we may trust to a hint in the frugal pages of Diogenes Laertius.

Of this Bion the mathematician, and native, like Democritus, of Abdera, we have only a line.

" He was the first person who asserted that there were countries where there was day for six months and night for six months."

That was all that remained of him to fame, when in the second century of our era Diogenes of Laerté came to write that curious history to which the larger part of our knowledge of the ancient philosophers is due. But consider for a moment all that this assertion of Bion's implies. There is not the slightest possibility that the land of the Midnight Sun was then 
known, even by tradition. Though the Phœnician traders may have penetrated to the Baltic, there is little to suggest that there were then dwellers or even voyagers within the Arctic circle; and lands no farther distant than Scythia were peopled with the fantastic legends of the Hyperboreans, a race that lived in perpetual happiness and everlasting youth.

Bion's belief, we may conjecture, was rather one of those splendid inductions which sometimes arise from a slender array of facts. Travel in his day, as in ours, was the correct procedure of cultivated youths, and whether or no Bion had crossed the seas to Egypt, we know that Democritus, his teacher, had. And he who will journey no farther to the south than by the breadth of the Mediterranean will note a curious change in the position of the stars. The questioning eyes of the Sphinx meet other constellations than those of our more northern climes; the pole-star lies lower upon the horizon. Furthermore, one discovers that in the southerly regions the days and nights are shorter, according as the sun has passed the summer or winter solstice, than in the north. At the equator they vary little throughout the year. It would be difficult to account for all this if the earth were a plane.

As the ships go out to sea, the earliest of observers must have noted that they disappear piecemeal. Returning, the lights of the harbour are visible from the mast-head some time before they may be seen from the deck. Ascending a high mountain the horizon steadily widens, and objects that from the lower lands lie below it come into view. If the surface of the sea and the land is curved, the earth must be a ball.

Bion was a geometer, something of a physicist too, evidently; he understood in all its implications the geometry of light. With him let us draw a circle to represent the earth, set the sun at a distance, draw straight lines for its rays, and see what will happen. With the sun at a certain height at noon its rays will illuminate a certain area; shift the angle and the area shifts with it.

\section{Let us put it on paper. (See Fig. I.)}

When the sun at noon stands directly in the zenith, the days and nights are of very nearly equal length - twelve hours day, twelve hours night. It follows therefore that, if the earth is round, the sun at a given time illumines just half its surface. If now the position of the sun at noon shifts, so that the days 
are much longer than the nights, as in the northern summers, for the other half of the world the days will be shorter, and shorter by as much as they are longer in the northern hemisphere. As you go toward one pole or other the condition is intensified.

So, when the sun is at the extreme point of its northern advance, its summer halt or "solstice," as at S in the figure, its rays will cover the northern pole; from $W$, the winter solstice, they will leave it in the dark. As this shifting of the sun's position from one point to the other occupies half the year it is clear that from the north pole (N P) the sun will be continuously visible for six months and then for six months disappear from sight. When the sun stands at $\mathrm{E}$ there will

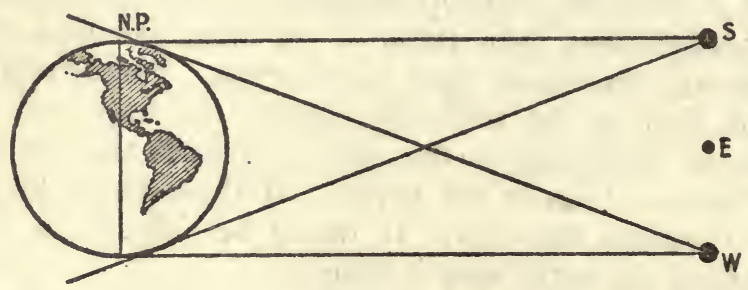

FIG. r.

Note.-It is needless to say that this scheme is based on the idea that the sun circles the earth, as it so doubtless appeared to Bion.

be equal nights and days all over the earth, save at the extremities of the poles. This is our equi-noctes, period of storms.

Here, then, was a geometrical construction which accounted for all the facts of observation. But to do so absolutely there was a difficulty to be surmounted. The theory of Bion required that the sun be at such a distance that the bulk of the earth cuts no figure. For it is clear enough that if the earth is very large, and the sun a small body not so very far away, the curve in the earth's surface would shut off the sun's rays from much more than half the earth, and no day anywhere would be twelve hours long. In order that the day occupy one-half the time from one dawn or one sunset to the next, the sun must illuminate half the earth, provided, of course, that the earth is really round. And there was no escaping the evident certainty of this last.

More than that, the shadow that falls upon the moon in 
the time of an eclipse required that the sun be larger than the earth ; for if the earth is a globe the shadow it throws will be, if not a cylinder, a cone, either upright or inverted, as the source of illumination is larger or smaller than the earth. Here is doubtless another diagram that Bion and others who thought about it must have drawn :-

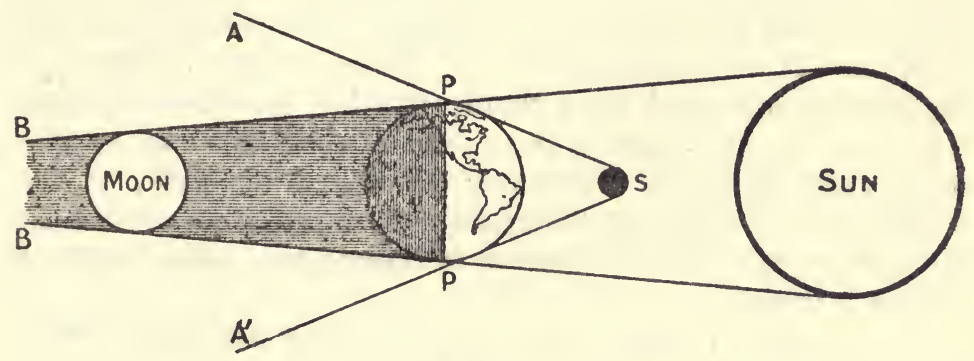

FIG. 2.

If the sun were small and near, as at $\mathrm{S}$, then the shape of the earth's shadow would be that indicated by the lines S A, S A', and the moon in travelling round the earth would be blotted out for many hours during an eclipse. This is not the case. Often only a part of the moon's disk is cut off during an eclipse ; never does it remain in the earth's shadow much more over three hours. Occultations of the sun make it clear that it is vastly larger than the moon: it must also be vastly larger than the earth in order to realise the conditions indicated in the figure.

One step further. If the sun be larger than the earth, then its distance must be immeasurably vast, for when its rays strike the earth they are to all intents parallel. That is attested by the fact that the shadows cast by sunlight alike of the Pyramids and of a knife-blade, are sharp. And again, if the sun were not at a great distance, at points on the earth near the poles ( $\mathrm{P}$ P in the figure), a part of the sun's disk would be cut out by the curve of the earth continuously.

On the other hand, if the sun is larger, and not at a very great distance, more than half the earth would be continuously illuminated, and we should never have equinoxes and equal days, as we do, nor, for example, would the poles have six months day and six months night as Bion taught.

Thus, as it chances often, the elucidation, the bringing into 
the light, of one obscure problem was the illumination of the other. The linking of fact to fact which revealed the mechanism of the changing lengths of the day brought with it the proof of a spheroidal earth. It must, too, have set men thinking out the mechanism of the seasons as well. It certainly accustomed the mind to the idea that the blazing ball which daily sweeps through its circle in the heavens is in reality a body colossal in its dimensions and therefore fixed at an enormous distance. It was among the first of these splendid flights of the imagination which have characterised all scientific advance; it was among the earliest of these difficult conquests over appearances upon which all progress of knowledge depends; it was among the first-fruits of that endeavour to introduce mechanical conceptions into the explanation of phenomena, upon which all science is based.

Not without a tinge of melancholy will the student of history take note of the date ; that among the freest people of antiquity, at near two thousand years before Columbus stood disputing with the wise men before Ferdinand and Isabella, there were thinkers who had made the first steps toward a correct knowledge of the earth, and from whom the superstitions of the vulgar, like an outworn mantle, had been cast away.

Whether all this had been done by the priests of Isis or the servitors of Bel, still two thousand years further back, we do not know. Among the pyramid-builders of Egypt a high level in both astronomy and mathematics had been attained. The truly marvellous geometrical construction of Cheops is proof of that. Its edges are the four points of the compass, determined with astonishing precision, and from the royal burial-chamber, in the far depths of the Pyramid, through the long inclined tunnel which leads to the entrance, a mirror kept ceaseless vigil with the polar star. There is little reason to suppose that the genial brain which planned that mightiest of human tombs differed in any appreciable degree in either its capacity or its scientific knowledge from Archimedes or Newton. Men who could thus observe and thus build must have been reasoners as well. But if any one among them had drawn the figure of Bion, the sands of the desert cover it as they cover him.

Until that figure had been drawn, or until such a train of reasoning had been followed out, men's ideas about this earth 


\section{THE DOCTRINE OF A ROUND EARTH 69}

could scarce have been less fanciful than those of a Moro Islander now. They were woven of dreams, and dreams to which, in their essence, the greater part of the human race still clings. But at least in the fifth century before Christ, while sacrifices were yet offered before the golden masque of Pallas in the Parthenon, and the wisest among men still consulted the oracle at Delphi, to a slender band a vision of the truth had come. As the truth spread and the earth widened the sacrifices ceased; the Homeric gods, too proximate to men, retired from Olympus to take up their residence in the vaguer spaces of the sky.

In another century Aristotle could note without surprise, without even naming the source or indicating the methods employed, that the geometers had put a girdle round the earth. Not merely its figure but its actual size had been determined. How was it done? 



\section{CHAPTER VI}

ERATOSTHENES AND THE EARLIEST MEASURES OF THE EARTH 
THE similitude which many have fancied between the superiority of the moderns to the ancients, and the elevation of a dwarf on the back of a giant, is altogether false and puerile. Neither were they giants nor are we dwarfs; but all of us men of the same standard, and we the taller of the two by adding their height to our own: provided always that we do not yield to them in study, attention, vigilance and love of truth, for if these qualities be wanting, so far from mounting on the giant's shoulders, we throw away the advantage of our own stature by remaining prostrate on the ground.

Ludovicus Vives; quoted by Lewes, Aristotle. 


\section{CHAPTER VI}

\section{ERATOSTHENES AND THE EARLIEST MEASURES OF THE EARTH}

ON a leisurely summer afternoon, as you lie and look up into the cloudless blue, one may agree that it is very charming and very well done; so much so that one may easily wish all life like that-and usually does ; but it hardly seems very informing nor even so very stimulative to investigation. For example, who, without a hint from history, would ever believe that there is in the sky a simple way to compute the circumference, and hence the diameter, the area, and the solid bulk of this globe ! -yes, and to measure the obliquity of the ecliptic, or tip of the earth's axle to the plane of its orbit round the sun as well.

Yet Eratosthenes of Cyrene, the myriad-minded keeper of the Alexandrian Library under Ptolemy Euergetes-scholar, poet, critic, geographer, physiographer, mathematician, inventor, mechanician, astronomer, wit and sceptic-found a way and did it. I have told of this method elsewhere; as I gaze into the non-committal emptiness above me, the marvel of it lingers still.

Watching the sun as it nears the height of the arching blue overhead, I note that a post near where I lie casts a slanting shadow, as a sundial does. I reflect that if I go southward the length of this noonday shadow grows less and less, and I know that there is a place where, in the longest day of the year, it will disappear entirely. This is when the sun is sheerly in the zenith, and has reached its summer station, where it will seem to stand still for a few days, then again recede; the solstitium of the Latins. If I can find out just how far to the south this point lies, it is evident that I hold in my hands the solution of the problem. I have only to take out my watch, or my jack-knife, hang it on a string and make a plummet of it, and holding it over the farthest edge of the shadow cast 
by the post, measure the angle between the plumb-line and the slant of the shadow thus :-

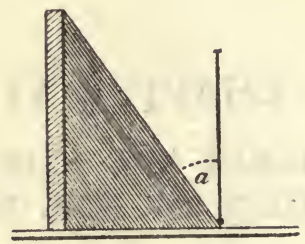

FIG. 3.

It is evident enough that, if the earth is round and the sun at a very great distance, the angle that is marked $\mathrm{A}$ will be to all intents the same as if it were taken from the centre of the earth. But this means that the angle will cut out the same arc in the circle of the sky as, from the centre of the earth, it would cut out of the circle of the earth's circumference, as another figure will make clear enough :-

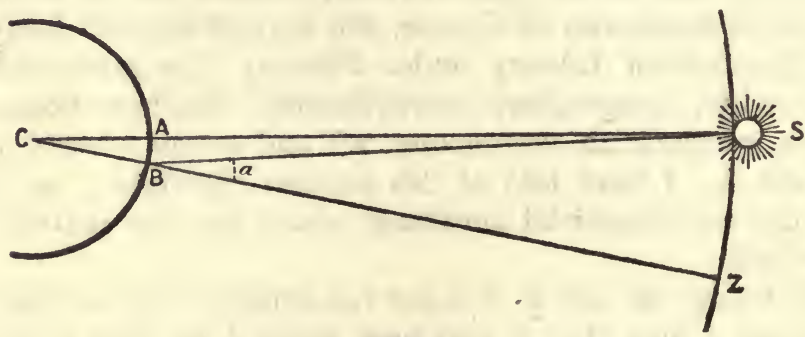

Fig. 4.

The line $\mathrm{B} \mathrm{Z}$ is my zenith, the direction of my plumb-line. The angle I have measured is the angle marked A, and for a rough calculation is the same as the angle $C$ at the earth's centre. The arc of the circle $\mathrm{S} Z$ is the same as the arc A B on the surface of the earth. If the angle $\mathrm{A}$ is about $7^{\circ} \mathrm{I} 2^{\prime}$, the arc $\mathrm{A} \mathrm{B}$ is onefiftieth of the earth's circumference. If the distance from A to $\mathrm{B}$ on the earth is 500 miles, then the earth is 25,000 miles around. The globe has been measured in half-an-hour. What could be simpler ?

I said above "It is evident enough." Laplace used to use this phrase rather freely in his expositions. Sometimes he 
was asked to explain why it was so evident, and it is recorded that it often cost the great mathematician half a day to work back through his calculations to make the fact clear. Much depends on the point of view. Eratosthenes lived at the apex of a civilisation inferior in but little to our own. To reach the point where his ingenious mind might divine the method I have described above was a long travail. Perchance a hundred thousand years stood between cave-dwelling man and the theorems of Euclid, which enabled the Alexandrian astronomer to take the earth in his hands as a vase and say: This is so many inches around.

Was Eratosthenes the first? Probably not by many centuries. Aristotle, in the work which has come down to us under the title $\mathrm{De}$ Coello, has a line about the geometers who had fixed the circumference of the earth at 400,000 stadia. He did not have the exact and measuring sort of a mind, and he is so little curious of the matter that he gives no hint of how it was done. It is not impossible that he did not know; that, as Bailly conjectures, the figures had been sent him by Callisthenes from Babylonia, when the latter journeyed thither with the silver shields of the Macedonian. It is Bailly's idea that the measure may have been even of Chaldean origin, and hence very old.

There was a curious tradition, preserved by Achilles Tatius, that the Chaldeans had measured the earth in terms of a day's march. They said if a man were able to walk steadily, and at good pace, he would encompass the earth in one year. They counted that he would do 30 stadia (about 3 miles) an hour, and so computed the great circle of the globe at 263,000 stadia, which was very close to the estimate made by Eratosthenes. Whether they employed the same scheme in their measurements as he did, we do not know. But there were others as simple and direct as the Alexandrian's. For example, the foundation which bears up the weight of the Great Pyramid was levelled with an astonishing accuracy; and we have already noted that the axis of the long tunnel leading from the subterranean chambers beneath it was directed toward the polar star. The lines of this remarkable passage-way and the foundation of the pyramid naturally form a certain angle, as the figure below will disclose. (See Fig. 5.)

As the foundation is the plane of the horizon, the angle 
indicated at $a$ gives the elevation of the pole-star above the horizon at that point.

With a party of geometers, here quite literally "earthmeasurers," we take boat and cross the Mediterranean, and from the Mosque of St. Sophia make the same observation. But the angle is no longer the same; the pole-star is higher up toward the zenith; the angle it makes with the plane of the horizon is greater. As we have calculated the two angles in degrees, then we may subtract the greater from the less; we do so, and find that the difference is about $\mathrm{Ir}^{\circ}$. Instructed by Bion, we know that this change is due to the fact that the pole-star is fixed, and that we have been travelling over the curving surface of a globe. A moment's reflection makes it clear

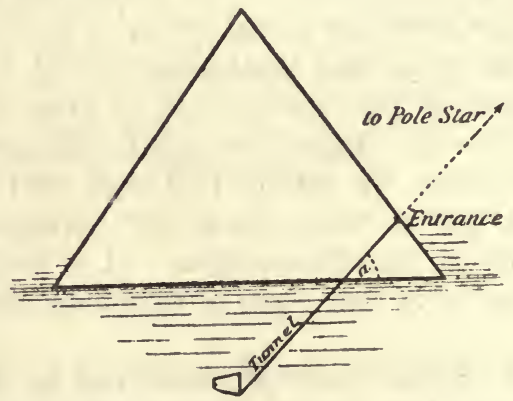

FIG. 5.

that these $\mathrm{II}^{\circ}$ are in reality $\mathrm{II}^{\circ}$ of a great circle of the earthsupposing, of course, that the Christian capital of Constantine is directly north of Cairo (it is a little out). We have then only to know the distance we have come to calculate the entire circumference of the circle.

This is to all intents the method now employed, and it requires for its successful application only a water-level, an angle measurer, and a known distance along a meridian. The device is practically the same as that of Poseidonius, friend and master of the accuser of Catiline. Instead of the polestar Poseidonius chose Canopus, which, viewed from the island of Rhodes, just grazed the horizon; at Alexandria it rose a certain height above, and he measured the angle, some seven degrees.

Yet these various measures differed greatly. That reported 
by Aristotle was 400,000 stadia ; $j^{1}$ Archimedes speaks of 300,$000 ;{ }^{2}$ Eratosthenes' figure was $250,000^{3}$ (or 252,000); Hipparchus wished to increase this to 275,$000 ;{ }^{4}$ Poseidonius to reduce it, fixing it at $240,000^{5}$ stadia according to Cleomedes, at I80,000 ${ }^{6}$ according to Strabo. This last figure was that adopted by Ptolemy, ${ }^{7}$ and this and other errors of Ptolemy were the basis of Columbus's belief that India was near. Had he known the true distance, possibly he never would have sailed.

How near was the truth ? We cannot answer, for the exact value of a stadium we do not know. The ill-fated Bailly, ${ }^{8}$ and following him (without a suggestion of credit) Laplace, ${ }^{9}$ noting that the varying estimates stand in a simple relation to each other, supposed that they might each be the transposition of an original measure of great antiquity and great accuracy into stadia of varying length. This may be true, but there is a remark of Strabo, ${ }^{10}$ near contemporary of Poseidonius, somewhat troublesome to this view, wherein he observes: "If, of recent measurements, we prefer those which diminished the size of the globe, such as that adopted by Poseidonius; which is about I80,000 stadia," \&c.-as against the 252,000 of Eratosthenes.

If the measures were really different, we may conclude that the closest was the latter, and that it was but little out of the way. It does not appear that any new measures were made in Christendom before those that were made by the French physician, Dr. Fernel, in I5I7, five years after the ships of Magalhaens had returned from their circumnavigation of the earth.

Seven hundred years before, in the golden age of Arabian culture, when all Europe had relapsed into barbarism and Bagdad shone as a centre of learning and of light, a series of measures had been effected on the plains of Shinar and of
1 De Callo, ii. I4.
2 Arenarius, ii., Introduction.
3 Pliny, ii. I08.
- Cleomedes, p. 65 ; ed. Blake.
5 Cleomedes, loc. cit.
- Strabo, vol. i. p. 140; ed. Bohn.
7 In his "Great Syntaxis" (Almagest of the Arabians).
8 Histoire de l'Astron. Moderne, tome i.
9 Exposition du Systeme du Monde, Book V. chap. ii.
10 Loc. cit., i. p. II 4 ; ed. Bohn. 
Mesopotamia, under the khalifate of Al-Maimun. When that princely patron of science and letters sat upon the Mohammedan throne, Eratosthenes had been dead a thousand years; so long did it take before his ideas, with the voyages of Columbus and $\mathrm{Da}$ Gama, might come into practical effect in the affairs of the world; so long did the weight of ignorance and a degrading superstition hang over and benumb the minds of men.

Eratosthenes, we know, was not merely one of the founders of astronomy, but the founder of scientific geography. And what a widening of horizons the new map of the world, as constructed by the Alexandrian geographer, must have wrought! Means of communication then were slow; no "liners" then raced straight and swiftly from port to port. Men did not venture far. Though there were records of the compass in use in China nine centuries back of this, it was unknown to the Greek and Tyrean mariners, who crept along the coast of the Sea-In-Media-Terra, the known terra, and out through the Pillars of Hercules to Ultima Thule. From the ports of Tyre to the Gateway of the Night was scarce 2000 miles. The Hellespont and the Euxine carried the map-maker's stylus scarce another thousand eastward. Half this combined distance reached from the mythical borders of Hyperborea to the fabulous regions of the Upper Nile. The known earth was a rectangle of about the present size of the United States. And the measures of Eratosthenes made this a scant fortieth part of the whole surface of the globe. In his estimate, what was known was to the unknown as 39 to I.

Is it the impression that we have here merely an intellectual conception-that the meaning of it in no wise came home to any of the ancients-that there was no vivid sense of new continents, new worlds to explore ?-Listen, then, to a passage in old Strabo; he is telling of the ideas of Eratosthenes, who, he says, held "that if the extent of the Atlantic Ocean were not an obstacle, we might easily pass by sea from Iberia (i.e. Spain) to India, still keeping in the same parallel (of the temperate zone), the remaining portion of which parallel, measured as above in stadia $(252,000)$ occupies more than a third of the whole circle; since the parallel drawn through Athens, in which we have taken the distances from India to Iberia, does not contain in the whole 200,000 stadia." 1

1 Strabo, i. p. Ior ; ed. Bohn. 
Here are the identical ideas of Toscanelli and Columbus put forth by the man most eminent in science and learning in the most learned, most innovating, sceptical, and restless city of antiquity; and, what is yet more extraordinary, with the same erroneous ideas of distance. The Alexandrian figures the span from Iberia westward to India at " more than a third" of the whole circle. We know now that it is twice this. He was misled by the estimates of the distance from India to Iberia, which could only be traditional, and not by his ideas of the size of the earth. Seventeen hundred years afterward, Columbus and his Florentine proponent, accepting the guidance of Ptolemy, were still further from the truth.

Again, is it to be supposed that, great as was the fame and authority of the Alexandrian geographer, his ideas fell upon listless ears ?-By no means, for in one way and another his Geographica stirred a whole host of commentators and disputants, among them Polybius the historian and the great astronomer Hipparchus. At near three hundred years after, Strabo writes a vast work that is little more than a running comment on the statements, estimates, and ideas of his predecessor. Strabo is especially interested in this thought of the circumnavigation of the earth, and, apropos of the passage given above, offers a curious muddle of prophetic insight and logic bad enough for Aristotelian; but you will recollect that Strabo was very old when he wrote :-

"Here, too, his reasoning (Eratosthenes') is incorrect; for this speculation respecting the temperate zone which we inhabit, and whereof the inhabitable earth is a part, devolves properly upon those who make mathematics a study. But it is not equally the province of one treating of the habitable world. For by this term we mean only that portion of the temperate zone with which we are acquainted. But it is quite possible that in the temperate zone there may be two or even more habitable continents, especially near the circle of latitude which is drawn through Athens and the Atlantic Ocean" (i.e. the Pillars of Hercules). ${ }^{1}$

What an amazing guess! And consider that all this was from four to seven centuries before the churchly fathers were gravely deciding that the earth could not be round, because then the folk at the antipodes would be hanging by their feet with 1 Loc. cit., i. p. ro2 ; ed. Bohn. 
their heads downward in the air, which was so manifestly absurd!

A shorter route to India; two or more new and probably habitable continents; but one-fortieth of the globe known; all the rest a field for exploration and conquest! - such were the broad and alluring vistas which the pages of Eratosthenes opened to the adventurous minds of that keen and teeming time. One would think that the spirit of the ardent youths of that day would have leapt within them to be gone upon the quest. It is fairly certain that the continent of Africa had by then been sailed about, perhaps more than once. There was a time when at its height the University of Alexandria numbered I4,000 students. On the wharves of the city were exposed the wares of a hundred nations. Yet if there was any Columbus to stand before the court of the Ptolemies to plead for ships, we have no word. Had there been, we may be reasonably sure that he never would have waited twenty years!

Why was there no one to venture out ? The unknown must have beckoned then as now; their pulses must have throbbed with the same fever of the Just-Beyond. But they knew then of no strange north-pointing needle to guide them over the trackless seas. Perhaps they did not half believe that what this gravely jesting old keeper of the books taught was true. No revolving cylinders had yet been so contrived as to reproduce his papyrus leaves ten thousand in an hour, and spread them through the lands; there were no lithographers to duplicate his curious map. All that was done by slaves, as scribes. Books cost them like Old Masters now. Trade was despised; and Alexander, immortal in the splendid city he had founded, was among the gods. The Incas and the Aztecs might rear their temples in peace for fifty generations more.

But at least the earth had been measured. It was no longer endless or indefinite; it was now a ball, 252,000 stadia at near count in circumference. A tremendous stride; a great and splendid piece of work. Above all the Alexanders, Cæsars, Tadema-Napoleons, I set the brain which first spanned an earth, over whose little patches these fought through their empty, bootless lives. Why should we have no poets to celebrate so great a deed ?

But advancing knowledge, which had thus envisaged a vast but not immeasurable globe, unsupported by the emptiness of 


\section{EARLIEST MEASURES OF THE EARTH 8I}

space, was not here to halt. The geometrical constructions of Pythagoras and Democritus, which in the hands of Bion and the Alexandrian had found so fruitful an application, were destined to yet wider conquests. If triangulation of the stars might thus disclose the size and figure of the earth, might it not reach out and span the moon as well-the moon and, yea, the sun!

But how ? 



\section{CHAPTER VII}

ARISTARCHUS AND THE DISTANCE AND GRANDEUR OF THE SUN 
INTELLECT is the swiftest of things, for it runs through everything. Necessity is the strongest of things, for it rules everything. Time is the wisest of things, for it finds out everything. Thales. 


\section{CHAPTER VII}

\section{ARISTARCHUS AND THE DISTANCE AND GRANDEUR OF THE SUN}

UPON some far crag of the Matterhorn, fancy, if you will, that a man was born and brought up with no other knowledge of the world than what he there might gain. Conceive that this crag is surrounded on every side by precipices, shelving down thousands of feet to depths hidden by the clouds, so that, by no construction he may devise, can he escape. He looks out over an Alpine waste, and sees in the distance other vast crags lifting their lion heads from out the mist. In intervals of guarding his flock of goats, - I picture him gazing across the grey expanse with a vague longing to form some estimate of how far these far-off peaks may be. What idea can he gain ?

He has no instruments save such as he may carve with! a belt knife; but in his cabin there is a volume of Euclid. Stimulated by the attentive study of that Open Sesame to the mysteries of space and form, he seeks to learn what he may.

One day I see him note that, as he holds up his hands to scan the mountain-side in search of his flock, he seems to have two hands; he shuts one eye, one of the hands disappears; at once he has begun to work out the theory of vision. $\mathrm{He}$ next observes that if he holds up his finger at arm's length, and with one eye open, sights across it to some object on the further wall of his hut, or against the mountains, the position of his finger seems to shift as he shuts the one eye and opens the other. Try, and you observe the same thing.

Just the same thing happens when he takes a long walk from his habitation and sees two peaks shift in their position to each other, as he changes his point of view. Aided by a theorem of Euclid, can he combine these new experiences to make a measure? He sits down, and on a smooth chip of wood traces this figure. (See Fig. 6.)

Seen from the door of his cabin, the two peaks, $P$ and $Q$, 
make a straight line. He walks away to a distant point at $\mathrm{M}$; the two peaks fall apart; they are now seen under a different angle, or, as the astronomers say, they have a different parallax.

Lines drawn from his new point of view to the two peaks and back again to his hut form two triangles, and these are, moreover, right-angled triangles. He has then only to measure the two angles at $M$ to construct these triangles in right proportion, and knowing the distance he has come from his hut (the line $\mathrm{H} \mathrm{M}$ ), he may quickly compute the respective distances of the two peaks.

The position of the man upon the Matterhorn differs in no essential way from that of man upon the earth, save perchance that our isolation is yet greater. We cannot leave the crag upon which we dwell, and though it conveniently revolves,

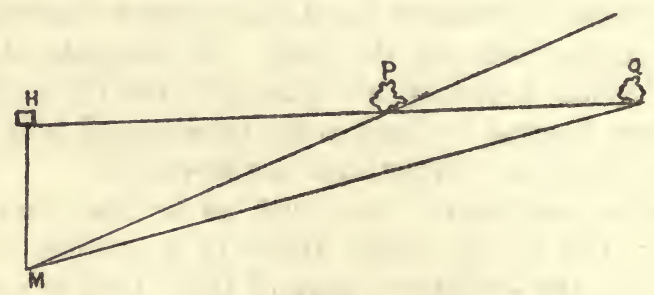

FIG. 6.

so that we can see what is underneath it, this is little material gain; we are bound to it as Ixion to his wheel.

It is evident that, at the time of a solar eclipse, the sun and the moon stand in something of the relation of the two peaks we have imagined; so that if, at the moment the moon touched the limb of the sun to the eye of one observer, the angles of their apparent separation were taken by another at some distant point on the earth, it might be possible to reckon roughly the relative distances. But science in the ancient times was not organised as now. Even in the golden days when the Greek kings ruled in Alexandria, they did not send expeditions to the Cape of Good Hope, or build observatories in Peru. As far as we can make out, there was little co-operation or concerted action, which is the very life of modern knowledge; though the great university at Alexandria was an exception, they mostly went it alone, unaided by church or prince or state. 


\section{DISTANCE AND GRANDEUR OF THE SUN 87}

Moreover, it was difficult then to get a long base for observations, such as their crude measures of angles required. So, beginning with the moon, they resorted to the ingenious plan of taking its parallax when it lay in the horizon of one point of observation. Obviously at this moment the direction of the moon was at right angles to a plumb-line at that point, and hence to the centre of the earth, as a glance will show :-

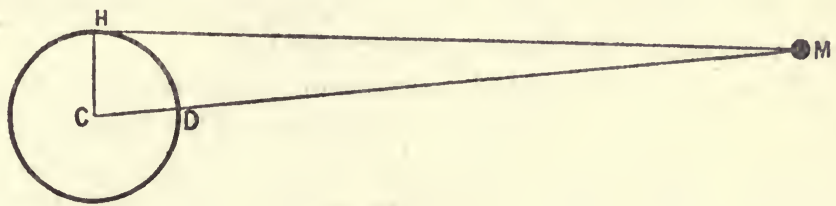

FIG. 7 .

It is clear that if a second point on the earth, as $\mathrm{D}$, can be found where the moon is at the same moment directly on the meridian, then a line from the moon through this point will equally pass through the earth's centre. As a matter of fact, it would be rather painful work to locate this point, but it can be reckoned, and we have again a right-angled triangle in which the distance of the moon is given in terms of the earth's radius, $\mathrm{C} \mathrm{H}$. Ptolemy, in his treatise, describes another simple method, and there were doubtless others still. They did not agree very closely; the distance is, in reality, a troublesome quantity to compute, because it varies. Its least and greatest distances were fixed at from 50 to 85 earth's radii, so that, taking 70 as a mean, they were not far out. And with the circumference of the earth fixed, they knew that the moon was somewhere around 240,000 miles from the earth.

They could likewise note that its apparent or visual diameter is half-a-minute, and, the distance known, could compute that this mild-mannered orb was in reality a colossal thing-a body some 2000 miles through, that is, a quarter of the diameter of our massy earth.

The temperature of the calculating spirit is proverbially low; but if the hand of Newton could so tremble with excitement as he foresaw that his figures would demonstrate the great law he had divined, with what profound amazement must he who first computed the moon's magnitude have laid down his pen! This softly glowing disk, whose apparent size is so 
slight that, looked at between thumb and forefinger held at arm's length, the fingers nearly close-is this a body so vast that it would almost cover the then known world ?-a body whose height or diameter is equal to the entire length of the Mediterranean, which cost the mariners in their vessels a fortnight or more to traverse. And this colossus of the skies swings free in space! It clearly revolves about the earth! What holds it in its place?-He to whom all this came first would doubt the validity of his own computations; he would be unable to realise that such a thing could be.

And yet, as he reflected, conviction must have come. In climbing mountains, whence, in a clear atmosphere, objects are visible a long way, he must have noted how, at a distance, huge edifices sink away to a point; a great city, even, becomes a patch. But, ascending even the highest mountains, the moon draws no nearer. Compared with its elevation above the earth, the height of the tallest peaks seems nothing. Certainly it must lie afar off ; and if this is true, the simplest of calculations enforces the belief that its bulk is vast beyond belief. Appearances had again been overthrown.

It remained to consider the problem of the sun. If the eye may be so deceived as to the grandeur of the moon, to what conceptions of immensity must the imagination rise to picture the extent and distance of the monarch of the day?

Here again simple geometrical considerations sufficed to establish the groundwork of a just estimate. The sun lies behind the moon: the eclipses showed that; and it must be far behind, because the shadow cast by the earth is a diminishing cone, and the sun is therefore larger than the earth. If it were smaller, the conical shadow would be divergent. The earth, they had found, was three or four times in diameter the size of the moon; the sun must therefore be at least six or eight times. And yet, averaging the various eclipses, the moon in transit just about covers the disk of the sun; their apparent size is the same.

A body which is eight times another in diameter and yet appears to be the same in size, is eight times as far away. If the moon is distant about sixty earth radii, the sun must, therefore, be distant at least four or five hundred earth radii. It must be at least two million miles away! How the world was growing! 


\section{DISTANCE AND GRANDEUR OF THE SUN 89}

So much was self-evident; was there any way to make an actual measure? The first we know of to attack the problem was the predecessor of Eratosthenes in the school of Alexandria, a contemporary and possibly the teacher of Archimedes, when the young Sicilian went from Syracuse to Alexandria to school. This was that Aristarchus who, to Laplace, " paroit être dans l'antiquité celui qui eut les plus justes notions de la grandeur de l'univers." He was, as we shall see, the forerunner of Coppernicus; if grandeur of conceptions be a measure of the brain, or ingenuity of its powers, then we must rank Aristarchus with Democritus and Archimedes as one of the three or four most acute intellects of the ancient world.

The eccentric actions of the moon, the varying shadow it casts, or receives, its so-called inequalities, were then among the principal problems of the heavens; and over them the Alexandrian astronomer must have puzzled with the rest.

Pondering over the various "phases" which the moon presents, it presently came to him that the extent of the moon's surface visible to us depends on the direction of the source of illumination-that is, the sun. So, as the moon swings in its circle, it will reach its first "quarter" in a little shorter time than it passes from this to the second "quarter," or full moon. This is clear from a moment's consideration; since the moon shines by the light of the sun, then when its disk is, to our eyes, just cut in two, it is at right angles to an observer on the earth, as the figure describes:-

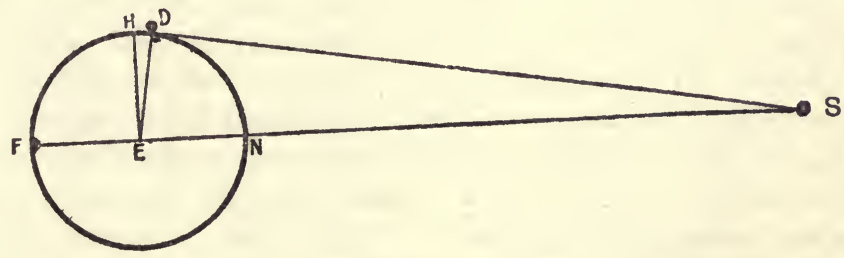

FIG. 8.

Now, unless the sun be at an infinite distance from both the earth and the moon, it is clear that the time of passage from a new moon at $\mathrm{N}$ to its first "quarter" at $\mathrm{D}$ must be a little less than through a full quarter of its orbit, i.e. to $\mathrm{H}$; so the time from the first quarter will be a little longer to a full moon at $\mathrm{F}$ by the length of the arc $H \mathrm{D}$. It is perfectly easy to time the 
moon's revolution and its phases. Aristarchus did this and believed that he found the first quarter twelve hours shorter than the second. To satisfy this result it was a simple matter to compute that the line from $\mathrm{E}$ to $\mathrm{S}$-that is, from the earth to the sun-must be about eighteen or twenty times the length of the line from the earth to the moon.

Here, then, was a measure of the distance of the sun! But was there any certainty that it was right? Was there any way to check it, to confirm it?

It is not very difficult to see that if, at its first "quarter," the face of the moon appears to us just cut in two, the moon forms with the earth and the sun a right-angled triangle, such as $\mathrm{S} \mathrm{DE}$ in the figure. It is then only needful to measure the angle at $\mathrm{E}$ - that is, the angle subtended by the moon and sun - to be able to draw this triangle in the right proportions. This would give the distance of the sun in terms of the distance of the moon.

All this seems simple enough on paper; but of an afternoon when the sun is setting and the moon is in the sky, it is worth a moment's thinking over as to whether such an idea would ever have come to you. Note, too, that the angle between the moon and the sun'is very nearly a right angle, so that the smallest error will have enormous consequences. Consider how difficult it is to tell just when we see exactly half the moon. One will think less then that Aristarchus failed than of the noble mind which could work out such an idea.

The Alexandrian's measure of the angle was nearly three degrees too small; his reckoning was out by the $\frac{1}{120}$ th part of a circle. It is only fair to add this has been computed from other data; the angle is almost as difficult to measure in our day as in his. So the line opposite this angle was about twenty times too short. It is evident that his error lay in fixing the moment when the moon was at right angles; for the time of passage to the first and second quarter was wrong in exactly the same proportion. Aristarchus reckoned this difference at twelve hours; in reality it is on the average only thirty-six minutes. He was right in his theory; his errors lay beyond his powers to control. With his resources we could do no better now.

But attend to the curious consequences. Involved in the same initial mistake, the impossibility of fixing the exact moment 
of the dichotomy of the moon, the one result was confirmed by the other, though the two seemed reached by wholly independent means. By yet more singular mischance, a third method came to the support of the other two.

This third means lay in a consideration of the size of the conical shadow cast by the earth and the time it takes for the moon to pass through it during an eclipse. Whether this idea was present to the same amazing brain from which had sprung the others, we do not know. It must have been very early perceived that in this shadow cone was some sort of a clue; Aristotle had studied it with attention, and he was not eminent either as an astronomer or a mathematician. Aristarchus had certainly given it a great deal of thought, for he had made a measure of it and set its diameter, which is not very far from the truth. It is certain that he had some method by which he estimated the relative diameter of the sun and earth, as we shall see; and the problem could have been worked out in this rough way :-

Knowing the size of the earth, and the size and distance of the moon, we may note, during the total occultations of the moon, the maximum time elapsed from the moment the edge of the moon touches the earth's shadow to the moment it begins to emerge. This will enable us to construct a figure showing the slant of the conical shadow of the earth, thus :-

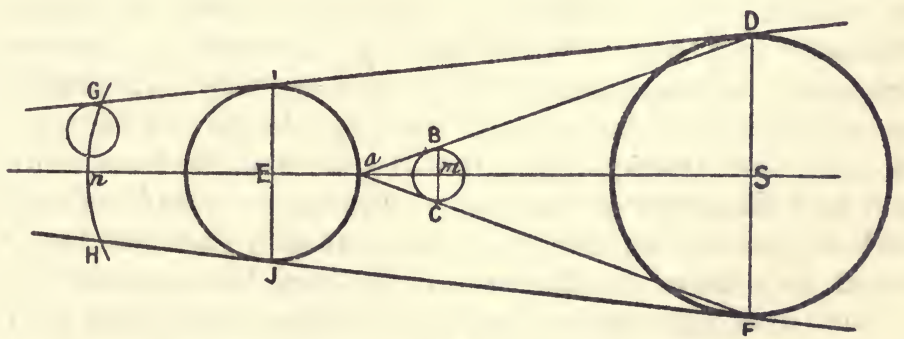

FIG. 9.

On the other hand, during an eclipse of the sun, the moon on the average just about covers the sun's disk. That is, to an observer on the earth at $a$, the sun and moon during a total eclipse of the sun subtend, on the average, one and the same angle, $\mathrm{B} a \mathrm{C}$ or $\mathrm{D} a \mathrm{~F}$. So, one has merely to prolong the lines 
of the earth's shadow, G I H J, and the lines, $a \mathrm{~B} a \mathrm{C}$, until the two meet as at $D$ and $F$, to have the figure we have drawn. Knowing the distance from the earth to the moon, one could measure the distance to the sun with a foot-rule.

Did Aristarchus do it? Possibly not. The device is not in his treatise "On the Distance and Size of the Sun and Moon." It is likely that it was a development of the next generation or so.

Living in that same wonderful day was another giant, Apollonius of Perga, styled "the great geometer." His was the glory, 'twas said, to have applied geometry to the problem of the heavens. Evidently by this was meant the higher geometry, for, as we have seen, Bion and Aristarchus and Eratosthenes and many another had already given good account of themselves in the use of geometrical methods. Apollonius developed the theory of conic sections, and introduced the idea of epicycles as an explanation of the motion of the planets. This latter idea was borrowed by Hipparchus, "greatest observing astronomer of antiquity," and it was doubtless the example of Apollonius which led him to the discovery of the idea of parallax usually attributed to him. It was doubtful, though, if he was the actual discoverer. The observation that the stars, like other objects, change in their apparent position under different points of view, must have been almost as old as astronomy, and a geometrical method for taking advantage of this must have been found very early. Be this as it may, the problem of the shadow cone, as is clear from the pages of Ptolemy, ${ }^{1}$ had been worked out by Hipparchus, apparently with great precision, but with the strange result of confirming the calculations of Aristarchus. He, too, found the distance of the sun about twenty times that of the moon, or from 1379 to I472 half diameters of our globe. Ptolemy, a couple of centuries later, tries his hand at the matter, but with no better success indeed, he reduces the distance to I2Io such half diameters.

But with three distinct methods leading identically to the same result, there could now be little question of their truth. There seems indeed to have been no question for another seventeen centuries, and until Galileo and the telescope had come. Hipparchus' method-it is generally so styled-is reproduced, with new proofs, but similar estimates, in the $D e$ Revolutionibus of Coppernicus, A.D. I543.

1 Almagest, Lib. V. chap. xiv. xv. 
The theorem of Hipparchus gave not merely the relative but also the absolute measures of the solar and lunar distances, hence a direct measure of their size. Cleomedes ${ }^{1}$ tells us that Hipparchus computed the sun's bulk at I50 times that of the earth; Ptolemy made it I70 times. But Aristarchus, by what method he does not state, figured the diameter of the sun at between six and seven times that of the earth, hence about three hundred times its bulk. He sets the moon's diameter at one-third that of the earth-an error of but one-twelfth; admirable, if yet imperfect approximations. The march of the mind had begun!

Yet was this the nearest approach which the ancients made to the truth? There is, in an oddly-jumbled work, Opinions of Philosophers, attributed, with slight probability, to familiar old Plutarch, a paragraph which says that Eratosthenes had engaged the same problem. True to his love of concrete measures, he gives the distance of the moon at 780,000 stadia, of the sun at $804,000,000$ stadia. Marvellous prevision of the truth! For though he makes the distance of the moon only about twenty earth radii-too small by two-thirds of the reality -his figure makes the sun distant 20,000 radii, which, as nearly as we may estimate the stadium, was practically the distance that, after three centuries of patient investigation with micrometers and heliometers, is set down as the reality. What was his device? how did he guess so wonderfully? We have no mortal idea. Perchance in some buried villa at Herculaneum, or elsewhere, a papyrus may exist which may one day tell us. Until then we have not so much as a conjecture.

The estimates of Eratosthenes are somewhat vitiated by a remark we find in Macrobius, ${ }^{2}$ that he gave the diameter of the sun at about twenty-seven times that of our earth. His great predecessor, Aristarchus, had already fixed the visual diameter of the sun at half a degree, which required that its diameter should be about $\frac{1}{115}$ th of its distance; this, on the figures of Eratosthenes would have made the sun at least ninety times the earth's diameter, or 700,000 times its bulk. But Macrobius came in the fifth century A.D., and it may be that his remark is an error. True, the figures of Eratosthenes

1 De Mundo, Lib. I. chap. i.

2 Somnium Scipionis, Lib. I. chap. xx. 
make the distance of the sun a thousand times that of the moon, an estimate two and a half times too great; but in the face of his predecessor's figure of twenty times what a sublime and daring error !

It is with a deepening interest, bordering even upon amazement, that we find yet another great investigator of antiquity announcing similar but quite distinct estimates. This was Poseidonius, the teacher of Cicero and of Pompey, one of the most contradictory of characters, now seeming but a merest polymath, now one of the most acute and original thinkers of that ancient day. We have already noted that his measure of the earth, adopted by Ptolemy, was the sustenance of Columbus. He had closely studied the refraction of light, and gives us a really wonderful calculation as to the height of the earth's atmosphere. In the pages of Cleomedes we learn that he equally attempted to establish the distance of the stars. He puts the moon at two million stadia away, the sun at five hundred million! This, on his earlier estimate of the earth's diameter, would place the moon at fifty-two radii of the earth, which would be nearer than the computations of Hipparchus. It would make the sun's distance 13,000 radii.

If we take his later figure (I80,000 stadia), the distance would become $I 7,400$ radii, an estimate which, considering the necessarily wide limits of error, does not differ greatly from that of Eratosthenes, and equally little from the truth. Compare it with the thirteen hundred radii of his forerunners! Compare it with the notions of Epicurus, almost his contemporary, a very wise and large-minded man in his way, who yet believed that the sun might be a body two feet across !

By what means Poseidonius reached these astonishing computations, what instruments he had, we do not know, or whether his method was the same as that of Eratosthenes. His own works have perished, though those of his friend Cicero have survived; and Cleomedes, who has preserved his figures, is silent. By means of a clepsydra, or water-clock, he had computed the sun's disk at a little over twenty-eight minutes of arc, whence he calculated the actual diameter at four million stadia, or seventy times the diameter of the earth. Consider his age, and you will realise how intrepidly he followed whithersoever his calculations carried, even to such unbelievable con- 
clusions as this. In the face of such consistent results it is with difficulty that we can credit the statement that he regarded the moon as a body larger than the earth. The report is the more incredible since he had so closely computed its distance, and since its visual diameter is so readily measurable. On the other hand, his computation as to the height of the earth's atmosphere, the first we know of, would command respectful attention for any physical investigation he might make.

But for either of these estimates, which reached so singularly near the truth, what sort of accuracy may we presuppose ? What idea can we gain of their value ?

The large armils erected at Alexandria for Eratosthenes by the enlightened Ptolemy Euergetes had a scale, as we know, divided down to the sixth of a degree. A moment's consideration suffices to show that, to be of any value for stellar measurement, they must have been at least fifteen or twenty feet in diameter. They were doubtless made with exceeding accuracy, for some of the observations made with them have been of value in verifying the conclusions of modern astronomers. Probably they were better instruments than any known in Christendom until Tycho's day. But even with these they could make but rather rough approximations. From a careful discussion of the evidence, Bailly ${ }^{1}$ concludes that the accuracy of the ancients did not surpass five minutes of arc, or onetwelfth of a degree. The parallax of the sun, as we know now, is less than ten seconds of arc, or not much more than onefiftieth of the limit within which these giants of the past could be sure. How then could they guess so well ?

Baffled by difficulties, the ingenuity of man will sometimes turn in unexpected ways. The ancients may have found a path that is lost to us. We cannot say. What we know is the sun's parallax could have been measured correctly by no instrument then known.

Galileo, with his telescope, sought it in vain. All he could know was that it was unobservably small, and the sun therefore almost infinitely far away. It was not until after twenty-threeyear-old William Gascoigne, who fell at Marston Moor, had slipped a wire-netting across the focus of the telescope, that the observation was possible. Galileo, Descartes, Kepler, all were dead when it had, at last, in 1670 , been made.

1 Histoire de l'Astronomie Moderne, i. 457. 
It revealed, as we know, that the distance and therefore the diameter of the sun was not nineteen but four hundred times that of the moon. But what did it matter? Even at nineteen times, the sun must be distant from the earth not less than five million miles; it must be a body not less than 50,000 miles thick, or seven times the diameter of our vast globe. Who could believe it then? How many dwellers upon this earth truly realise it now?

And let your fancy linger for a moment over this singular fact of history: a space of three centuries separates us from the invention of the telescope, the microscope, the thermometer, the air-pump, the first electrical machine; from the days when the Pilgrims landed in America, when the plays of Shakespeare were first acted in London, and when Bruno was burned in the flower-market of Rome.

At a space of three centuries before the first Christian had knocked at the Roman gates, before the first Cæsar had been crowned, and when Carthage was still mistress of the seas, the astronomers of Alexandria had in their possession at least a correct relative knowledge of the bodies of the solar system.

Was there any thinker among them to go further, and seek to unravel the tangle of their apparent motions, to fix the common centre of these motions, and set this solid seeming earth for ever spinning

"Down the ringing grooves of change"? 
CHAPTER VIII

THE TURNING OF THE EARTH : THE FIXITY OF THE SKY 
For Plato brings in the Egyptian priest, saying to Solon: "You Grecians are ever children, having no knowledge of antiquity, nor antiquity of knowledge."

BAcon, Advancement of Learning.

History, at least in its state of ideal perfection, is a compound of poetry and philosophy.

Macaulay, Essay on Hallam. 


\section{CHAPTER VIII}

\section{THE TURNING OF THE EARTH: THE FIXITY OF THE SKY}

WE seem to go through the world nowadays with eyes upon the ground. We are no longer interested in the pageant of the sky. The shows of earth enchain us. City streets are full of a restless life, and when, grown weary of the stir and din, we take flight to the country, it is the green of the fields, the splendour of the sun, we see. The vivid lighting of the cities hides the stars, and on the lonely hill-tops the patient shepherds no longer guard the night.

In the olden days, on Mesopotamian plains, or along the untroubled current of the Nile, life fared strangely otherwise. There were cities, true; and the days of the eager and restless Athenians, the gay and sceptical Alexandrians, the future St. Augustine in the arms of the frail beauties of Carthage, differed little, doubtless, from our own. But the nights were warm; in those cloudless lands the stars blaze and burn like carbuncles, and are full of that mystic fascination from which astrology was born. To the watchers of the flocks they were a theatre, with an ever shifting scene and a nightly change of bill.

How intently they must have studied the motley crowd of lights that filled the stage, for presently groups of stars took on names and shapes; there were Great Bears and Little, Fishes and Swans, Centaurs and Dragons and Scorpions, Archers and Charioteers. Hercules, turned a god, showed his form nightly to mortals, and through the depths of the blue, Boötes drove with his dog. The intense and realistic imagination which we observe in children's play, and which the greater poets, discoverers, and men of science never lose, finds its counterpart in the fancies of those days, when the thoughtfullest of men looked up at the spectacle of the world with the eyes of a child.

Nightly they saw the constellations, as they named them, 
wheel through the dusky vault; nightly they watched the planets come and go, the moon show crescent and then wane; and through the changing seasons saw the heavens change, some groups to drop beneath the horizon's edge for a space, while others came in view. How intimate their feelings must have grown for all these clusters which had to them a name, a myth, and a function in the births and deaths of men. Their legends of the lost Pleiad reveal how closely they observed, and with what poetical felicity their nascent science was robed. It must have been all very real to them, and despite their crude fancies, their groundless imaginings, their mythopoetics, I think in some ways they must have been nearer to the Wonder than the theatre-goers of now, who glance occasionally at the sky to exclaim its beauty, as they hasten from the shut-up playhouse of puppets and tinsel to their suppers or to bed.

Doubtless the earliest of these figure-groups observed of the ancients was the striking arrangement of seven stars which outlines so exactly the shape of a dipper and its handle. Known to them was the constellation of the Great Bear ; to our English speech as Charles's Wain, there are probably very few of even the most indifferent eyes who have not noticed its curious shift of position through the night. Seen in the early evening when the stars first emerge, the bowl of the dipper may be upright, and could be filled to the brim. As midnight peals, and the curtain falls and we stumble out into the hubbub of the street with the strains of "Tristan" still throbbing through dazed and drunken senses, the group has been displaced and raised, and the bowl would now spill its contents; but still the two outermost stars which form the bowl point steadily toward a gleam of light that, while all things else in the heavens change, does not seem to stir. At a yet later hour, when from some function the carriages roll homeward through the silent avenues, the dipper is seen to lie still higher in the sky and has turned its bowl downwards. Yet the two pointer stars still indicate unerringly the centre, round which the whole group seems to revolve.

Studying other groups in the same region, it came to the early observers that they, too, seemed to describe an orbit round this central star, sweeping through larger and larger circles as they were more and more distant from this unmoving point. It was all as if the heavens formed a vast and measure- 
less sphere, with the stars set in its surface, and that the whole sphere was wheeling round an invisible axis of which this one fixed star was the extremity.

It was from such a mental image that the Greeks gave to this radial point of the skies their word for a pivot, $\pi \omega \lambda \omega s-$ and so we have Polaris, our pole-star. All this must have been noted very anciently, for in the construction of his pyramid, from four to six thousand years ago, Cheops had, as we have seen, oriented his colossal tomb towards the pivot of the heavens of his day.

Later on, when the idea of the globular form of the earth grew into acceptance, among astronomers at least, and the beginnings of a climatology and geography were made, they came in their poetical way to dress this globe in "zones," or girdles; the circle described by the sun at its northern solstice was the boundary of one; that described at the southern station, of the other; and as it was at the edges of this belt that the sun seemed to turn back, they named the boundary line the "tropics," the same as our word trope, or turn. Midway between the two, they noted that the sun in its revolution described a great circle of this globe, and when it was at this point, the days and nights were equal all over the earth; whence they gave this great circle the name of the equant, or equator. It must have puzzled the early observers vastly to know why the sun should thus shift up and down in the sky. Their puzzling must have deepened when they made a further step. The planes, they noted, formed by these circles, were parallel one to the other, and a line drawn through their centres, and perpendicular to them, passed through the centre of the earth; projected into space, it pointed straight to the polestar. In a word, it seemed as if the earth had an axis like the heavens, and this seeming axis of the earth and the seeming axis of the skies were one. Here was something to ponder.

Of course, so long as they had no mortal idea of the distance of the sun and stars, they had no trouble in believing that it was the sun and the crystal sphere of the stars which moved. But very early some penetrating mind must have struck in with the thought that this motion might be explained another waythat the daily revolution of the sun, the nightly wheeling of the stars, was the effect of the slow turning of the earth, and that the sphere of the sky stands still. Just as on a very large 
vessel, we sometimes have the illusion that it is the shore and docks which are going by, so it might be that we have the same illusion regarding the stability of the earth.

By common credit, Pythagoras is held to have been the first to have taught such a doctrine; but it is not very clear that he did; it is many times certain that he was not the first. Pythagoras was a product of that highly intelligent society which rose among the Greek colonies in southern Italy, while Athens was still the home of marauding pirates. He travelled widely, and it was doubtless in Egypt that he heard of this monstrous paradox of the earth's motion. He seems to have imbibed the notions of the old priestly caste that science and knowledge were to be guarded by a secret band and to be com. municated only to the initiate.

Among his disciples it is evident that the paradox was bruited openly, so that by the time of Plato and Aristotle, it is a matter of general debate. Aristotle, who cuts rather a sorry figure as a thinker, had no hesitations; he chose a fixed and immovable earth. But Plato, who had made a journey to Italy to learn of the new doctrine, seems in his old age to have wavered, and thought perhaps he had made a mistake in taking the same view. But it was on purely sentimental grounds, from esthetic considerations, that he wavered; reason or fact did not disturb the Platonic soul. Indeed, to read the monstrous wish-wash which passed for logical argument in those days, and for a thousand years thereafter, one might now readily imagine that since that day the processes of reasoning had completely changed, and hence might completely change again, in another millennium or so. It is a curious and disturbing thought; but we need not be agitated. Happily we know there were among the Greeks thinkers of the highest order, men of trained and logical minds, like Democritus and Anaxagoras, Euclid and Aristarchus, whose conceptions, so far as they got, differ but little from our own; and we may conclude that, with its Platos and Aristotles, Greece was then, as our own time now, full of vain babblers, imposing upon a generation, in Carlylean definition-" chiefly fools."

With the advent of mechanical conceptions, this abracadabra which passed for philosophy and sense ceased to satisfy men's minds. They began to scrutinise more closely.

It is clear from the work of Coppernicus, which probably 
contains little in the way of general considerations which had not been eagerly discussed by the Greeks, that one especial argument against the revolution of the fixed stars was the frightful speed at which they would have to travel in order to complete the circle of the heavens in twenty-four hours. The sling in those days was a common weapon; and they would be led to consider that while it is easy to whirl an object about on, say, a foot leash, at a high rate, this becomes increasingly difficult as the leash is lengthened. So also with a little wheel and a big one.

If, therefore, it seemed preposterous that so great a thing as the earth could turn, it was still more difficult to imagine the flight through space of other large bodies, like the sun, in an enormously larger orbit. This difficulty must have become of increasing moment, as it became clear that the sun was even larger than the earth, and hence almost inconceivably distant.

But if, as is abundantly attested by various fragments, there were close reàsoners like Philoläus of Crotona, Hicetas of Syracuse, Heraclides of Pontus and others, who could maintain the daily revolution of the earth, there were still difficulties enough. The turning of the earth explained with exquisite simplicity the apparent revolution of the heavens; it did not clear up the curious shift of the sun with the seasons. This shift was double, first with reference to the circle the sun describes in the heavens each day, with which the length of the day seemed bound up; and second, with reference to the fixed stars.

Why should the sun seem thus to wobble in the sky? why should the days be nearly twice as long as the nights in summer, and in the winter hardly half ? If the earth be in reality a revolving globe, a vast barrel-churn, one might go a step further and suppose that, for some reason or other, it was wobbling on its axis as well-back and forth, swaying six months one way and six months the other. This would explain the change in the sun's apparent position, the change of days, and of seasons too. But if it was a mental wrench to try to think of a whirling earth, it was sheer deracination to propose an earth that not only whirled, but in whirling swayed! The mind grew vertiginous over the abyss of such a thought. Turn it might, upon an axis that was fixed-the idea was even 
plausible. But turn upon an axis that seemed to lurchwho was there to venture on so outrageous a notion? What, then, im Teufelsnamen, did this axis rest on ? It cannot sustain the earth if it is supported on nothing. Moreover, on a second thought, the axis did not appear to lurch. Always, in season and out, it pointed steadily toward that mystic pivotal star of the north. The explanation must lie elsewhere.

Perchance not alone the earth but the sun moved too! So it actually seemed, for watching its risings and its settings from month to month, the ancients very early noted that it came up amid one group of stars at one time, and in a different one a little later. From one end of the year to the other it seemed to traverse a sort of belt, which they duly decorated with names and fantastic shapes.

Taking the year at roughly twelve lunations, they divided the belt into twelve signs, put a lobster in one, a goat in another, a virgin in a third, fishes in a fourth, a bull next, and so on. The various animals were ranged in a circle, much as the cages in a circus tent, and the whole menagerie they called the Zodiac, or " circle of the animals." In a given season the sun was said to rise, or set, in Aries or Pisces or Virgo, and due and dire things depended thereon.

There were but two ways in which all these puzzling appearances could be explained; two, and only two. Either the sun goes round the earth as a centre each year, in a circle that is inclined at a considerable angle to the plane of the earth's equator, or else the earth goes round the sun in the same sort of a plane-in brief, has a dual motion. Small wonder that common folk shook their heads when the learned astronomers began to indulge such speculations as this.

But the world and the wonder of it was very new; and the new science of geometrical constructions seemed to do such wonderful things. Starting from the simplest proposition, which even a child could understand, the geometer carried the mind along from theorem to theorem, until the solid earth seemed to have been left far behind; yet no link of proof seemed lacking; all was rigidly enchained. It was thus-wise that men were able to get away from the bondage of appearances, and by a process of abstraction, reach beneath the surface to the inner core of things. So, the history of these ancient speculations being lost, we may imagine some among them drawing a circle, 
setting the sun at the centre, the earth in an orbit about it, and the "circle of the animals" still outside of that. Let us do the same.

It is easy enough to see that if the earth is on one side of the sun, as at E, and its daily revolution makes the sun appear to " rise," the sun will be seen to come up in the direction of the group of stars which lie against the face of the sky opposite, say the constellation of Leo. When the earth has swept round a quarter of a turn, at $\mathrm{E}^{\mathrm{l}}$, then the sun will seem to rise in Aries, and so on around the whole circle. All this is simple enough and satisfactory too, in a way; but there are many points to tax credulity. For example, one must suppose that, as the

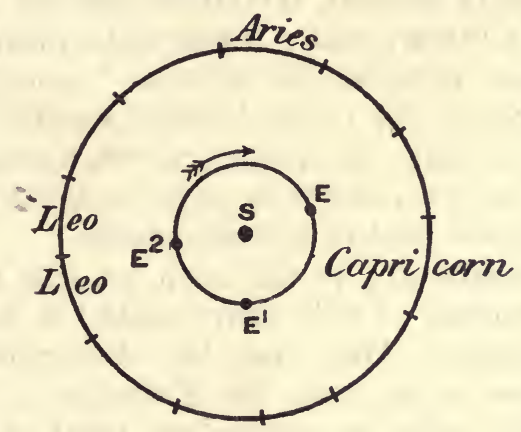

FiG. 1 .

earth's axis is always pointed in the direction of the pole-star, it sweeps round the sun always tilted on its side, and always at the same tilt. But this would explain the change of the length of days. If the earth on one side of the sun leaned a little so that one pole would be in darkness all the time, then if it kept leaning the same way, when it got around to the opposite side of the circle, this dark pole would be constantly in the sunlight. And this is exactly what happens. So the seeming difficulty becomes an added proof.

But what a tipsy and disconcerting vision it summons !this giant earth, careening about the sun in a plane, but always turned partly on its side, as a ship buoy often floats upon the surface of the water. Yet, how much it explains; how it simplifies! What must have been the glow of pleasure to him who first reasoned it out! 
"Felix qui potuit rerum cognoscere causas!"

So Virgil sings; life has no purer joy. Yet whosoever was this first, the lips of history are mute. Some king's " magician," or soothsayer of the Nile, perhaps; no mighty cenotaphs immortalise his name; not for such as he do a hundred thousand burdened slaves sweat and grunt through thirty years to rear a tomb.

For that matter, there may have been no one. Great conceptions, great discoveries, have no Minervan birth. So, here and there among the old Greeks, we find men who seem to have caught sight of the idea, but did not " see it clearly and see it whole." Thus old Hicetas of Syracuse, or Nicetas, as Cicero calls him-Cicero's account, doubtless, was not very accurate, for Cicero was a literary man; it may quite misrepresent. But Hicetas, he says, pictured the earth as "turning and twisting on its axis while all else in the heavens stands still." Quaint and ingenious thought. In another century a great Alexandrian will take out the twist, and thus, away back there, work out in all its essentials our modern welt-anschauung.

But the proposal to give the earth not only a rotatory but a translatory motion as well, drove against a simple but very formidable obstacle. That was the dislocation which two bodies-our two peaks from the Matterhorn, for exampleseem to undergo when we change our point of view. If the sun be at an enormous distance from the earth, and the earth goes round it, then from one side of the circle to the other we shall view the stars from two enormously separated points. Some of the stars must appear to shift their position one to another if this be true.

No one could find the slightest change in the stellar sphere. Alone the sun and planets moved.

True if one could think, with Eudoxus, that the stars were set in the face of a solid sphere, so all would be at an equal distance, there would be no difficulty. But it was clear that the planets were widely ranged in space; the eclipses left no doubt of that; their brilliancy suggested the same. There was the same varied brilliance among the unmoving stars; they differed from the almost planet's glow of Sirius and Arcturus to the faintest gleams.

There was one escape, and one alone. That was to conceive the fixed stars as so remote from all mundane relations that, 


\section{THE TURNING OF THE EARTH}

compared with this, even the distance of the sun was as nothing. But so doing seemed to loose the earth from its moorings, and toss it like a fragile bark upon the wastes of a boundless sea. It was to view the sun and earth and its vast orbit as but a point in the unending marches of the sky. Lost in such reverie of the infinite, the imagination reels in drunken sublimity; the ways of space became a welter of whirling specks; the aimless motions of a cloud of insects, the image of the handiwork of God. Staled by custom, by constant iteration, we have become a little steadied to the view. But to what somnambulist of space did it come first? Is there any mind in Hellas to rise to such an outlook on the world?

What said Aristarchus? 


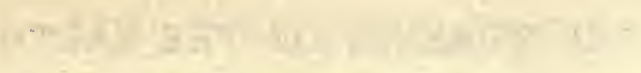

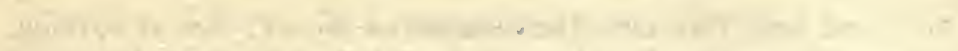

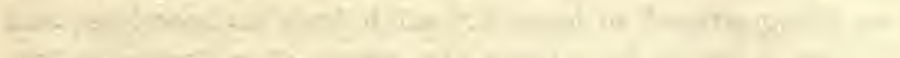

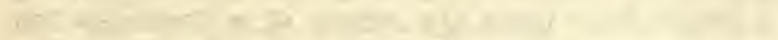

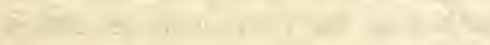

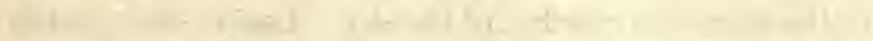

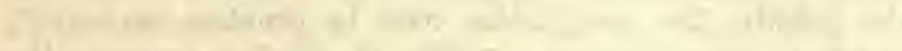

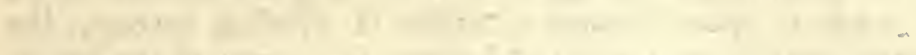

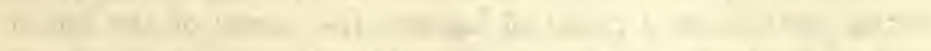

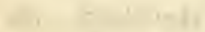

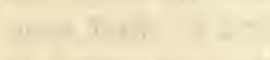

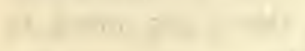

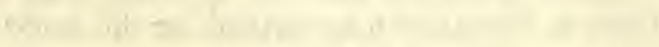

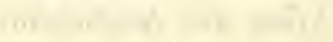

\section{-}




\section{CHAPTER IX}

THE FEYING EARTH: THE FIXITY OF THE SUN 
THE human mind has been young; it was poor, but it has become rich; it was ignorant of what it now knows. Ideas have been successively gathered together, heaped up; they have mutually engendered each other, the one has led to another. It remains therefore merely to rediscover this succession, to begin with the earliest ideas; the path is traced out; it is a journey that one may make again because it has already been made; the individual may now cover in the course of some hours' reading an extent of knowledge which it has cost the race long centuries to acquire.

Barlly, Histoire de l'Astronomie Moderne. 


\section{CHAPTER IX}

\section{THE FLYING EARTH: THE FIXITY OF THE SUN}

From out the wrecks of time not much of the learning of the ancients has been saved. Goth and Hun, priestly zealots and fanatical conquerors, left little, and on what they left the worms have fed. The library in Alexandria was, all things considered, certainly the most wonderful gathering of books which ever existed-700,000 volumes, copied by hand. It would represent a hundred times the value of the great libraries now existing. We do not know that a single volume of it remains. From the torch of Cæsar's legions, and the wild rabble of Christians under Theophilus who sacked and burned it four hundred years after, not much was spared to give body to the myth of the conquering Omar who came four centuries later still.

So of the works of Aristarchus there has come down only the thin volume wherein he sets forth the measures of the sun and moon. It is to another small volume, four lines at that, that we owe our knowledge of what views he held of the world he had thus surveyed. This was that strange Arenarius, or "sand-reckoner," wherein Archimedes attempts to show how it is possible to express in figures the number of grains of sand that the whole celestial sphere might hold were it filled full. It is the play of an intellectual prestidigitateur, a juggler who takes numbers for balls to toss and the universe for his stage. He tells us that he will not take for the radius of the stellar sphere merely the distance of the sun from the earth, " as most of the astronomers do"; he will show that he may cope even with the ideas of Aristarchus. And so we chance to know what this celebrated Aristarchus taught-that the distance of the stars is incommensurable to men.

It is easy to think that these ideas of the ancients were merely fancies; that they thought over things a little, then hazarded a guess; and guessing much and often they might 
sometimes guess aright. Listen then to what Archimedes says :-

"Aristarchus of Samos, confuting the hypotheses of the astronomers, concludes that the world is yet many times greater than the estimate we have just given (about 1300 earth radii). He supposes indeed that the stars, like the sun, remain immobile; that the earth revolves, following the circumference of a circle, round the sun as a centre, and that the sphere of the fixed stars, having this same sun for a centre, is of such vastness that the circle in which the earth moves, has to the distance of the fixed stars, the same proportions as the centre of a sphere to its surface," - that is to say, a circle millions of miles across, looked at from the fixed stars, would be but a point in immensity !

This was in the third century B.c. At the beginning of the seventeenth century A.D., when Tycho Brahe, Kepler, Galileo, and a host of others, were debating the theory of Coppernicus, the objection brought by Tycho, as we have already noted, was that if the earth does revolve, then the stars would shift a little in their relative positions. That point Galileo could not meet. Though he sought eagerly to find a parallax, if only for a single star, he sought in vain. It was not until some seventy years ago that such a shift of position was conclusively demonstrated; and with it the last link set in the chain of proof which establishes the Coppernican theory. Two thousand years before Tycho, Aristarchus had met this objection in the only way it could be met, and had divined the truth.

$\mathrm{He}$ had divined, had guessed, rather than demonstrated. Was there, then, any way to prove this idea of the distance of the fixed stars?

In the opening of Coppernicus' work there is to be found a theorem of amazing simplicity which does offer this proof. But it did not originate with the Polish astronomer; he copies it from the Almagest of Ptolemy; it is in the treatise of Cleomedes ; where Cleomedes got it we do not know. Both appear to have been chiefly compilers. Moreover, the idea is such a one as might readily have occurred to the earliest of those who had demonstrated that the earth is round. It was doubtless very old.

The chapter in Coppernicus is entitled, "Considerations on the Immeasurable Extent of the Heavens in Comparison with the Size of the Earth," and his theorem is this :- 
At any given moment of time the horizon of the earth divides the sphere of the heavens exactly in two, and this is true, not merely through each twenty-four hours, but throughout the year. It follows, therefore, that neither the great mass of the earth nor its distance from the middle point of the world occasions the slightest difference in this continuous bisection of the heavens. Did either the one or the other enter into consideration, we should see always less than half the sky. Test it any moment and you will see that this is never the case. Long observation had taught the ancients to fix, with a precision still of great value, the exact position of the different constellations of the zodiac. They knew, for example, the beginning of the sign of Capricorn was precisely opposite, in the zodiacal circle, to that of the Crab. Take now one of their old diopters or horoscopes, or sight across a water-level, and you see that at the moment the Crab "rises," Capricorn "sets"; a line from one to the other is a diameter of the zodiacal circle, or, as we say, of the plane of the ecliptic. Now when the heavens have turned about so that we just see Capricorn rising, the Crab is just slipping under the opposite horizon. You may draw a circle, if you like, just as did Ptolemy or the unnamed genius who first worked it out, like this :-

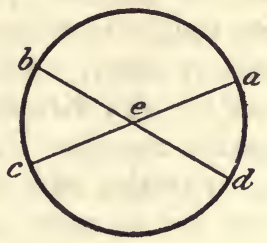

FIG. II.

You have now two diameters which cross a common centre, and it is easy to show that this centre is likewise the centre of the earth. Lines from the surface of the earth and from its centre to a common point cannot be the same; nevertheless, so far as the observation of the stars reveals, they are not only parallel, but, on account of the vast distance of the stars, one and the same line. The half diameter of the earth, therefore, is, with respect to the distance, an entirely negligible quantity. Not merely this, but if you believe, as Aristarchus did, that the earth moves round the sun as a centre, and that 
the sun is the true centre of the stellar sphere, then it follows that, with respect to the distance of the fixed stars, the diameter of the earth's orbit is likewise negligible; as Coppernicus puts it, it is the "relation of a point to a body, of the finite to the infinite."

This is to all intents the language of Aristarchus, though Coppernicus does not quote him either here or elsewhere. Whether the Alexandrian knew of this simple demonstration of his belief, is buried with his lost treatises. He certainly had the idea in all its consequences. We may believe he was, in all probability, the first of the human race to see the world as it is; the first adequately to understand what infinitude may mean.

And if this be true, an injustice to history has been done. Yielding in no wise the honours that time has paid to that patient mind which, in an obscure corner of Poland and through forty years of silence, laboured to set the universe in its order, the system of the planets, if it bear a name, should transmit to posterity not that of Coppernicus but that of his far greater predecessor in the gay capital of the Ptolemies.

If we may trust Sextus Empiricus, and others who make mention, Aristarchus founded, in some sense, a school. His authority was clearly of the highest, yet in all antiquity he seems to have had but one notable follower, Seleucus of Babylon, who came perhaps a century later. Archimedes did not seem to accept his views; neither did Eratosthenes, nor the great Hipparchus, nor Poseidonius, nor that Ptolemy the astronomer, whose luck it was, like Aristotle, and with as little worth, to be a standard among men for so many centuries after. What was the reason?

One may sometimes meet with a curious statement that Hipparchus had in his hands a means of demonstrating the truth of the Aristarchan theory, but failed to make use of it. This lay in his new method of computing the distance 'of the sun and the moon, and in uniting these with Eratosthenes' measure of the earth. But as the preceding pages have already disclosed, Hipparchus did make use of this method, with the singular result of confirming the surprising though inadequate results of the Alexandrian astronomer.

Moreover, we have seen that Aristarchus himself, a century or more before, had computed the grandeurs of the sun and the 
moon in terms of the earth's measure, demonstrating that the diameter of the sun compared with that of the earth is greater than I9: 3 and less than $43: 6$, that is, between six and seven times; he therefore estimated the grandeur of the sun at three hundred times that of the earth. And we have the word of Aristotle that an approximate measure of the earth had been made yet another century before Aristarchus had pointed his astrolabes at the Alexandrian sky. It is an error to suppose that it was a mere question of geometrical methods or measures -of mere dimensions; for the dimensions were known, at least in the right relative proportions, to the founders of the two rival systems.

The difficulty, as the learned Schiaparelli has been at the length of an interesting memoir to prove, lay elsewhere. One was the invention of a new system, which represented all the known facts equally well. That was the theory of epicycles, picturing the planets as gyrating through a circular path round a circle. This system, worked out in detail by Hipparchus from the mathematical developments of Apollonius of Perga, was adopted by Ptolemy, and held the field until Tycho Brahe's day. And it is curious to reflect that, within the confines of pure astronomy, the absolute disproof could not come until the establishment of the parallax of the stars, in our own time. Even the simplicity of the Coppernican scheme could not prevail over it until a new science was born. That was dynamical mechanics, the mechanics of motion, unknown to Hipparchus' and to Aristarchus' era. Though the one might think it absurd that about the lesser earth the greater sun should turn, the other evidently did not.

The keen and restless-minded Eratosthenes could conceive the sun as a body not three hundred, but twenty thousand times the bulk of this globe we live on, set it at eighty or ninety millions of miles away, and yet have no difficulty in revolving such a colossus round an unmoving earth, once in each twentyfour hours. The unthinkable speed it must attain seems to have brought no dismay to his mind. He could calculate as easily as you and I that this meant a body at least 200,000 miles in diameter, whizzing through space at the rate of 400,000 miles per minute, 23,000,000 miles per hour; and still always describing a perfect circle (so far as he could judge) about this central speck of earth. 
Even so, and even more, Poseidonius. Though he makes the sun hardly less distant (50,000,000 of miles); though he has a truer idea of the sun's immensity than any other man in antiquity, fixing it at 400,000 miles, or at near half the reality; though he thus conceives it, apparently, as a body seventy times in diameter, therefore three hundred and fifty thousand times in volume the earth, and sets its orbit at near ten thousand times the earth's circumference ; though he seems the first of physical investigators to perceive that the height of the tides is dependent upon the positions of the sun and the moon; not even he can find it singular that so vast a thing should move in a rigid. curve about the earth. It does not seem absurd to him, nor to his near contemporary, Cleomedes, though Cleomedes perceives the truth that our globe is a body so comparatively slight that, seen from the distance of the sun, it would appear but a point. It does not seem absurd even to the mechanical and inventive mind of Archimedes, himself the founder of two great branches of mechanical science.

The failure of the penetrating intellect of the great Syracusan to grasp the truth of the Aristarchan conceptions is the more amazing from the fact that he was the first, apparently, to devise a mechanical representation of the motions of the heavenly bodies; he was the first world-mechanic. The planetarium he constructed, the orrery of our day, was the just marvel of the ancients. In the Commonwealth of Cicero, there is a naive and charming page that is well worth transcribing here:-

"I recollect that Caius Gallus, who was a man of profound learning, while he was staying at the house of Marcus Marcellus, asked to see a celestial globe which Marcellus' grandfather had saved after the capture of Syracuse, from that magnificent and opulent city, without bringing to his own house any other memorial out of so great a booty; which I had often heard mentioned on account of the great fame of Archimedes. Its appearance, however, did not seem to me particularly striking. But as soon as Gallus had begun to explain, in a most satisfactory manner, the principle of the machine, I felt that the Sicilian geometer must have possessed a genius superior to anything we usually conceive to belong to our nature. For Gallus assured us that the solid globe, made by the same 
Archimedes, and deposited by Marcellus in the temple of virtue at Rome, was a very ancient invention, and that the first had been made originally by Thales of Miletus; but that the motion of the sun and the moon and the five planets, or wandering stars, could not be represented by this primitive solid globe; and that in this the invention of Archimedes was admirable, because he had calculated how a single revolution should maintain unequal and diversified progressions (of the planets) in dissimilar motions. In fact, when Gallus moved this globe, we observed that the moon succeeded the sun by as many turns of the wheel in the machine as days in the heavens. From whence it resulted that the progress of the sun was marked in the heavens, and that the moon touched the point where she is obscured by the earth's shadow at the instant the sun is at the opposite side."

The remainder of the passage is lost. But as any one who has ever inspected an orrery must know, the construction of this highly complex mechanism required not merely an extraordinary ingenuity, but all that mathematics might teach as well. We know, moreover, from many a passage in the works of Cicero and elsewhere, that it was the demonstrations of Archimedes, rather than of Aristarchus, which spread among the enlightened people of that day the doctrine of the vast size of the sun, the littleness of the earth.

We know, too, that even in Archimedes' day, some reflective minds had already begun to picture certain of the planets as having the sun at the centre of their orbits, rather than the earth. Long and thoughtfully had they watched the course of the "wanderers," had seen them rise and set like the sun and the moon, wax and wane in brilliancy; observed Venus when it casts a shadow, and again when it has shrunk to the size of Saturn; seen Mars blaze out in redness, then shrink away to hardly more than a point. That Venus and Mars, Saturn and Jupiter were of the same general nature as the moon, had long been known. It was clear enough that the moon revolved about the earth and not about the sun. This naturally led to the idea that all planets did the same; but it was disturbing to see Venus now crossing the face of the sun, now obscured by it. And so perchance with Mercury.

Perhaps the sun, like the earth, might have its satellites, and it was thus, apparently, that Mercury and Venus were 
ranged in the scheme of Apollonius of Perga, he whose ideas seem most deeply to have influenced Coppernicus.

From this, to set the earth among the planets was but a step. No, not a step, it was a leap across a chasm, the abyss that lay between the old geometric world-conceptions and the new. The mind of Aristarchus could make the leap; Archimedes, Apollonius, Eratosthenes, Hipparchus, Poseidonius, Cleomedes, Ptolemy, and the rest could not. On the other side one giant figure stands alone.

In the planetarium, as constructed by Archimedes, the five planets which, in the lack of the telescope, could be known, seem to have been placed in their proper order, save in this one regard: their orbits centred in the earth. How a man with a brain to work out and the cunning hand to build such a mechanism could thus stop short, passes understanding. $\mathrm{He}$ was at once one of the greatest mathematicians and inventive geniuses that ever lived. He had in his hands, and was, so far as we know, the first actually to employ that happy combination of the three sciences which have made possible the marvellous attainments of modern astronomy. Yet more, his studies and discoveries in mechanics were leading him straight toward that mechanical explanation of planetary motion which immortalised the name of Isaac Newton. He was familiar with the problems of the ellipse eighteen centuries before Kepler's birth; the idea of a centre of gravity was his idea; he was even a measurer of the force of gravity. One further step and the discoveries of Galileo, and perchance of Kepler and of Newton too, might have been perfected before the Roman dominion had set heel upon Hellenic culture, and before the gospel of an avenging Jehovah had been carried beyond the confines of the little country of Palestine to make of truth blasphemy.

It was all so astonishing, they came so near : it may lend some helpful insight into the workings of the human mind to consider attentively their failure. 


\section{CHAPTER $\mathrm{X}$}

ARCHIMEDES AND THE FIRST IDEAS OF GRAVITATION 
FIRST let us examine the earth, whose situation is in the middle of the universe-solid, round, and conglobular by its natural tendency.

... What is most wonderful is that the world is so durable, and so perfectly made for lasting that it is not to be impaired by time ; for all its parts tend equally to the centre, and are bound together by a sort of chain, which surrounds the elements; this chain is nature, which being diffused through the universe, and performing all things with judgment and reason, attracts the extremities to the centre.

If, then, the world is round, and if on that account all its parts, being of equal dimensions and relative proportions, mutually support and are supported by one another, it must follow that, as all the parts incline to the centre (for that is the lowest place of a globe), there is nothing whatever which can put a stop to that propensity, in the case of such great weights. For the same reason, though the sea is higher than the earth, yet because it has the like tendency, it is collected everywhere, equally concentres, and never overflows, and is never wasted.

The stars have their revolutions in the sky, and are continued by the tendency of all parts towards the centre; their duration is perpetuated by their form and figure, for they are round; which form, as I think has been before observed, is the least liable to injury.

Cicero, Nature of the Gods. 


\section{CHAPTER $\mathrm{X}$}

\section{ARCHIMEDES AND THE FIRST IDEAS OF GRAVITATION}

THE earth is round, but water flows. Why do not the oceans run down hill and spill away into the void?

The cause, the "reason," seems so obvious to us now that it is a little difficult to realise that this was once a puzzle and stumbling-block. Let us go back and consider the problem with the earliest of the physiographers. One of these was that same Eratosthenes whom we have seen measuring the circumference of the earth, the tilt of its axis to the plane in which the sun revolves; computing the distance of the sun with greater success than any investigator of antiquity; a giant mind, and, moreover, one of those finely trained imaginations which seems able to escape the enveloping trammels of accustomed methods and beliefs, to reach a larger view. But no man can shake himself wholly free from the web of his own time; so we find in Strabo such an extraordinary passage as this :-

" However, so nice a fellow is Eratosthenes, that though he professes himself a mathematician, he rejects entirely the dictum of Archimedes, who, in his work, On Bodies in Suspension, says that all liquids, when left at rest, assume a spherical form, having a centre of gravity similar to that of the earth; a dictum which is acknowledged by all who have the slightest pretensions to mathematical sagacity. He says that the Mediterranean, which, according to his own description, is one entire sea, has not the same level even at points quite close to each other; and offers us the authority of engineers for this piece of folly. He tells us that Demetrius intended to cut through the Isthmus of Corinth to open a passage for his fleet, but was prevented by his engineers, who, having taken measurements, reported that the level of the sea at the Gulf of Corinth was higher than the opposite side, so that if he cut through the Isthmus, not only 
the coast of Egina, but Egina itself, would be laid completely under water." 1

And Strabo laughs. Is this Strabo some philosopher of the days, say, of Elizabeth or Louis Quatorze, sneering at the wisdom of the ancients? No, somewhat further back-back even to the time when they were setting a crown on the head of the first Imperator of Rome. And this cheery old Strabo, writing his celebrated geography, if we may trust Humboldt, when he had passed eighty, goes on to reprobate these ideas of the Alexandrian as plain nonsense. These currents in the Mediterranean, between Scylla and Charybdis, and elsewhere, which Eratosthenes adduces, are, he says, the effect of the tides; and the tides and their dependence on the rising and the setting of the moon, have been sufficiently treated by Poseidonius and Athenodorus, so that he does not need to go into the matter. So the flat misprisions of his predecessor seem to him simply absurd. "Whoever," he exclaims, "imagined the surface of the ocean to be on a slope? For water is not like the earth, which, being of a solid nature, is capable of permanent depressions and risings, but by the force of gravity spreads equally over the earth, and assumes that kind of level which Archimedes assigned to it! "

Thus Strabo, A.D. 25. In Poseidonius, a full century before, and in Archimedes, yet another century back of him, we find clear enough conceptions that the oceans lie at a general level over the surface of a spherical earth, perforce of a power directed towards the earth's centre. That gravity draws always to the centre, seems to have been present, hazily, in the hazy mind of Aristotle; it was clearly one of the established verities in the Alexandrian school a century later. Strabo even makes of it an argument for the sphericity of the earth, since " all things however distant, tend toward its centre." A weight hung on the end of a string is always perpendicular to the plane of the horizon, that is, to a tangent to the earth's surface, anywhere. If the earth is a sphere, it follows that the plumb-line points always to the centre of the sphere.

Bodies falling from no matter what height fall always in the same line; they form a perpendicular to a water level. This the ancients knew well. It was as if there is an attractive force, acting from the earth's centre. And this force seemed constant,

1 Strabo, Geography, i. p. 85 ; ed. Bohn. 
it did not diminish, highsoever as they could go; indeed the greater the height from which a body falls, the longer the time it is falling, the swifter the speed of the fall.

Does this force extend then indefinitely up into the sky? What, for example, is the meaning of this curious connection which seems to subsist between the moon and the tides, which Poseidonius and Seleucus have studied so attentively. Does the moon pull the waters of the sea? And if so, is this pulling force between moon and earth reciprocal ? Why, for example, does the moon move round the earth in a circle ? Why does it not fly off into space? What holds it? Is this same attractive force, acting towards the earth's centre, constantly pulling the moon downwards towards the earth, as an arrow shot into the air falls back again when its force is spent ?

There were surely minds before which this far-reaching conception floated; in foremost line that rich, proud Anaxagoras, whom Pericles saved from the vengeance of the Athenians for his cold disdain of their rabble of gods. Humboldt quotes Jacobi as commenting on " the profound consideration of nature evinced by Anaxagoras, in whom we read with astonishment a passage, that the moon, if its centrifugal force ceased, would fall to the earth like a stone from a sling." It was this same Anaxagoras who pictured "the ether surrounding the earth as a fiery substance which by the power of its rotation tears rocks from the earth, inflames them and converts them into stars," " a curious antithesis of present-day ideas of meteorites. It was doubtless in following out his idea that Anaxagoras came to regard the sun as a colossal body of redhot iron.

In Diogenes of Apollonia, in Democritus; in Empedocles, in Plato and others, are to be found notions more or less vague, of this same force of attraction. It seems almost to have been common property. In Plutarch, in his Life of Lysander, is to be found a curious passage regarding falling stars, "which are," he says, " according to the notions of some of the physicists, not eruptions of the ethereal fire extinguished in the air immediately after their ignition (!), but these meteors are rather a falling of celestial bodies, which, in consequence of a certain intermission in the rotatory force, have been hurled down." 
Yet clearer is Simplicius, one of the last of the great Alexandrian school, who, in his commentary on Aristotle, attributes the "non-falling of heavenly bodies" to the fact that "the rotatory force predominates over the actual falling force or downward attraction." That this was no mere guess, and that Simplicius had perfectly definite ideas of the physical fact of which he is speaking, is evidenced in his illustration from the familiar instance that "water in a phial is not spilled when the movement of rotation is more rapid than the downward movement of the water." 1

Moreover, it is clear that Aristotle and Hipparchus as well, knew of the acceleration of falling bodies, but neither they nor any one apparently seems to have thought of the simple expedient of measuring the rate of the fall, and hence finding out the rate of the acceleration.

This is the more notable in an observing genius like Hipparchus, who, unlike Aristotle, had that exact and measuring mind which is essentially the type of the modern creators of experimental science. It was Hipparchus who discovered the precession of the equinoxes, a fact which required not merely the most delicate observations, but a mind intensely alive. $\mathrm{He}$ was a mathematician, and he constructed the first table of chords. Apparently it was he who first worked out the wonderful idea of parallax and applied it to the measure of distance. The highly ingenious theorem, determining the distance of the sun from the diameter of the earth's shadow, generally attributed to him, has already been noted.

It was Hipparchus, probably, of all the ancients, who determined most accurately the distance of the moon, and it was he furthermore who understood the variations in its distance, who first drew a map of its path in space. His ideas on the grandeur of the sun were the same as those of Aristarchus ; and after all it made very little difference in the problem that was before them whether the diameter of the sun was six or eight times that of the earth or a hundred and six or eight times. The physical difficulty of conceiving the revolution of a larger body around the smaller was merely intensified by our modern methods, it was in no material way changed. Moreover, Hipparchus must have known of the ideas of Eratosthenes, who made the diameter twenty-seven times and the distance

1 Simplicius, Scholia. 
a hundred times that of the moon; he must have known it, because an extensive commentary upon Eratosthenes was one of his principal works.

But the same limitations which forced Hipparchus to the rejection of the heliocentric doctrines of Aristarchus, the same indifference to the mechanics of the problem, the disregard of considerations of relative weight and relative mass, would, it is obvious, have guided his mind away from, rather than toward, the problem of gravitation, the curious acceleration of the fall of bodies, and its possible connection with the circular movement of the planets. It is not so clear how this possible connection could have escaped the Titan mind of Archimedes.

It is to the great geometer of Syracuse that we attribute the foundation of mechanics. The principle of the lever doubtless had been known for thousands of years, perhaps tens; but it seems to have been Archimedes who worked out its theory and made it the basis of a science. Concerned with the problem of weight, the means of its determination, it was he perhaps of all the ancients who must have come nearest to the distinction between weight and mass. He was profoundly interested in considerations of gravitation. Not merely the method of determination, but the idea of centres of gravity seems to have been his. It was Archimedes, as we have seen, who gave the explanation of why it is that upon a round earth the waters of the ocean did not run down the sides and spill away.

Strangely did he not see the implication. Since bodies appear to be attracted towards the centre of a sphere, it follows that at the centre of the sphere this attraction will be zero. If it increases outward from the centre to the surface, what reason is there to suppose that it stops at the surface? Not to the utmost height to which any of the huge engines Archimedes constructed might hurl a heavy body was there the slightest evidence of the diminution of this force. The fall of meteorites, evidently from great heights, and pretty obviously under this same force of gravitation, carried the mind yet further outwards into space. It seems incredible that such a mind, working amid such problems and in contact with other minds like those of Aristarchus and Eratosthenes, busy with the measures of the moon and the sun, could not have made the one further step.

Yet, as we shall see, the same limitations hemmed that 
modern mind which most resembled the Syracusan's. Archimedes did not make the measures of acceleration; Galileo did, but as little to Galileo as to Archimedes did the light come.

It is to be noted, apropos of the failure of Archimedes, that they seemed to lack in that day a minute and accurate measure of time. They had hour-glasses, and the clepsydra, a waterclock. They understood well how to "weigh" time-that is, to measure in the balance the amount of water or mercury escaping in the interval covering any given action to be observed; but while it has been used with more success in our modern day, it was a clumsy method. It is evident that it was Galileo's discovery of the pendulum and his application of it as a pulsecounter, which opened the way for his measure of the rate of acceleration-yet another among ten thousand instances of the dependence of progress and discovery upon machines, that is to say, mechanical devices supplementing the crude human implements of hands and eyes.

It is curious to reflect what might have been the effect had the measure of acceleration been made. They had a highly developed geometry, an astronomy as well. They knew the distance of the moon, and its size, almost as well as Newton; they knew its orbit, and could calculate the distance it falls toward the earth, each moment of its flight, almost as well as he: Galileo's Discourses and Mathematical Demonstrations concerning Two New Sciences, dictated by a blind old man under confinement at the hands of the Roman Inquisition, appeared in 1638 ; therein these measures were first related. Newton's "Mathematical Principles of Natural Philosophy," the Principia, in which the law of gravitation was announced, was given to the world in I687. Just half a century lay between.

When Xerxes crossed the Hellespont, says Diogenes, Anaxagoras was twenty; he was born, then, about the year 500 B.C. The sack of Syracuse and the butchery of Archimedes came nearly three centuries after. Three centuries later still the University of Alexandria and its great line of physical investigators still flourished; Ptolemy, the astronomer, was writing his Syntaxis-the Almagest, and his treatise on the refraction of light.

Six hundred years! Time moved slowly then. Though in the reign of Neku I., 600 B.C., Phœnician mariners might achieve 
the circumnavigation of Africa; though before the Christian era the rotundity of the earth was taught to children throughout the Greek world, and though Strabo had conjectured the existence of " many other habitable places" far beyond the Pillars of Hercules, there was no Greek or Phœnician Columbus to venture across these uncharted wastes-they had no "guiding arrow." So, in the same way, there was no great organising brain to put together the geometrical demonstrations of Aristarchus, the mechanical constructions of Archimedes, and the conjectures of Anaxagoras, and thus, as it were, disclose the mechanism of the world. They had no reliable measure of seconds, and they lacked a science of dynamics-a mechanics of moving bodies.

The foundations had been admirably laid by Archimedes; but he seemed to find no followers to carry on his work. The sword which estopped that marvellous brain seemed to strike down not a man but a school; he had practically no successors. In pure astronomy Hipparchus and Ptolemy made brilliant discoveries; but there was no further advance toward a mecanique céleste. Though Ctesibius, at Alexandria, could invent suction-pumps and fire-engines; though his more famous pupil, Hero or Heron, could invent the steam-engine and other marvels, they were of no use, they bore no fruit.

There was a something in the spirit of the age which was fatal to any advance. The organisation of society into masters and slaves brought just such a contempt of industry as was to be seen in England in the land-owning days, and in the southern States before the war. The whole atmosphere of the time was simply stifling to practical things. Industry, labour, was the vile occupation of slaves; mechanics, as we see in Plato, was an art despised. Experimental science, almost wholly dependent on mechanical devices, could not flourish.

Perhaps, too, it would be hopeless to suppose that men would look for, or readily accept, mechanical explanations of phenomena until they had grown accustomed, in their daily lives, to the workings of machinery, and the obvious relations of force and matter, of energy and work.

After Hero, in a thousand years, you cannot find trace in all Christendom of a new instrument or a new tool. After Ptolemy and Galen the spirit of initiative, of investigation, seemed to disappear. Exhausted by incessant and savage 
warfare, debauched by universal slavery and superstition, their brilliant and slender civilisation went down. The advance of six wonderful centuries came to an end. What had been learned was forgotten. For the space of ten centuries after there is not an experiment, not an inquiry, not a book, not a tract, produced in Europe that is worth ten lines in a history of human thought. The empire of the mind was given over to Platonising mystics and to dreary theologasters.

On the side of astronomical investigation, then, Greek science just failed by a step to attain the point upon which our modern world conceptions are pivoted: the representation of cosmos, and more especially of the planetary system to which we belong, as a mechanism. - Was there any other path by which the human mind might reach the same point of view ?

In that English Lake Country, where the charm of the landscape grows by times so intimate and penetrating as to stir the heart of poet and dizzard alike, there lived at the beginning of the last century a Quaker schoolmaster, a diffident and retiring man, who filled his vacant hours studying the weather and the rain-gauge. They say that this John Dalton got to wondering about the process of evaporation and how it could be effected. It was a small beginning; to it our modern atomic theory and the foundations of modern chemistry are due. Though he did not seem to know or care, Dalton had a forerunner among the same old Greeks, who, from much the same beginnings, followed nearly the same course of thought.

If we look back into that ancient day, we shall meet with a solitary and dominating figure, attached to no school, pursuing his own way, a profound and original investigator, perhaps as near to a universal genius as this world has ever known. Who was this Democritus of Abdera, the whole of whose two and seventy works Plato wished to burn, and of which time, not more lenient, has left us scarce a page ? 
CHAPTER XI

DEMOCRITUS AND THE CONCEPT OF AN ATOMIC UNIVERSE 
AND therefore the natural philosophies of Democritus and others who allow no God or mind in the frame of things, but attribute the structure of the universe to infinite essays and trials of nature, or what they call fate or fortune, and assigned the causes of particular things to the necessity of matter without any intermixture of final causes, seem, so far as we can judge from the remains of their philosophy, much more solid, and to have gone deeper into nature, with regard to physical causes, than the philosophy of Aristotle or Plato; and this only because they never meddled with final causes, which the others were perpetually inculcating.

BAcon, Advancement of Learning. 


\section{CHAPTER XI}

DEMOCRITUS AND THE CONCEPT OF AN ATOMIC UNIVERSE

Ir was late in the intellectual awakening of Greece that Athens became its centre. While the little peninsula, whose after life was to shed such a glow in the world, was given over to the sack and slaughter of warring tribes, the shores and the islands of the Egean were astir with a varied activity. There, and along the coasts of southernmost Italy, the Doric and Ionic Greeks, driven from the mother-land, had flung wide their line of colonies. They were navigators and merchants, pirates, too, perhaps; they vied with the Phœnicians for the trade of Egypt, and whithersoever they went, they planted their depots and grew rich. And with nations as with the nouveaux riches always, with their wealth they became civilised, built palaces, and dabbled in philosophy and art. Some of their people, the Sybarites, in Italy, studied so well the ulterior refinements of pleasure as to supply luxury with a synonym. In Miletus on the Asian shore, Thales, and with him Greek physical inquiry, was born. For a century or so half the great names in Hellas were Ionian.

At the top of the Egean where it washes the coast of the ancient Thraké, now a part of the Turkish dominion, lay the Ionian city of Abdera. In that time it seems to have been noted for its prosperity and general culture. It must have been very rich, for there is a legend that when Xerxes came with his Persian hordes on their way to Thermopylæ, he was entertained in Abdera by a private citizen. As a token of time well spent, Xerxes, so the legend runs, left with this Hegisistratus certain magi or wise men, for the instruction of the rich man's sons. One of them, Democritus, must have been a marvellous pupil. When he had learned all the magi had to impart, he took his share of the parental estate in coin of the realm, and diligently squandered it in seeing every corner 
of the earth he could reach. True, the accessible world was not then very wide; be that as it may, the youth returned when youth was gone, versed in all the priestly lore of Egypt and Chaldea-rich beyond any contemporary in knowledge, and without a sou.

There in his native Abdera he thought and worked, observed incessantly, tested minutely his perceptions and his sensations; joked too, it seems, reflected, read, and wrote. By-and-by, in the public square, Democritus opened the pages of his great work, Diakosmos, and read aloud to him who would listen. It was said that he predicted the weather, and other events as well, and remembering his training at the hands of the magicians, the simple Abderites had little trouble in believing him very near a god. Pliny tells a story of how he could raise the dead; but this, of course, was a common legend of credulous antiquity, and told of many men.

Whether he did or no, they put up votive tablets in his honour whilst yet he lived, and as there was then a law that whoso had spent his patrimony should be denied a decent burial, 'tis told they gave the philosopher a purse of five hundred talents. The sum is large; the revenues of Alexander's empire were annually scarce so great. The historians of that day were as prodigal of money and numbers as the Chinese of time. No matter, 'twas said he laughed so hard at all the follies of the world, some thought him mad, and sent for the famed Hippocrates to cure his distemper. But Hippocrates, when he had come, smiled and went away, remarking upon the charm and fascination of his discourse.

He lived to be fabulously old-a hundred or more; but before he had finished he seems to have swept through every science known to his day. Diogenes Laertius gives a list of seventy-two of his books; not one remains. We may regret the loss, for not only does he seem to have had one of the most acute and piercing minds of any age, but evidently he knew as well the witchery of the syllables, the charm of the cadenced period, the enchantment of the deftly-woven phrase. It is the testimony of Cicero, and here at least there could be no weightier judge, that he wrote in a style which, for its poetic beauty, was worthy to set beside that of Plato.

He was a modest man; he began his chief work, "I am going to write of everything," and he very nearly did. If we 
may judge from a fragment, he prided himself most on his travels and his skill in geometry, for he says :-

" Of all my contemporaries, it is I who have traversed the greatest part of the earth, visited the most distant regions, studied climates the most diverse, countries the most varied, and listened to the most thinkers; there is no one who has surpassed me in geometrical constructions and demonstrations, no, not even the geometers of Egypt, among whom I passed five full years of my life." 1

The mere list of his studies reveals their extraordinary range. Aristotle, we know, left a work on some of Democritus' theorems, and there were few philosophers in antiquity who did not write for or against him in some way. He seems to have been abreast, if not in advance of the astronomy of his day; he writes on the Planets, the Map of the Heavens, the Great Year, and much else. He was a geographer, and wrote a treatise on that and on Navigation by means of the Polestar. He was learned in physics. We read with especial interest of a work on the Magnet, others on Rays of Light, on the Clepsydra, or water-clock. He was evidently fond of music and poetry, for he left treatises on Rhythm and Harmony, on Song, on the beauty of the epic poems, on Homer. He counted himself a critic in matters of art, evidently, for he wrote on Painting. He must have been a physician, for he left a book on Fever, another on Dietetics, or The Opinions of a Physician; another on Prognostics, another on Pestilences, another on the Right Way of Living. We find another on Agriculture, and Causes Affecting Seeds, a book on Tactics, and Fighting in Heavy Armour, possibly not his, a discourse on History, a book on the Principles of Laws, a discussion of the Calendar, another on Colours. He writes on Pythagoras, whom he seemed greatly to admire; he gives us a sketch of the Disposition of the Wise Man, an essay on Cheerfulness, a number of others on Ethics and similar topics.

He was a zoologist and an anatomist; 'twas said he practised dissection, and we find a work on Animals. He was a psychologist, and we find an essay on the Mind, another on the Senses. We have a glimpse of his penetration and his knowledge in his ideas as to the seat of the mind. Aristotle had no conception of the truth; he fixes it in the heart. A hundred years before

1 Mullach, Frag. Philos. Grac.; 370. 
Democritus had found in the brain "the monarch of the body."

These were his works; and you gather that his was one of those omnivorous minds which range everywhere, consume all things. You surmise that it may have been also one of those ragbag minds which in the end produces a crazy quilt like the Anatomy of Melancholy. No, he is a thinker, an intense and originating genius, ein bahnbrecher, as the Germans have it.

When we consider the fragments of his philosophy as they have been preserved to us by his critics, his detractors and his friends, it seems as if there were few things betwixt heaven and earth that he had not thought upon. He preceded Descartes by two thousand years in the consecration of doubt. He was a sceptic twenty centuries before Hume. He explained, "we know nothing really, for the truth lies in the depths."

Democritus endeavoured to reduce all sensation to the primal sense of touch, as we learn from Aristotle, who blames him. In this he precedes many a modern thinker. So far as we know he was the founder of the sensational school ; at least he wholly anticipated Locke. He clearly discriminated between "primary" and "secondary" qualities. "What is cold is cold in opinion, and what is hot is hot in opinion." He saw that there is a class of sensations that is wholly subjective and that exists only in the mind.

His seems to have been a fertilising mind, a kind of a fount from which others draw their store copiously and without stint -after the fashion of the ancients, too, largely without acknowledgment.

Eucken says that Aristotle copies from him page after page, and gives little credit; Mullach conjectures that the Stagyrite was in great part indebted to the Abderan for the reputation of vast learning he gained. Cicero tells us that Epicurus borrowed bodily all of his physical theories, his philosophy as well ; spoils what he borrows and gives no credit at all. It is evident that Democritus acquired a great renown, else why should Aristoxenus say that Plato wished to burn all of his works he could lay hands on, "but was prevented from so doing." Cicero, again, of a wholly opposing school of ideas, yet says : "Who is there whom we can compare with him for the greatness, not merely of his genius, but of his spirit?"-What were his ideas of this world? 
Remember that he came four hundred years before Cicero, a full hundred before Aristotle, a century and a half before the founding of Alexandria. He was the contemporary of Pericles, of Phidias, and of that Socrates who said of astronomy that it was "impossible to understand and madness to investigate." Apparently he did not have the idea of a rotund earth, a fact that is the more astonishing in the face of all his other cosmical views, and because he was the friend of that Philoläus of Crotona, who may have been the first in Greece to proclaim the motion of our globe.

Not over laden, then, is the glowing phrase wherein M. Martha remarks of the ideas of "this great philosophical geometer, who by the sole intuition of a penetrating genius, and without the resource of those instruments which chance has subsequently given to modern science, had penetrated many mysteries of the heavens." $\mathrm{He}$ appears clearly to have anticipated Aristarchus; he taught, for example, "that the sun is not the small disk such as we see, but is of immense size; that the Milky Way is an assemblage of stars, which from their distance elude our sight, and which by reason of being so thickly sown in space, illuminate each other; and that the shapes one sees in the moon are to be attributed to the heights of its mountains and the depths of its valleys." 1 He held, moreover, to the idea of the infinity of worlds, their slow but incessant destruction and reformation; for him as for us the stars were suns. Amazing previsions, that the advance of knowledge has so strikingly confirmed !

Here was enough, no doubt, to lift Democritus far out of the tribe of quibbling pedants who passed for philosophers in those opulent days. He was no mere shriftsteller; no superficial Aristotle, no shallow, empty and pretentious Bacon. We have now to see how, by the sheer force of his reasoning, he could rise to a world conception which, in its main features, is still the most tenable we possess.

Democritus, like John Dalton, was evidently a weather sharp; it was the success of his predictions in meteorology which gained him so great a vogue among the Abderites. We may picture him watching, like Dalton, the water in a stone crock disappear in the sunshine, wondering how it could be taken up into the air, as so it must have been. He had heard,

1 Martha, Le Poíme de Lucréce, 239. 
no doubt, of the notions of Anaxagoras, that all things are made up of homeomerice, or similar parts ; of the ideas of Leukippus as well. It seems to have been the latter who first pictured bodies as made of indivisible particles or atoms. The spirit of inquiry was in the air, and Democritus, starting from these suggestive ideas as did Spencer from the speculations of von Baer, was carried far. The scheme of the world, as it shaped itself in the mind of Democritus, was crystalline in its simplicity. The ring upon the finger, the stone steps before the door, the toe of the graven saints under the incessant kisses of the faithful, wear away, subtly, imperceptibly, without that from day to day one may perceive aught of change. The pot, boiling upon the hearth, the pools of water in the sun, dry up; their contents disappear, one scarce knows how. Linen, hanging by the shore, before a beating surf, becomes damp; expose it to the heat, it dries again. Evidently the water, the stone image, the metal of the ring, is made up of particles too fine to be visible or perceptible to touch.

Doubtless the same is true of all matter whatsoever, whether it be "living " or " dead." The grain sprouts, the stalk forms, the flowers or the great oak unfurl, in precisely the same way as the idol's toe disappears, subtly, imperceptibly, elusively. Obviously they are formed by the aggregation, as the others are destroyed by the disaggregation, of exceedingly minute parts. We witness the same process when a lump of sugar dissolves in a glass of water, or when a layer of salt crystallises out of a pan of salt water when it is evaporated.

When the sugar or the salt disappear in the solvent, how far does the process of disaggregation go ?-infinitely? We may take a glass of salt water and mix it with another of fresh ; the salt taste grows a little weaker; but it is evenly distributed throughout every drop of water. Repeat the process, and the result, though the salt taste grows still fainter, is the same. May we keep on doing this for ever? By-and-by the salt taste is gone utterly; but we have only to evaporate the mass of water again and secure all of the salt; none has disappeared.

But how far can the process of disaggregation be carried; how finely can the grains of salt be split up ? So constituted is the human mind that any limit is unimaginable. We cannot think of an object so small that it cannot be cut in two, each of these parts divided again, and again, and again, and so on 
world without end. We may pursue the operation to the mental extinction of infinitude, and the mind will set no bar.

But, on the other hand, it is equally unimaginable that any number of parts or particles, infinitely small, can make up an actual tangible something, when brought together. We may, if we like, try to conceive of an infinitude of infinitesimals; but a collocation of these for every grain of salt or sugar is a trifle wearisome, to say nothing of the fact that it eludes clear mental presentation. Common-sense folk will hardly waste good time over such cobwebs, though it is curious to recall that this seemed the most satisfactory view to such an eminently practical and concrete mind as Faraday's.

For the ordinary affairs of life, our bodies, so alive to pain, the foods we eat, so needful, the liquids we drink, the gases without which we cannot for a moment survive, the houses we live in, the stones we tumble over, seem very real. So do the folk, disagreeable and agreeable, that we find about us; the earth we tread, the hills we climb. How account for their existence? Democritus chose the least tenuous of the two unthinkables : the infinitely divisible and the finitely indivisible -that is, the latter. He called these ultimate particles by a name which described them just as he thought of them, as a-tomic or undivisible - that is, atoms.

Doubtless in this he had many predecessors. Some such idea must have drifted across the mind of many a thinker many hundreds of years before. It is a conception that must soon unfold in any reflecting mind. If a chink in a wall lets through a beam of sunlight into a darkened room, seen sidewise the air is full of dancing particles. It is merely an illusion of the senses, then, to think of the room as empty. It is full of dancing motes. If we are very careful to leave a room undisturbed, by-and-by on objects in the room a fine dust gathers, and the motes will have almost disappeared from the sun's gleam.

Evidently, then, these motes are not air; but float in the air. And if they can float in the air, even as other bodies float in water, then the air is equally real, conceivably also made up of parts or atoms. It is perfectly clear that so Democritus thought of it. In the pages of Lucretius, in which the thoughts of Democritus, filtered through the writings of Epicurus, reappear after three or four centuries, there is a vivid and striking 
argument to prove that the air is material, that it has weight; they had, in brief, very much the same idea about it as we have now. They probably had no air-pump to make a vacuum; but they could observe the tremendous force of the winds when this same air was set in motion. From the gentlest zephyr to the wild tornado which could throw down the walls of houses, uproot trees, even cut them off sharply as if they had been smitten with an axe, there was no gap. One graded into another. It was very clear that the air, in its way, is just as real a substance as water, even though in so many ways it escapes our senses.

Over the illusions of sense, indeed, Democritus seems to have spent a deal of time. It is told of him that he used to go out into his garden, where he could be quite unobserved, and spend hours upon hours "testing his senses." It is fine mental exercise. Nothing can open the gateways of the mind more surely to the great thoughts that came to his.

Perhaps it was from the suggestion of the motes in the sunbeam that Democritus rose to the conception of particles not merely indivisible but invisible as well, and far beyond the palpation of the senses. It is only in their aggregations that they became sensible, yet of them all things are made. Their aggregations may be as minute as the particles of air, the motes of the beam; they may be worlds and suns. For Democritus space was infinite; through space the atoms rained downwards for ever in an infinite stream; they fall by reason of their weight, the heavier particles falling faster than the small ones. This gives rise to clusters or clumps of atoms, these in turn to others, until you have the solid stuffs which our hands may grasp, our eyes may see.

Democritus pictured these atoms as indestructible as well. Two thousand years before Lavoisier he clearly saw that the forms of matter change, but none is lost. In the transmutation of the atoms we have the varied shapes of things; but as to the elements of matter itself, there is no annihilation, no creation. Nothing comes from nothing. That was a dogma, doubtless, that was very old before Democritus came upon the scene, but no one that we know of in that ancient day taught it so clearly, or followed it so far.

He had, then, the first of the two great "laws" which our modern time regards as fundamental to all experimental science. 
So far as mere philosophical reasoning could carry him, he had the second as well. Ideas of force and energy were nebulous enough in those days. Forces could hardly be studied before they were known. Of electricity the ancients knew practically nothing at all; of magnetism, but little more. They had observed, of course, that some substances, like amber, repelled or attracted light particles when they were smartly rubbed up with flannel or cat's fur; but the idea of associating this with lightning of the thunderstorms on the one hand, with light and heat on the other, probably never entered their minds. Nor could they have had any very clear idea of the relations of electricity and the actions of the magnet.

Nor, again, could very definite ideas of energy arise before they had developed the science of dynamics and begun to invent and to use varied machines. It was beyond the powers of any man, therefore, then to conceive the doctrine of the conservation of energy-at least in its modern sense-that is, the idea that there is no motion, no force, no power to do work which is ever "lost" to the universe ; that energy, as little as matter, cannot be created nor destroyed. Yet the idea in all its essentials Democritus had unequivocally attained. $\mathrm{He}$ had

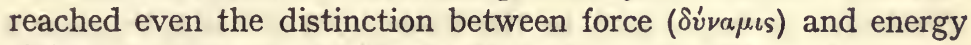

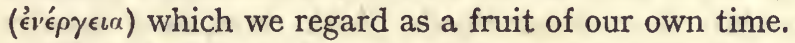

His ideas waited many centuries for definitive experimental proof; but that in no wise detracts from the merit of his genius. He was the father of modern physics and of modern chemistry as well. True, the idea of chemical affinity, of attractions among the atoms, did not come into his system; that was reserved for a later day. But, Empedocles': vague poetical concept of loves and hates among the atoms disregarded, there was no one, apparently, among the ancients who got any further than he. When in our modern time men again began to turn their minds to physical problems, it was to begin where Democritus left off.

The Abderan philosopher founded no school. His philosophy and his system were far too severe for the volatile and phrase-loving Greek mind. So we find here, as in the field of astronomy, that a space of eighteen or twenty centuries intervenes before any further progress is made-before, indeed, there was apparently any further thought upon the subject at all.

In the sixteenth and seventeenth centuries we find philo- 
sophers going over the same ground and digging from obscurity Democritus' ideas. Along about the middle of the seventeenth century we find Boyle utilising them to found the modern science of chemistry. A little later, with Newton, was revealed the law of that force of attraction which exists between every atom of matter in the universe.

Democritus has often been styled the grandsire of materiaiism. It is a school of philosophy that is a little out of fashion nowadays; yet it is worthy of note that practically all of the modern advance in our ideas of this world has been grounded upon his conceptions. Practically speaking, materialistic assumptions are simply unescapable in physical investigations. But it is to be noted that philosophically Democritus was far from the crude dogmas of Buchner and his kind. It is difficult to judge of a doctrine from fragments. Moreover, as dreary shelvesfull of vacuous volumes on the history of philosophy so amply attest, it is possible to read into the ideas of the ancients much of anything that one likes. But so far as one may judge, Democritus in his order of ideas came nearer to those of Herbert Spencer than perhaps any of our moderns, with the difference, perhaps, that to the Underlying Reality he gave a name where Mr. Spencer declined. Both recognised equally that the ultimate is in its essence unknowable; "the truth lies in the depths."

If Democritus is to be accounted a materialist at all, it must be in that larger Tyndallian sense which sees in matter " the promise and potency of all terrestrial life." This was clearly the teachings of the Abderan. The body was made up of material atoms, the brain as well ; the mind is a function of the brain, and for him the soul was the mind. It was made up of "fine smooth round atoms, similar to the atoms of fire"; these are the most mobile of all; penetrating the body, they give rise to the phenomena of life. Substitute for the "fine smooth round atoms" of Democritus the "animal spirits" of Descartes-and we know as much of one as the other-and it will be perceived that his ideas did not differ very differently from those of the founder of modern neurology.

Thing curious to note: so far as modern thought forms any picture of mind, memory, and the soul, it is largely along lines of Hartley's vibrations, to all intents a parallel to the un- 
dulatory or vibratory theories of energy. Conceive our ether theories of light and electricity falling to the ground and Newtonian conceptions of corpuscles-coming back in their stead -we should needfully revert to essentially Democritan ideas for our picture of mental processes.

$\mathrm{Be}$ this as it may, and whether we choose to regard this early prophet of the Unknowable as a materialist, what is certain is that we owe to Democritus, so far as our knowledge extends, the idea of a world machine. His mechanical conceptions, the mechanical conceptions of the ancients, could scarcely have been the replica of ours. Such steam engines as existed seem to have been little more than toys, or machinations of the priests to strike terror and wonder into the minds of the vulgar. Nor is it in the least clear that Democritus had a mechanical turn of mind like, for example, Archimedes, Archytas, or Hero of Alexandria. But in his idea of all existing things as made up of particles, these particles in their motions able to do work, to exhibit energy, Democritus had, in its essence, a purely mechanical conception of the phenomenal world. His atoms were its instruments.

Atoms and space, matter and the motions of matter, and nothing more; you perceive the consequence. If motes and moons, if worlds and waters, if insects and trees, and all things else but represent the permutation of eternal atoms, what we call chance is but a phrase with which we clothe our ignorance of events. From the simple combination of the atoms result the phenomena which we observe, the events of which we are a fleeting part.

Democritus does not seem to have proclaimed himself an atheist any more, for example, than did Mr. Spencer. Among the Greeks the first of the deniers of the gods and their rule of this world seems to have been his disciple Protagoras. We gather that Democritus may have conceived the existence of a race of super-men; but if they existed, even these were a part of a scheme which persisted through space and time. In the Democritan concept, if there was a god, its name was law.

It is needless to add that Democritus admitted no such thing as freedom of the will. Since all was enchained; since one event inevitably follows from another; since, again, in the order of things which exists nothing can ever happen otherwise than as it does, Democritus pictured all phenomena, the actions 


\section{THE WORLD MACHINE}

of our human kind as well, as governed by a rigid and unescapable necessity.

There are types of mind which recoil from this conception of the world with a kind of fright. For Democritus it seemed to have no such terror. He taught that the highest good was tranquillity of mind; he preached cheerfulness as the most admirable of human qualities, and what is more to the point, he seems to have practised it as well. He appeared thoroughly to enjoy life, for all his ideas; it may be because of them. At any rate, he lived to a green old age, and by a curious fate passed into the history of Greek thought as "the Laughing Philosopher."

There might be profit in his example for our modern men of science, who seem to take their learning a trifle seriously and with little relief of gaiety. One would imagine they most times forget that science, like letters or art, can have hardly any other aim than to make life a little easier, a little pleasanter, more varied, more interesting, more serene. Democritus, we may believe, did not. 


\section{CHAPTER XII}

THE LËGACY OF THE GREEKS: THE REBIRTH OF TIME 
WhAT we are is in part only of our making; the greater part of ourselves has come down to us from the past. What we know and what we think is not a new fountain gushing fresh from the barren rock of the unknown at the stroke of the rod of our own intellect; it is a stream which flows by us and through us, fed by the far-off rivulets of long ago. As what we think and say to-day will mingle with and shape the thoughts of men in the years to come, so in the opinions and views which we are proud to hold to-day we may, by looking back, trace the influence of the thoughts of those who have gone before. Tracking out how new thoughts are linked to old ones, seeing how an error cast into the stream of knowledge leaves a streak lasting through many changes of the ways of man, noting the struggles through which a truth now rising to the surface, now seemingly lost in the depths, eventually swims triumphant on the flood, we may perhaps the better learn to appraise our present knowledge, and the more rightly judge which of the thoughts of to-day is on the direct line of progress, carrying the truth of yesterday on to that of to-morrow, and which is a mere fragment of the hour, floating conspicuous on the surface now, but destined soon to sink, and later to be wholly forgot.

Sir Michael Foster, Hist. of Physiology. 


\section{CHAPTER XII}

\section{THE LEGACY OF THE GREEKS: THE REBIRTH OF TIME}

THE appraisal of the Greek achievement has varied widely. To the scholars of the Renaissance it seemed wondrous. In our later day it has suffered somewhat from neglect. "It may be doubted," says Huxley, "if even-handed justice, as free from fulsome panegyric as from captious depreciation, has ever yet been dealt out to the sages of antiquity, who for eight centuries, from the time of Thales to that of Galen, toiled at the foundations of physical science."

The observation is just; the explanation perhaps is not distant. The quality of mind which finds adequate mental pabulum in the mere records of another people or another time is not high. It will as a rule be ignorant of the achievements of its own age. It will then reckon large the deeds of antiquity.

On the other hand, the modern man of science, dipping into the ancient day, is impatient with what to him seem inexcusable absurdities. $\mathrm{He}$ is accustomed to exact methods of research, and the Greeks were not exact. Accuracy and precision are to him the elementary principles of investigation, and the ancients often failed even of that degree of accuracy which was readily attainable from the instruments and methods they employed. The modern mind is trained to rigorous demands for proof; the ancient mind was not. Plato and Aristotle are credulous to a degree which in the most ordinary man of enlightenment to-day would render him absurd.

And again, the greatest measuring geniuses of antiquity, men like Eratosthenes and Poseidonius, seemed to have been quite content if the limits of error were within ten, twenty, or, in extreme cases, fifty per cent. It was not that they were uninstructed; it was not that they lacked ingenuity. In the latter regard they have been surpassed by no modern mind. It was simply that the temper of the age was careless. So it is 
that the present-day hierophant, lacking somewhat the sense of historical perspective, draws a little the frowning brow as he contemplates the rather lighter-hearted science of that lighter-hearted time.

Is it possible to effect a just adjudication ? Let us consider with Kant that the extent of knowledge in any given field is measured by the amount of mathematics which it'contains, and make the attempt. We might think of the matter in this light :-

The century that saw the end of the Roman Republic and the beginning of the Empire may be accounted the apogee of Roman culture. The glory of Alexandria was on the wane. There were richer prizes in the new world-capital. It was the time of Cæsar and of Augustus, of Cicero and of Pompey, of Lucretius and of Virgil. It was an age of freedom and enlightenment. The study of Greek philosophy and ideas was widespread. Greek physical investigation had practically reached its term; its fruits had been gathered. They were then among the common possessions of mankind, and doubtless taught to children as are the teachings of Newton and Darwin now. In what regard, let us ask, would a highly enlightened Alexandrian, or his compeer at Rome, heritor of the Greek tradition and fully abreast of the knowledge of his time, differ, in his larger world ideas, from a man of the same temper and standing now ?

It is evident enough from the pages of Lucretius, of Cicero, of Pliny, of Strabo, and of Cleomedes, that in many ways the difference was slight. The youth of that time were taught the geometry of Euclid. It is taught to the youth of our time with little addition and little change. The trigonometry of the Greeks was but slightly developed, their algebra scarce at all. Their system of notation was not decimal. It follows that they had no logarithms. The calculus was quite unknown. Their processes of computation were clumsy. There are some problems which the modern mind has solved by means of the higher mathematics. But in a large view it is doubtful if there was any fact of deep import which was beyond the powers of Greek methods of analysis.

In their application of mathematics to the mensuration of space, time, and mass, alike their methods and their instruments were crude; yet the accuracy attained in the construc- 
tion of the pyramids, several thousand years before this era, is sufficient evidence that for most practical concerns they were not greatly inferior to our own.

Some of their methods were roundabout. They calculated, for example, the visual diameter of the sun from the time which elapsed between the appearance of its edge above the horizon to that in which its full disk was visible. They did this by weighing the quantity of water which ran from one vessel into another in the interval. Such means of observation seem to us primitive. It is to be noted that they were fairly effective.

They had applied mathematics to the problems of mechanics, of optics, of acoustics. They understood the elements of musical theory - that a vibrating string divides successively into halves, thirds, and so on, and that the notes of the scale are in simple ratio to the fundamental tone. They understood the principle of the lever ; they had developed fairly well the statics of bodies. They had fairly well worked out the geometrical side of optical theory. They knew that the sun appears before it is actually above the horizon; and from this Poseidonius was able to calculate with a fair approximation the height of the earth's atmosphere. Through the applications of geometrical optics, they were able to solve the more essential questions which pertain to the place of the earth in cosmos. Let us sum up precisely what they knew :-

They understood that the earth is a sphere, and that it hangs, so far as any one may see, in empty space. Their minds had reached the conception that it rests on nothing.

They understood the size of the earth, had fair ideas of its variety of climate, had measured accurately the width of the tropical zone. They knew in theory at least of the land of the midnight sun. They discussed with enlightenment the question of other habitable continents beyond the seas. They had fixed with close approximation the distance of the moon, and realised its great size. Some of them at least knew of the relations of the moon to the tides.

They understood something of the distance and grandeur of the sun. They knew that it was a body far larger than the earth. Two of them at least had more correct ideas, had made better measures, than had any one before Cassini and Newton, fifty years after the telescope was in general use. The sombre reflections of Cicero and many another make it clear that the 
moral of these astonishing measures had come home to them. Their minds, too, had left the inconsequence of earthly concerns in the face of cosmic immensity.

They had correctly apprehended the character of the "wandering" stars, and had set them in circular or epicyclic orbits, in revolution about the earth and the sun. They do not seem to have computed their relative distances; but they had enough of an idea of the solar system to make mechanical models of it.

They knew well the enormous distance of the stars, and they understood clearly that, compared with this distance, the great bulk of the earth was scarce more than a mathematical point. Some among them at least conceived the stars as suns. Simplicius, upon what grounds we do not know, stated that some of them were larger than our own. The infinity of worlds was a commonplace to which Lucretius and Cicero refer rather than contend for.

Through five or six centuries-through a far longer time than our modern world has believed in the fact-a considerable sect among them, the Pythagoreans and their numerous adherents, taught the motion of the earth upon its axis. Some few among them taught as well the fixity of the sun and the movement of the earth about it. One among them at least had submitted the possible extent of the universe to a mathematical calculation.

Their insight into the problems of more immediate terrestrial concern was less penetrating. The studies which we now group up under the name of the physical sciences found a much slighter development at their hands. They were metallurgists of long standing; but of chemical theory they had next to none. Their ideas of heat and other natural forces were of the crudest. They had not deciphered the hieroglyphics of the rocks. Of true conceptions of the age of the earth, or its formation, or of world formation in general, they could have had none at all.

And yet there were not wanting among them piercing minds which had caught some glimpse of our modern ideas. Zenophanes could find evidence of a time when the seas had stood above the tops of the highest mountains. Anaxagoras could look forward to a time when the highest mountains would be again beneath the sea. Empedocles caught distantly the idea of the immutation of the species. In Lucretius' marvellous poem "On Nature" there is a sketch of the struggle for exist- 
ence that is probably as good an account, on its larger side, of the Darwinian theory as, let us say, the late Matthew Arnold could have written without reference to some accepted exposition.

In Pliny there are recipes for foretelling the weather. Democritus had written upon the same subject at a time more distant from Pliny than the later crusades from our own.

It is evident enough that a very large number of minds had widened to the perception of nature as a series of phenomena, orderly and more or less predictable, and understandable among themselves. It is evident that for five or six hundred years the clearer thinking portion of mankind had given over its beliefs in interfering deities and malevolent demons, and had quite ceased to look out upon creation with the naive fancies of their far forbears.

Consider now the world ideas of some of the foremost men of letters, of politics, and of affairs in the present age. It is evident that there were among the ancients not single minds but scores who undoubtedly had better apprehended the scheme of this world than, let us say, Tolstoi or Mr. Gladstone, the last representative of the Russian autocracy, or the possessor of the greatest fortune in America.

Again, let us ask ourselves, in what regard does the average man, even among the most enlightened, nowadays pursue the game of life in a manner different from the busy traders of Alexandria or the land-holders of the Roman Empire? Then, as now, money ruled the world. Then, as now, the central power of the State was a plutocracy. Then, as now, politics was a road to wealth. Cæsar left Rome for Spain at thirtyeight or so, owing 250 million sesterces-perhaps two million sterling. He died worth perhaps as many more. Crassus became the wealthiest man in Rome through real-estate speculation, just as did George Washington, and by building houses to sell, doubtless on the instalment plan. Then, as now, to be rich, to marry among the rich, to have a place among the society of the rich, to win applause or secure political preferment by scattering a fortune with a lavish hand, was the supreme desire of the great body of mankind.

f. Scientific investigation then interested but few. It interests but few now. The number of men of culture and intellectual distinction, of freedom from the prejudices and passions of the vulgar, from the cant of religion or patriotism or a smug and 
unctuous morality, of high aims, of a large and wide-eyed humanity, was scant then as it is scant now. They were the remnant set over against the vast majority, as they are the remnant set over the vast majority still.

Three or four centuries of Hellenic freedom from superstition, of clear thinking and a rational investigation of nature, could not transform the mind of the populace, just as three or four centuries of modern scientific development has not transformed it. If the spirit of rationalism in its modern day renascence has struck deeper, has taken a firmer hold, the fact is due to forces in some sense extraneous to the scientific spirit. It is because of what we have come to call applied science, the practical use of knowledge, the development of machinery, and the consequent diffusion of comfort and advantages, that our own time is cleaner, saner, less cruel, less brutal, less credulous, than that of two thousand years ago.

To sum up: Hellenism, Hellenic art, literature, science, was a stage-all things considered, a very high stage-far nearer to our own than anything in the twelve or fifteen centuries which intervened. It was by a slender space that the Greek mind failed wholly to anticipate our present-day cosmical theory. They had attained to grandiose ideas of infinitude, which modern research has somewhat extended but not changed. They had gained, in all its fundamental characters, a true representation of the place of this earth in space, its form, its size, its motion, the grandeur of the sun, the distance of the starsin brief, a correct and reasoned picture of creation as it is. There were giants among them who would be giants no less, and, it may be added, no more, to-day. They reasoned as we reason, measured as we measure; their achievement was immense ; it deserved to endure.

What we may regard as the crowning discovery, they missed. The conception of a single mechanical force acting across the furthest confines of the universe alone was wanting. This idea, which was finally to banish the crude notions of the intervention of gods and demons in the course of the heavens, which eventually was to destroy the notion of the intervention of gods and demons in the affairs of men, finally and for ever to establish the idea of a universal order and universal law, they lacked. Let us not on this account belittle the splendour of their deeds. 
It is with a melancholy interest that we reflect that this exquisite flowering of the human intellect was to pass utterly away and to be forgotten for a thousand years; that a craven and baseless superstition was to come in the stead of this civilisation of beauty and of light; that the empire of life and mind was to be given over to venal and licentious monsters robed as the vicars of the Most High; that the race should be despoiled of its fairest attainments; that art should wither and literature decay; that freedom of thought should become a crime; that noble souls should rot in dungeons or agonise in flames; that grown men should scream with the torture of the rack; that whole peoples should be butchered; that the riches of classical times should be piled in heaps and burned as impious.

But the spectacle of history seems like that of nature. After a period of fruitfulness the field must lie fallow. A mighty creative effort is ofttimes followed by a long period of exhaustion and recuperation. Sometimes the human mind will spend all its energies in one splendid burst. So it seems to have been with Newton in the production of the Principia. One might imagine that the same thing might be true of the mind of the world. We shall perhaps not go wrong in believing that the period of Hellenic fructification came as a sort of climax to ten thousand groping years. As if the earth had borne too heavily, the seasons came, and with them the generation of men, emptyhanded and without fruit, through a thousand or fifteen hundred sterile years.

It is only in this vague wise, apparently, that we may picture the extraordinary eclipse which seemed to come over not merely the whole of Europe, but the whole of Western civilisation. It would be a mistake to suppose that this was merely the recrudescence of paganism, or, again, that it was due merely to a triumph of religious fanaticism. The new faith of Europe was, it is true, but little more than a revival, with some additions, of the old pagan cult. But in some sense the period of darkness had set in before the Church had gained its hold. Nero and the monsters of the purple preceded St. Augustine and the fathers. Imperial Rome was the penumbra; Christian Rome was the full shadow.

There has been in recent years a tendency to revive somewhat the accepted picture of the Interregnum, to discover that 
the Dark Ages were not so very dark, the fanatics of the Church hardly so maniacal as the earlier historians would have led us to believe. Doubtless there were some exaggerations, many inaccuracies. Gregory the Great may not have burned the Palatine library. In the monasteries some faint traces of ancient learning survived. A closer scrutiny will no doubt reveal some relief in the heavy lines of the now classical picture, drawn in the pages of Ranke, Draper, Llorente, Taine, and many another.

But in general the attempt to rehabilitate what we term the Middle Ages resembles very much that sort of exaggerated reaction which proclaims the virtues of a Nero and the humanity of the misprised Tiberius. Let us not lose sight of the main facts. Freedom of thought was stifled. Natural inquiry was dead. The arts of civilisation all but perished. Sanitation, and with it civic decency, almost disappeared. The Paris of the twelfth century was a pig-sty. This was generally true of Europe, outside of the Arabian dominion, through eight or ten centuries.

Great libraries were a characteristic of ancient civilisation as they are of modern; one might almost call them an index. In the long Blight they were sacked, burned, and dispersed. At the close of the Ptolemaic dynasty it is estimated that the Alexandrian Library contained a total of 700,000 papyri. In the fourteenth century, when Charles V., surnamed The Wise, founded the Royal Library of France, he could amass 900 volumes. He was a patron of learning, and so highly did he prize his collection that he had a catalogue made of it. So drear was the time that the fact has descended in its annals.

The great collection of Alexandria was but typical of the age. It was begun by Ptolemy Philadelphus, successor of Ptolemy Soter, half-brother of Alexander the Great, who took for his portion the dominion of Egypt when the Macedonian fell. It was originally a part of the museum or university. The collection numbered 400,000 volumes when it was burned by Cæsar. A second library established by Ptolemy Physcon in the great temple of Serapis, containing 300,000 volumes, escaped. To atone for the loss of the first, Mark Antony presented to Cleopatra the rival library which had been collected by Eumenes, King of Pergamus. The latter consisted of 200,000 volumes.

What was true of the gay capital of the Greeks was almost 
equally true of the Latin metropolis. As late as the fourth century of our era, it is said there were twenty-eight public libraries in Rome. One of these had been the fine Ulpian library, another that of the Palatine. Even in minor cities throughout the empire do we read of collections of considerable value and extent.

Mournfully does the lover of books contemplate the fate of one and all. Three hundred years after the first destructive fire, the Alexandrian Library was pillaged, and in large part destroyed, by a wild rabble under the lead of the fanatical Bishop Theophilus, and countenanced by that Saint Cyril who instigated the atrocious murder of Hypatia. Three hundred years later still, its remnants were fed to the flames by order of the conquering Omar. Even then, so great was the number of papyri remaining, that, used to fire the baths of Alexandria, it is recorded that six months were barely sufficient to consume them. An insane and burning hatred of learning seemed to inflame the heart of Christian and Mohammedan alike. Doubtless the great majority of these works were of mediocre value. Some few were not; and to no man is it given to anticipate what will be held of most. worth a thousand years beyond his age. It is with difficulty that he who reads now restrains his resentment against the destroyers of these interesting relics of the ancient mind.

What the zealot left the hand of fate seemed to seize. The history of the libraries of Rome is a history of fires, which came as a part of the incessant conflagrations which visited the imperial city. Scant wonder is it then, that, suffering such adversities, so slight a portion of ancient literature should have come down to us, that the immensely larger part-more than ninety-nine per cent., we may imagine-should have been utterly and irretrievably lost. It hardly needs be added that the portion which appealed to the scholar and to the reading public least, that which dealt with the several sciences, should have been the most neglected and the least preserved.

Of great libraries we hear no more until the rise of the Saracens and at the close of their era of conquest, along in the eighth and ninth centuries. Then it was that their more enlightened Khalifs began again the sedulous hoarding of books. Al-Maimun, son and successor of the distinguished Haroun Al-Raschid, is reported to have brought into Bagdad hundreds 
of camel-loads of manuscripts. The spirit of collection eventually extended over the whole empire. Its rival divisions vied with each other in their accumulation. The Fatimite Library at Cairo numbered, it is said, 600,000 volumes-figures which may be taken perhaps with some reserve. Yet its catalogue alone was said to occupy forty-four. In Andalusia-that is to say, in Mohammedan Spain-there were seventy public libraries recorded. The collection of private individuals was often extensive. A modest physician Draper reports as having refused the invitation of a Sultan of Bokhara because the carriage of his books would have required four hundred camels.

Retribution for their evil deeds in the earlier time fell upon the Mohammedan when the hordes of Christendom swept through his dominions. A great library at Tripoli was burnt by the Crusaders. It was fancifully said to contain three million volumes. When the Moors were driven from Spain, so the story runs, the Cardinal Ximenes made a bonfire in the squares of Granada of 80,000 Arabic manuscripts, many of them translations of classical authors. The position of the nations had become strangely reversed. The aforetime foes of learning had become its protectors. The legitimate heritors of the Greek tradition had become its implacable enemies.

The Saracenic civilisation, indeed, presented a singular contrast to the sodden and seemingly irretrievable stagnation which had settled upon the rest of Europe. By a curious and violent paradox, the like of which has seldom been known, a fierce, ignorant, and warlike race, dominated by as intolerant a religion as perhaps had ever been known, became the conservators of such science and such knowledge as yet remained among men. They had not merely libraries; the empire was dotted with colleges, with great universities and medical schools. The first of the latter established in Europe was said to have been that of the Saracens at Salerno in Italy. The first astronomical observatory was that erected by them at Seville in Spain.

The order of culture that obtained for a time among the Saracens was high. For two or three hundred years, from the time of the Khalif Al-Maimun, the wide area from Samarcand to $\mathrm{Fez}$ and Cordova was the theatre of a rich and varied life. Letters were again cultivated; a taste for the classics was revived. All the stores of ancient learning were exhumed, were 
translated, and subjected to exhaustive commentary. The measure of the earth was again undertaken. Astronomy again found high favour. Men of learning were again held in honour.

The making of books became a trade. In Bagdad, Honian set up the earliest publishing house of which we know. The study of mathematics was again ardently prosecuted, our modern algebra developed.

Familiar Omar Khayyám may serve as a type of the time. $\mathrm{He}$ seems to have been a singularly accomplished and gifted man. He was by profession a mathematician and an astronomer, wrote a treatise upon algebra, calculated elaborate astronomical tables, still of value, and reformed the calendar. This was at the command of the Sultan, Jalal-u-din, and his chronology was known as the Jalali era. Gibbon refers to it as "a computation of time which surpasses the Julian and approaches the accuracy of the Gregorian style." It will be recalled that he was the friend in youth of Al-Hassan, a powerful and evil genius, who became the founder of the famous and infamous sect of the Assassins. With Hassan he rose to high favour at the court, and as he seemed to covet little and enjoy much, he must have passed an unwontedly serene and agreeable existence. The ancient chronicles refer to him as "The King of the Wise," " in science unrivalled, a very paragon of his age." His poetry must have been a diversion; he seems to have been one of the rare instances known to literature of an intellect of a really high order, commanding the full knowledge of his time, and united with a true poetic gift. Beside him Lucretius and Goethe, in a more restricted sense Tennyson and Leconte de Lisle, are among the few conspicuous examples which could be cited.

Omar was not merely a poet and man of science; he was a philosopher as well. His tenets perhaps most resembled those of Epicurus. With the latter he might have inscribed over the door of his garden the legend reported by Seneca: Hospes hic bene manebis ; hic summum bonum voluptas est (" Tarry, stranger ! here pleasure lords the day "). But on the whole he was not so much an Epicurean as a complete hedonist. His philosophy of life bore as much resemblance to the chaste and reticent stanzas that FitzGerald fashioned for the edification of young minds of both sexes as the life and teachings of Sakya-Muni to the late Sir Edwin Arnold's beguiling romance in verse. He was a frank sensualist, and as utter an infidel as ever roamed the 
highways of human thought. In this, if we may judge from the unaffrighted impudicity of the prevalent literature and chronicles, he represented perhaps better than any other the cultivated Arabian spirit of the eleventh and twelfth centuries.

But if this ardent and somewhat fanatic people could produce genius of so high an order and sense of so rare a make, if it could reach a stage wherefrom it could brook without disquiet so candid a denial alike of morality, faith, and the solemnity of life, its limitations were still sharp.

The character of the Saracen resembled much that of the faithful servant entrusted with the one talent, who carefully treasured it in the earth until his master should come again. If they preserved much, they added little. If they became the heritors of Greek culture, in no notable degree did they imbibe the Greek spirit. On the more serious side they displayed but slight originality. They copied; they transcribed; they made, as it were, copious notes. But a genius for independent inquiry, for new synthesis, they nowhere displayed. They produced encyclopædic works; but of such a type as those of Pliny and Aristotle. Indeed, the formal mind of Aristotle, with its extraordinary miscellany of information, its empty definitions, its unfruitful classifications, represents fairly well the intellectual level of this very remarkable race. Al-Hazen, Ibn Junis, and their kind did better, did real things; but Averrhoes, Avicenna, and their like thought and wrote after the manner of the Greek mind before it had developed its genius for measuring, for weighing, for computation, and for daring induction.

This characteristic was by no means insular to the Saracen. It was shared equally by Bagdad and Byzantium, by Paris as by Cordova. The worship of Aristotle-for it was no less than that-was indeed one of the most curious phenomena of this enigmatical time. Infallibility was attributed to his works in hardly less a measure than to the Hebrew scriptures. To doubt them, among the more northerly peoples at least, was impious. In England and in France there were statutory enactments which made it a crime.

Moreover, in no wise did the Saracen mind ever attain to that complete intellectual freedom which was the characteristic of the Hellenes. They were weighted with the cult of a gloomy religion as Europe was weighted. They bore it more successfully. Their cleanly and ofttimes beautiful cities, their magni- 
ficent palaces, their splendid libraries, their literature, their restless and inquiring, if still somewhat subjugated spirit, amply attest the fact. They made some progress in their physical investigations; in some sense they transformed alchemy into a science. Many of our scientific terms are transferred directly from their language.

But there was something in their mental organisation or something in the time which held them in check. We may not inaptly compare them to the Hindu or to the Chinese. Our decimal notation is an evidence of the success with which the Hindu cultivated mathematics. We know that the Chinese possessed the compass a thousand years before our era; the printing-press and gunpowder yet more anciently. Yet with the aid of his more facile methods of calculation the Hindu made no contributions worthy of his invention. With the printingpress the Chinese spread wide no wonderful literature. By the aid of the compass they made no great discoveries. With the aid of gunpowder they made no vast conquests. Neither Chinese nor Hindu made any notable additions to the stock of human knowledge. They left no deep impress upon human civilisation. They made interesting beginnings, then stopped. The same is true of the Saracen.

Doubtless, if the arms of Charles the Hammer had not stayed the northern sweep of the Mohammedan hosts, the six or seven centuries of European history that followed would have been written in far different fashion. It is scarcely believable that they could have fixed their faith upon the North. It is scarce believable that their yoke would have remained for long. But in the clash of warring creeds, in the mingling of alien peoples, in the diffusion of Arabian culture, the reintroduction of the manners and modes of civilised life, the utter stagnation which had fallen upon European lands, we may believe, would have come to an end. We may conjecture that from this foreign invasion might have resulted something of that same freedom and stir of life which came with the struggle of the sects in the Reformation, eight centuries later.

It was not to be. The tide of the Saracen was rolled backwards, its energies of conquest were turned into the channels of intellectual development. Europe was left to rot on, until in the obscure order of events, time for it should be born again. 
There are in the history of the last twenty centuries two events of incomparable interest. The one was the extinction of Hellenic civilisation; the other was the Renaissance. Perhaps at a later day, when history has ceased to be a babbler's chronicle, the causes which resulted in these two momentous events will be divined, and we shall understand the periods of ebb and flood of the human mind as accurately as we now follow the waters of the ocean. As yet they are profoundly obscure. We may remark the introduction of gunpowder; but gunpowder was apparently known in some form to the Greeks, and throughout the whole of the dark time. We may consider the printing-press; but the printing-press merely substituted the turning of a wheel for the hands of forty slaves. We may note the incoming of the compass; yet it is not improbable that the compass, too, was obscurely known to the Greeks, and that through travellers and conquerors who may have come in contact with the peoples of the East it might have been imported at any time within, say, fifteen centuries before its use became general.

We may prattle of the fall of Constantinople, the incursion of Greek scholars into Italy, and the ensuing revival of a taste for ancient letters; but there is no evidence that the study of Greek was ever wholly banished. And when we have idly enumerated these inconsequent and insufficient "causes" we are no forwarder.

We cannot comprehend why it was that after a splendid fruitage the vineyards should wither and their bearings cease. We know as little why it was that after so many weary and hopeless years the seed should spring again from the ground and a new and vigorous life come again to men. Perhaps the atmosphere of freedom and enlightenment in the earlier time brought a kind of intoxication which ended in debauchery and excess. Something of the sort appears obscurely to have been the case. When the removal of every restraint to their power bred madmen for emperors, Rome became less a capital than a lupanar.

Certainly there seems to have ensued a period of weakness and exhaustion, and perhaps we may regard Christianity as a sort of a fever which, in its period of weakness and exhaustion, seized upon the race.

This fever had to run its course. We know that in the end 
it produced something of that same sense of aridity and depression and a sterile and profitless atheism which came to the earlier day. Faith crumbled, we know not why-perhaps more from physiological than intellectual reasons. Religion ceased to satisfy men's needs, and the new Evangel had not come. At the end a pope, Urban VIII., wrote upon the tomb of his brother: Hic jacet pulvis et cinis; postea nihil; "dust and ashes, and in the after-nothing!"

But even while this disillusioned pontiff, like another Cohelet, or whoever may have been the author of Ecclesiastes, was thus writing down the vanity of life, the futility of human concerns, to the world about him a marvellous awakening had come. It had come subtly, unobtrusively, without that any man knew why, or that the most of men were aware. At the opening of the quattro cento, into a cup of exquisite chasing Dante had poured the alembic of the new Italian tongue. Fleeing before the invading Turk, the exodus of the pedants into Italy had brought resurrection to the immortal works of Greece. Petrarch and Boccaccio, fired with enthusiasm for the new study, had made ancient learning again the fashion. From Marco Polo, from Mandeville, and other travellers had come dazzling tales of unknown lands. The spirit of adventure stirred anew.

At the same time trade and commerce were flourishing as they had not flourished in centuries. The northerly lands of Europe were becoming rich. To the leisured class came time to learn, and with it the vanity to affect tastes and cultivate aptitudes which lifted them yet a little further from the crowd.

The intellectual movement was widespread. The introduction and prevalent use of gunpowder resulted at last in a demand for a theory of explosions. A mingled chemistry and alchemy had been imported from the Moors. The zest for inquiry ran into channels the most diverse. In Leonardo da Vinci was incarnated one of those multifarious minds which appear once in a century or more. Painter, poet, engineer, strategist, inventor of canal locks, a student of shells and stones, of plants and trees, of pigments and the effects of light, he became the founder of half-a-dozen sciences.

To still larger results, in the far-off wilds of Great Britain, in the solitude of the cloister, and persecuted as a necromancer, Roger Bacon had toiled at the resuscitation of physical science. 
His works, filtering through the pens of Cardinal d'Ailly and others, caught at last the ear of a strange and masterful man, a wanderer and a thinker, half a pirate and half a seer; and out of the tumult of his ideas came at last the project of a voyage to India through the waters of the unknown west. The mystic needle which would pilot the mariner without the aid of headland or star had come into general use. Adventurous voyages were being undertaken. An era of maritime discovery had been begun. The circumnavigation of Africa was to be attempted anew. From one of his most distinguished countrymen, the Florentine astronomer Toscanelli, Columbus had found reassurance for his great design. The ancient speculations of Eratosthenes and Strabo as to the feasibility of such a voyage and the existence of other and doubtless habitable continents, were being ardently discussed. For a century or more these ideas had been revivified and popularised through the curious and widely read writings of Sir Jehan Maundeville, "Knight of St. Albans."

The mistaken measures of the circle of the earth handed down from Ptolemy, the equally mistaken ideas as to the distance of India to the East, gave to the project a far less hazardous air than the reality would have presented. Still, it was difficult enough; in the minds of most, a fantastic dream.

The discovery of the New World came to Europe like a bolt from the blue. Yet the quest of Columbus was in some sense as definite an inquiry as a laboratory experiment. Measurements had been undertaken; a fund of fact and theory had been evolved; vast inductions had been framed. The prows of the Santa Maria and its companion vessels were turned towards the west to test the validity of these conceptions. It was experimental science put to the proof. With the news of the discovery the enlightened spirits among mankind saw, as it were, in the skies a sign-

\section{"In hoc signo vinces."}

The scientific method, the rational use of experience, of inference from careful observation, of hypothesis and verification, had won its first brilliant victory in the new time. The march of the mind towards the intellectual conquest of the worlddestined, we may believe, never again to be interrupted or thrown back so long as the human race survives-had begun again. 


\section{CHAPTER XIII}

COPPERNICUS; THE TRUE SYSTEM OF THE WORLD 
IF there be some babblers who, though ignorant of all mathematics, take upon them to judge of these things, and dare to blame and cavil at my work, because of some passage of Scripture which they have wrested to their own purpose, I regard them not, and will not scruple to hold their judgment in contempt.

Coppernicus, De Revolutionibus (Dedication to the Pope). 


\section{CHAPTER XIII}

\section{COPPERNICUS; THE TRUE SYSTEM OF THE WORLD}

IF we search the later annals of mankind for its most pivotal, most momentous event, we shall mark beyond doubt the voyage of Columbus. There is no other single fact, no circumstance, no happening, so fraught with vast issue. Its effect upon Europe was simply dramatic. After the three thousand, five thousand, years known to history, after perhaps ten or twenty thousand years of timid groping, of piece by piece conquest and discovery, wherein a chance wind or storm may have played the ruling part, the ranges of the earth were suddenly doubled. In ten or twenty years they had been extended thirty or forty fold; the ships of Magalhaens effected an actual circumnavigation of the earth. The truth that it was a globe had been experimentally and irrefutably demonstrated. Europe began again to think, to wonder, to reason.

The ferment was profound. The heart of the world was aflame with a lust for gold, with a fever of conquest, with a passion for discovery, with a longing to see, to explore, to know. For centuries, for near a thousand years, the chief external concern of the great body of humankind had been their souls. Their speculations touched the nature of God, the remission of sin, the life to come. Their thoughts turned suddenly towards the new Indias beyond the sea. It was as if the curtain had been drawn aside upon some wondrous prospect, some theatre of the unimagined, the unsuspected, the unknown. Kings dreamed of new empires; to the peasant in the fields, to the monk at his orisons, the scholar in his cloister, the spinner carding his wool, came the vague stir of a larger life:

The ferment, at first a confused awakening of new impulses, new ideas, speedily became moral. Within twenty years of Columbus' voyage, Luther had nailed his theses on the cathedral door of Wittenberg; in an age of universal submission to 
authority a blow for the right of private judgment, the liberty of the human conscience, had been struck; the long struggle against the benumbing yoke of an all-powerful ecclesiasticism had been begun. Servetus, Vanini, Bruno had yet to go to the stake; but the term of religious persecution, which the careful and unimpassioned Ranke estimates had cost Christendom ten million victims, was approaching its end.

With this moral revolt came a kindred awakening of the intellect. Ten years after the outbreak of the Reformation, Jean Fernel, a French physician, made the first measure of the earth, so far as we know, on European soil. Twenty years before him, a Roman Catholic priest, in an obscure corner of Poland, had begun upon a work that, by a favouring accident, was destined to accomplish a greater revolution in the thoughts of men than any single volume before or since.

Nicolaus Coppernik's book on the Revolution of the Heavens did not see the light until the year and near the day of his death - that is, in I543. In his dedication he records that he had been at work upon it for nearly forty years. He was a fearless thinker, but doubtless he loved his peace of mind, and Europe was then a vast holocaust of heretics. The papal Inquisition had been established when Coppernicus was a boy; Llorente, its historian, figures that in eighteen years Torquemada and his collaborators had burned ten thousand victims, and tortured and punished a hundred thousand more.

Coppernicus dedicated his book to the Pope ; he had been an instructor in mathematics at Rome, his uncle was a bishop, and his feeling about the sort of criticism his book would meet is shown well enough in the lines that preface this chapter. But still he did not dare. A cardinal became its sponsor, and the frightened Osiander, who put it through the press, wrote for the book a foreword in Coppernicus' name, exhibiting it as simply an hypothesis, this motion of the earth. What a state of the world!

Whoso reads now the De Revolutionibus will close its pages with mingled feelings. So far as mere facts go, there was not, to speak strictly, a great deal in it, of value, that was wholly new. A great deal of it-six of the twelve chapters of the first book, for example, and much of the rest-was little more than an abstract and commentary of the Almagest of Ptolemy of Alexandria. Coppernicus was an exact and lifelong observer 
yet there is little in his work that could not have been, and probably was not known to Ptolemy and Hipparchus. His instruments were, of course, the same; he had his unaided eyes to see with, as did they-nothing more. He can hardly be said to have made any great discovery-possibly one; nor did he bring forward many new and decisive facts. He met objections to his theory in the same way that Aristarchus had; his arguments were the same. He can estimate no better the distance or the grandeur of the sun, the moon, or the stars.

This seems rather sweeping and assuredly caviare to the general view. In most popular accounts you will find it stated that "Coppernicus did not merely speculate, he proved" that the earth was a planet like the rest, and revolves about the sun. The general opinion of astronomers is otherwise. We have it in the words of the learned Schiaparelli that-

"The two systems (the Ptolemaic, which reigned so long, and the Coppernican) could be adapted to represent the phenomena of the heavens equally well; geometrically, they were equivalent between themselves, and likewise to the system of Tycho. Even Kepler, with his ellipses, was not able to overcome the possibility of sustaining the immobility of the earth. It was only Galileo and Newton who, setting out from physical principles better grounded than those up to that time dominant in the schools, were able finally to overturn it." 1

In truth, the absolute demonstration did not come until the middle of the nineteenth century. Why, then, does the work of Coppernicus in some sense mark an epoch in the history of human ideas?

First of all, because it turned out to be the truth, to portray the unbelievable reality; but as much more because it is among the highest products of the imaginative faculty. You will read in many a place that Coppernicus was not a great and original genius, in the sense that Newton and Darwin were. With all that he borrows from Ptolemy, a careful study of his work assuredly gives one a different impression. Consider that he lived in an age when astronomy and astrology had not parted company, and that amid all the wild fancies then prevalent you find it a sane and modern work. Very often its mode of reasoning is not satisfying; you meet at times with the same empty verbal explanations, as that the earth is round "because

1 I Precursori di Copernico nell' Antichita, Milano, 1873. 
a sphere is the most perfect form," \&c., which is characteristic of Aristotle and the ancients. But it bore no trace of that errant-minded mysticism from which even Kepler in the next century had not freed himself.

For the rest, it is written in such a straightaway, calmly confident manner that, knowing how nowadays, and in the old days too, successive works of science are as a rule little more than compilations from some previous work, you might readily suppose a high state of astronomical science in his time. We know, of course, that it was full of the wildest fancies, that almost anybody's guess found credulous attention.

Despite the faint-hearted preface inserted by other hands, Coppernicus does not in the least put forward his ideas as a mere hypothesis. He believes in them serenely, proves them to his own satisfaction, and, more curious still, for any alternative suggestions has only the scantiest word. He does not sketch out the old Ptolemaic ideas so long in vogue; he goes straight to his task. First of all, the world-that is, the whole cosmos-is a sphere. This takes only ten lines to prove. The sphere is the most perfect form. It is evident that the heavenly bodies are spherical, just like a drop of water, therefore the heavens too must be spherical.

This is logic that limps, and, coming on the earliest page, it gives you an unfavourable impression. It is almost the weakest point in the whole book. In the next chapter he details all the familiar reasons to prove that the earth is likewise a sphere. He points to the discovery of America as further proof, and it is evident that this central fact had taken a strong hold upon his mind.

In another section he goes on to prove that the motion of all heavenly bodies must be in a circle. We know he was wrong here, but in this assumption he dismissed the clumsy system of epicycles of Hipparchus and Ptolemy. Then he plunges abruptly into the question of the motion of the earth. Since it has been shown that the earth has the form of a globe, it is now in order to inquire whether, from this fact, it does not also possess a motion; likewise what place it occupies in the universe. Most writers, he says, agree that the earth is the middle point of the world, and find any other suggestion not only inconceivable but laughable. Coppernicus does not. He has been pondering the matter for forty years, and has set 
himself free, at last, from the bondage of appearances. $\mathrm{He}$ offers a simple demonstration of the infinite range of the heavens, which has already been sketched on a former page. ${ }^{1}$ $\mathrm{He}$ very briefly outlines the ideas of the ancients, then sets himself to disprove them. You turn the leaf, and with no flare of trumpets, hardly an air of novelty, you find a chapter inquiring whether or no the earth has not one motion, but several.

You reflect that this is a work which turns the world upside down. You have somehow the idea that the proof should be as long and detailed as Darwin's demonstration of natural selection; instead, the subject is swiftly compassed in a few pages. The next chapter sets out the order of the planets. Then comes the final section of the first book, wherein Coppernicus sets forth what he calls the third of the earth's motions. This last alone would have entitled him to a high rank among astronomical discoverers, yet he gives it simply as a part of his system, without any ado, making no note that it is wholly and entirely his own. You perceive how carefully and patiently he has thought his subject out and woven it into a firm and connected piece.

In the expression of his ideas regarding this third motion, Coppernicus was unfortunate. To account for the changing seasons, the varying length of the days, he speaks of a " motion of declination," as though the tilt of the earth's axis to the plane of its orbit were variable throughout the year. Hence he assumes a motion of the axis. We know now, of course, that the assumption was needless. There is no annual motion as he thought; the tilt remains very nearly invariable. But, in following out this idea of a changing inclination, he got sight of the real sway of the axis, and works it out clearly; though, of course, he could not at that day divine the cause, nor, geology unborn, could he surmise the effect.

Every school student of astronomy knows what this third motion was. Hipparchus and others had made it clear that what we call a year falls a little short of making a complete circle of the heavens, that the sun seems to move a little in its position, say, from one spring to another. This gives rise to the so-called precession of the equinoxes. That there was some such a shift there could be no question; it was an incontestable fact; but there was no theory to account for it.

1 "The Ideas of Aristarchus," p. Ir 3 . 
Coppernicus saw that if the earth in its circling round about the sun did not hold always to exactly the same tilt, that if its axis swayed ever so little, this would produce precisely the effect noted. He works it out, writes the very briefest description of it that he may, gives you a diagram to make it all perfectly clear, then goes on his way. He may have disclosed his discovery to some of the enthusiastic young men who had heard a rumour of the new teachings and came to ask concerning them. Beyond this, there is no evidence that he ever wrote a line about it outside of the work which immortalised his name.

But consider what it all meant. Not only had he seen with the Pythagoreans that we must conceive the earth as slowly turning on its axis; not only had he reached the far more difficult point of view of Aristarchus, that the earth swings in a vast circle about the sun; but he had in his mind's eye pictured this vast globe careening slowly as it sweeps along the plane of its colossal orbit. Consider that he had no miracle-working telescopes with which to search for demonstrations of his ideas, nor to bring to his notice curious appearances that might suggest these ideas to his mind. He had such eyes to look upon the heavens as you or I, no more; but he saw with that inner eye, with that inner sense, that we call imagination. Consider that he wrought alone, that he had to dig his very foundations himself; consider that he made no part of a brilliant school of astronomers, thinkers, philosophers, as at Alexandria, but that he followed through his simple and exemplary life in a lonely corner of Poland, far removed from the stimulating plaudits of the world, and we shall not go far wrong perhaps in reckoning him, in power of abstraction, as among the greatest of mankind.

The more important part of his work is summed up in the fifty pages which comprise the first of his six books. The rest of them is devoted patiently to working out in all their detail the conclusions he had reached. He discusses the inclination of the ecliptic, the equinoxes, the solstices, and makes clear the intimate mechanism of nights and days. He goes deeply into the revolutions of the moon, its variations, its inequalities; discusses in this connection its distance and size, and the distance and size of the sun; getting no further, as we have seen, than had the old Alexandrians so long before him, never- 
theless fixing clearly in the mind of the reader that a simple way exists to measure these distances and magnitudes, and that this is all a part of the solid chain of his theory.

In the fifth book he sketches the placing and the motion of the planets, determines their relative distances, and for the first time in history, so far as we know, the human eye has seen the world machine in motion, just as it is. True, he does not see it whole; he knows nothing, of course, of the two outermost planets, Uranus and Neptune. He knows nothing of the asteroids, of the "shattered planet"; he knows nothing of the moons of Jupiter, and neither for him nor for any man for a long time after do the comets come and go in obedience to natural law.

But such of it as his unarmed eyes could see, he saw true. For the first time, so far as we know, all of the known planets were set in their true position, with the sun at their centre of motion. Some of the ancients, Apollonius of Perga perhaps, had correctly pictured Mercury and Venus as satellites of the sun. Aristarchùs, in picturing the motion of the earth, must have conceived the moon describing its epicyclic motion about the moving earth, and having caught the truth so near, he may have seen it all; we do not know. If he left any treatise other than the slender brochure which has come down to us, it is lost. More sheerly than it has been given to many great discoverers in the history of science, Coppernicus' vast theory was his own.

He quoted little; he showed, indeed, a kind of aloof indifference to the opinion of friend or foe. He must have cared but slightly for applause. He seems to have shared something of the old Pythagorean idea that the truth was for the elect alone. It was his original intention to communicate his theory only to friends. You catch a little of his spirit when he refers to Lactantius, "who had spoken so childishly of the form of the earth, deriding those who held it to be spherical." $\mathrm{He}$ observes: "On mathematical subjects one should write only to mathematicians." His style is simple, homely, direct. Occasionally you feel that his quiet pulses might, in Tyndall's phrase, have been the seat of a nascent thrill. Defending his heliocentric arrangement of the planets, there is a passage which runs :-

"By no other arrangement have I been able to find so 
admirable a symmetry of the universe and so harmonious a connection of orbits as by placing the lamp of the world, the sun, in the midst of the beautiful temple of nature as on a kingly throne, with the whole family of circling stars revolving around him."

It is the mediocre imagery of a simple priest. For the rest, he speculates little: he is content to describe; he does not guess. His mind was that of a geometer. He does not try to seek out causes which lie at the base of this wonderful scheme whose secret he has at last penetrated. The force which moves the planets, which so tormented the mind of Kepler, did not trouble his. Some attempt has been made, by Humboldt among others, to show that some crude notions he had of the force of gravitation. There is a passage with these rather striking lines :-

"The earth cannot be regarded as the middle point of all these planetary motions; that is apparent from the unequal and variable movements of the planets themselves, and from their varying distance from the earth, which cannot be explained by means of concentric circles with the earth as a common centre. Inasmuch, now, in this view, several middle points would necessarily exist, so no one can be in doubt as to whether this middle point of the world be that of terrestrial gravity, or elsewhere. I at least hold to the view that gravity is nothing else than a natural inborn endeavour impressed upon every particle by the divine providence of the Master of the universe, whereby these particles tend to coalesce into the shape of a sphere, and thus gain their unity and wholeness. And it is to be supposed that this inclination or tendency dwells also in the sun, the moon, and the other planets, and it is to this cause that the spherical form in which they appear is due, while they nevertheless in varied fashion cruise about their orbits." 1

The passage is interesting as a curiosity ; it is evident enough from many another that the idea of the sun as an attractive centre was wholly foreign to his thought. He does not seem to have been interested in the speculations of the ancients. The ideas of Anaxagoras he does not mention; neither those of Simplicius. There is nothing in the mental habit of the time to impel him to think upon such matters at all. Machines, mechanical arrangements of any sort, were almost wholly lack-

1 De Revolutionibus, Book I. chap. ix. 
ing in his day. Men could hardly construct a mechanical theory of the heavens before they had felt the need of a mechanical explanation of the simple facts of their daily lives.

These were his limitations-the natural limitations of his age. They should in nowise detract from the just measure of his strength. He achieved a lasting work. This comes to few. It was enough.

He died as he had lived, in far-away Poland, seven years after Erasmus, three before Luther, while Henry VIII. ruled in England and François Premier in France, and while the Medici still moulded the brilliant life of Florence. No doubt he died content-content and convinced; but neither his death nor his book made any stir. He wrote, of course, in Latin; his book seems never to have been translated into any other tongue until the four hundredth anniversary of his birth. It could not be read by the vulgar. The lives of men went on just as before. There is little evidence to show that any one dreamed that he had exploded a bomb-shell. It was just seventy-five years before the Church thought enough about the matter to ban his book from Christian eyes. How came it, then, that his ideas were not to live a little, then to be forgotten, like those of Aristarchus, for another eighteen hundred years? 
$x+1$

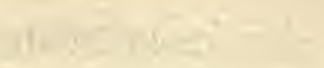

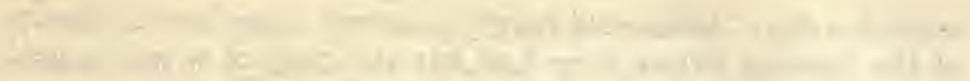

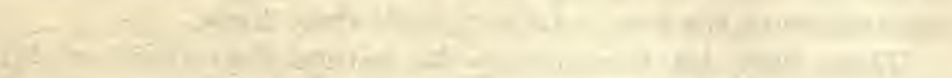

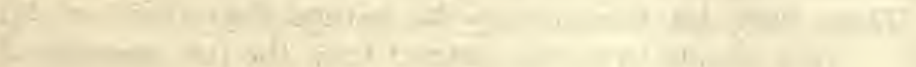
- 1 ,

The

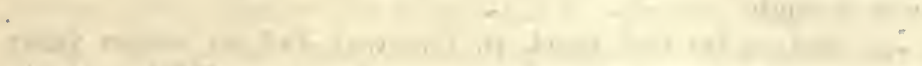

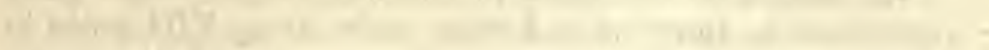
nit

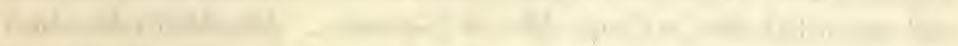
We the

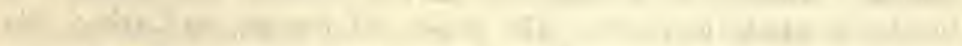

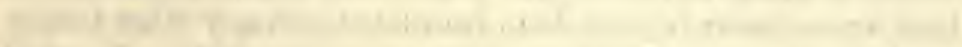
| 1 (2)

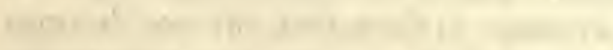

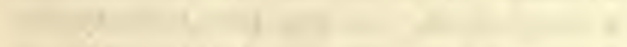

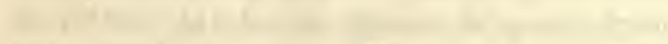

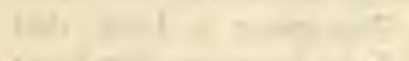

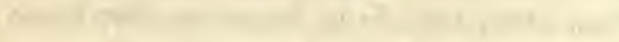




\section{CHAPTER XIV \\ BRUNO AND THE RECEPTION OF THE COPPERNICAN IDEAS}


Thoughts that great hearts once broke for

We breathe cheaply in the common air. The dust we trample heedlessly

Throbbed once in saints and heroes rare, Who perished, opening for the race

New pathways to the common place.

LOWELL, Masaccio. 


\section{CHAPTER XIV}

\section{BRUNO AND THE RECEPTION OF THE COPPERNICAN IDEAS}

IN the fifteenth century chance shook from its box of miracles another wonder than the discovery of the New World, hardly less fateful in its effects. That was the printing-press. It is with an ineffectual effort that we endeavour to realise now what was the world like when it had no printed bulletins of happenings on the earth, no chronicles and reviews for the easy dissemination of ideas, impressions, discoveries; no means for the rapid duplication of a book.

If now we look back into this time, we shall see how vitally separated were the conditions under which Aristarchus in Alexandria, Coppernicus in Frauenberg, wrought. The work of the Polish innovator was printed. A little later yet another invention was to confirm, for all time, their common idea. There seems little to doubt that, alone, the introduction of the printing-press into Europe would have saved the system of Coppernicus from the fate of that of his forerunner in Alexandria.

It was not so much the mere preservation of the printed word. The papyri upon which the ideas of Aristarchus were inscribed will last longer probably than any work of paper and print. The employment of slaves as copyists ensured a tolerable circulation for any work of note. We know that they had vast libraries; there were booksellers in that day as in this. Nevertheless, prodigious as was their industry, the hand could not compete with the machine. The price of books even in Alexandria was exorbitantly high; they were the treasures of rich men and kings.

With the coming of the printing-press, says Draper, the price of books was reduced by four-fifths. The use of electricity in our time has not spread more swiftly than did the printing art in the first thirty or fifty years after Gutenberg and Coster. Between the years 1470 and 1500 more than ten thousand 
editions of books and pamphlets were printed. You realise, then, how it was that the discoveries of Columbus, of $\mathrm{Da}$ Gama, of Magalhaens were so soon the common property of all Europe. You realise that of the thousand "reformations" which had been started in the thousand years of the ascendency of the Church, it was Luther's, in the second decade of the new century, which could make head, which no papal power could stay. You realise that it was a changed world into which, twenty years later, the work of Coppernicus was born. The habit of books, the habit of reading, was spreading fast.

Still, his disciples were few enough. There was, while he lived, a young professor of mathematics in the University of Wittenberg, Rheticus by name, so eager to know more of the new ideas that he travelled to Poland to sit at the master's feet. It is evident that even then reports of Coppernicus' theories had begun to circulate. As early as I536, from far-off Capuaand Southern Italy was a long way off then-the Cardinal Schonberg had written to him, saying :-

"I learn that you have established a new system of the world, according to which you teach that the earth moves; that the sun occupies the deepest and, therefore, the middle place of the world; that the true heavens remain immovable and eternal; and that the moon, together with all the included elements between the heaven of Mars and that of Venus, turn in their yearly course about the sun. I hear that you have set forth your entire system of astronomy in a commentary; that you have gathered up the carefully reckoned movements of the planets into tables, to the profound wonderment of all who have seen. Therefore do I beg you, most distinguished scholar, that you communicate to the instructed among men your discoveries, and that you will send to me as soon as possible your nightly labours over the structure of the world, together with the tables and anything else that you may have."

$\mathrm{He}$ sends this by messenger, with money to defray all expenses, so keen is the cardinal to learn of the new Word. After the book had appeared, it found defenders here and there. Rheticus teaches it at Wittenberg; Michael Moestlin inculcates it at Tübingen. It is his largest claim to fame that it was under his influence that the mind of Kepler was formed. In England, Gilbert of Colchester, physician to Queen Elizabeth, founder of the new sciences of magnetism and electricity-he, indeed, who 
coined the latter name-becomes its hearty advocate; he expounds the evidence in its favour with sobriety and force.

But it is evident that the new scheme of the world took hold slowly. When Galileo gets into correspondence with Kepler, at the close of the century, he tells his new-found friend that he " has long been a convinced Coppernican "-evidence enough that there are very few who are. The greatest observing astronomer after Coppernicus, and the greatest scientific figure in Europe, Tycho Brahe, sets his face against the new doctrine. It is Tycho's accurate and admirable observations which guide Kepler's hands in the perfectioning of the Coppernican ideas; yet he will remain unconvinced so long as he lives. So will the other great figure of the time, Lord Bacon, even though he lives long enough to know of all of Galileo's discoveries ; and the heavy, peasant mind of Luther, in daily active combats with the devil, could see in Coppernicus only " an upstart astrologer," " a fool who wishes to overturn the whole science of astronomy." "Does not the sacred Scripture tell us that Joshua commanded the sun to stand still, not the earth ?" Even Leonardo da Vinci, as myriad-minded a genius as ever lived upon this earth, born nine years after the De Revolutionibus had come from the press, pioneer in half-a-dozen sciences, interested enough in astronomy to figure out that the dim figure of the whole moon seen with the new moon is due to earthshine, still does not enter the lists in its defence.

One strange and haunting figure there was who caught up the new doctrine with the impassioned ardour of an apostle, who bore it through Europe like a torch, and until its flames were to turn and light the faggots of his own pyre. This was Bruno, monk of Nola, last of the great martyrs of the Inquisition. $\mathrm{He}$ must have heard the message early, for even as a young acolyte in the cloister, he had turned back his monkish cowl to bear the message to his kind. "At the door of the soul of youth sounded Coppernicus' imperative word," he writes in after years; the thrill of the youthful impress stirs him still. The reading of the book was epochal in his life; he feels as if he had been suddenly freed from chains. The truth which he now may see, which he may almost grasp with his hands, had seemed to him hitherto hid as with a veil. He seizes upon the new teaching as if it responded to something in his innermost soul. By a flash of genius his vision ranges beyond that of Coppernicus 
himself; he looks upon the firmament of stars and proclaims them suns. Marvellous prevision that another scant halfcentury will confirm!

Bruno was not an astronomer; he was a poet and a metaphysician, and perforce of these something of a mystic. So far as demonstration or proof go he contributed little to the establishment of the new theories. Still, in a worldly way his influence must have been wide. He became a sort of evangelist of the larger light.

It is evident that in the face of such a philosophy as he had evolved, the oriental fictions which then served the world for faith could hardly keep their hold. At barely twenty he is summoned under accusations of heresy. There must have been a deal of it abroad, for friendly tapers lit him by night from monastery to monastery until, after three years' wandering, the borders of Italy are reached and he is free. He tarries for a little at Geneva; but it is only twenty-six years since the hand of Calvin had given over the philosopher Servetus to be burned. He goes to Toulouse, famous for its university; then to Paris. There he becomes a high favourite of the astrologyloving Henri III. A special chair is created for him at the university, because as a heretic he may not say the mass; his eloquence attracts great audiences. A little later he goes to England in the suite of the French ambassador. He must have been fascinating in conversation; Elizabeth was among those who felt his charm. He is incidentally a maker of plays; Shakespeare, impartially appropriating everything in sight, as was his wont, revamps several of them as his own.

Bruno's stay in England was the happiest, as it was the most fruitful, of his wandering life. He is holding public disputations at Oxford, going about among the homes of the titled and the enlightened. London was then hardly larger than, let us say, Brighton or Omaha. Here he may readily have met Bacon, Shakespeare, Ben Jonson. It may have been his influence which made Gilbert a Coppernican. Bruno was then near thirtyfive, and in the plenitude of his powers. It was there that he perfected his philosophy, developed his ideas. It was there that he turned from academic Latin to express his ideas in a language understanded of the people. With Montaigne he is the first of the moderns to deal with philosophical and scientific questions in the common speech of the people, as did the 
ancients. He chose for the most part the form of the Platonic dialogue. He handles it lightly and easily. A little later, when Galileo wins literary renown, he employs the same form.

It was in England that Bruno wrote the two volumes in which he gave the widest expression to his cosmical theories. The first of these was La Cena de le Ceneri, the Ash-Wednesday Evening's Supper. It owed its title to its peculiar origin. Sir Fulke Greville, a friend of Sir Philip Sidney's, had invited a company of philosophers to dine and hear his defence of the Coppernican ideas. When the book finally appeared, even though it was written in Italian, it must have aroused a tempest ; he was compelled for some time to remain in concealment. Yet this was in the England of the Golden Age of Elizabeth.

But Bruno was not content merely to announce the new truth; he stood forth to do battle. He must have been a disturbing guest; wherever he goes he sows unrest; he is a warrior against his time. When he returns to Paris with his patron and friend, the French ambassador, he offers the rector of the Sorbonne a modest tract of one hundred and twenty theses-it is the habit of the time-in which he sets forth his philosophy and his variance from the accepted belief with a boldness and precision which must have made that distinguished functionary gasp. Strange to say, the document was printed and publicly read. Perhaps they were preoccupied with other things; Paris was then in civil tumult; he takes his way across the Rhine. At Marburg he is denied a hearing; but at Wittenberg he meets with a remarkable reception. The stately little mediæval town passed then for the Athens of Germany; he spent here two happy years, writing, lecturing, defending his faith.

The civil power changes; he dwells for a time in Prague, in Helmstatt, finally in Frankfurt-am-Main, finding his living as a corrector of proofs, publishing his own books, and living, since he is denied right of residence in the city itself, in a near-by monastery. There he receives an invitation from a rich young man, son of a noble family, to come to Venice. It is his end. Whether or not he was deliberately trapped is not clear; at any rate he is shortly after denounced to the Inquisition by this wretched miscreant. In Venice he might well have thought himself safe ; but even there the power of the Inquisition was strong. 
$\mathrm{He}$ is human; he offers to recant and forswear. It is not enough. For six long years he languishes in prison. There, from the visions of the stake the terror falls; his soul grows great and strong. When he stands at last in Rome before his judges to receive their decree, he answers it with splendid courage: "It is you that tremble at your sentence more than I." In the customary formula, he is handed over to the civil authorities, "to be dealt with as mercifully as possible and without the shedding of blood." Lest there should be any confusion, it should be noted that the civil government of Rome was still in the hands of the Church: the governor was a monseigneur.

They burn him in the Campo di Fiori, the flower-market; the day is a fête for the populace. A ghastly crowd of prelates hovers round to see him die. The Pope from the distant palace by St. Peter's watches the curling smoke. But his agony brings not one shriek; his tongue was bound lest in the end he should blaspheme. In the flower-market to-day stands the slender, hooded figure of this knight-errant of the truth, looking with mournful and relentless eyes over across the river towards this same palace of the popes. They could give his slight and quivering frame to the flames; but the message had gone forth. The hand of the monster has been struck with a palsy; it will burn no Brunos now.

Bruno was truly a martyr to the new world system. He taught a plurality of worlds, and it was this, and not the Coppernican ideas of the motion of the earth, which was absolutely irreconcilable with the teachings of the Church. The inhabitants of distant planets could hardly all be derived from Adam; it could hardly be for them that the Son of God had been crucified. The purely Coppernican ideas of the earth's motion, though they involved essentially the conception of the grandeur of the sun, the comparative insignificance of the earth, might still be entertained perhaps without utter discredit to the Hebraic teaching. In the whirling cosmos sketched by Bruno; the idea of a Fall and Redemption became simply grotesque. It must have been this that aroused the churchly guardians; they were not yet awake to the danger that threatened them. It is not until sixteen years after the murder of Bruno that the work of Coppernicus was put upon the Index.

It is tragic to reflect that Bruno's frightful fate seemed to 
have all the effect that its authors could have desired. His books were forgotten; Galileo hardly ventures to mention his name. He seems to have found no disciple.

In the face of the grandeur of his ideas, and his unquestioned powers of exposition, this seems strange. The truth is that Bruno was in advance of his time; more than that, the parts of his system most original to him, and which to-day make us marvel at the previsions of his genius, were unsusceptible of proof. It is simply amazing now to go back and consider how far beyond the ideas of Coppernicus the marvellous deductions inspired by his powerful and fervid imagination had swept him. Among moderns he is the first to reach again the heights of vision of Democritus and proclaim the infinity of worlds. The spaces of the heavens, he taught, are peopled with other systems resembling our own. The stars are suns; round them circle other planets, or, as he more vividly put it, other earths, doubtless like unto ours. The only reason that we cannot see these other systems is due simply to the unthinkable distance at which they lie and to the littleness of their planets. Seen from a similar distance, our earth would be equally invisible, our sun but a twinkling star.

He divines much more. From Nicholas of Cusa he had learned to see flecks upon the sun, whose veritable existence Galileo was afterwards to prove. From these he imagined the turning of the sun. With increasing astonishment do we read that not merely does the sun revolve upon its own axis, but it has a movement of translation as well; and, again, that there are probably other planets belonging to our own system which cannot be seen because of their distance. It took one hundred and sixty years of study with the telescope to verify the latter fact, while the truth of the former has only been demonstrated in our own day.

So far does his vision reach beyond that of his master that we may agree with Riehl in believing that he was the first to conceive the true construction of cosmos. He was a sort of somnambulist of the infinite. More than any other man for two thousand years he had put off the fetters of space and time. He pictured the infinitude of worlds as peopled with an infinitude of created forms, perhaps similar to those upon our earth, perhaps higher than these. Only a fool could believe that in unending space the unlimited creative might of the cosmos 
would result in the formation of but a single inhabited world, lighted by a single sun. Life in all its stages was a universal fact. He seems even to have caught some dim glimpse of the idea of evolution. As a philosopher he must explain the exist. ence of evil; what we call evil he believes is, in truth, but the limitation of our view. In an infinite universe all things must and do exist in order that it may have completeness. He whose eyes may see but parts of the whole cannot see the glancing beauty and the glory of the All. In the larger universal life he found the compensation of the ills that burden the slender part we know.

Bruno was the godfather of Spinoza; of pantheism, too. His was the first scientific religion invented by man; probably it is still the only rational religion which advancing knowledge will permit us to retain. What is certain is that this earth has seen few more heroic figures. His ideas, like his trust, were sublime. Much that he taught could have been with him but conjecture. Yet in so far as we have advanced in knowledge his ideas have been confirmed, point by point. We know to-day that the stars are suns, that dark planets exist in systems beyond our own, and that the material of the universe is the same.

It is pathetic, if it be not the essence of tragedy, to reflect that this John the Baptist of the new evangel might have been forgotten from the memory of men were it not for the chance discovery which came eight or nine years after his soul had passed in flame. It is pathetic, if it be not the essence of tragedy, to reflect that his heroism accomplished nothing. The aged Galileo, forswearing the truth upon his knees, took the part of civil wisdom. The invention of a fumbling apprentice was to be worth more to the advancement of the race than the martyrdom of the greatest intellect then walking amid the ways of earth. 


\section{CHAPTER XV}

KEPLER : PIONEER OF THE MODERN IDEAS OF NATURAL LAW 
" And who were they," I mused, " that wrought Through pathless wilds, with labour long, The highways of our daily thought? Who reared those towers of earliest song That lift us from the throng to peace Remote in sunny silences ?" LOWELL, Masaccio. 


\section{CHAPTER XV}

\section{KEPLER : PIONEER OF THE MODERN IDEAS OF NATURAL LAW}

THERE is much in history to make it seem as if genius were a thing born to triumph spite of every difficulty. Village Hampdens, mute Miltons there may be, in uncounted number; but the history of the men who have made history leaves a doubt. The thing seems innate; circumstances appear to have little to do with its development. This is more or less Darwin's view, and Darwin, we know, was counted in his youth not so very bright, and so intended for the clergy. Buried, it would seem, tenfold deep in his canonry at Frauenberg, and spite of his priestly tasks, Coppernicus could still evolve the system that dethroned the earth from its position as the centre of the world. Isaac Newton's mother would have made him a farmboy, but he neglected his work ; it was no use trying. From a like obscurity came the strange figure which bore onward the flame kindled by Coppernicus, and lighted the way for Newton's triumphs.

Along in the waning years of the sixteenth century, at about the same time that Shakespeare was holding horses before the doors of the London theatres and Francis Bacon was a struggling young barrister, there was a pot-boy in the little province of Würtemberg, serving the peasants round about, their beer. $\mathrm{He}$ was a sickly lad, prone to violent illnesses. Perhaps it was on this account that he was sent to a monastic school near by. Perhaps he found favour with the monks who taught him. Anyhow, he found his way to the University of Tübingen. There he fell under the influence of Michael Moestlin, sectarian of the new gospel. Even in this out-of-the-way corner the leaven was at work. It had set-a ferment in the brain of Michael Moestlin. He passed it on to this sickly, eager lad

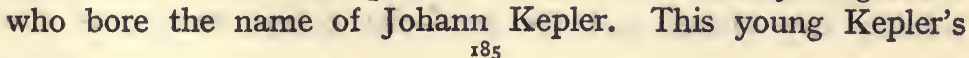


first bit of writing was on the double motion of the earth. Soon he got a professorship at the little University of Gratz.

All the time his teeming head was busy with a problem that had got into it and would not out. This was as to the cause of the motion of the planets, and why there are just six. $\mathrm{He}$ makes what he thinks is a great discovery-a purely fanciful one, however-that the number is due to the fact that there are just five regular solids, and this obviously corresponds to the gaps between the six planets! His idea is in thorough keeping with the time; it is a survival of the old Pythagorean mysticism of numbers. He writes a book about it, which contains, for the rest, some curious speculations about a force emanating from the sun which may be responsible for planetary motion.

The little volume wins for him the friendship of Galileo, then a rising young professor at the old University of Padua. It likewise brings him into communication with Tycho Brahe, a Danish nobleman turned astronomer, and greatest scientific figure of the age. Kepler is a convinced Coppernican. Tycho is not, and will not be so long as he lives; instead, he devises a system of his own. Full of his theories, Kepler goes to see him, and they discuss a great difficulty.

Coppernicus had swept away the clumsy system of epicycles handed down from Ptolemaic days. He made the planets move in circles; but it was plain as a pikestaff that they did not. Tycho was one of the greatest observing astronomers that ever lived - the Herschel of his time. His observations made it all too clear that the planets would not always appear where the simple theory of circles supposed them to be.

If there be any one who would know how great discoveries are made, let him listen to the dictum of Newton: "I intended my mind." Upon this problem Kepler intended his mind for eight long years. He tried every device under the sun; none of them would work. One day he thought to see if the planetary motions would fit into an ellipse; he sought after these things with that almost insane intensity that some men seek gold; his joy at finding that he had hit the truth at last was almost a delirium.

Even before this his meditations and endless, ceaseless calculating had disclosed one great law. This was that a line joining any planet and the sun-the radius vector, as the 
geometers say-sweeps out in its revolution equal areas in equal times. This fitted perfectly with his second discovery, that the orbit of the planets was an ellipse. He could now announce the first two of what have ever since been known as Kepler's Laws. This was in I609, the same year, by chance, that news of a curious optical contrivance in Holland was brought to the ears of Galileo.

Does the idea lurk anywhere that these world-explorers, reaching, through their studies, to larger and larger views of the cosmic adventure, work on in a cold and bloodless equanimity, unimpassioned, unmoved ? The stuff that explorers are made of is not this. Perhaps the ultimate spirit of scientific endeavour may best be personified in an image of truth carved of impeccant marble; the temper of her devotees who have laid at her feet her richest garlands is far otherwise. Discoverers are seers, poets-poets in the largest and highest sense. In the flush of divination the hand of Newton trembles, the pen of Kepler sings. When the long nights of vigil, the days of toil, are ended, when success has come, he breaks into rhapsody, in the strain of the Hebrew prophets of old.

When he had at last worked out the formula which goes by the name of his third law, he was nearing fifty. The volume in which it was announced opens with a burst of poetic splendour as naive as it is rare-lines that leap and words that thrill :-

"What I prophesied two-and-twenty years ago, as soon as I discovered the five solids among the heavenly orbits-what I firmly believed long before I had seen Ptolemy's Harmonieswhat I had promised my friends in the title of this book, ${ }^{1}$ which I named before I was sure of my discovery-what sixteen years ago I urged as a thing to be sought-that for which I joined Tycho Brahe, for which I settled in Prague, for which I have devoted the best part of my life to astronomical contemplations, at length I have brought to light, and recognised its truth beyond my most sanguine expectations. It is not eighteen months since I got the first glimpse of light, three months since the dawn, very few days since the unveiled sun, most admirable to gaze upon, burst upon me. Nothing holds me; I will indulge my sacred fury; I will triumph over mankind by the honest confession that I have stolen the golden vases of the Egyptians to build up a tabernacle for my God far away from

1 Harmonices Mundi (1619), Introduction. 
the confines of Egypt. If you forgive me, I rejoice; if you are angry, I can bear it; the die is cast, the book is written, to be read either now or by posterity, I care not which; it may well wait a century for a reader, as God has waited six thousand years for an observer!"

The third law, announced in this exulting pæan, came nine years after the other two. It embodied his discovery of the simple relationship which subsists between the distance of the planets from the sun and the time of the planetary year-that is, that the cube of the distance is proportional to the square of the time of revolution. Stated in other terms, the speed of each planet in its orbit is inversely as the square root of its distance from the sun. The product of the distance into the square of the speed is the same for each planet; the ratio of $\frac{r^{3}}{\mathrm{~T}^{2}}$ for every planet is the same.

Simplicity, predictability, mechanical fixity, the whole scheme under the governance of law, in lieu of mystery or caprice or the whims of the gods! This is what the discoveries of Kepler meant. They were among the earliest of the attempts to reveal a single common principle at work throughout broad groups of phenomena, among the first of those "laws of nature" which measure the degree of progress attained in any branch of natural inquiry. Archimedes, it is true, had established the laws of equilibrium in a time long gone. Galileo was even then at work on the "laws" of motion. But Kepler's were the first of the great generalisations which, like mighty monuments, mark the advance of the human mind. He was a pioneer. His fame is just.

He had triumphed; he had established for all time a truth - the greatest work, says Taine, open to man. But he did not, could not, see the further meaning of the laws he had unveiled. He could not divine the cause, the mechanical necessity, which lay beneath his laws of planetary motion; before that could come a new science must be developed; it was even then being developed, and, stranger than all, by his friend and correspondent in the University at Padua.

Still, it is amazing to find how near he came to divining it all. We have seen that some idea of planetary attraction floated vaguely before the mind of Coppernicus. With Kepler 
it took on a very definite form. The work which appeared in r6og, in which he announces the first two of his laws, contains an introduction which came perilously near to a complete anticipation of the ideas of Newton.

Every natural substance, ${ }^{1}$ he says, by nature remains in repose when it is isolated and outside the sphere of activity of bodies which have an affinity for it. He anticipates Galileo. Gravitation, he goes on, is an affection or quality with which bodies are endowed in order to hold them together. This faculty or property is general; but the globe of the earth does not attract a stone any more than the stone attracts the earth. Bodies are not drawn towards the earth's centre because it is the centre of the world, but as the centre of things of the same species and of the same family. If the earth were not round, bodies would not be drawn towards its central point, but would tend in different directions. If the earth and the moon were not held in their orbits by some force, the earth would mount towards the moon by the fifty-fifth part of their distance, and the moon would descend the remainder of the distance in order to be united to it. The sphere of the moon's activity extends as far as the earth and attracts the waters of the torrid zone. The moon passes to the zenith; the waters follow it and mount with it, more notably in the deep and open oceans, with less liberty in the Mediterranean and in gulfs.

If this action of the moon extends to the earth, it follows equally that the force of the earth's attraction extends to the moon. No portion of matter which exists on the earth can lift itself up and escape from its powerful grasp. There is nothing intrinsically light or weightless. All bodies are material ; lightness is only a less degree of weight. Even the moon cannot slip its leash.

Surprising in the last degree it is to meet with these perfectly just ideas in a work appearing a generation before Newton was born. But Kepler does not stop here; he has shown that the planets which have the swiftest movement are those nearest the sun; the farther they are from the sun, the slower their motion. What is their motor force? It can reside only in the planets and the sun itself. These two recognised effects, diminution of the speed with the increase of distance, must have one and the same cause. But the centre of the world where

1 Quoted from Bailly, Histoire de l'A stronomie Moderne (1779), ii. 4I. 
this motive force resides can be only the sun which, as the regulating power of the universe, determines the distance and the speed of each planet. Just as the moon moves round the earth in virtue of the earth's attraction, so are all the planets held in chains and kept in their orbits by the preponderant force of the sun. You read and you gasp a little to find how close he presses the quarry.

Still, these general ideas are not sufficient; he is a mathematician as well as one of the earliest of modern physicists. He has studied deeply the phenomena of light. He has found that mathematical law determines distance and speed. Is it possible that a mathematical law can express the force of this attraction? He has observed that light grows feebler the greater the distance from the source of illumination. Conceivably the motor force from the sun is weakened in the same way. You perceive wherein he erred.

If there be such a force acting outwards from the sun, it is evident that it must extend in all directions-that is, in the three dimensions of space. It is not a question here simply of the contour of a circle, but of the surface of a sphere, and since spherical surfaces are to each other as the squares of their radii, it follows that light grows feebler in proportion to the square of the distance. It is astonishing, but this obvious fact escaped Kepler and his time-yet another illustration of the truth that the human mind does not march; it creeps. Bound up to the erroneous idea of a simple proportion, Kepler concludes that the attractive force of the sun is the same. Only a step separated him from the law of inverse squares.

He seeks even to identify this attractive force. Gilbert of Colchester's great work, The New Physiology of the Magnet (how quaint the title to our ears!), had appeared in 1600. Kepler had read it with profound attention. Gilbert had compared the earth to a huge magnet; he surmised even that this might be the attractive force of the planets; he had said that the earth and moon act towards each other like a pair of magnets. Kepler takes one step further; he likens the sun to a vast and still more powerful magnet, and this magnetic force for him was the secret of the sun's attraction. He even meets the objection that if such a force existed, it would be cut off during an eclipse. He points out that just as magnetism may act through other solid bodies, it may act through the planets 
themselves. It may be true, he says, that during an eclipse there is some change, some alteration in this force, and hence in the direction of the planetary motion. This may, he conjectures, explain why the orbit of the planets is not a perfect circle. He just misses the splendid intuition of Newton that this attractive force being reciprocal, when one body circles about another it pulls this other out from the centre, so that its own path becomes an ellipse.

His fancy knows no rein : thus will he endeavour to explain why it is that the earth and other planets do not fall into the sun. Some force must hold them in their course. Kepler is a poet ; he is dowered with one of the most vivid of imaginations, quite as wonderful, we may believe, as that of any Milton or even Shakespeare. For him the universe is alive; the earth is a great animal-the tides are its breath. He considers the spheres, the stars, as inhabitants of the ether. In the ether they are born, in the ether they live like plants and animals; they are the butterflies of space. They maintain their motion by virtue of an animal force which resides within them.

His exuberant imagination leads him astray. He has perceived clearly enough the first part of the first law of motion, that bodies at rest tend to remain at rest so long as they are not acted upon by any exterior force. He does not perceive that the planets need no urging force, that once set going and unimpeded, they will go on for ever. It is not given to any one human mind to grasp the truth whole. Newton could not. What wonder if Kepler failed? The minds even of the greatest of each generation are bound up, limited, in some sense perverted, by the preconceptions born with them. When the tireless, teeming brain of Kepler was searching, searching, searching for causes, reasons, effects, no science of mechanics existed. It is this alone, we may conceive, which withheld from him the glory of having demonstrated what he had divined, from having reduced all planetary motion to a single principle, from having revealed the whole solar system as the workings of a vast machine.

No matter, it is enough; the paths of the planets are now absolutely known, proved. The Coppernican idea has received a perfectionment that amounts almost to a demonstration. Hardly any longer will it be possible for any timid Peter to deny the truth. One step more and it will no longer be possible. 
Still, it is the old story. $\mathrm{He}$ is a generation ahead of his time. His ideas must wait. It does not seem as if his publications made any considerable impress. They were, in truth, so written as to repel more sober minds. Amid his wild flights and mystical fancies, the great truths they contained were almost lost. His Epitome of the Coppernican Theory is a sane and admirable work, long used as a textbook. ' His Optics was one of Newton's earliest treasures. The Inquisition does him the honour to put his books on the Index, but this is simply because the Church is then engaged in suppressing the whole Coppernican heresy, which has been stirred to a dangerous flame by the discoveries of Galileo. The Grand Duke of Tuscany sends him a golden chain; but this was probably at Galileo's instigation.

But not one mind among all his contemporaries, not even Galileo's, sees the importance of his discoveries. Galileo, perhaps from a deeper weakness, quite ignores them. Descartes will be busy in a few years constructing the universe out of the simple ingredients of matter and motion. He is devising a mechanism, and he has need of every scrap of help he can get, for as yet the facts are scant; but he does not appear ever to have read a line of Kepler's works. The Novum Organum appears eleven years after the New Astronomy, in which Kepler gives the first two of his immortal laws, - two years after the Harmonies of the World, in which the third and final law is announced; but for the whole Coppernican scheme Bacon has only a sneer, for Kepler no word.

Almost the whole of Kepler's life was passed in bitter poverty. Now he is getting old, his salary is long in arrears, the pinch grows tighter; his child had died of smallpox, his wife of a slow fever, and he had scarce money enough to pay for their burial.

At last, exhausted by a journey to Prague to plead for the payment of his due, his slender meed of strength depleted by days and nights of tireless research, disheartened by failure, worn out by the vicissitudes of an existence for the most part wretched enough, he too takes a fever and dies at fifty-nine. He had struggled up from a pot-boy in a country tavern, struggled through lifelong ill-health, through difficulty and misfortune. But he did not live to enjoy his fame. The Golden Fleece for which he sought, time laid upon his bier in after years. 
It is a sorry story, not of persecution, not of torture, but of that long agony of martyrdom that lies in utter neglect. The times had strangely altered when the nations, through their representatives, might gather to do homage to a Pasteur. They had indeed changed greatly in the succeeding fifty years. But meanwhile yet another brilliant investigator, leading a far different life, had likewise to drink the cup of bitterness for his services to the truth. The far north had produced Coppernicus. Germany had added Kepler. Let us journey southward, and along the quiet ways of sunny Tuscany, list to the story of Galileo and his starry woes. 


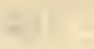

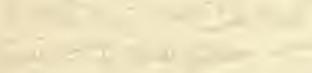

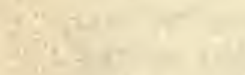
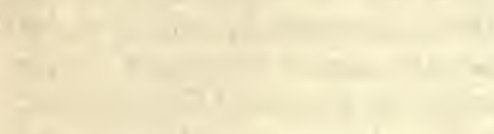

3. 


\section{CHAPTER XVI \\ GALILEO AND THE OPTIC TUBE}




\section{THE JUDGMENT AGAINST GALILEO}

To assert that the sun, immobile and without local movement, occupies the centre of the world is an absurd proposition, false in philosophy, and moreover, heretical, since it is contrary to the testimony of the Scriptures. It is equally absurd and false in philosophy to say that the earth is not immobile in the centre of the world, and this proposition, considered theologically, is at least an error of faith.

Congregation of the Index, 1633.

\section{THE ABJURATION}

" I, Galileo Galilei, son of the late Vincenzo Galilei, of Florence, aged seventy years, being brought personally to judgment, and kneeling before you Most Eminent and Most Reverend Lords, Cardinals, General Inquisitors of the universal Christian republic against heretical depravity, having before my eyes the Holy Gospels, which I touch with my own hands, swear that I have always believed, and now believe, and with the help of God will in future believe, every article which the Holy Catholic and Apostolic Church of Rome holds, teaches, and preaches. But because I have been enjoined by this Holy Office altogether to abandon the false opinion which maintains that the sun is the centre and immovable, and forbidden to hold, defend, or teach the said false doctrine in any manner ... with a sincere heart and unfeigned faith, I abjure, curse, and detest the said errors and heresies, and generally every other error and sect contrary to Holy Church; and I swear that I will never more in future say or assert anything verbally, or in writing, which may give rise to a similar suspicion of me; but if I shall know any heretic, or any suspected of heresy, that I will denounce him to this Holy Office, or to the Inquisitor or Ordinary of the place where I may be. . . A At Rome, in the convent of Minerva, 22nd June 1633, I, Galileo Galilei, have abjured as above with my own hand." 


\section{CHAPTER XVI}

\section{GALILEO AND THE OPTIC TUBE}

YE who listen with credulity to the teaching of authority, and pursue with eagerness the fictions of life, who believe that human goodness may survive the temptations of power, or that the virtues of a religion are exemplified in the deeds of its adherents, attend to the melancholy history of a prince of the human mind.

A few years after the birth of Francis Bacon, a few months before that of Shakespeare, and on the day that Michael Angelo was closing his long and stormy career in Rome, the wife of Vincenzo de Galilei, descendant of a noble Florentine family, brought into the world the child who came to be known by his forename of Galileo. The father was poor; he was a musician, something of a mathematician too; he even wrote a book defending the freedom of scientific inquiry. He was poor, and he had no mind that his son should follow the same hard path as he. He thought to make of the boy a cloth-dealer; it was no use. In school he showed the most precocious talent, out of school he was for ever inventing mechanical toys. This was not the stuff for a shopkeeper; so, at a hard sacrifice, the boy is given a chance to attend the university in his native town of Pisa. The Medici in their glory had endeavoured to make it a rival of the schools of Bologna and Padua; they had done well by it. There was none better anywhere.

The boy is now destined to be a physician. He shall at least follow the most lucrative of the sciences, if his bent be that way. His mathematical father knows to his cost how little mathematics are prized; the chair in the University of Pisa receives the magnificent salary of sevenpence-halfpenny a day. Old Vincenzo will save his son from that; but fate is strong.

The family is a good Catholic one, so is the boy; but his mind is restless. On his knees one day in the cathedral, his wandering eye watches the swing of a great lamp which the 
verger had just lighted and thereby set in motion. In that day there is a dearth of clocks, and the young student of medicine wants a machine that he may count pulses by. He observes that the time of the lamp's swing remains, so far as he can decide, the same, though its path of motion grows less and less. He reflects upon his observation, tests the matter when he has a chance; the isochronism of the pendulum is discovered anew. Not that the pendulum had not been known before. We may trace it back to the Arabs. It was even known in Europe a century before Galileo's time. But discoveries made headway slowly then; it had not come into general use. Galileo gave it a practical turn, made of it a pulsilogy, a pulse-counter.

His mechanical instincts were now wide awake. One day, soon after, he overhears a lesson in Euclid. It is good-bye to medicine. A few years later, at twenty-six, all the apprehensions of his practical father are realised; Galileo is appointed professor of mathematics, with the princely income of sixty scudi a year, something like $£$ I3. No matter ; destiny, in Emersonian phrase, is working through him and in him; already he has made a discovery great enough to bear his fame through all the coming years.

One day a treatise of Archimedes falls into his hands; he gets to thinking over the laws of falling bodies. For the first time in history, so far as we know, he measures the rate of the fall. His earlier discovery with the pendulum here stands him in good stead, and he lays the foundations of a new science, the science of bodies in motion, what we call to-day dynamics.

$\mathrm{He}$ is young, ardent; this restless, inquiring habit of mind gets him into difficulties. One of the foolish, unverified dogmas that had come down from Aristotle is that heavy bodies fall faster than light ones-that a twenty-pound weight will fall twice as fast as a ten-pound weight. There are plenty of people in the world who believe this still. Galileo questions it, stirs up a hot controversy about it, and to prove his ideas he mounts Pisa's celebrated Leaning Tower, and lets fall a hundred-pound and a one-pound shot. The whole university is there to watch the weights fall; there is no question that they strike the ground together. Any one who has eyes to see may see. But the philosophers of the books will not believe. They simply intensify their dislike of the young man who had shown them they were wrong. In a little while he gets an offer 
of another post, and is very glad to go. It is a hard day for the university. His glory might have been its glory; but he never returns.

At his new post at Padua he perfects the new mechanics, and meditates upon the great work which, other interests having been sated, he will dictate and give to the world in his blind and helpless old age. All the while he is growing to a profound interest in astronomy. He studies his Coppernicus long and thoughtfully, opens his correspondence with Kepler, and, as we have seen, writes to Kepler in his first letter that he has long been a convert to the new ideas. There is a paragraph in this letter which reveals well his state of mind, and very vividly the state of the times. He says :-

"I have collected many arguments for the purpose of refuting the accepted hypothesis; but I do not venture to bring them to the light of publicity for fear of sharing the fate of our master, Coppernicus, who, although he has earned immortal fame with some, yet with very many (so great is the number of fools) has become an object of ridicule and scorn. I should certainly venture to publish my speculations if there were more people like you. But this not being the case, I refrain from such an undertaking."

"So great is the number of fools!" Remember that from near by Venice very soon after, a champion of these same views is taken to Rome in chains to be roasted over a slow fire. By-andby, when his fame is spread wide, Galileo will have more courage ; but for his courage there is scarce a schoolboy who does not know how dearly he will pay. He will wait, but in the interval he is polishing that mordant wit, perfecting that strength of exposition, which is to make him one of the masters of modern Italian prose.

In the year I604 such little part of the world as thinks upon such things is disturbed. A new star swims into its ken. In the bible of Aristotle there is no accounting for this. Still, the star is there. Galileo lectures about it. They must have been wonderful lectures, for such a throng gathers that the university theatre is inadequate; he speaks in the open air. The philosophers of the books are again irritated. A great controversy springs up, and now it is that, with all the polished weapons of the subtlest dialectics, with a wit and gorgeousness of illustration and clear and convincing argument that make 
him a deadly antagonist, he stands boldly forth as the defender of the Coppernican system.

It is given to no man to construct the orbit of his time. The outcome of the controversy we know; but those who listened to his flashing satire, his impassioned defence, could hardly have guessed. Probably there were open-minded, impartial men in that day who heard and were still unconvinced. Not the sanest and the wisest among them, not even Galileo himself, could have dreamed that in neighbouring Holland a meddlesome apprentice was possibly even then stumbling upon a curious device which was to be a stone in a sling for the slaying of one of the most Goliathan of myths that ever stalked the camps of human thought.

It is curious to think now how long men had before them the elements of this toy which in the hands of Galileo was almost to shake the earth from its foundations. When spectacles were invented we do not know. The burning-glass must have been thousands of years old; of Archimedes' achievements with the burning-mirror old Plutarch has left us an entertaining legend. The explorer Layard found among the ruins of the palace of Nimrud, at Nineveh, a convex lens of rock-crystal, which makes it clear that even in that far-off day something of the powers of this especial shape of rock-crystal must have been known. Ptolemy of Alexandria wrote a treatise on refraction. Roger Bacon in the thirteenth century described a telescope, though he probably never made one. Still, the wondrous result of putting a pair of lenses one before the other remained undisclosed.

Be that as it may, we know that along in the fourteenth century, perhaps before, spectacles came into use. Then, as the story runs, a Dutch apprentice mounted a pair of lenses on a stand, and looking through them, it was noted that the neighbouring church steeple appeared to be drawn very near, and to be turned upside down. This was the initial discovery. It seems clear that some sort of telescope, more likely just a kind of field-glass, came speedily to be made and sold in Holland. It is on this ground that Galileo's title to the discoverer of the telescope is disputed. But no one seems to have thought for a moment of pointing one of these affairs at the stars. That at least was all Galileo's own.

In some fashion a vague report of these odd little affairs 
came to Galileo's ears. Mark that he was then long past the age at which great inventions are usually made. He was then forty-six. But his youthful enthusiasm, energy, resourcefulness, were not gone. He travelled back to Padua from Venice, where he had heard the story, and sat up all night thinking about it. He had mastered all the physical knowledge of his time. Kepler had written a book about optics, which he had doubtless read. By morning his invention was complete. A piece of old pipe served him for a tube, a pair of spectacles glasses for lenses. His device was not that of the Dutchman at all, and though it would only magnify three diameters, it did not invert the image. He took his invention back to Venice, and all the senators and distinguished men of the place had a look. It made a big sensation, and Galileo enjoyed it to the full. Immediately they doubled his salary, and made him a professor for life. Then he set to work grinding bigger and better lenses. Soon he had a telescope, the first real telescope ever made, one that was capable of magnifying thirty-two diameters; and with that he was off in the starry ways, reaching into depths of space no man had ever reached before, and bringing back such marvels that the world was in amaze.

This is in the year I6og, the same year that Kepler, all in ignorance of the impending discovery, had completed and sent forth his New Astronomy or Celestial Physics. It is just sixty-six years since Coppernicus' book had come from the press. How the patient old Polish canon would have stared if only he might have had a look along with the Venetian senators! Could he perchance have written then so calmly, with such even pulses, of the things he would have seen ? Galileo could not. He is in a fever of excitement. Time will not run half slowly enough to make all the discoveries he sees within his grasp; and he is making them, coining them, as Americans would say. He starts what is near to a newspaper to publish them to the world.

Reflect that this telescope of thirty-two diameters is the best he ever had-no better than a good ship's glass now. But what a flood of light it sheds! Almost at the very first the moons of Jupiter are disclosed, four of them, turning round about the larger planet. This, too, is not in the books. It is disturbing, upsetting. Had not Aristotle taught that the number of the planets is seven, and could Aristotle lie ? But 
Galileo had also looked upon the face of the moon, found it full of mountains and valleys and volcanoes, and not at all the smooth, bare, and crystal surface that Aristotle, again, had taught. He had explained the appearance of "the old moon in the new moon's arms" as due to earthshine; he made the earth a planet shining like the rest. He turned upon the Milky Way, and showed that its nebulous haze was in reality a crowd of stars, so thickly sown and individually so faint as to give the appearance of a gossamer cloud. Then he saw that Saturn appeared to consist of three parts; he had the first sight of the famous rings. The old Aristotelian world was crumbling in his hands.

Then came the final blow. It followed from Coppernicus' theory that Venus and Mercury, could we see them closely enough, would show phases like the moon, though Coppernicus himself did not make such a prediction, as is so often said in the books. Galileo with his glass saw Venus grow from a crescent to its full splendour and then back again. His discovery of the satellites of Jupiter had shown that other planets might have moons revolving round about them, just as has the earth. The phases of Venus was almost the last stone required in the Coppernican structure. Kepler is overjoyed; he longs for a telescope with which to see it all himself.

But for the last and final proof Galileo searches long and in vain. When he turns his telescope to the stars he is astonished to find that they appear to grow no larger. Their distance from the sun must be unthinkably immense. What is more, when he tries to discover if any among them change their apparent position as they should, seen from one side of the earth's orbit and from the other-that is to say, in the spring and in the fall-he can detect no motion. He cannot even find any parallax for the sun. The answer that Aristarchus made to objectors to his theory must remain the answer of Galileo and the Coppernicans of that day; but it is hard to believe. Try a moment to grasp it all now. In the sky is a body so vast that it has an appreciable visual diameter-a huge disk, in fact-and yet it is so distant that from two distant points on the earth it will show no parallactic shift of position, even with a telescope, at least any such a telescope as Galileo could contrive. Yet vast as is its distance from the earth, the stars themselves are so remote that even this immeasurable distance becomes a point. 
Sometimes in our haste we condemn men like Bacon because they could not see the new truth, despite all the proofs that Galileo brought to bear. We judge Bacon for his vain boasting, not for his ignorance, or lack of comprehension; for is it so clear that if it could all be brought to us afresh, untrained to an unreasoned acceptance of such ideas from the thoughtless days of childhood, we should find them so easy and convincing, even now ? We may venture not. The world has little changed.

Still, the arguments brought against the new doctrines were for the most part sorry stuff. There is one preserved to a luckless fate which illustrates the mush and muddle which even then could pass for argument. No sketch of the period could well be without it ; we may have it here. It is an extract from the pen of Francesco Sizzi, a Florentine astronomer, who exposes the absurdity of Galileo's discoveries thus :-

"There are seven windows in the head, two nostrils, two eyes, two ears, and a mouth; so in the heavens are there two favourable stars, two unpropitious, two luminaries, and Mercury alone undecided and indifferent. From which and many other similar phenomena of nature, such as the seven metals, \&c., which it were tedious to enumerate, we gather that the number of planets is necessarily seven.

"Moreover, the satellites are invisible to the naked eye, and therefore can have no influence on the earth, and therefore would be useless, and therefore do not exist.

"Besides, the Jews and other ancient nations, as well as modern Europeans, have adopted the division of the week into seven days, and have named them from the seven planets: now if we increase the number of planets the whole system falls to the ground."

Crumbling, falling, is this old system, to carry down in its fall all that is bound up with it; but it has time, strength, to deal out through the arm of its upholders one last shameful blow.

The establishment of the phases of Venus gave to the Coppernican system that plausible air of reality which comes from successful prediction, from the verification of any truth which follows as a necessary consequence of a theoretical view. When by deduction from a broadly generalised system of facts we may reach out into the unknown to foretell that which is as yet 
obscure or even undivined, the human mind finds a comforting sense that it is upon solid ground.

The knowledge of the system of satellites which circle about Jupiter offered yet stronger support. This little world about the great planet, says Humboldt, " presented to the intellectual contemplation of men a perfect image of the larger planetary and solar systems." It was soon recognised that these satellites, or planets of a secondary order, obeyed the laws discovered by Kepler. The squares of the times of their revolution were as the cubes of the mean distances of the satellites from the primary planet. The mere discovery of the existence of these satellites threw the whole old-time conceptions into confusion. The establishment of the fact that they followed the general laws of planetary motion brought in anew the element of predictability, of consequence, and completed the rout.

These were among the services which Galileo and his glazéd tube rendered to the intellectual advance of the world. There was yet another which seemed to still more profoundly influence the mind of the time. This was Galileo's discovery of the sunspots, and through these the sun's rotation. The human kind had not yet left off all relics of the primitive sun-worship. The disclosure which the telescope had brought that the face of the moon was crossed and scarred with mountains and valleys, had sorely troubled the Aristotelian dogma of the perfection of the planets; the spots upon the face of the sun was the finishing stroke.

The triumph of the telescope and its creator was now complete. Kepler could write proudly to his friend: Vicisti, Galileo! He had won. The Florentine court had brought him back in honour to his native Tuscany. There was no more celebrated man now in all the earth. Perhaps he gloated a little in his strength. The rapier of his wit made enemies; they gathered for his undoing. The Church kegan to awaken to its peril. The Mosaic cosmogony was being sundered and riven by the hands of its friends. It is to be remembered that Galileo, nominally, at least, was, like Coppernicus, a good Catholic; and so he remained to the end.

In Florence was a zealous priest whose enmity he had incurred. Soon came mutterings from Rome. Thither Galileo was called. Never did his powers of dialectic shine more. He writes back that he is winning all along the line; but he reckons 
ill. The forces of obscurantism were too strong. Kepler had written an admirable exposition of the Coppernican idea, backed up with all the new knowledge and the new proof. To Galileo's dismay, this and the work of Coppernicus himself are now put upon the baleful Index of the Forbidden and their circulation interdicted to Catholic lands. Galileo himself returns home under formal orders never again to teach or believe in the motion of the earth. He could plead never so eloquently the new cause. Kepler might write from beyond the Alps :-

" Eighty years have elapsed during which the doctrines of Coppernicus regarding the movement of the earth and the immobility of the sun have been promulgated without hindrance, because it is deemed allowable to dispute concerning natural things, and to elucidate the works of God; and now that new testimony is discovered in proof of the truth of these doctrines -testimony which was not known to the spiritual judges-ye would prohibit the promulgation of the true system of the structure of the universe!"

It was of no avail. The might of the Church bent to crush this formidable new heresy.

This was in $16 \mathrm{I} 6$, the year that Shakespeare ceased upon the Avon. A time goes by. There is a new Pope; he is Galileo's friend. Things will go better now. Galileo goes again to Rome, and has many talks with his friend. The Pope writes back to the grand-duke in warm terms of approbation. Galileo returns, and sets to work upon his most noteworthy literary achievement, Dialogues on the Ptolemaic and Coppernican Systems. By 1632 it is done, through the press, and being read with an avidity which never greeted scientific work before. It is a wonderful piece of literary skill, not in Latin, but in rich and nervous Tuscan, full of keen-edged irony and flashing like a sword. It is one of the treasures of Italian prose. It brings a storm.

There is no need to tell again the oft-told shame. Galileo is again summoned. Honours and age-he is now nearing seventy-will not save him; he had disobeyed. Apologists of the Church have attempted to mitigate the infamy that followed by refutation of the belief that he was ever put upon the rack. It is possible he never was. How far his courage held, we do not know. He may have been taken to the torture chamber; the threat may have been enough. When Bruno 
went to the stake Galileo was thirty-six, and not two hundred miles away. When he went the second time to Rome, it had been but eight years since Archbishop Antonio de Dominis, philosopher and man of science, known to us as the explainer of the rainbow, had been sentenced to the same fate: "to be handed over to the secular arm to be dealt with as mercifully as possible without the shedding of blood"-so the hideous formula ran-a sentence that was carried out upon his lifeless body and writings after his death in the dungeons where he had languished six years. It had been but three years when, at Toulouse, these same vicars of Christ had cut the tongue from the living Vanini and given his body to the flames.

Ah, yes! he recanted; the miserable abjuration was signed. The greatest mind in Europe went home a prisoner. Friendly offices saved him from the papal dungeons. He was kept imprisoned in his own house. The degradation, the ordeal, perhaps the torture, broke his splendid spirit. He had been a sufferer almost all his life from a racking malady; his beloved daughter died ; then darkness came. "Alas," he writes sadly, in one of his letters, "your dear friend and servant is totally blind. Henceforth this heaven, this universe, which by wonderful observations I had enlarged a hundred and a thousand times beyond the conceptions of former days, is shrunk for me into the narrow space which I myself fill in it. So it pleases God, so therefore shall it please me."

Still he labours on. His disciples were allowed to gather round him-Torricelli, Castelli, Viviani; their devotion helped to lighten the heavy burden of his years. He is allowed an amanuensis, and then it is that he gathers together the fruits of his long studies in mechanics, and dictates the most enduring of his works, the Dialogues on Two New Sciences. It appears in 1638 . He is then seventy-four years old.

But the relentless vengeance of his persecutors never ceased ; they tried to stop the publication of his last great work. They did delay it for some years. He was allowed visitors rarely. One of them was young John Milton, doing his wanderjähre. His visit to the wonderful blind old man must have impressed him profoundly. It must have come back to him strangely when he too, in the living darkness of his old age, sat down to dictate his masterpiece. You see it reflected in some of the finest passages of Paradise Lost. 
But the talons of the Inquisition could not hold their prisoner long. At seventy-eight he passed beyond their reach. $\mathrm{He}$ passed in poverty, in blindness and disgrace-the greatest intellectual glory of Florence and modern Italy. At Arcetri, a little hamlet in the hills back of the Tuscan capital, they show you the wretched hovel where he died, a prisoner of the bloodhounds of the Church.

It was his discovery and enlargement of the powers of the telescope, and the things that he saw thereby-doubtless also the tragic ending of his brilliant life-that gave to Galileo his wide renown. But by far the most important of all his varied contributions to the intellectual wealth of his kind was his treatise founding the science of mechanics. While Kepler was establishing the lawes which govern the motion of the planets, Galileo was penetrating the laws which govern the motion of bodies on the earth.

Now, here is a singular thing-not singular, perhaps, if looked at aright, for it is a familiarly recurring fact throughout all the intellectual development of the race, but puzzling none the less. Kepler in Germany, as we have seen, was haunted with his endeavours to explain the cause of planetary motion; he had likened the sun, as we have seen, to a vast magnet, and tries to find out if its force weakens directly with the distance or with the square of the distance. He can find no facts, no data, which will give him a clue. Yet Galileo had mined out the material for him and put it in a little Latin treatise on mechanics, written in I592. Their friendship began early, and ended only with Kepler's death. They exchanged many letters, exchanged ideas, exchanged books.

But Kepler, so quick to grasp the ideas of Coppernicus and carry them still further, so proud of Galileo's discoveries in the heavens, hailing them with delight even when they overturn some of his most cherished notions, yet cannot link with his own thought, nor see the bearing of Galileo's measures of motion and his mechanical laws. These would have given him just the material he sought ; could he have grasped the import of his friend's far more important discoveries in mechanics, he would have completely anticipated Newton, as he came so wonderfully near to doing. But no, he cannot see.

You marvel, but it is the same with Galileo. What, so far as we know, no other man who had ever lived had thought of 
doing, he had done; he had conceived gravity as a measurable force, and himself made the measure. He had established the rate at which bodies fall, shown that it was independent of the slope or angle of the descent, shown that any projectile, rifle-bullet or cannon-ball even, follows this same law and falls to the ground by virtue of this same force. He had even gone further and divined the last needful element of a complete theory; he had seen with Kepler that not only does a body at rest remain at rest if acted upon by no extrinsic force, but, further than Kepler, that a body in motion remains in motion unless there is some force to stop it.

The puzzle of the ancients with regard to the movement of the planets-and it was Kepler's puzzle too-was the force that kept them going. Galileo showed that once in motion no further force was needful. Unless something got in their way, they would simply keep on going. It was but a step from the earth to the skies, from the movements of terrestrial bodies to those of the heavens; but ah! what a step! Kepler had all but built a bridge; Galileo had in his hands the keystone that would complete it. Like Kepler, he had read the work of Gilbert. But he, too, could not see the import of the thought and work of his friend, even as Kepler could not see that of his.

Galileo was deeply interested in the tides; the true theory of the tides had been worked out by Poseidonius and others, far back in the Greek days. Galileo prided himself as a scholar; he had studied Archimedes with larger results than any man before or since. He must have known well the writings of the ancients. Kepler, mixing therewith some of his too exuberant fancy, still had a tolerably correct idea. Galileo went all wrong, and going wrong just missed, as Kepler missed, robbing Newton of his fame. He fumbled the movement of the earth and the movement of the oceans. Could he but have caught the true theory, instantly his combining, measuring, experimental mind would have seen that if the moon can draw the tides, the earth may draw the moon. He would have seen in a flash the connection between the fall of bodies, the path of a cannon-ball and the path of the moon.

He would have caught up his pen and calculated the rate of the moon's descent towards the earth each moment, fifty or eighty years before a raw lad had come up from Lincolnshire to Cambridge to study mathematics because he was no use on a farm. 
His failure brings no reproach; it cannot dim his glory. He did a work which, in sheer variety and quantity as well as decisive effect upon the thoughts of men, has never been surpassed, and has been equalled but once or twice in the history of the race. His industry was incredible. It is said that many of his manuscripts were burned or lost. The complete edition of his extant works fills seventeen solid volumes. That day had no stenographers nor typing machines; sixteen hundred of his letters upon scientific subjects have been preserved. $\mathrm{He}$ made his own telescopes, ground and polished his lenses with his own hands. He was one of the inventors of the thermometer. If he did not invent the microscope, at least he perfected it and made it practical. In Florence they have a museum wherein they proudly preserve the endless variety of instruments which he devised and made.

As an inventive genius you may put him beside Archimedes, as an experimental investigator beside Faraday. He was a wit, a poet, and a musician, a critic of art and letters and a great stylist as well. "He had such a myriad mind as Democritus, Eratosthenes, Leonardo, Thomas Young. Persecution, imprisonment, poverty, a blind and pitiful old age, accentuated it may be by the fright, if not the actual fact, of torture at the rack, were his reward. The Powers of the Dark could crush him in his helpless age; but not the fruits of his splendid mind. $\mathrm{He}$ died miserably, but his work survives. In some sense, the conception of a world machine is his creation.

With a deeper meaning than when Kepler penned the line, the years have written for his epitaph :-

\section{Vicisti, Galileo !}




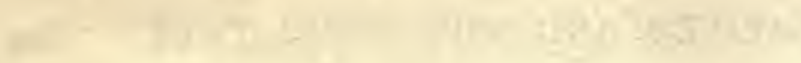

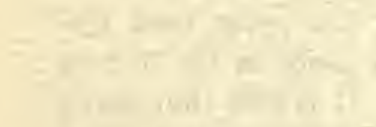

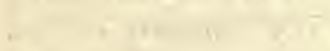

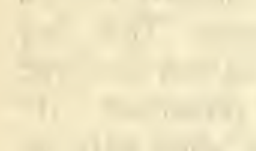

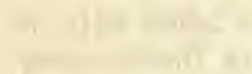

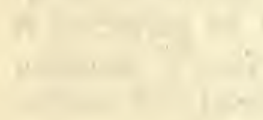

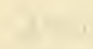

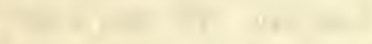

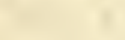

$=1$

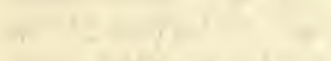

, 


\section{CHAPTER XVII}

THE ADVANCE TOWARD A RATIONAL WORLD CONCEPTION 
For these dogmas are long since exploded which asserted that all parts of the firmament are wheeled round in perfect circles, with excentric and epicycles to preserve their circular motion. The absurdity of which notions have thrown men upon the extravagant ideas of the diurnal motion of the earth, an opinion which we can demonstrate to be most false. And it is likewise evident that although the opinion of Coppernicus about the earth's rotation cannot be confuted by astronomical principles because it agrees with phenomena, yet it may easily be exploded by natural philosophy.

BAcon, Advancement of Learning.

It is not the aim of nature, we must needs believe, that all men should see the truth; but that the truth shall be seen by some, and that by tradition it shall be conserved.

Renan, Dialogues Philosophiques. 


\section{CHAPTER XVII}

\section{THE ADVANCE TOWARD A RATIONAL WORLD CONCEPTION}

Ar the close of the sixteenth century and in the beginning of the next, a revolution was accomplished in the thoughts and ways of men. It was effected by the disclosure of new facts, by the invention of new instruments, mechanical devices which widened and extended the primitive faculties with which man is endowed. The fore-figures in this revolution were the men who devised the instruments, who dug out the facts-men who made permanent additions to the stock of human knowledge.

If we were to believe literary history, the case is far otherwise. It is for this reason, and for this alone, that any word were needed of an extraordinary figure who claimed, and who has received from the literary students of the scientific advance, a pretentious place. That is Lord Bacon. There is a chapter of interest which might be written, in a larger history of intellectual development, on the worth of philosophers-pure philosophers, as opposed to the school of investigation and experiment. If one were to put together a list of their mistakes, one might be led easily to the captious conclusion that their worth has been of the least.

Than Lord Bacon there has been no more notable example. Few men have ever received more fulsome eulogy; few have ever deserved it less. The work of Bacon has been appraised by many a hand; the appraisal has ranged from something akin to deification to that of unmeasured denunciation. The literary estimate of the author of the Great Instauration is exemplified, and it perhaps reached its apogee, in the famous essay of Macaulay. There are few who do not recall his glowing lines:-

"It is by the Essays that Bacon is best known to the multitude. The Novum Organum and the De Augmentis are much talked of but little read. They have produced a vast effect 
upon the opinions of mankind; but they have produced it through the operation of intermediate agents.

"No book ever made so great a revolution in the mode of thinking, overthrew so many prejudices, introduced so many new opinions. . . . Cowley, who was among the most ardent, and not among the least discerning followers of the new philosophy, has, in one of his finest poems, compared Bacon to Moses standing on Mount Pisgah. It is to Bacon, we think, as he appears in the first book of the Novum Organum, that the comparison applies with peculiar felicity. There we see the great Lawgiver looking round from his lonely elevation on an infinite expanse; behind him a wilderness of dreary sands and bitter waters, in which successive generations have sojourned, always moving, yet never advancing, reaping no harvest and building no abiding city; before him a goodly land, a land of promise, a land flowing with milk and honey. While the multitude below saw only the flat, sterile desert in which they had so long wandered, bounded on every side by a near horizon, or diversified only by some deceitful mirage, he was gazing from a far higher stand on a far lovelier country, following with his eye the long course of fertilising rivers, through ample pastures, and under the bridges of great capitals, measuring the distances of marts and havens, and portioning out all those wealthy regions from Dan to Beersheba." 1

The picture is enchanting, but from it the opinions of men of science differ widely. The obverse of the shield you may find in the candid pages of Liebig and in many another. "If," said Sir David Brewster, "Bacon had never lived, those who study nature would have found in the writings and in the work of Galileo not only the principles of his vaunted Inductive Philosophy, but likewise their practical application to the highest efforts of invention and discovery." His real place is uncompromisingly laid down in a savage page of Draper :-

"Bacon never produced any great practical result himself; no great physicist ever made any use of his method. He has had the same to do with the development of modern science that the inventor of the orrery had to do with the discovery of the mechanism of the world. Of all the important physical discoveries, there is not one which shows that its author made it by the Baconian instrument.

1 Collected Essays : Francis Bacon. 
"Few scientific pretenders have made more mistakes than Lord Bacon. He rejected the Coppernican system, and spoke insolently of its great author; he undertook to criticise adversely Gilbert's treatise, De Magnete; he was occupied in the condemnation of any investigation of final causes, while Harvey was deducing the circulation of the blood from Aquapendente's discovery of the valves in the veins; he was doubtful whether instruments were of any advantage, while Galileo was investigating the heavens with the telescope. Ignorant himself of every branch of mathematics, he presumed that they were useless in science but a few years before Newton achieved by their aid his immortal discoveries.

"It is time that the sacred name of philosophy should be severed from its long connection with that of one who was a pretender in science, a time-serving politician, an insidious lawyer, a corrupt judge, a treacherous friend, a bad man." 1

It might be urged in Bacon's defence that, in truth, he was born too early to take in the full character of the revolution going on around him-a revolution whose consequences he did grasp with a prophetic insight, and which he sketched in pages which are among the enchantments of the English tongue. He was forty-eight the year that Kepler issued his New Astronomy and that Galileo's discoveries with the telescope began. $\mathrm{He}$ died a year before Harvey's treatise on the circulation came from the press, though he knew something of his work.

But the defence does not stand in the light of the parallel career of his contemporary, Gilbert of Colchester. The author of the Nere Physiology of the Magnet was born twenty years before the author of The Advancement of Learning, yet he could accept the Coppernican doctrine where Bacon could not. In the midst of a busy life he could make a multitude of new observations and lay the foundations of a new science, as Bacon never did.

The pages of The Advancement of Learning and the Novum Organum are filled with foolish jeers of Gilbert's work; of Harvey's, too. He could neither make discoveries himself nor appreciate those of others. He was as jealous as he was ignorant. Compared with the great thinkers of his time, he appears, moreover, as a mediocre philosopher whose reasoning ofttimes is simply childish. He who looks now through the two

${ }^{1}$ History of the Intellectual Development of Europe, vol. ii. 
volumes of the Great Instauration finds a work devoid of a single contribution to human knowledge of even the remotest value. While a half-dozen of his contemporaries were making a beginning in a half-dozen new sciences, doing a work which the centuries will not undo, Bacon in his study conceives that he is the founder of all scientific method. He begins his famous Instauration :-

"Francis of Verulam thought thus, and such is the method which he determined within himself, and which he thought it concerned the living and posterity to know."

In this sounding preface we learn that its author is not ignorant that he "stands alone in an experiment almost too bold and astonishing to obtain credit; yet he thought it not right to desert either the cause or himself, but to boldly enter on the way and explore the only path which is pervious to the human mind." 1

The italics are not Bacon's. How this vain and emptyhanded boaster could have so imposed upon his generation, to say nothing of the generations which followed, is one of the curiosities of literary history. The truth as to the author of the "Baconian philosophy" is that he was simply a philosopher; he dreamed while others worked. He may have been of some inspiration to others who followed him, and who were stirred by his fervid vaticinations; he must have seemed to the truly scientific spirits of his time a sort of Duke of Argyll.

It is with far greater justice that claims as the father of modern scientific method have been put forward for René Descartes. It is so that he is regarded by Huxley; the authority of the opinion is assuredly high.

Man, observed some reflecting sage, unlike the animals, is born to think. If ever there were a man to whom this would literally apply, it was Descartes. He came of a distinguished family in Touraine; as a child he was known as le petit philosophe; philosopher he remained to the end of his days. He had all the faults of his calling.

When he came of age, most of the great discoveries which blazoned the seventeenth century with such a cachet of distinction had been made; his especial mission in life was to disclose the mechanism of the world, and, with a single exception, he

1 Advancement of Learning, p. 2. 
seems to have ignored them all. There is evidence that he read with avidity all that might be written about himself or his opinions, either for him or against. He appears to have read little else. He had a contempt for the learning of books; doubtless his disdain was not unfounded. Though he wrote many himself, it is recorded that when a company of distinguished savants came to visit him in his retreat at Holland and they asked to see his library, he showed them his dissectingroom, decorated with dismembered chickens and cats.

Descartes was, says Huxley, an unwearied dissector; in physiology and in mathematics he did an undoubtedly original work. It was on the side that probably interested him most that he most signally failed. It is as a philosopher possibly that he takes highest rank; he invented an elaborate system, which has inspired almost as many imbecile pages as that of Kant. His life, if we may trust his English admirer already quoted, "was the consecration of doubt," yet few men ever taught more dagmatically of things which they did not know, nor described more vividly things that do not exist. It was a remark of a witty compatriot that he established doubt as the corner-stone of his philosophy, then calmly ignored it the rest of his life.

After all, his philosophy was but an incident, a means to an end. Descartes. was a mathematician. It was he who applied algebra to geometry, and therefore became the founder of the analytic department of that excellent art. It was he who, in some sense, made possible the achievements of Newton. It was in geometry that Descartes believed that he had found the key to the invisible-for that matter, to the universe as well.

When he was twenty-four, on a campaign in Germany with Prince Maurice of Nassau, he had a sort of a dream in which the whole future of knowledge seemed to lie before him as through an open door. It must have been a remarkable experience. He has described it at length in his celebrated Discours de la Méthode, the work which made his early fame. Up to this he had led the easy life of a young man with plenty of money, had made extensive researches in the gay society of Paris, had travelled much. He speedily found that, for him, the most interesting things in this world were inside of his head, and he spent the rest of his days in tracking them out. He tried Paris for a few years more; but it would not let him 
enough alone. He retired to Holland. He must have thought well of the advice of Epicurus-"Veil thy days"; only one or two of his friends knew of his address.

In Holland he changed his residence twenty-four times in not so many years. He never married. He had a daughter, like Galileo, at whose death he was deeply moved. Beyond that, this world seemed to exist for him only as a subject for meditation and analysis. In pages that are models of clear and simple exposition-like Galileo, again, he was a writer of distinction, one of the founders of the exquisite prose literature of France-he has detailed at length his method and his ways. It is of interest to know that he never worked but a few hours a day, and that in bed; he did not get up until eleven. His life was comparatively brief; he died at fifty-four, having been lured to the court of Queen Christina of Sweden and there contracting a fever. His real career hardly began before he was thirty-three, yet few men ever covered a more extraordinary range in their studies.

You catch a glimpse of his method in his famous aphorism, cogito ergo sum. This is the keynote of his metaphysics; it is typical of his whole philosophy. He lays hold of the simplest, surest, most obvious fact that he may discover. Certain of his foundations, on this he builds. And just as the geometer, starting with a few simple lines, puts them together into triangles, squares, and other figures, and beginning with the simplest propositions, mounts step by step to others the most complex and abstruse, so Descartes, beginning with propositions over which there could seem no possible doubt, rose to conceptions that were certainly grandiose if they were not sublime. Unfortunately, they did not turn out to be true. Never did any system-monger lose himself more hopelessly in the baseless abstractions of his own thoughts. Descartes sought nothing less than a complete system of the universe. His mistake lay in believing that he might construct it from a series of axioms like a geometer.

Absorbed in the elaboration of his wondrous fancies, for him his contemporaries did not exist. His deepest interest in Galileo appears to have been the stories of Galileo's persecution and torture. He was not in the least of the martyr mould; his fright was so great that he straight away left off publishing his chief work, upon which he had been engaged for years, and 
in which he had revealed his adherence to the Coppernican doctrine. Of Kepler he seems to have known little. His vast system of tourbillons or vortices is of interest to-day scarcely more than as a philosophical curiosity. It bears just the shade of a resemblance to the vortex-ring theory of Helmholtz and Lord Kelvin. Some day it may be rejuvenated; but for its own time it was a seduction. With the incoming of the simpler ideas of Newton, firm grounded upon experimentally demonstrated facts, it was forgotten.

Nevertheless, and in spite of the ultimate downfall of the vast house of cards which he had reared, to Descartes belongs a distinction that is unique, and that places him among the highest of those who have reflected upon the construction and march of the bewildering theatre upon which we are born. Not forgetting the chance phrase of Coppernicus nor the brilliant conjectures of Kepler, it is fairly certain that Descartes was the first concretely to picture this world as a mechanism, the first to explain, its phenomena upon a mechanical basis, the first to analyse the universe into terms of matter and motion. This he did, not as pure astronomer, not simply as regards the sun and planets; but through the tides and winds, through physiology and all the phenomena of life, and down to the last flutter of an eyelid.

Descartes found a militant adversary, the Coppernican system a suave but insistent defender, in Pierre Gassendi, the worthy abbé of Digne; he is scarcely remembered now outside the musty pages of the history of philosophy. Gassendi bore an unmistakably important rôle not merely in French thought in the seventeenth century, but in that of Europe as well. $\mathrm{He}$ was the first conspicuous defender of the Coppernican ideas in France after the fugitive propaganda of Bruno; he was its first expositor at the Collège de France. It was Gassendi, moreover, who dug out and gave new life to the ideas and doctrines of Epicurus - that is to say, to the physical and atomic theories of Democritus.

The result was a curious alignment. The ideas of Descartes and the whole bent of his mind were mechanical; and the first worked-out theory which distinctly presented a mechanical world conception was the system of Coppernicus. Descartes did not reject the system; but even in the writings published 
long after his death one sees how little it really gripped his imagination. The ideas of Gassendi, far less original, no doubt, than those of the author of the Discours, were wholly Democritan - that is to say, atomic-a system of materialism rather than an endeavour to represent the cosmos as a machine. The distinction is worthy of note, since the mechanical doctrine, contrary to popular superstitions, assiduously cultivated by ignorant or sophistical minds, in no way involves the conception of a material substratum. One may be excellent Coppernican and good Berkeleyan, firm materialist and no Newtonian. Yet Gassendi, perilling his standing as an orthodox theologian, was both materialist and Coppernican.

A reproach is often brought to the door of Gassendi, as to that of Descartes, that the ardour of the evangel was subdued by an excess of worldly caution. Such ideas come as a rule from minds lacking in historical perspective as well as historical information. Consider for a moment the state of the times in which these men lived. Gassendi was born in I592, four years before Descartes. He was therefore thirty-two years old when the Parliament of Paris sanctioned a decision of the learned tribunal of the Sorbonne, forbidding " on pain of death that any one should teach or hold any doctrine against the ancient and approved authors "- that is to say, any one who should dispute the doctrines of Aristotle and the Church. Remember that at this time the ruler of France was its great Cardinal Richelieu, and that this decree was obtained from the Paris council by Richelieu himself. Take note that this is but eight years before the condemnation of Galileo to imprisonment for life; the ardour of persecution flamed no less violently in the north than in the south.

Moreover, this same enlightened cardinal-minister gained from the same tribunal a special decree expressly condemning the system of Coppernicus, at near fifteen years after the discovery of the telescope and all its revelations. The new doctrines spread in spite of the official ban; you might infer, perchance, that this decree was but a belated survival of mediævalism and was speedily forgotten. Reflect, then, that as late as I675, when all of intellectual Europe had turned Coppernican, the university asked for a renewal of this decree and the Parliament of Paris was ready to grant its demands. It desisted only before the storm raised by the satire of the good Bishop Boileau. 
Gassendi had signalled his adhesion to the new doctrines in two letters addressed to Galileo in I625 and again in I632. In I646, named to the chair of mathematics in the Collège de France, he gave a detailed exposition of the new theories with all the arguments that might be urged in their favour. $\mathrm{He}$ observes that the partisans of these theories are very numerous ; but that they " do not dare declare themselves because of the sentence of the Congregation pronounced on Galileo by some cardinals." Ostensibly he professed adherence to the bizarre scheme of Tycho Brahé, since he says it is needful to reject absolutely the system of Ptolemy, and because the Bible teaches positively the movement of the sun. The farce was so obvious that probably no one was deceived, and the excellent abbé was able to keep his chair. For the rest, he was, as Lange remarks, one of those happy natures that we pardon more readily than others. Intellectually a disciple of Charron the sceptic, he was not, like Bruno, a disturber. He was amiable, he was gay; he had an inexhaustible fund of good stories; it seemed absurd to burn such a man or cut his tongue out. By way of revenge the practitioners of medicine, against whom much of his raillery was directed, accomplished what the Church did not. He died of a blood-letting.

It was the fortune of Gassendi not merely to be one of the earliest of the Coppernicans, or, let us say, Galileans, in France, but to have made an observation which offered the most distinctive piece of proof of the new theory since Galileo's observations of the phases of Venus. It followed, of course, from the Coppernican scheme that we should observe the periodical transit of Mercury across the face of the sun. The Arabian Averrhoes thought that he had observed it; Kepler as well. It is now known that the transit cannot be observed by the naked eye.

Kepler had taken pains to calculate the moment of solar eclipse, and had announced the passage of Mercury across the sun's face for the 7 th of November 163I. Gassendi, something of an astronomer, made preparations to observe it. That day the sun appeared half-hidden by the clouds. He thought he could perceive a small black spot, but it seemed too slight to be the body of a planet. Happily, however, he observed the spot carefully, and was rewarded by finding that its movement was much more rapid than that of any sun-spot which had ever 
been observed. When it reached the borders of the sun he was able to follow its exit distinctly; there could be no doubt that it was in reality the planet. He had the pleasure of observing a phenomenon unknown to antiquity; he liked a good phrase, and in allusion to the ancient quest for the philosopher's stone, he said: "I have seen what sages have sought with such ardour; I have found Mercury in the sun."

It was one more heavy buttress added to the Coppernican fabric. In the ancient Ptolemaic system, Mercury had been set in revolution round the earth like Venus and the sun; but it was difficult on this theory to understand how Mercury could be eclipsed by the sun and march across its face as well. The thing was simply inexplicable.

Gassendi sought likewise the transit of Venus, equally predicted by Kepler for a month later. Unluckily for him and for other observers, awakened by his discovery of the transit of Mercury, the passage of Venus seems to have occurred during the night. At any rate the first actual observation was reserved for a young Englishman, Robert Horrox, eight years later.

Gassendi was a voluminous writer; several astronomical works were among the number. He had in a high degree the historical sense; he was one of the earliest of the moderns to adopt the historical form in the treatment of scientific questions. $\mathrm{He}$ wrote excellent lives of Coppernicus and of Tycho Brahé, on the life and death of Epicurus as well ; it is by the latter work, perhaps, that he is best known. His criticisms of Descartes were models of polemic, keen, politely ironical, good-natured, and substantial none the less. He was the first to point out that the principle of doubt expounded by Descartes was but a fiction, and that the famous "I think, therefore I am " involves a quantity of dogmas no one of which have we any absolute proof for whatever. He anticipated the nihilism of Berkeley by a century.

Of interest merely as noting the advancement of the new ideas, was the unqualified adhesion to the Coppernican doctrine by the English philosopher Hobbes. While Bacon was making the ideas of Gilbert, Harvey, and Coppernicus a triangular target for his fretful animadversions, the father of English materialism boldly embraced them all. It is true that he was only thirty-two when the Novum Organum appeared, and that 
by this time even Bacon appears rather as a belated owl blinking confusedly in the flooding light.

None the less, if Hobbes was not a pioneer like Gilbert or like Bruno, the weight of his influence on English thought was great. He was the first prominent thinker, the first widely read writer in England boldly to signal his acceptance of the new faith. It is to be noted that he was the lifelong friend of Gassendi; it may have been to his acquaintance with the Coppernicising abbé that this was in some part due; what is certain is that Hobbes, forerunner by forty or fifty years of Boyle, Hooke, Wren, and Newton, turned English philosophy from the vanity of the schools and paved the way for this brilliant coterie that, in a few years, was to lift England from its barbarian estrangement and isolation from the rest of the world and make of this dark land the light of Europe.

The author of the Leviathan lived to an extreme old age; Gassendi was dead in I655, five years after his great adversary, Descartes. Despite the decrees of Rome and the Parliament of Paris, it is clear that for some time before thisthat is to say, in a little more than a century after the publication of the De Revolutionibus, and certainly within a half-century of the invention of the telescope, the more enlightened portion of mankind had become Coppernican.

Already the thought of the time was reaching out to conceptions of infinitude and of a grandeur of the universe before which the great globe of the earth seemed to shrink, to shrivel, almost to disappear, even as some vast creation of legerdemain, obeying the will of the conjurer, before our astonished eyes grows subtly less and less and downwards to a point.

What was the observation which would make it clear to all thinking men? 


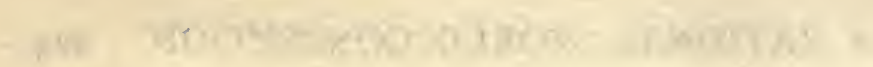

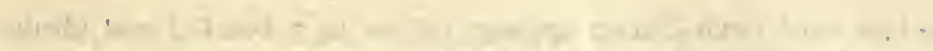

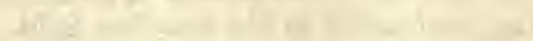

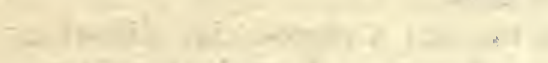

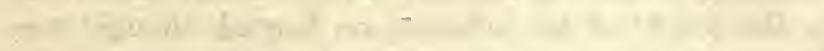

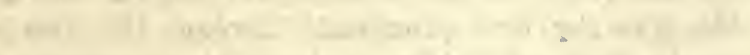

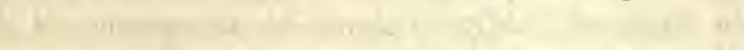

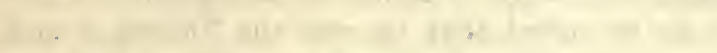

2hat

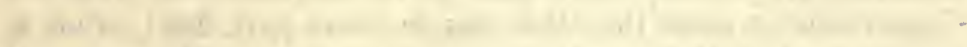
a n

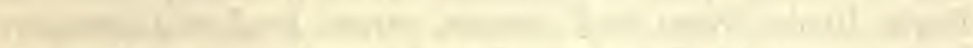

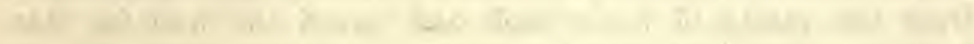

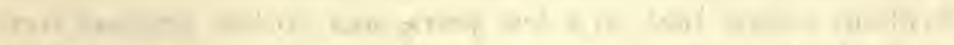
1.

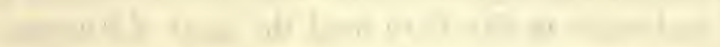

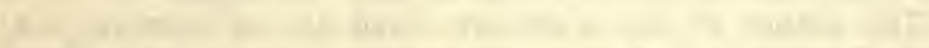

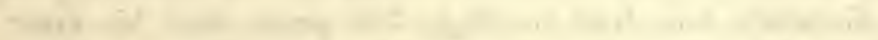

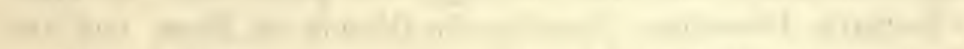

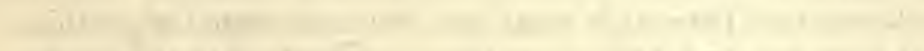

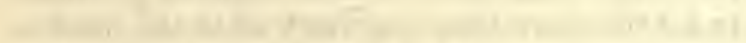

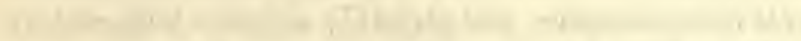

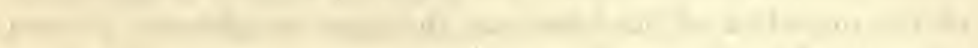
, W.

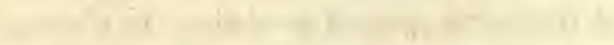

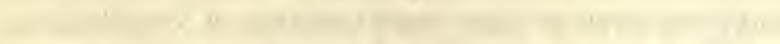
, thent

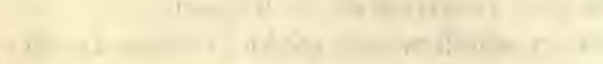

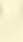




\section{CHAPTER XVIII}

THE TRUE GRANDEUR OF THE SUN 
Astronomy considered in its entirety is the finest monument of the human mind, the noblest essay of its intelligence. Seduced by the illusions of the senses and of self-pride, for a long time man considered himself as the centre of the movement of the stars; his vainglory has been punished by the terrors which its own ideas have inspired. At last the efforts of several centuries brushed aside the veil which concealed the system of the world. We discover ourselves upon a planet, itself almost imperceptible in the vast extent of the solar system, which in its turn is only an insensible point in the immensity of space. The sublime results to which this discovery has led should suffice to console us for our extreme littleness, and the rank which it assigns to the earth. Let us treasure with solicitude, let us add to as we may, this store of higher knowledge, the most exquisite treasure of thinking beings.

LAPLACE, Exposition du Système du Monde. 


\section{CHAPTER XVIII}

\section{THE TRUE GRANDEUR OF THE SUN}

While Descartes was busy with his air-castles, fabricating the world from dreams, others less ambitious to construct a universe de toutes pièces were endeavouring to build up a rational knowledge of that corner in which we live, from a foundation of solid fact. Without the aid of the telescope, and merely from patient observation by means of the two eyes with which he had been endowed by nature, Coppernicus was able correctly to delineate the relative positions of the planets and depict the order of their revolutions round about the central sun; something of their actual spacing as well. But the ideas which men still might form of the true dimensions of the solar system-the relative grandeur of the earth to its companion bodies-were of the crudest. Even at the death of Galileo there remained one great mystery.

The simplest of considerations required that if the sun's distance were not infinite, seen from two widely separated points upon the earth it should show an apparent shift of position with reference to any intervening body-that is, a parallax. Thus, if in the transit of the moon or a planet across the face of the sun, to the eye of one observer the edge of the planet just touched the edge of the sun, to that of an observer at a sufficient distance a slight gap between the two should show. And if the angle subtended by this gap could then be measured, the true distance of the sun might be known. No such parallax or apparent displacement could be found; Galileo, as we have seen, sought it in vain. The crude measures of Aristarchus, open, as more accurate observations disclosed, to errors of hundreds per cent., was still the best that men could find.

The restless mind of Kepler busied with the problem. Turning it over and over, a simple geometrical construction sufficed to show him that if the estimates of Hipparchus, not materially changed, as we have seen, by Ptolemy or Coppernicus, were 
in any way correct, the sun must needs show a parallax of at least three minutes of an astronomical degree. But the surprising accuracy attained by his friend and patron, the great Tycho, made it clear that no such parallax existed. So did he perfect his instruments, that Tycho was able to reduce the possible errors of observation to a single minute. As no apparent displacement even of this slender amount could be found, it followed that the distance of the sun must be at least three times that computed by the ancients.

But even the ancients had been able to fix with a fair degree of certainty the distance of the moon, and this, on the ancient calculations, had already spaced the sun at five million miles away, and given it a volume three hundred times greater than that of the massy earth. Scant wonder is it that even in Coppernicus' time these estimates should have been deemed simply absurd.

Now, however, Kepler would set the sun not at four or five, not at a lower limit of thirteen million miles; he would give it a diameter, not six or seven, but at the least eighteen or twenty times the diameter of the earth; he would compute the dimensions of this glowing ball in the sky, not at three hundred, but at seven or eight thousand times our globe. The thought was grotesque. It was only by a sort of acrobatic leap of the imagination, by an immense and violent somersault of the mind, that men could reach belief in such unbelievable things.

Consider that the most enlightened people of that time had not left off their credulous trust in astrology; that such as were dabbling in the chemic art were still in search of the philosopher's stone and the elixir of life; consider that throughout all Europe the most advanced of nations were still hanging, burning, torturing miserable wretches for witches (almost without exception, be it observed, from among the outcast poor), and it will not be difficult to understand why it was that a true conception of the world should have such difficulty in battling against the prejudices and superstitions which still dominated the great body of mankind.

But the telescope with its disturbing revelations had effected a breach; bit by bit it widened. In free and heroic little Holland, where Descartes had found a refuge, there were men of a mind to attack the problem anew. One of these was the 
astronomer Vendelinus. He took up again the theorem of Aristarchus, but with the advantage of a weaponed eye, to determine anew the exact moment of the dichotomy of the moon. He had carefully considered the spots upon the moon, and determined those which lie at a median point separating the half that was illuminated from the half that was obscure. This done, in order to detect the exact moment at which the moon reached its quarter, it sufficed to mark the instant at which these spots were illuminated. Better instructed than Aristarchus or any of his successors could have been, he took into account also the possible deviations of angle due to refraction by the earth's atmosphere. It will be remembered that at the moment the face of the moon was cut in twain, Aristarchus had calculated the angle subtended by the moon and sun at about eighty-seven degrees-that is, within three degrees of a right angle; Vendelinus found that it varied but little more than half a degree from a right angle. It followed from his measurements that the sun must be not twenty times, but more than two hundred times the distance of the moon-that is to say, not four or five millions, but forty or fifty million miles away. The boundaries of the universe, which Galileo had boasted he had pushed back hundreds of times from anything hitherto imagined by men, were receding farther still. Vendelinus had made half the step; the true distance was soon to be disclosed.

Between Galileo and Newton the most prominent figure among observers of the heavens was Dominico Cassini. $\mathrm{He}$ was a compatriot of Galileo, and acquired a considerable reputation through his bold and somewhat fantastic projects for the construction of telescopes of enormous size. He was a tireless worker; when he was not sweeping the heavens he calculated and wrote. His discoveries were numerous; among others, the rotation of Jupiter and Mars, and four new satellites of Saturn. He likewise constructed astronomical tables of great value.

It was at the instance of Cassini, who had come to Paris to take charge of the fine observatory then being erected there, that the French king sent out the celebrated expedition to Cayenne. One of the results of this expedition was to reveal the fact that pendulums beat more slowly at the equator than in the latitude of Paris; by revealing the varying intensity of gravitation, it suggested that the earth was not a perfect sphere ; 
it was this that enabled Newton and his successors to calculate the figure of the earth. But of still greater importance were the observations taken upon the position of Mars simultaneously with like observations of Cassini in Paris. The idea was to utilise the transit of Mars instead of the moon for the determination of the sun's distance.

It was the first attempt which had ever been made on such broad lines-that is to say, from such widely separated points of the earth. It was with a fever of impatience that the French Academy awaited the return of its deputies. The observations were successfully carried out; combining their results with his own, Cassini was able to fix the parallax of the sun, not at three minutes, such as the estimates of the ancients had required; not at one minute, which Kepler had thought probable, but at slightly less than one-sixth of a minute. Cassini set it at nine and a half seconds.

This fixed the remoteness of the sun at three hundred and sixty times the distance of the moon, or eighty-seven millions of earthly miles. This was in 1673 -that is, thirteen years before the Principia, fifty years after the Dialogues on the Two Great World Systems; it was in the midst of the reign of the elegant and easy-going voluptuary, Louis XV., which, like that of his similar in England, the second Charles, proved so favourable to the advancement of rational ideas.

A century and more of minute and repeated observations, checked and verified by methods most diverse, has not impeached the substantial accuracy of Cassini's results. It was still a little under the reality. But before this prodigious calculation how men must have stood in amaze! There was now no easy or contemptuous brushing it aside. France was then the political, the social, the literary, the scientific centre of Europe. The expedition to Cayenne had been sent out by the king, under the direction of the Royal Academy. The calculations were the work of the Royal Astronomer, the official head of scientific investigation in the most enlightened of the nations. The results had in some sort a royal sanction; they had, moreover, been carried out with a care and precision hitherto unknown; to contest their value was to set one's face against all that stood for truth and knowledge in that day. It was a wonderful change; a short fifty or sixty years since the Holy Congregation of the Index, sitting at Rome, had denounced the 
Coppernican theory as heretical and impious, and blasphemy against the Most High God.

Instead of endeavouring to smother the truth, a Catholic monarch in a Catholic land could now contribute from the revenues of his Catholic subjects to advance it. A century later, when a yet more favourable opportunity presented itself to determine the sun's parallax, not one government but half-adozen would contribute. This was during the transit of Venus in I76I and I769. Halley, the friend of Newton, had pointed out the advantage of observations on this planet; like the moon, it crosses the sun's face, but its apparent magnitude is too small to cause any serious diminution in the sun's light; the moment it touches, the sun's disk is more sharply defined. But the plane of the earth's orbit is somewhat inclined to that of Venus, so that we are able to witness the transit of Venus only twice in a little more than a century.

When at last it came again, the interest manifested in the event was extraordinary-observing parties were scattered from the Cape of Good Hope to Siberia and India; at the second transit, from Hudson's Bay to Madras, from Siberia to California, from far northern Norway to the South Sea Isles. The results, however, were far from satisfactory. They did not greatly improve upon the accuracy attained a hundred years before. It is only within the last half-century that, by the concurrence of a variety of methods, it has been possible to attain a result which no further investigations can materially change.

These methods were grounded upon bases very diverse. Even while Cassini was observing the transit of Mars, Roemer was deducing the velocity of light. Later on, ingenious contrivances in the laboratory have made it possible to fix this velocity with great precision, so that, knowing the time which light takes to cross the diameter of the earth's orbit, it is possible to deduce the distance of the sun by this means. Two others were worked out by Leverrier from the observed variations in the earth's orbit-one due to the gravitational influence of the moon, the other to that of the near planets. These and several others of less value unite with more recent and more accurate observations on Venus to fix the solar parallax at $8 / \cdot 8$, with a probable error of less than one five-hundredth of the distance. 
Some idea of the extraordinary accuracy of modern observations may be gained from the curious discovery of an actual variation in the latitude of several observatories. This variation of latitude is apparently due to a minute change in the position of the earth's axis, so that it describes a circuit around its mean position in the course of about a year and a quarter, though never varying from the mean centre more than thirty feet. This, it may be remarked incidentally, is the seventh of the known periodical movements of the earth, four having been discovered since Coppernicus left Europe vertiginous by announcing three.

The solar parallax now agreed upon fixes the mean solar distance at very close to ninety-three millions of miles-that is to say, approximately four hundred times the distance of the moon. Cassini had computed the distance at but six million miles less. His error was not great. But reflect upon the fearful wrench it brought to all the world conceptions which men had treasured from practically the beginning of the intelligent consideration of nature. A sun six or seven times the diameter of the earth was unbelievable enough; the measurements of Cassini made its diameter more than a hundred times. To our eyes the moon and sun appear of exactly the same size; could the sun be brought as near to the earth as the moon, its apparent diameter would be more than two hundred degrees; it would seem to us as large as I60,000 moons; it would fill the entire heavens, and there would practically be no night. As the amount of heat which the sun may shed upon a planet depends upon the square of the distance, it follows that with the sun at the distance of the moon, the earth would be 160,000 times as hot as now. Nothing living could exist for a second; it would shrivel in a flash, and the earth itself return to the incandescent mass from which it sprang.

The determination of the sun's true distance first made it possible to gain a correct idea as to the size and the dimensions of the solar system. Coppernicus was able to fix, with an accuracy that is still admirable, the relative distances and somewhat of the relative sizes of the six planets known to him; it is obvious that he could have but little idea of their absolute measures. So long as the sun was assumed to be but twenty times the distance of the moon, it followed that, for example, Venus, at three-tenths of that distance, or six times the distance 
of the moon, was a body not vastly greater. Jupiter, of course, was something of a stumbling-block. At five times the distance of the sun, it must be at least a hundred times as far away as the moon; but though it evidently had an appreciable disk, it was beyond the measuring powers of the instruments of that day and for long after.

With the sun at four hundred times the distance of the moon, Venus must be nearly a hundred times, and at its brightest it glows like a little moon; its disk has an apparent diameter of over one minute. It takes only a moment to reckon then that it must be a planet as large as the earth. It is obviously considerably hotter than the earth; on the other hand, even the greatest telescopes show no clear markings such as we may observe upon the moon; it is possible it may have a very dense atmosphere and therefore be inhabitable with beings like unto ourselves.

The fortunate career of Cassini fell amid the charming time of the salons, when women of wit drew around them brilliant coteries of savanits, and when the most erudite and accomplished of men did not think it beneath their dignity to clothe knowledge and recent discovery in language so simple as, not to seem dull amid the brilliant conversation of that engaging day. A little later Fontenelle, discoverer, with Voltaire, of Newton to France, and knowing like Voltaire how to temper the arid phrases of science with the elegancies of style, caused a polite little rustle in the polite little monde of France by announcing the plurality of worlds. His slender volume is charming reading still. For proclaiming the same fact Bruno had been burned just eighty-six years before.

A plurality of worlds and our earth in no wise uniquethis was the new angle from which mankind had now to consider the problems of human destiny and the worth of human effort. The earth was not, in all probability, the sole inhabitable planet even of our system; it was not unique in size; it was soon clear that it was, in point of fact, utterly insignificant. Even Galileo's little tubes could measure Jupiter's disk; at its brightest it is almost as large as that of Venus, and it was now clear that the son of Jove was sixteen times as far away, even at the nearest point which he comes to the earth. If he travelled in the orbit of Hesperus he would be two hundred 
and fifty times as bright; and as the earth appears from Hesper of just the same size as Hesper from the earth, it followed that here was a planet a thousand times more vast in bulk than either. Saturn at nearly twice the distance was almost as huge.

Huge as they might be, yet all of them taken togetherthe colossal bulk of Jupiter and Saturn, the earth and all the other known planets, and two more yet to be discovered, with all their satellites, and five hundred asteroids besides-all of them combined would not make a thousandth part of the total volume of the sun. It was as if in Vulcan's smithy the gods had moulded one giant ball, and the planets were but bits and small shot which had sputtered off as the glowing ingot was cast and set in space. Little man on a little part of a little earth -a minor planet, a million of which might be tumbled into the shell of the central sun-was growing very small; his wars, the convulsions of a state, were losing consequence. Human endeavour, human ambitions, could now scarce possess the significance they had when men could regard the earth as the central fact of the universe.

Neither then, nor now, did the new knowledge exercise greatly the thoughts or lives of men. Still, then as now there were a few who reflected a little. It was the fashion of those graceful days to say smart things when one could. "What," said Maria Theresa to the philosopher Maupertuis, when she had captured him from the armies of Frederick the Great, against whom she was then at war-" what does your philosophy teach you to think of two princes who squabble over little patches of the planet you have measured ?"

"I have no right," was the sedate response of the hero of Dr. Akakia, "to be more philosophic than kings."

There can be little doubt that the New Revelation of the true grandeur of the sun, the utter insignificance of our own planet, did more to fix the Coppernican idea in the common mind than all the arguments from Aristarchus to Galileo and long after. So long as the sun could be thought of as small, or even as not greatly larger than the earth, it was thinkable that it revolved while the earth stood still. After the measures of Cassini, it was unthinkable. No stretch of ignorant fancy could conceive of a planet or the earth revolving round a minor satellite or the moon, or, in varied parlance, a huge cannon-ball around a single buckshot. 
To still greater purpose, it was when the earth and its companion "wanderers" could be pictured in such guise; when the sun could be thought of as a body so vast that its monstrous bulk would envelop a space near twice that occupied by the earth and its circling satellite-that the moon pursues its orbital way about the earth within a space of half the shell of the sun-it was this that could build up the idea of the sun as the dominant fact, the ruling force, the monarch of our world. It was this which could bring conceptions of its power, and then of a power which holds the planets as dogs within a leash.

But before this latter conception could take hold, men had to gain more definite conceptions of power-that is to say, of force. And this could, in its turn, arise only from the development of machines, and out of these, a mechanical science.

This development was even then in full swing. 


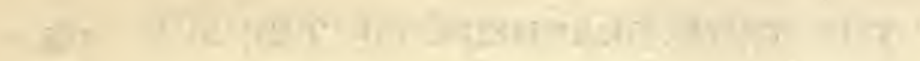

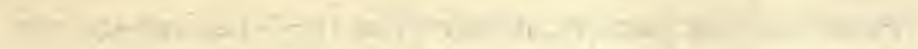

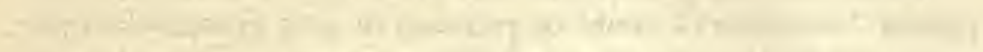

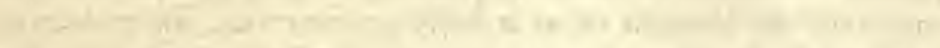

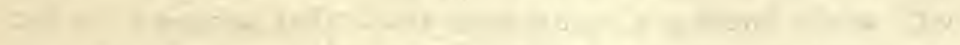
-

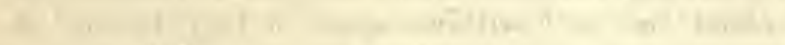

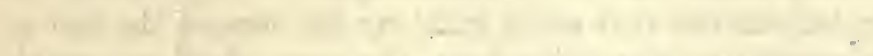

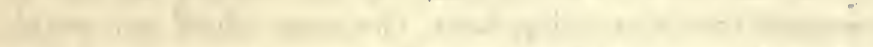
1.

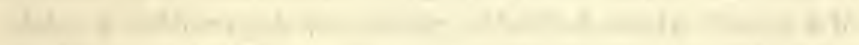

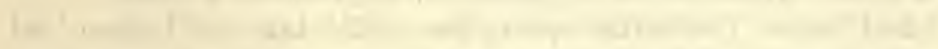
(20) W. and

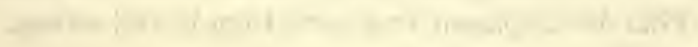

. 


\section{CHAPTER XIX}

THE DEVELOPMENT OF MECHANICS: THE FORERUNNERS OF NEWTON 
THE theories established in one generation become the startingpoints of successors. Newton, with all his genius, would not have detected the law of gravitation had not Kepler and Galileo preceded him; nor could they have made their discoveries had not Greek mathematicians supplied the means. It was by the bold and happy identification of celestial with terrestrial physics that the great thinkers of the seventeenth century made physical Astronomy an exact science, making it a part of Mechanics, explaining its phenomena by those very Laws of Motion which were proved to regulate the phenomena of terrestrial bodies.

LEwES, Aristotle. 


\section{CHAPTER XIX}

\section{THE DEVELOPMENT OF MECHANICS: THE FORERUNNERS OF NEWTON}

BEYOND doubt, with all his dreams in the day, the mechanical conceptions and ideas of Descartes, his thought of reducing all phenomena to the regular and calculable movements of a mechanism, exercised a profound influence upon the thought of the time. His Principia appeared in I644; its preponderant influence outlasted near a century; physical science has perhaps never quite lost its impress.

The work of Descartes did much; that of Galileo, with its more solid foundations, did more. Galileo's Dialogues on Mechanics came in I638. With the faithful aid of Viviani and Torricelli, he added during the last three months of his life two supplementary dialogues. The work appeared from Leyden; they would not, of course, let him publish it in Italy. Coming from such a man it was read all over Europe with a profound interest.

It is curious to observe how distinct was the work of the two men, to note what little use Descartes made of Galileo's discoveries. His intellectual egotism carried him so far as to put out of his reach materials of the greatest value. It appears that of any sort of writing, that which influenced him most was Harvey's little tract on the circulation of the blood. It had appeared in I629. It was written wholly in the mechanical spirit; it shows clearly that Galileo and Descartes were alike but a part of their time, and that the time had taken on a distinctly mechanical bent.

That bent was intensified, the seventeenth century became pre-eminently the century of mechanics through the remarkable discovery that came the year after Galileo's death. This was the elucidation of the theory of the suction-pump, and through it the discovery of the weight of air, the development of pneumatics. Our common pump is old enough; its 
invention is commonly attributed to Ctesibius, the forerunner of Hero in Alexandria. Probably it was known in a crude way thousands of years before that. To explain its action the ancients had invented the idea that nature had a horror of a vacuum, and that if in any way a vacuum was created, whatever of a material nature lay next would rush in to fill the emptiness. It is evident enough from the pages of Lucretius that they had a clear idea of the weight of the air; but, so far as we know, it never occurred to them to connect the pressure of the air with the action of the pump. The simple binding link escaped even Galileo himself-another of the thousands of instances which might be adduced showing the sharp delimitations even of the most piercing and far-seeing minds.

It is told that some workmen, in constructing a house near Florence, had put down a rather long pipe and discovered that it would not work. The water would rise in the pump to a height of about thirty-two feet and no more. When Galileo was asked about it he simply made a jest. He loved a fling at the ancients; and observing that evidently nature had a horror of a vacuum only to a height of thirty-two feet, gaily went his way. Still he and his disciples must have discussed the subject; and how keen a joy it must have been to these young men to talk the new things over with the man who was creating the most of them.

One of these Galilean disciples was Torricelli. Pondering over the matter, Torricelli came to the conclusion that if the air would sustain a column of water about thirty-three feet high, it would hold up other liquids in proportion to their weights ; as mercury is fourteen times as heavy as water, the column of mercury that it would sustain would be only one-fourteenth as high. Viviani tried it and showed that his friend's expectations were correct. The meaning of it all was very clear. Air and the mercury, or air and the water simply formed a balance : the weight of the air was equal to the weight of the column it sustained.

Torricelli's discovery came in the year that followed his master's death. It excited the liveliest interest; the news of it travelled fast. In France it reached the ears of twenty years old Blaise Pascal, already revealed as a mathematical genius of the highest order. It could have been but a rumour, for he repeats the experiments in a great variety of ways; he makes 
it perfectly clear that there is a complete analogy between the weight and pressure of water and the weight and pressure of air-that their effects are the same. But he goes a step further.

In the course of his experiments Pascal had noted that the pressure of water in a vessel is greater towards the bottom than at the top. The idea came to him that the same should be true of any considerable body of air. Doubtless he had deeply studied optics and the refraction of light; probably he knew of the various attempts that had been made to determine the height of the earth's atmosphere. It had been measured by the Arabian Al-Hazen in the eleventh century and by Poseidonius a thousand years before that. If the analogy between water and air is complete, then at the top of a high mountain the pressure of the air will be less than at its base-the column of mercury will sink. Possibly the slight but curious variation from day to day in the height of the mercury column, first observed by Torricelli, had already given him a prescience of the discovery he was to make. At any rate, he sends Perier up to the top of a mountain with a column of mercury to test the question. It turns out just as he had foreseen. The barometer in its present-day sense had been discovered.

Six years later Otto von Guericke, burgomaster of Magdeburg, had invented the air-pump. With it he had shown further that a pair of copper hemispheres, when tightly fitted together and the air pumped out, could not be separated by teams of horses pulling in opposite directions. Nature's "horror of a vacuum" was simply the pressure of the air. A new science -ærostatics, pneumatics-was born.

It is easy to see what an impulse towards mechanical ideas and conceptions all these new discoveries must give. They had a curious effect in another way; they emptied the spaces of the inter-planetary ways of air ; they left the heavens, save for the planets, comets, meteorites which we may see, a void. This was a great step. One of the most puzzling problems in celestial physics, as we have seen, was the force which urges the planets, the earth as well, in their rapid flight. Galileo, by the force of his genius, could rise to a clear and definite conception of inertia, but he had no thought of applying it to the movement of the planets. There was nothing to suggest such an application. It was clear enough that bodies shot through the air meet with a resistance. If the air extends indefinitely 
throughout space, as most good folk suppose, then what was it which enabled the planets to overcome the resistance which they must meet ? Poseidonius and Al-Hazen could make their calculations as to the height of the earth's atmosphere : there was nothing to prove that they were right.

A very few experiments with the barometer, its revelation of the decrease of air pressure with the vertical height, sufficed for a new calculation as to the height the atmosphere might extend. This agreed fairly well with the estimates made from the appearance of the sun and the stars when they are still below the horizon. Men could then rise to a conception that was wholly new-that, save for material bodies, space is empty.

After that a propelling force for the planets was no longer needful. Speeding through a vacuum with no resistance to overcome, it was clear that once set going they would go on for ever.

It was the development of these new ideas which made it possible for the human mind to conceive of action at a distance, that is to say, to conceive of a force which could reach throughout all space. It was this which opened the way for Isaac Newton, and let his understanding pass to conclusions where Kepler, Galileo, and Descartes had failed.

The human mind was reaching at last to clear and practical representations of force-what we to-day call energy. Instead of the vague notions of levitation and gravitation which they had found in the physics of Aristotle, Kepler and Galileo had substituted definite notions of a power acting always towards the centre of the earth, a force which could exert a certain pull, which acts upon all bodies alike. Guericke had demonstrated that Galileo's law as to falling bodies applied equally to all bodies regardless of their weight, that a cannon-ball and a feather dropped in a vacuum reach the bottom together. For mystical notions regarding nature's predilections as to a vacuum, they had established a clear conception that the air is a fluid which may exert a pressure precisely as does water. With the establishment of the practical identity in their actions of air and water had come a mechanics of fluids. In a very little while Boyle and Mariotte had discovered the law which governs the "spring " of air, that is, that air occupies a volume directly proportional to the pressure exerted upon it. Galileo's primitive thermoscopes were being developed into accurate thermometers; they were making the first crude measures of the energy of heat. 
Moreover, and this was of the greatest importance, men were developing the measuring habit, the habit of exact observation, of comparing one force or power with another, generalising these observations, and deducing from general laws other effects up to then unforeseen or unknown.

It is easy to understand that very soon there were practicalminded men alert to take advantage of all this new knowledge, and keen to apply it in a practical way. In the very early years of the century, while Galileo was at work upon his experiments with falling bodies, a rich compatriot, della Porta, was throwing out some interesting guesses as to the way advantage might be taken of the force of steam. Very soon Rivault had imprisoned water within a cannon-ball, and blown the ball to pieces simply by heating it. Before Galileo's death a number of inventors were at work reviving the old contrivances of Hero and Ctesibius for doing work with steam. Somewhere about I628, says Thurston, Lord Somerset, second Earl of Worcester, had a rude contrivance for raising water working in Vauxhall. A little later he had a still more developed machine at Raglan Castle. In I666 he had taken out the first patent for a steam-engine.

It was about this time that a new mechanical device lent an added perfection to astronomical observation, for that matter, to the whole art of physical investigation-a perfection which neither could have otherwise attained. This was the invention of an accurate measure of time-in a word, of clocks. It is almost beyond belief that they should have come so late. Not, indeed, that clocks of one sort and another were not known to the most ancient times. Sun-dials were in use, not perhaps in the Garden of Eden, where a reminder of the flight of time would have been an annoyance, but certainly in prediluvian days. Even the Chaldeans knew how to "weigh" time-in a word, had clepsydras or water-clocks. Some very wonderful examples of the latter were constructed by the Arabians. The famous clock sent by Haroun-al-Raschid to Charlemagne indicated the hours by the fall of little balls and by the coming forth of small horsemen from as many open doors.

It is to the Arabians, too, that we probably owe the first application of the pendulum as a time measurer. This was certainly made by the great astronomer Ibn-Junis along at the end of the tenth century. He thus anticipated Galileo by some 
six centuries. Even before Ibn-Junis it appears that clocks had been constructed to run by the aid of weights and not by the fall of water. To Pacificus, Archdeacon of Verona, in the early part of the ninth century is attributed the first clock moved by wheels and weights. It is clear, from a passage in Vitruvius, that even the complicated " machina hydraulica," an actual astronomical clock, constructed by Ctesibius under Ptolemy Euergetes in Alexandria, was worked by toothed wheels.

What Pacificus really appears to have done was to invent the escapement, an ingenious device wherein he employed the inertia of a balance to retard and regulate the movements of the hands of the clock. But the pendulum and the escapement were not successfully combined in the construction of an accurate clock before the seventeenth century was well advanced. It is probable that Galileo in his old age had constructed a pendulum clock-he certainly gave a description of it ; and Young ${ }^{1}$ attributes to Sanctorius the same invention in I6r2. Neither the one nor the other came into any general use. The practical invention remained for a young Dutch investigator, Christian Huyghens, living at the Hague. He combined all of Galileo's skill for invention and the construction of telescopes with something of Kepler's genius for the divination of laws, something too of Kepler's mysticism and incorrigible tendency to dream. $\mathrm{He}$ patented his clock in 1657 , when he was twenty-eight years old.

A little later the celebrated Dr. Robert Hooke added the device of the escapement, and the observer of the heavens had in his possession a new weapon. It was far from perfect, however, even then. You gain some idea of its value from the fact that in the next century the British Government voted the clock-maker, Harrison, a reward of $£ 20,000$ for his perfectionment of the chronometer.

Huyghens' clock gave to the searchers of the heavens a means of reducing their observations to the same degree of accuracy in point of time as two other devices had given to their measures and localisations in space. These were the mounting of the telescope upon the index bar of a graduated instrument, first accomplished by the French astronomer, Morin, in I634; and the rigging of fine threads in the focus of the telescope to attain micro-metric divisions of the field

1 Lectures on Natural Philosophy, 1807. 
of view, introduced by Gascoigne and Auzout not long after. It was the combination of these which made possible the undreamed-of precision attained by Cassini and all his long line of successors.

Huyghens was not merely an inventor of clocks and a grinder of beautiful lenses; he was an astronomer and a thinker. With the telescopes of immense length which he constructed, he was able to discover the first satellite of Saturn and likewise clearly to reveal Saturn's rings. The discovery of the latter was likewise made before he was thirty, and published by him in an elaborate study. He made profound investigations into the nature of light; he was the founder of the undulatory theory. $\mathrm{He}$ had a wonderfully incisive mind, but an unbridled imagination as well. The fantastic Cosmotheoros, wherein he sets down his wild speculations as to the inhabitants of other planets and a hundred other things, reads like Kepler's Somnium Astronomicum. You catch a glimpse of the survival of medieval traditions, even to this late day, from his remark when he discovers Saturn's satellite. It is his idea that the number of planets and satellites having now reached twelve, and this being the perfect number, no more remained to be discovered. He would be puzzled, no doubt, could he return now to learn of five hundred more found since his day.

Beyond doubt Huyghens' most noteworthy work was his Oscillatorium Horologium, published in I673. Therein he describes in full the pendulum clock, and with it a number of important investigations into the theory of the pendulum and the allied problems of the motion of bodies in a curve. It was in this treatise that he announced the law of centrifugal force, obtaining a numerical measure for the tendency of a body moving in a circle to recede from the centre. He worked this out quite independently of any considerations of planetary motion. It was with him a simple problem in mechanics. $\mathrm{He}$ seems never to have thought of extending this principle to the motion of the bodies he had studied so successfully and so well. He was upon the very edge of the discovery of the law of gravitation. He made distinct contributions to the developing science of mechanics; he had an essentially mechanical mind, and half his life he had spent in the study of planetary motion. But so far was he from realising the 
consequences of his own studies and discoveries that thirteen or fifteen years later, when the law of gravitation was announced, great mathematician as he was, he pronounced it " absurd."

But with the clearance of the sky, with the emptying of space of any resisting medium to retard a planet's flight, with the development of mechanical ideas, mechanical formulæ, measurements of motion, it is easy to understand how there were other and younger men interested in the study of the stars, eager to apply the new knowledge towards a solution of the great problem. They would take up again the fascinating suggestions thrown out by Gilbert of Colchester and by Kepler, that there is a force acting outwards from the sun, holding the planets in their orbits, and decreasing probably in direct proportion to the distance from the centre of the system.

These ideas had by no means been lost from view. That they were in a sense current coin is evident enough from a passage in the Novum Organum. Though Bacon had ignored Kepler as he had ridiculed his own countryman, he borrows the ideas of both, to refurbish them as his own :-

"Again, if there be any magnetic force which acts by sympathy between the globe of the earth and heavy bodies, or between that of the moon and the waters of the sea (as seems most probable from the particular floods and ebbs which occur twice in the month), or between the starry sphere and the planets, by which they are summoned and raised to their apogees, these must all operate at very great distances." 1

As early as I645-that is, a year after the appearance of Descartes' Principia-a French mathematician, Bouillaud, endeavours to refute Kepler's idea that such a force would decrease in simple proportion to the distance, and shows that it would be as the square. But he seems to be as far as any from connecting up such a force with common gravity.

Borelli, in Pisa, attempts the problem. He is a disciple of Galileo, one of the founders of the famous Accademia del Cimento, which is the forerunner of the Royal Society, the French Academy of Sciences, and all their like; the author too of the celebrated book in which the principles of mechanics are first applied to animal motion. In his theory of the "Medician planets," the satellites of Jupiter, not published until I $665_{5}$ but probably written long before, Borelli speculates upon " a natural

1 Novum Organum (1620). 
inclination which the planets have to approach the central body round which they revolve, an inclination which is held in equilibrium by the force of their forward motion." This is not much nearer than Anaxagoras or Simplicius, though he offers an experiment to clinch his idea. $\mathrm{He}$ avoids the use of the word attraction, and he does not try to reduce the force of this inclination to any mathematical expression.

Along about I66o there is a company of gentlemen meeting in London to discuss all sorts of physical problems. Their head is the Honourable Robert Boyle, one of the founders of pneumatics, the author of the Skeptical Chymist, and often referred to as the founder of modern chemistry. Among others are Sir Christopher Wren, the architect of St. Paul's, mathematician, astronomer, and all-round man of science; Edmund Halley, future Astronomer Royal, then not long up from Cambridge; Robert Hooke, who begins as an assistant of Boyle's, reveals a marvellous capacity for experiment, becomes the author of a hundred inventions; one of those restless-minded investigators who scatter their fire and begin a hundred researches which others will take up and complete.

This company is the nucleus of the Royal Society; in 1662 Charles II., restored to the throne of the Stuarts, gives it a charter, and its great work is begun. In the very first year after its founding, it appoints one of its earliest investigating commissions to report on the subject of gravitation. Boyle is a member of the commission; already he is so thoroughly interpenetrated with mechanical conceptions that he likens the world to the wonderful clock in Strasburg - that is to say, like Descartes, he conceives it as a machine.

But what is the force which makes this machine go ? Evidently he does not see that it is gravity, about which the commission is to report, for the inquiry bears no fruit. But Hooke is restlessly fretting over the problem. As early as I666 he has a paper before the Royal Society, "On the Inflection of a Direct Motion into a Curve by a Supervening Attractive Principle." Seven or eight years later he had another communication to make which contains this remarkable passage :-

"I shall hereafter," he says, "explain a system of the world differing in many particulars from any yet known, but answer. 
ing in all things to the common rules of mechanical motions. This depends upon three suppositions :-

"First, that all celestial bodies whatsoever have an attraction or gravitating power towards their own centres, whereby they attract not only their own parts and keep them from flying from them, as we may observe the Earth to do, but that they also do attract all the other celestial bodies that are within the sphere of their activity; and consequently, that not only the Sun and Moon have an influence upon the body and motion of the Earth, and the Earth upon them, but that Mercury, Mars, Jupiter and Saturn also, by their attractive powers, have a considerable influence upon its motion, as in the same manner the corresponding attractive power of the Earth hath a considerable influence upon every one of their motions also.

"The second supposition is this, that all bodies whatsoever that are put into direct and simple motion will so continue to move forward in a straight line till they are, by some other effectual powers, deflected and sent into a motion describing a circle, Ellipsis, or some other more compounded curve line.

"The third supposition is, that these attractive powers are so much the more powerful in operating by how much the nearer the body wrought upon is to their own centres. Now what these several degrees are I have not yet experimentally verified; but it is a notion which, if fully prosecuted as it ought to be, will mightily assist astronomers to reduce all the celestial motions to a certain rule, which I doubt will never be done without it. $\mathrm{He}$ that understands the nature of the circular pendulum and of circular motion will easily understand the whole of this principle, and will know where to find directions in nature for the true stating thereof.

"This I only hint at present to such as have ability and opportunity for prosecuting this inquiry, and are not wanting of industry for observing and calculating, wishing heartily such may be found, having myself many other things in hand which I would first complete, and therefore cannot so well attend it. But this I durst promise the undertaker, that he will find all the great motions of the world to be influenced by this principle, and that the true understanding thereof will be the true perfection of astronomy."

You perceive how closely they are pressing the quarry. 
Wren and Halley as well as Hooke have worked it out that such a force exists, and that it acts inversely as the square of the distance. But all of them realise that they lack the decisive proof. They do not as yet see how this theory can be brought into agreement with Kepler's laws, as it must; they have many a debate on the subject. A few years later Hooke shows a curious experiment with a pendulum, which he likens to a planet going round the sun; but the thing is to prove that the path of the planet will be an ellipse.

One day, doubtless as a jest, Wren offers Hooke and Halley a book worth forty shillings if they bring him the demonstration within two months. Hooke declares that he has it, but he withholds his proof. Since it is not forthcoming, young Halley finally travels down to Cambridge to have a talk with one of the members of the Society there, a Dr. Newton, Lucasian professor of mathematics, a retiring and secretive man, who had already sent many interesting communications to the Society, his newly invented telescope as well.

There Halley finds that the whole subject had been worked out nearly twenty years before. Such, at least, is the accepted tradition. The story is so extraordinary that it is worth inquiring a little as to whether the tradition will altogether hold. 


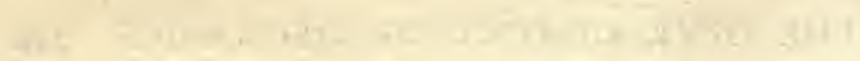

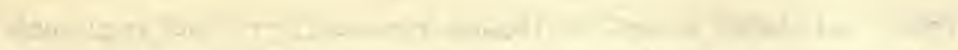

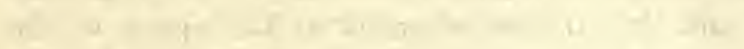

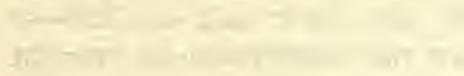

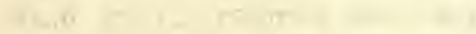

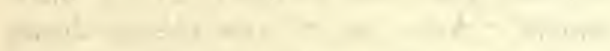

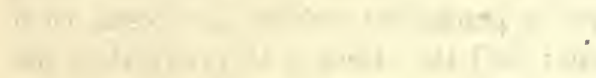

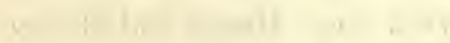

- it

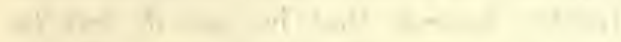

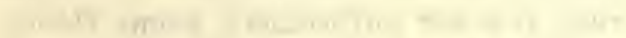

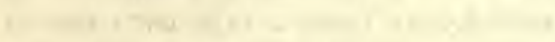

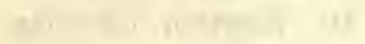

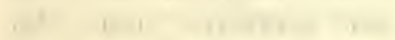

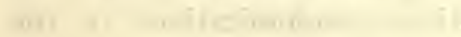

(1) the 


\section{CHAPTER XX}

NEW'TON AND THE MOTOR FORCE OF THE WORLD MACHINE 
THovgr the human mind will ever remain very remote from the mind imagined by Laplace, yet this is only a matter of degrees, in some measure like the difference between a given ordinate of a curve and another immeasurably greater, though still finite, ordinate of the same curve. We resemble this mind, inasmuch as we conceive of it. We might even ask whether a mind like that of Newton does not differ less from the mind imagined by Laplace, than the mind of an Australian or of a Fuegian savage differs from the mind of Newton. In other words, the impossibility of stating and integrating the differential equations of the universal formula, and of discussing the result, is not fundamental, but rests on the impossibility of getting at the necessary determining facts, and, even where this is possible, of mastering their boundless extension, multiplicity, and complexity.

DU BoIs-Reymond, Limits of Natural Knowledge. 


\section{CHAPTER XX}

\section{NEWTON AND THE MOTOR FORCE OF THE WORLD MACHINE}

In the idle days of the long gone by, and especially with the revival of learning, men were wont to indulge in disputes, often lively, sometimes acrimonious, as to the superiority, especially in matters of the intellect, of the ancients or the moderns.

Regard the matter as we may, among moderns at least the first place by a sort of common consent of mankind, without regard to nationality or calling, is awarded to Sir Isaac Newton. Without doubt, if one were asked to point to a single volume through all the ranges of literature, whether ancient or modern, which exhibits in the highest degree the powers of the human mind, one would fix without further thought upon Newton's Principia. It is amazing to reflect that it was as sheerly a product of chance as any event to which one might point.

Various letters make it clear that Newton himself had no intention whatever of writing the Principia, though he was forty-four when he began it. But for the accident of a visit from young Edmund Halley in I684, it is unlikely it ever would have been undertaken. Probably no book ever issued announced discoveries so great alike in number and importance; had it not been for the importunate urgings of his disciple, they probably would have been buried among Newton's papers, perhaps to be exhumed as curiosities long after his death. Newton himself would have been known to his contemporaries only as an amazingly ingenious mathematician who had invented fluxions, who discovered dispersion, and devised the reflecting telescope.

His life, unruffled by tragedy, hardly by events, was, in an outward way, as commonplace as that of a railway president. He was born in the year of Galileo's death. He came up to Cambridge in I660, the year of the Restoration, the year of the founding of the Royal Society, and while blind Milton, hunted by the partisans of the king, sought for a shelter for his head. 
The youth was rather more ignorant and uninstructed than most country boys, even from the Lincolnshire whence he came. He was of simple farm folk; his mother had done what she could to make him a good farmer lad like the rest, even to settling a small holding upon him. In the economy of events, fate had other uses for his wondrous brain.

As a boy, like Galileo, he spent most of his time contriving curious bits of mechanism, and devouring everything he could get hold of upon such subjects. He made sundials, he made water-clocks, windmills, and curious kites. It is even said that he devised a four-wheeled carriage to be propelled by an occupant; he may have constructed the first motor-car. They preserve a part of his sundial in the Royal Society. The thrifty, practical mother was in despair; she appeals to the parish rector, and the rector finds Master Newton one morning under a hedge studying mathematics when he ought to have been marketing the farm's produce in town. Evidently the rector had sense enough to see that such a boy had good stuff in him; and so on his advice Isaac gets a little schooling, and then is off to the university. Beyond a question he would have found his way eventually. As it is, it is a saving of time.

$\mathrm{He}$ has a boy's devouring mind. At the Stourbridge Fair he invests in a book on astrology, and is vexed to find that he cannot understand a simple figure in trigonometry. So the next he buys is an English copy of Euclid; and it seems to him childishly easy. Descartes' Geometry baffles him for a little; in the end, his opinion of it is not very high; note that he is then about twenty. Kepler's Optics fascinates him; so does a book on logic. There is an entry in his diary that at this same time he read Wallis' works. The item is significant. Wallis was at this time the most celebrated mathematician in England. He had just put forth a treatise on Gravity and Gravitation. This may have been a subject of Newton's reflections when, a year or so later, the plague breaks up the university term and he goes back to Lincolnshire, his head in a violent ferment with all the new knowledge that has come into it.

Already he has made three or four considerable discoveries : the binomial theorem, familiar enough now to every student of algebra ; the theory of infinite series which is to lead to fluxions -in our modern parlance, the differential calculus; he has 
worked out the theory of the moon's halo; he is deeply interested in astronomy and optics.

Precisely what set him pondering gravitation we do not know. In any of his own writings he makes no mention of the famous anecdote of the apple-that we owe to his niece; who told it to Voltaire, who embalmed it in the celebrated English Letters published a few years after Newton's death. The tree was there; no doubt the apple fell. It is more likely that the germ of his discovery lay in his reflections over Kepler's laws, or in some passage in Wallis. Among the Portsmouth papers an old manuscript has been found giving his own account -giving, too, a glimpse of the amazing activity of his mind at this time. It runs :-

"In the beginning of the year I665 I found the method of approximating Series and the Rule for reducing any dignity of any Binomial into such a series. The same year in May I found the method of tangents of Gregory and Slusius, and in November had the direct method of Fluxions, and the next year in January had the theory of Colours, and in May following I had entrance into the inverse method of Fluxions. And the same year I began to think of gravity extending to the orb of the Moon, and having found out how to estimate the force with which [a] globe revolving within a sphere presses the surface of the sphere, from Kepler's rule of the periodical times of the Planets being in a sesquialterate proportion of their distances from the centres of their orbs, I deduced that the forces which keep the Planets in their orbs must [be] reciprocally as the squares of their distances from the centres about which they revolve ; and thereby compared the force requisite to keep the Moon in her orb with the force of gravity at the surface of the earth, and found them answer pretty nearly. All this was in the two plague years of 1665 and 1666 , for in those days I was in the prime of my age for invention, and minded Mathematicks and Philosophy more than at any time since." 1

The account was written in after years, probably in his old age. It is not likely the discovery came to him with all the heavy armament of mathematical proof in which it appears in

${ }^{1}$ Quoted by Berry from the Preface to the Catalogue of the Portsmouth Papers. 
the Principia ; as a matter of fact the problem, if not the proof, was elementary. He had doubtless read Kepler's conjectures that the attractive force of the sun varies in some fixed proportion, simple, or as the square of the distance. Galileo had shown that under the force of gravitation the speed of a falling body increases with the square of the time. Perchance this same force of gravity, which the fall of the apple may have put in his mind, is the attractive force of the sun. It will be likewise the retaining force which holds the moon as well. The moon is about sixty times as distant from the centre of the earth as are we upon the earth's surface. If the force of gravitation projects outward to the moon, and it varies inversely as the square of the distance, then the earth's pull upon the moon will be just $\frac{1}{300}$ what it would be at the earth's surface. If, under the influence of this force, bodies fall in proportion as the square of the time, then the moon in a second will fall towards the earth a distance proportional to the square root of 3600 -in other words, at sixty times the distance it will fall as far in a minute as a body at the earth's surface does in a second.

As the story goes, this lad of twenty-three tries it, taking the then accepted figures as to the diameter of the earth and, accordingly, the distance of the moon. It does not work out. It ought to fall sixteen feet per minute; the calculation says less than fourteen. A man like Kepler, feeling the discovery so near, would have worked at it night and day, as he did at his Laws, for years and years. Newton was not metal of that temper. He put his calculations aside. He does not doubt that the law of duplicate proportion, as he calls it, is involved; but it may not be the whole explanation. Possibly Descartes' vortices, with visions of which his head no doubt is then full, may play some rôle! Evidently for him Torricelli's experiment has yet not swept clean the spaces of the sky. It is strange that he thinks of the matter as of so little importance; but in truth his head is then full of questions in optics. As soon as he gets a chance he will be buying prisms and lenses, inventing telescopes and discovering the spectrum. Consider that all these ideas come before he is twenty-five, and you will scarce wonder if he hardly sees the drift of some of them himself.

Five or six years after, Picard made a more accurate measure of the size of the earth ; it appears that it was some years later still when, in London, Newton hears a discussion in which the 
new measures of the earth are related. He is stirred up to try anew. He goes back, rummages out his old papers, and begins again. As he foresees that the calculations will verify his surmise, his hand trembles so that he must lay down his pen. Still he does not publish his results. He has had annoying controversies with Hooke and others respecting the originality of his invention of the reflecting telescope, his discovery of the composition of white light. He seems to care little for publicity, and disputes disturb the pursuits of his peaceful life. Thus it is that four or five years later yet, when Halley comes down to inquire as to what will be the path of a body acted on by force of attraction varying inversely as the square of the distance, Newton is able to reply promptly, "An ellipse." How does he know ?- "I have proved it." Halley travels back to London big with the news of the great discovery. Newton cannot find his papers just at the moment, but sends them a little later. A little later still, under the reiterate urging of Halley and the ofhers, the Principia is begun.

Such is the classical tale as you find it in Brewster or the encyclopædias. The history of perhaps the most far-reaching single discovery in the whole range of scientific development is assuredly worth knowing, and correctly, if that be possible. We may believe with Rosenberger, whose learned and impartial monograph ${ }^{1}$ considers the question at length, that the story of the apple is doubtless a myth ; likewise that the reputed discovery in 1665 was rather one of those ideas which boom into the teeming brain of youth, to be put aside or forgotten as easily as it had come.

That Newton should be consciously so near the solution of so vast a problem, then give it up because the figures do not quite agree, does not fit with his character. His tenacity was extraordinary. Afterwards, to test out whether or no the law of gravitation was of universal application, he tries with his own hands every kind of substance which he may lay hold of. Even in 1665 the measures of the earth, which are said to have led him astray, were out of date. It is scarcely believable that a man of his original and investigating mind would have been content to accept the erroneous figures without further question, when the error was so slight, and when he, moreover,

1 Newton und seine Physikalischen Principien. Leipzig, 1895. 
knew that many different estimates had been made. The truth seems to be that the law of gravitation had a gradual development in Newton's mind; when the originality of his discovery was called in question perhaps he yielded to an impulse, natural enough, to date it back as far as his earliest conjectures.

There are doubtless few things in this world more hopeless than to attempt a just estimate of character, let alone that of Newton. We read with a smile the easy pages in which a Macaulay and his like lifts to his pedestal a venerated Whig and damns to perdition the hated Tory. Whoso will but attentively watch the flux and changes of his own interests, impulses, motives, deeds, from day to day, from year to year, from one period of life to another, will hardly be so ready with his judgments. When Newton's Principia appeared, Hooke promptly put in a claim to priority. It was the second of their encounters; he was a battling man. Newton was annoyed and disgusted. They had had an extended correspondence over planetary motion. Newton's work appeared years after Hooke had suggested, if he had not demonstrated, the central law which gave the book its fame. Hooke was aggrieved that it should contain no mention of his claim; possibly Wren and Halley had something of the same feeling regarding themselves.

In the controversy that followed, the character of Newton does not shine. He did not have that breadth of mind which enabled Kepler generously to applaud the discoveries of his friend Galileo, nor that magnanimity which enabled Darwin to give to Wallace an equal place beside himself in the discovery of the origin of species; the fact is rather painfully evident. In small charities, he was generous beyond his slender means, to relative or stranger. Towards his contemporaries he seems to us, at this distance-perhaps, as we may gather, to his friends as well, rather grudging.

In after years a still more serious controversy, bitterly to be carried on by partisans long after his death, was to arise over his discovery of the calculus. Alike in this as in the others he discloses a human weakness to hold, unaccompanied, the centre of the stage. In a second edition, the more generous Halley induced Newton to make some recognition of Hooke ; but he will minimise the claim of the latter so far as he may by dividing the recognition among all three-Hooke, Wren, and Halley too. 
It is quite probable that Newton did not realise at their just value the contributions of others. His own ideas, as we know, were icily clear; he thought things out until every trace of turbidity was lost. Probably he had a very human impatience with that confusion of thought which all of us find so troubling in the mental processes of others. Hooke's ideas never reached complete clarity.

That a letter of Hooke's was the especial incitement which led Newton to take up his old calculations and conjectures and give to the law complete and irrefragable proof that will last with time, seems clear from Newton's own letters. That Hooke was deserving of much credit is certain. That the law would have been discovered within a very few years without a Newton is patent beyond question. But Hooke did not write the Principia-Newton did. In the Principia the law of gravitation is not put forth as a special fact-it is but a part of a vast scheme. What Descartes bravely attempted Newton achieved. With the aid of a single principle he disclosed our planetary or solar system as a vast yet simple mechanism, all of whose motions were not merely fixed but calculable. This principle he applied everywhere, alike to the flight of the planets, the revolutions of their satellites, the flux and reflux of the waters of the earth. In the Principia, the human intellect reached for the first time a clear mental presentation of the workings of the world amid which its dream-like existence is passed. So far as the mechanics of the solar system is concerned nothing of consequence has been added since, and nothing has been taken away. It is this, and not simply the discovery or the proof of the law of mass-action, which is the true glory of Newton.

Yet the discovery alone was a great deed. Its precise nature is often strangely befuddled. One may read in many a book that Newton did not discover gravity but simply the law of its action-that the force of gravity had been known for thousands of years. This is trifling. What Newton discovered, and demonstrated, was Attraction, not merely by the law but the fact, not merely the attractive force of the planets but of all matter whatsoever, from a molecule to a moon, from a grain of sand to the colossal mass of the sun. This discovery was wholly independent of gravity or any other consideration. It was, and might so have remained, complete in itself. So even does it appear to have been for a time in Newton's own mind. 
The identification of the force of attraction with the well-known fact of gravitation constituted a second great step, a second discovery. It was simply an incident that they came together. Either the one or the other would have brought a large meed of fame.

These two discoveries and the statement of their underlying Law are the foundation of the Principia.

It is not easy now to realise the vast stride forward which the publication of this single work represents; it is equally difficult to separate out what was wholly Newton's own. It was not a large book, five hundred pages or so, so replete with diagrams that it looks like a geometry. The impression is further borne out by the fact that it is written in the style and language of Euclid, proposition succeeding proposition in an unbreakable chain; it is the application of Euclid to the astronomy of the heavens. It is in no sense historical ; reference to the specific work of others is sparse; it might readily be used as a textbook in a university. Without a precise knowledge of the state of the science when it was written, one might readily believe that none, or all of it, was new.

Newton had a mind that was at once comprehensive and synthetic, a gripping mind that made the whole cohere. It was he first of all who foresaw the consequences that followed from the law he had demonstrated. The moon is held by the earth, the satellites by Jupiter, the earth and other planets by the sun, in virtue of the force of attraction. This attraction varies directly with the mass of matter contained in each planet. He introduces, therefore, a new conception-that of mass as distinguished from mere weight. In the mind of Galileo this separation had not yet taken place. Newton saw and stated the logical inference-that is, that between every ultimate particle of matter in the universe there exists an inherent force or power which tends to draw them together, a power that grows less with the square of the distance which separates them. Consider that there was scarce a contemporary, or any one for some time after, who could grasp this simple, central truthnot Huyghens, nor Leibnitz, nor Jean Bernouilli, nor Cassini, great mathematicians all-the greatest of the time, and you will see how far this single mind outstepped its age.

Newton was not merely the founder of celestial mechanics 


\section{MOTOR FORCE OF THE WORLD MACHINE 26I}

in the broadest sense-he was the founder of molecular mechanics as well. He gave, moreover, to general mechanics the last of the great conceptions needed for the perfection of the science ; he saw that action and reaction are equal. This, applied to planetary motion, gave a complete explanation of the curious perturbations of their orbital motion, long observed and mapped out, but until then inexplicable. It was not merely that the earth attracts the moon; the moon in proportion to its mass attracts the earth and gives to its daily revolution the form of an eccentric. Could we watch it spin, we should see its axis wobble about a centre just as does the eccentric of a steamengine. This same pull of the moon, exerted upon the unequal shape of the earth, gives to the direction of its axis the peculiar disturbance known as nutation, which will be discovered a few years later by Bradley. The combined pull of the sun and the moon, acting on this same uneven mass, produces the second displacement of the earth's axis, to which the precession of the equinoxes, discovered by Hipparchus, is due.

Newton saw that the moon is attracted not only by the earth but by the sun as well; hence its orbit will not be a true ellipse. By this means he explains and works out many of the disturbances of the motion of the moon, the variations in its inclination and the like. From the developments he had given to Kepler's laws he perceives that, knowing the distance of any body and the time of its revolution, he may calculate its mass in terms of the central body; he calculates the mass of the moon, and, further than this, lays the foundations for a second means of verifying the calculated distance of the sun itself; further yet, the mass of the sun. With this method, from careful observations of the variations of the planets from their natural paths as they react upon each other, it will one day be possible for Leverrier to determine at what distance the sun must be in order to produce the precise effects which it does.

Newton laid the foundations for a knowledge of the true figure of the earth, and calculated that figure in its main details. He foresaw from the observed effects that the earth could not be a perfect sphere, that it was flattened at the poles, that its equatorial diameter was greater than the polar diameter, and that therefore the force of gravity at the poles was less than at the equator. He thus pointed out the path whereby in after 
days mathematicians might work out the origin of the earth and of the solar system as well.

He explained the tides. Poseidonius had done that in a way; Newton gave the mathematical theory of the tidal flow, calculated how much was due to the moon, how much to the sun, explained why it was that the spring and autumnal tides were higher than at other times, by the conjunction of the attractive forces of the two bodies. Further consequences of his discoveries: he perceives that from their observed shapes it was possible to estimate the time of rotation of the planets -that is, the length of their "day." Thus Jupiter, despite its huge bulk, a thousand times that of the earth, has a much more violent rate of revolution; its day is less than half our earthly day.

And these are but the important matters of this kindling book. It was a wonderful advance; you perceive that there was comparatively little left for those who were to come after. This is not saying that he made no mistakes; they were astonishingly few. It is not saying that he had wholly exhausted the subject; Laplace, Lagrange, and many another were yet to come; but the fact remains that in the essential theory neither discovery nor subsequent investigation has effected any radical change. The system of the world now taught to school children is the system of Newton. Perhaps the larger number of present-day works upon physical astronomy are a digest of the Principia.

The work appeared within two years after it had been begun. Originally the Royal Society intended. to defray the cost of its publication; its funds ran low; Halley put the book through the press out of funds from his own purse. He became thus not merely the godfather of the Principia; it was his ward as well. The outlay involved a sacrifice; it is pleasant to know that eventually he made well from his venture. It was written, of course, in Latin. Like Bacon, unlike Galileo or Bruno, Newton did not trust to his mother-tongue. England was then regarded by the rest of Europe as a half-barbarous land. Even Shakespeare was unknown. An enlightened continental as little thought of learning English then as he might think of acquiring Hungarian now.

The Principia brought its author neither to the torture chamber nor the stake; they gave him a Government post 
at a salary of $£$ I500 a year instead. The times had wonderfully changed. Revolution and counter-revolution, the wars of Catholics and Anglicans and Independents, had left England the freest country in Europe. The reign of Charles II. was a sort of Golden Age in English science. Weak and profligate monarch as he was, the kingdom prospered. The toleration he had encouraged was the downfall of his successor. The Principia came forth a year before the quietest revolution in English annals. Instead of Galileo's prison, when they began to realise Newton's greatness and found that he was poor, they gave him a position first of Warden, then of Master, of the Mint. The Royal Society soon elected him its president-was proud to retain him there through four-and-twenty years. He enjoyed his fame ; the anchorite and recluse became a good liver ; death did not reach him until the ripe age of eighty-five. They throned him in Westminster Abbey; peers carried his pall. It was a singular contrast from the fate of his great forerunner, who had died the year of Newton's birth, banished from association with his fellows, imprisoned and disgraced, at first denied a decent burial.

Yet the work of Newton was far more atheistical than that of Galileo. Leibnitz, then rising to his place as one of the most widely read philosophers of Europe, declared that " $\mathrm{Mr}$. Newton robs the Deity of some of his most excellent attributes, and has sapped the foundations of natural religion." No matter; it is a Cambridge divine who translates the Principia into English and becomes one of its warmest defenders. There arose in the English Church a sort of school, bent on establishing a new theology, based upon the new conception of the world as a mechanism. You see a last expression of it in the famous work of Paley.

Curiously enough, in this development of his own philosophy Newton took no part. He spent a goodly share of his remaining days writing theological dissertations and tracts. They betray no gleam of the new light he himself had brought. Coming from such a mind, they are amazing products; they would be inexplicable if we did not know of the unhappy fatality which befell him shortly after the publication of the Principia and to all intents closed his scientific career. There seems to be little doubt or question that the strain which the production of the Principia involved told heavily upon Newton's strength. 
Few men ever had greater powers of absorption in their work. In his waking hours he was literally lost in calculation and thought. Often he forgot to eat, sometimes to finish dressing in the morning after he had arisen.

This intense application, evidently, brought on an illness. For a time there is little doubt that his mind was clouded. There was a natural effort, alike on the part of friends and subsequently by admiring biographers, to conceal or minimise this. His own letters and the testimony of those who visited him leave no question as to the fact. He recovered his health, but never the vast powers of his intellect. At forty-five his work was done. Years after, with the help of younger men, he brought out a second edition of the Principia. His work on Optiks was not published until I704; it had been written long before; the delay was due purely to his controversy with Hooke.

The Principia had appeared on the eve of a dramatic revolution in the political world; in its own world it produced none. The history of science is rarely spectacular. One might readily think that such a work and such a man would have given rise to a great school which for a long time after would have ensured the precedence of England in the scientific advance. They did nothing of the sort. One wonders less, when considering this, that the bold theories of Aristarchus should have seemed to make so slight an impress in the Alexandrian days. For a century after the Principia there is hardly a single great discovery in English astronomy. Newton's work was taken up, carried on to the last perfection of its details, by the mathematicians of Germany and France.

Highly regarded in England, it was yet forty years before the Principia began to take effect on the Continent. Near a half-century after its appearance, the French Academy of Sciences, the most considerable body of its kind then existing, was awarding a prize for the paper in which the movements of the planets were explained on Descartes' theory of vortices -tourbillons. And the award was to Jean Bernouilli, one of the three or four foremost mathematicians of the day.

But what the impervious academic mind could not understand, the freer mind of the laity might. So it was to a layman, to the celebrated Voltaire, largely, that Newton's European fame was due. A refugee in England, that myriad-minded 
prestidigitateur had learned to admire English institutions and English thinkers. When, with a comfortable fortune acquired in clever speculation in corn, he was allowed to return, it was to publish his celebrated Lettres Philosophiques sur les Anglais, and the Epitome of the Newtonian philosophy. European thought was still dominated by the fantasies of Descartes. In the battle royal that followed the militant pen of the Newtonian protagonist found an able lieutenant in his charming companion at arms, the learned and amiable Marquise du Chatelet. It was the latter who translated the Principia into French, adding thereto a highly creditable commentary of her own.

Newton's neglect or disregard of feminine society or association during his life appears to have been complete. It was his fate to be introduced to the larger audience of Europe through the pen of one of the most interesting adornments of her sex. The volume of Madame du Chatelet to-day commands a considerable price, testimony to one of the rare episodes in philosophy touched with any colour of romance.

As to the judgments of Newton's immediate contemporaries, it scarce needs be said, since the fact is universal, that their rejection of the ideas of the Principia was all but unanimous. Strangest of all was that of Huyghens, whose law of centrifugal force was one of the strongest weapons in the Newtonian argument. It was simply the old story; for mystery Newton had substituted simplicity and law, and to mystery purblind authority will cling so long as it may. But soon the generation of rejection will pass; a newer generation will come which accepts. In another century a man who doubts what the greatest mathematicians, thinkers, and philosophers in Europe had doubted or flouted will be regarded simply as a fool.

What Newton taught will not cease to be the truth so long as the world lasts. Unto him it was given to unveil a secret of the universe. Until Newton came man could scarce have any rational conception of the world into which he is born. The event was worthy of the sumptuous phrase it found in the epigram of Pope :-

"Nature and Nature's laws lay hid in Night; God said, Let Newton be, and all was light."

There yet remained an absorbing mystery which must be solved before the description of the celestial machine was com- 
plete, before all of its parts and its workings could be accounted for. It seems slight enough to our modern time, rubbed so clean of der Sinn für das Wunderbare," the sense of the miraculous," which was the native hue of the mind of our forbears. It did not seem so then.-What were the argent flames, sometimes soft and nebulous, often dazzling and vast, which come by times across the quiet heavens ? 


\section{CHAPTER XXI}

\section{HALLEY AND THE MESSENGERS OF}

THE GODS 
The human mind enjoys to-day an enormous possession of ideas, heaped up, selected, sifted out by the centuries. The multitude of men have disappeared without contributing to this store a jot. Those who have had the fortune to add something, to leave something, should have their part in the glory and the recognition which is their due.

BaIlly, Histoire de l'Astronomie Moderne. 


\section{CHAPTER XXI}

\section{HALLEY AND THE MESSENGERS OF THE GODS}

As we wander nowadays among the broken pillars and mouldering columns which tell of the grandeur that was Rome, the time seems long. Yet may we hardly doubt that, could we be transported back to the days when these were palaces, arches and temples of marble, we should find a civilisation and a society which in its polish, its elegance, its urbanity of manners, its scepticism and audacity of thought, would differ from our own only in the minor essentials of a different fashion of dress, of speech, of dining, and their like. Some things have changed, however, and one of these is the singular belief-singular now to us-in signs, in portents, haruspices, good and evil omens.

Cicero was a highly enlightened man, dipping into all the science of his time, writing out his views in a sensuous and flowing Latin whose charm the intervening centuries have not dimmed. On fate he wrote like a philosopher; on divination, the reading of the future from the entrails of chickens or the turn of a sieve, he wrote with a faith that one might expect to find in a fishwife or a child. $\mathrm{He}$ is hurt because the great Democritus, whom he so much admires, should treat the subject so lightly; he adduces a whole row of names of the eminent and the learned to indicate how wrong it is of the Abderan sceptic to consider so little a belief which had been unquestioningly entertained by so many excellent minds. The views of Cicero were but the refinement of the gross superstitions which then dominated not merely the cultured society of Rome, but the whole world. You perceive it in many ways.

The death of Cæsar was a momentous event; by common suffrage he was voted a god; the shows and pageants of earth seemed too slight to do honour to the passing of this god-like man. As heralding his demise, does not Horatio tell us in the play :-

"The graves stood tenantless, and the sheeted dead

Did squeak and gibber in the Roman streets." 
Shortly after his assassination a flaming apparition visited the sky, a vast and graceful trail of light. It shone so brilliantly that it could be seen for several hours before sunset. It held its portentous way in the heavens for eight days, then disappeared. Small wonder that the Romans should have given to this effulgence the name of the Julian Star, and regarded it as a celestial chariot sent to convey the soul of Cæsar to the skies.

These apparitions were not uncommon; the terror they inspired was sometimes beyond measure. In the year 1456 came one of unwonted splendour. Constantinople had just fallen before the invading arms of the Saracen. "The apparition," says Draper, " was considered a harbinger of the vengeance of God, the dispenser of the most dreadful of his retributions, pestilence, famine, and war." By order of the Pope, all the church bells of Europe were rung to scare it away; the faithful were commanded to add each day another prayer. As they said their Ave Maria, they joined to their supplications to the Holy Mother the words: "Lord save us from the devil, the Turk, and the comet."

In the year IgIo one of these flaming messengers will appear in the sky; the time of its coming will be calculated perhaps to a day. The faithful will not fall upon their knees; no new prayers will be said; the church bells of Europe will not ring. It will not be regarded as a portent of famine or war; if the greatest of living statesmen dies upon its approach, it will not be thought of as a special vehicle to waft heavenward his soul. What has wrought the change?

The answer may be a little technical, but we may say with some approach to accuracy, Newton and his law of attraction. Up to Newton's time the comet was still a mystery. Its appearance inspired an instinctive dread in even the stoutest hearts. In the year I680 came a wonderful specimen. Newton watched it rush downwards towards the sun, spin round about it in an abrupt turn, then rush away again and disappear from sight. He did not tremble; he observed. Then he calculated. Newton, despite his theologising predilections, had a very concrete and material sort of mind; he reflected that if this apparition were of a material nature it must be subject to the influence of gravitation and obey the formula whose secret he had seized. It would then move in one 
tiles; the sun would be in one focus, and following out Kepler's law, its radius vector would cover equal areas in equal times.

The observations made from different points were carefully examined; the path of the orbit, so far as might be, was plotted; it answered in every way to Newton's anticipations-it obeyed a law of expectancy. Thereafter the mystery of the comets was gone. From that time onward their paths and the date of their return, should their paths be of such a shape as to bring them back, was simply a matter of mathematical reckoning. Newton found that the comet of 1680 moved in an orbit so near to a parabola that its period was some hundreds of years at the least. Later observations tended to indicate that its path might be that of a very much drawn out ellipse. If this be true, it will return in some three centuries, probably around the year 2255. If this idea of its periodicity is correct, it had appeared previously in IIo6 and in 53I A.D.; it would be the same which bore Cæsar to his resting-place among the gods.

Newton was not the first to suspect that the comets might move in orbits like planets. Kepler had so surmised. In his day there came a very splendid comet, afterwards to acquire an especial significance as the first of these apparitions whose orbit was reckoned and its predicted return realised. In the year I6I8 there were three more. Kepler made a book about them, speculating concerning their nature in his wild and unrestrained way; but in this as in so many others, coming wondrously near to the truth. His master, Tycho, had been deeply interested in the subject, had likewise written a book upon them. It was Tycho, indeed, who first showed from accurate observations that these apparitions are not generated within the earth's atmosphere, as had so long been supposed, but that they come from beyond the orbits of the planets. It was his boast that by means of his observations he had destroyed for ever the seven-and-seventy solid crystalline spheres which the ancient imagination had invented to account for the movements of the planets and the stars.

Tycho did not see that they travel in orbits, but he held firmly to the view that they were celestial and not terrestrial bodies. Following him, Kepler accounted for their appearance and disappearance by supposing that they moved in straight lines; having once passed near the earth, they would then recede indefinitely into space. He did not seem to think it 
worth while to test out his theory by actual observation. Had he done so he might easily have anticipated Newton. But he reflected upon the fact, noted by Fracastor and others, that the tails of comets point always away from the sun; he explained this on the supposition that the tail is formed by rays of the sun which penetrate the body of the comet and carry away with them some portion of its substance.

We do not think of light as a hail or bombardment of extremely minute corpuscles as Kepler did, and Newton too; but with this difference, his theory was in close coincidence with our modern ideas. Within the last two or three years it has been shown that, as Maxwell predicted, light may exert a pressure, even though it be a form of motion and not a substance. It is apparently this pressure which swings the tail of the comet around so that the body of the comet usually points towards the sun.

Galileo got no further. But two years after the appearance of the great comet studied by Newton, came another. From careful observations, Halley was able to compute its orbit in accordance with Newton's principles. In I705 he too published a work on comets, in which no less than twenty-four orbits were calculated. He had been struck by the resemblance between the paths described by the first of these and one of seventyfive years before. Looking through the old records, he found mention of another in I53I and again in 1456 ; he conjectured that they were perhaps all of them but different appearances of the same comet, revolving round the sun in a period of about seventy-five and a half years. Inspired by this coincidence, he stepped out into space, as it were, and watching its path with the eye of the imagination, predicted its return in 1758 .

Truly a splendid flight of the mind it was, thus to throw off the heavy shackles which tie us down to the here and now, and sweep through the centuries, backwards through history, forward through history yet unmade ; but his faith was justified. Not only did the comet reappear, but long after the soul of Halley had followed that of Cæsar, in the common way of all our human kind, the mathematician Clairaut, utilising the materials he had left, calculated its return within a month. It returned again in I835, its appearance this time being predicted within three days. The existence of the planet Uranus, which had been a disturbing influence in the previous calculations, 
had in the meantime been discovered and its effect measured. This is the comet which in all probability will return again in I9Io.

Four others are now known which revolve in an elongated ellipse like Halley's comet, with a period of between seventy and eighty years; about twenty-five are known with lesser periods, and perhaps as many more with periods of over a century. Altogether the paths of upwards of two hundred comets have been plotted in whole or in part. So much, then, is known, that they all obey the same laws as the planets; they are therefore material substances and under the domination of a simple mechanical law. So far from being a stumblingblock towards the acceptance of the theory of attraction, they have been a help to show its universal application. Their appearance is to-day no more of a mystery than the daily and hourly flight of the earth through space.

Whatever be the substances which compose the comets, they are in an exceedingly tenuous state. Their tails are often millions upon millions of miles in length; sometimes they reach clear across the orbit of the earth. This implies necessarily an enormous amount of matter of some kind; nevertheless it is so thinly distributed that very often on a clear night we may look quite through these nebulous masses and see the stars shining in their customary way. Even the slender flicker of light from far-distant suns suffers little obstruction in passing through them.

Moreover, it is now known that the earth has twice shot through a comet's tail ; so little disturbance did it create that the fact was only made clear from calculations after the event. Still again, the comet of 1843 swept so swiftly about the sun that it had made the turn from one side to the other within a couple of hours. In order to accomplish such a feat the speed must have been something so enormous, that beside it the earth, at nineteen miles per second, would seem to creep. And this was simply for the head of the comet; if the tail of the comet, which was unusually long, followed the usual observed actions of comets' tails and pointed away from the sun throughout the curve described by the head, the rate at which its particles moved would have been simply inconceivable.

The obvious inference, therefore, is that the tail is not a 
permanent part of the comet at all, but that, as Kepler had partly guessed, it is simply a stream of matter driven off from the head, or nucleus, by the pressure of the sunlight. It would be more tenuous than any mist or vapour we may conceive. It would bear perhaps the same relation to the comet proper as the thin line of smoke and flaming cinders thrown out by a flying locomotive to the locomotive itself. This inference seems fairly substantiated by the fact that the tail only appears as the comet approaches the sun; when at a great distance the comet represents only an indistinct patch of nebulous light. Finally, if this view be correct, we should expect to find that the shortperiod comets which sweep around the sun every few years or so would, through a long series of observations, show a diminution in their volume, owing to the quantity of matter driven off into the tail and left in space. This is precisely what has been found.

It remains, then, merely to find out the nature of the nucleus, or head, and the mystery of these fiery portents is completely solved. The question has a double interest from the "fact that it may shed some light upon the stuff of which the universe is made. While the great majority of the comets appear to describe closed orbits, some certainly do not. They are simply drawn into our solar system by the chance of having come within the clutches of solar attraction in their flight through space. They appear but once, and then are gone for ever. Could we but know their chemic composition, we should know a little more than we do of worlds beyond our own. It is only within the last thirty or forty years that the clue has come.

It was unexpected in its simplicity. Watching the heavens by night, the eye is often thrilled by the spectacle of a gorgeous flash of light which we are wont to call a shooting-star. Sometimes, as we know, these shooting-stars come in a kind of a shoal ; we speak of these as meteoric showers. As a rule the headlong dash of these bodies through the earth's atmosphere generates so fierce a heat that they are dissipated into vapour, and their substance is left to float about in the air as a part of the dust which gives the sky its wonderful hue of blue. Eventually it settles down to the earth ; and this, it seems likely, is the origin of the fine metallic dust which will cover snow-fields even of far northern climes, where the atmosphere is of the purest and where smoke and dust seem almost excluded. This surmise has ap- 


\section{THE MESSENGERS OF THE GODS}

parently been confirmed in a very simple way. Merely by melting down a quantity of long exposed snow, in filtering it out are found once molten globules of iron and other materials, as well as larger bits.

Occasionally, however, there comes a shooting-star of great bulk which plunges through the atmosphere like a glowing ball, to bury itself in the earth with a loud report. These are the great meteoric stones, some of which have been known to weigh many tons. Fine specimens are usually to be found in the natural history museums. They may be assayed or analysed chemically, precisely like any other bit of rock. They contain no new kind of material, no element which is not found upon the earth. If therefore they come from the far depths of space, the material of the universe is all the same.

It was a splendid surmise. But what reason have we for supposing that they do come from outside our solar system, and what have they to do with comets? The curious answer is that these meteorites or shooting-stars are simply little comets ; the great comets seem merely vast swarms of meteorites. If the comets come from beyond the confines of our system, the meteorites probably do the same. We have fair evidence that with some of them this is the fact.

It is strange how little interest the subject seemed to have inspired until the discovery made by Professor H. A. Newton, of Yale University in America. Tracing out all the records of meteoric showers which he could find, Professor Newton arrived at the conclusion that some of these showers at least had a definite period. In particular, there seemed one shoal of meteors through which the earth passed, in November, once in every thirty-three years. He could find an apparent record of this swarm back to the year 599 A.D. Their last appearance, when he had counted them up, was in I833. Following the path of Halley, he boldly predicted their return in I866 or the year following.

They came just as he had calculated. They did not appear again in 1899 , but came straggling along two or three years later, and the display was far less brilliant than in '66. It seemed as if the shoal had to some extent been broken up. Nevertheless there seemed no mistaking the fact that these shooting-stars move in an orbit like the planets. When this especial shower appears, its radial and axial point in the heavens is in the constellation Leo; hence their name of the November Leonids. 
The swarm is enormous in extent, almost countless in number. The display lasts for four or five hours; this means that the earth, shooting along at 70,000 miles per hour, requires this length of time to cover it from side to side. Its velocity of motion has been calculated; it comes out, at least in the earth's atmosphere, at twenty-five miles a second; yet it takes nearly three years for the whole swarm to pass a given point. So, in a rough way, we may compute its size. The breadth of the swarm is greater than the distance from the earth to the moon; if its speed in space is the same as near the earth, its length is many times the distance of the earth to the sun. Perhaps if we conceive a shoal of fish, some large, some small, some not so big as tadpoles, rushing along at twenty miles per second-a shoal perhaps several hundreds of millions of miles in length-we may form some picture of how they might look, could we see them as a whole. We cross the orbit of this swarm every year, yet it is so tilted to that of the earth that it is only once in thirty-three years that we encounter this enormous mass.

When the orbit of the Leonids was laid down in a diagram, it was found to bear a close resemblance, in its general form, to that of comets like Halley's, which move in a very long ellipse. The instant conclusion was that there is an intimate relation between these meteoric swarms and the comets. This became a practical certainty when the paths of four different swarms were computed and found to agree closely with the paths of known comets.

One of these comets had an extraordinary history. This was Biela's, a carefully observed teleścopic apparition, making its round of the sun once in six years. It was duly observed on several successive returns; but along about 1846 it was calculated that, at its next revolution, it would come very near to Jupiter. Naturally there was a great deal of wonderment as to what would happen to Jupiter, or the comet. It was the idea that we might see, as on a stage, the representation of what would happen, in case, as the old-time terror had so long anticipated, a comet should strike the earth.

When it came again, it was seen that Jupiter was not destroyed; but the comet itself seemed to have been cut in two. Both portions of the split-up comet appeared again in 1852 ; but in 1858 it was nowhere to be found. The astronomical authorities duly sent out notices that kindly disposed individuals 
might give any information they might be possessed of as to the whereabouts of the lost comet. It never reappeared.

But the orbit of the comet was well known, and it was calculated that in 1872 the earth would just about cut across the point where the missing comet ought to appear. The night came, but no comet. What did come was a shower of shootingstars. The same thing happened in 1885 . There seemed no mistaking the fact that Biela's comet had gone to pieces; it had simply degenerated into a meteoric swarm. It does not stand alone. Brooks' comet of 1889 was found to be accompanied by three smaller companions, and as this comet often passes very near to Jupiter just as did Biela's comet, it seems likely that it is undergoing the same disintegration.

Probably the same thing is going on with several others; it is yet too early to know. The subject is new ; but there seems little reason now to doubt that the meteorites are simply comets in decay, the stragglers of a lost battle, and that on the other hand the comets are vast swarms of these meteoric stones. The evidence of the spectroscope makes this a practical certainty.

It is of interest to know that, at least in one instance, it seems probable that these meteoric swarms, like some comets, have been incorporated into our system within historic times. The great French mathematician Leverrier, in calculating the orbit of the November meteors, found that it was an oval extending out beyond Uranus. The paths of the comets are disturbed by the attractive influence of the planets ; calculating back the past positions of the Leonids, Leverrier came to the conclusion that under the influence of Uranus the form of its orbit had been completely changed. Very likely it once described a parabola about the sun; it was, therefore, in all probability a comet moving through space which closed within the grip of the sun or of one of the outer planets. It would have been torn to pieces by their combined influence, pulled and hauled about until it had lost its great velocity, and was but the rags and tatters of its former self. On Leverrier's calculations it entered the solar system a century or so after the death of Cæsar, that is, in the year I26 A.D. It was a beautiful piece of computation, not so brilliant perhaps as another which we shall meet with soon, but surely calculated to excite admiration for the perfection of the astronomer's art.

But the study of meteorites and the paths of the swarms 
was to lead to something more than a striking exhibit of the powers of calculation. The bombardment of the earth by the meteorites is incessant; we see them, of course, only at night ; but the hail of these bodies, large and small, continues through the day as well. One careful series of counts was made which indicated that the number may reach fifty or sixty thousand in each twenty-four hours, perhaps twenty millions in a year. Most of them, of course, are very small. Taking an average, Professor Newton, who virtually created the modern view of meteorites, calculated that the earth in its flight sweeps up a hundred, or it may be several hundreds of tons of meteoric matter per day. It is not a great deal, perhaps, set against the vast bulk of the globe. In a million years, perhaps, they would not at this rate cover the whole surface of the earth with a layer more than an inch thick. But their number probably is growing less year by year; it may have been far greater in the long ago. If we prolong our vision far backward, through geologic time, through hundreds of millions of years, we see that the cumulative effect must have been great.

Moreover, just as the comets and meteoric swarms may be pulled apart, disintegrated by large bodies, so evidently they may come together, may coalesce, may be integrated among themselves. Instantly in the reflecting mind comes the question : is it from these that worlds are born ; is it thus that through the æons, suns and planets grow? Though such an idea has come to more than one mind, it remains as yet rather an interesting possibility than a tenable theory.

Step by step the mystery slips away. With the terror of the comets a large part of it had gone; not all. Back in Newton's and in Halley's time there was one they must have pondered oft. It brought no terror; it was a puzzle none the less. What is light? Does the effulgence of the sun, the radiance of the stars, flash to us in no lapse of time? Can its traverse of space be instantaneous?

So it seemed. And yet the fact was unthinkable, just as the fact of gravitation is still. Already one young observer had seen that some curious appearances could not be so explained. Until the matter was cleared up, certain avenues to investigation were blocked. Science cannot deal with infinities. The path to the solution was devious. 


\section{CHAPTER XXII}

ROEMER AND THE PROOF OF THE EARTH'S MOTION 
Whether the sun predominant in Heaven Rise on the earth, or earth rise on the sun; $\mathrm{He}$ from the east his flaming road begin,

Or she from west her silent course advance With inoffensive pace that spinning sleeps

On her soft axle, while she paces even, And bears thee soft with the smooth air along;

Solicit not thy thoughts with matters hid ; Leave them to God above, Him serve and fear.

Paradise Lost, viii. (1667). 


\section{CHAPTER XXII}

\section{ROEMER AND THE PROOF OF THE EARTH'S MOTION}

Wiтн the demonstration of the law of attraction, the triumph of the Coppernican theory seemed complete. Tested in every direction in every land where observations were carried out, the ideas of Newton were subjected to inquiry only to be confirmed, their application extended. There seemed no flaw, no difficulty. And yet a difficulty remained. It was the same that had met Aristarchus and Coppernicus, that had baffled Galileo. It was left unsolved by Newton or by any contemporary. That was the unchangeable position of the fixed stars.

To escape the difficulty, sometimes like the ancients men had imagined a crystal sphere wherein the stars are fixed like so many nails studded in a wall. Galileo considered this, but in his third Dialogue he said :-

"Still I do not believe that all the stars are scattered over a spherical surface at equal distances from a common centre; but I am of the opinion that their distances to us are so various that some of them may be two or three times as remote as others, so that when some minute star is discovered by the telescope close to one of the larger, and the former is yet highest, it may be that some sensible change may take place among them." 1

In the century that followed the invention of the telescope no such change could be detected, and a truly marvellous precision had been attained. The accuracy of observations had been carried down from limits of error of the fraction of a degree, obtainable by the ancient instruments, first to a minute, finally down to a few seconds. The telescope with which Galileo had discovered the "little world" of Jupiter, magnified only seven diameters. All his great discoveries, as we have seen, were made with a telescope which did not magnify beyond thirty-two diameters. Within fifty years Auzout had constructed colossal

1 Dialogues on the Two Great World Systems, III. 
telescopes without tubes, 320 feet long and magnifying 600 times. So far from reducing the distance of the stars with the new instruments, they seemed but to recede farther and farther into the depths of space. So long as it was possible to measure angles with accuracy down only to a minute of arc, as in Tycho's day-that is to say, an arc the 20,000 th part of a circle-this meant merely that the nearest of the stars must be nearly 3500 times the mean distance of the earth from the sun. Already it was taxing the limits of credulity. The sun, eighty million miles or more away; the starry firmament, 3500 times eighty millions ! It was unthinkable ; it was almost unbelievable.

The new instruments carried these distances almost to infinitude. The little wire-netting which Gascoigne had stretched across the focus of the telescope made it possible to measure down to a second. The lower limits of stellar distance rose to 200,000 times the distance of the sun when this degree of precision had been reached. Yet even with an instrument capable of disclosing this minute variation in the position of a star, no certain change like that predicted by Galileo could be found. One astronomer after another believed that a parallax, a change of position, could be observed. One after another their results were discredited or disproved. Such was the state of the science when Newton was borne in honour to Westminster Abbey. So it was to remain for more than a hundred years thereafter, that is to say, down to the second or third decade of the nineteenth century.

Slight wonder, then, if some shadow of a doubt still remained, slight marvel if some of those whose instincts of conservatism made them still cling to the ancient beliefs, might hope that some observation, some event might come which should reveal this new and godless system of the world as the baseless fabric of a dream. Inspired by the magnificent conquests which a few decades of the telescope had achieved, the astronomers did not despair; they went on observing. As many times happens in the history of invention and discovery, they found not what they sought, but great things none the less. A Columbus in the quest of India reveals the new world; the observers in search of stellar parallax disclosed the finite velocity of light. With this came the proof which sets the motion of the earth beyond intelligent doubt.

Probably the most ancient of physical investigators had at- 
tempted to solve the problem as to whether or not the transmission of light is instantaneous. Every schoolboy has observed the difference in the propagation of light and sound. The flash of a rifle from a distance is seen long before we hear the report. It required tests of no great delicacy to approximately measure the speed of sound. The phenomena of light had been studied from the most ancient times; Ptolemy of Alexandria had left a treatise upon the subject. The laws of reflection were known to his day; refraction, the bending of light as it passes through media of varying density, had been observed closely by Poseidonius, by some of the Arabians, and by Friar Bacon. With the tremendous awakening of physical investigation which followed the discovery of America, and especially with the invention of the telescope, the subject was taken up anew by scores of eager minds. Lord Bacon fumbles with it, as with so many other of the current ideas of the time. There is a passage in the Novum Organum that may be worth the quoting, alike as an excellent example of the later Bacon's stumbling logic and confused thought, and of the notions prevalent in his day. It runs :-

"... The flight of the musket ball is too swift to allow an impression of its figure to be conveyed to the sight. This last instance, and others of a like nature, have sometimes excited in us a most marvellous doubt, no less than whether the image of the sky aud stars is perceived as at the actual moment of its evidence, or rather a little after, and whether there is not (with regard to the visible appearance of the heavenly bodies) a true and apparent time, as well as a true and apparent place which is observed by astronomers in parallaxes. It appeared so incredible to us that the images or radiations of heavenly bodies could suddenly be conveyed through such immense spaces to the sight, and it seemed that they ought rather to be transmitted in a definite time.

"That doubt, however (as far as regards any great difference between the true and apparent time), was subsequently completely set at rest, when we considered the infinite loss and diminution of size as regards the real and apparent magnitude of a star, occasioned by its distance, and at the same time observed at how great a distance (at least sixty miles) bodies which are merely white can be suddenly seen by us. For there 
is no doubt that the light of the heavenly bodies not only far surpasses the vivid appearance of white, but even the light of any flame (with which we are acquainted) in the vigour of its radiation.

"The immense velocity of the bodies themselves, which is perceived in their diurnal motion, and has so astonished thinking men, that they have been more ready to believe in the motion of the earth, renders the motion of radiation from them (marvellous as it is in its rapidity) more worthy of belief. That which has weighed most with us, however, is, that if there were any considerable interval of time between the reality and the appearance, the images would often be interrupted and confused by clouds formed in the mean time, and similar disturbances of the medium. Let this suffice with regard to the simple measures of time."

It should be needless to remark that again the italics indicated are not Bacon's. While the prophet of the Great Instauration was balancing speculations, the more practicalminded Galileo was attempting a crude measure of the actual speed of transmission. Others perfected his methods; the velocity still seemed infinite, the passage of light from star to earth instantaneous.

So it appeared to Descartes ; so it remained until a curious observation by a young Danish observer, Olaus Roemer. While Cassini is making a correct measure of the distance of the sun, revealing the enormous breadth of the earth's orbit, this young Dane is taking note of an extraordinarily minute but certainly observable difference in the times of revolution of one of Jupiter's moons. It seems a far-away cry from the subject in hand; this is what he observes : Carefully comparing observations of forty immersions and emersions of the satellites, he finds that there is a variation in the moments of their reappearance of some seconds, depending on the time of the year. It is slight, but of the fact there can be no doubt; how can it be explained? The times of revolution ought to be absolutely equal. There seems no reason to suppose that the orbital time of the satellites varies ; they should be eclipsed and reappear with the punctuality of a clock. Can it be explained by the varying distance of the earth?

On the new estimates made by Cassini. when our globe is 
in opposition to Jupiter it is about a hundred and eighty million miles farther away than when it is in conjunction. If the transmission of light is not instantaneous, then the discrepancy in the observed times of the occultation will represent the time it takes light to cross the diameter of the earth's orbit. This Roemer estimated at twenty-two minutes. The speed of light, then, will be one hundred and eighty million miles divided by twenty-two minutes-that is, about eight million miles per minute. This is Roemer's explanation; he presents it in a paper to the French Academy in November 1675.

The history of science is full of fatuities. Roemer's discovery was laughed at by some, mostly ignored by others. Perhaps there was some reason. A few years later in the Principia, the disturbing influence of the planets and satellites one upon the other was disclosed. Newton records that the chapter on the inequalities of lunar motion cost him more labour than all the rest of the book. Jupiter had then four known satellites ; they mutually pull each other about. Their motions represent one of the most difficult problems in astronomy. This might explain the inequality in the duration of their eclipses.

Then, too, a speed of a hundred thousand miles or more per second was something too vast for the mind easily to grasp. Such a speed did not, however, appear absurd to Newton, for at least in the second edition of his Optiks he utilised Roemer's method, and calculated the time for the light of the sun to reach the earth at seven and a half minutes. This was an error only of a little more than half a minute; but the close approximation was an accident; he set the sun at only seventy million miles away. Yet even so great an authority could not induce general acceptance of Roemer's theory. It was another observer, travelling a widely different path, who was to confirm his results in a singular way.

As far back as 1667 Picard, the French astronomer whose measures of the earth were to confirm Newton's discovery of the law of attraction, had observed a periodical movement of the pole-star to the extent of about $20^{\prime \prime}$. This, he saw, could neither be the effect of parallax nor of refraction; it was very regular, and extreme at opposite seasons of the year. $\mathrm{He}$ could not divine the cause, neither could his young protégé 
Roemer. Not even after Roemer had worked out the velocity of light did the cause of this wandering occur to him; not to him nor to any one else for half a century.

Fifteen years after Roemer's death, two years before that of Newton, Samuel Molyneux, a wealthy amateur, had set up at Kew a magnificent sextant of twenty-four feet radius. His intent was to confirm or disprove the parallax of some of the fixed stars which Hooke had claimed he had observed. He associated with him the young Savilian Professor of Astronomy at Oxford, James Bradley. A little later, Molyneux gave up the work for other duties, and Bradley went on alone. Their idea had been to take a single star, watch it very closely from one season to the other, that is to say, from one side of the sun and the other, thinking that by means of their new instrument the question could be settled.

What they were in search of was some shift in the relative position of two stars very close to each other; such a shift as one might observe in the relative position of two peaks or two church spires seen from two distantly separated points. What Bradley found was an odd shift in the position of the star itself. $\mathrm{He}$ had made the same observation as had Picard, but on another star. It was not in the least what he was looking for, but it was certainly something new, and he followed up his observation with others through three or four years. Wherever he turned his instrument the disclosure was the same, with this difference, that whereas some of the stars seemed to describe a little ellipse, others would wobble in longer and longer ellipses, until it amounted simply to a movement back and forth along a straight line.

The movement was extremely small, only about $20^{\prime \prime}$ at the most; that is, a little more than the hundredth part of the apparent diameter of the sun and moon. But it was there; moreover it was universal. So far from being fixed, the whole firmament was in a wobble-very minute, indeed, but nevertheless measurable. What was the explanation? Obviously, until the matter could be cleared up, 〔it was no use to think of measuring parallax.

As the story runs, the explanation came to Bradley one day in a boat on the Thames. Whenever the course of the boat was changed, the apparent direction of the wind changed with it. It flashed across the astronomer's mind that the position of an 
observer on the earth is just the same as that of a man sailing in a boat; and if light, like the wind, has a measurable speed, as Roemer and Newton supposed, then obviously the apparent direction of the stars would be an effect compounded of the double movement of the earth and the light.

Up to that time observers had been going upon the theory that the flash of light from the stars is instantaneous-therefore, that the motion of the earth need not be taken into consideration. To them the problem in fixing the location of the star was much the same as that of the professor of mechanics in a familiar tale, through whose window one night a bullet came crashing from across the green. By observing carefully the hole in the window and in the wall opposite, and calculating the path of the projectile, it was an easy matter for a mathematician to determine from which student's room the careless shot had come.

But suppose that the observer is aboard a vessel flying along at tremendous speed; then, in calculating the point from which the shot is fired, the speed of the vessel must be taken into consideration. If its speed be great enough, the hole in the wall opposite the window will lag a little behind the point where the bullet would have struck had the vessel been standing still. Obviously the lag will be greatest when the shot is fired directly at right angles to the path of the ship's motion; it will grow less the nearer the path of the projectile agrees with the path of the ship, and disappear entirely when the agreement is complete.

All this is precisely what Bradley observed. If the effect he had detected is due to the finite speed of light, then it was not difficult to calculate from his measurements that the velocity of light must be very close to ten thousand times the speed of the earth. The earth shoots along its track at nineteen miles per second; ten thousand times that is one hundred and ninety thousand. The figure was considerably higher than Roemer's, very close to Newton's. There could no longer be any doubt that the speed of light is finite, and that its measure was known. It is to be noted that Roemer had computed the velocity of reflected solar light, Bradley the direct light of the stars. For a time it was supposed that the discrepancy might be in this difference; but from the discussion of a thousand eclipses of Jupiter's satellites, instead of the forty which Roemer could 
utilise, Delambre found that the agreement with Bradley's estimates is very close. Other measures have confirmed the result, correcting it a very little. It is now possible to effect the measure by mechanical means-with revolving mirrors, for example-along something of the same lines as the futile experiment of Galileo.

Bradley's discovery was a great step forward. It added a new and undreamt-of accuracy to astronomical observations ; it proved a great impetus in the study of optical phenomena of light. But it had a further and distinctly greater import : it demonstrated unequivocally the motion of the earth. The aberration of the stars could be explained upon no other supposition. The accuracy of the observations was unquestionable. It was inconceivable that one section of the heavens should show this foolish little wobble while another section did not, on the supposition that the earth was the fixed centre of the universe.

It was given to Bradley to make yet another noteworthy discovery. That was the nutation or nodding of the earth's axis. Coppernicus, it will be remembered, had pointed out a conical movement of the earth's axis, extending through a period of about twenty-six thousand years. Newton had given the explanation of this movement in the Principia. Bradley discovered a displacement of some of the stars which could be explained neither from this motion of precession nor of aberration. He must have been a tenacious, patient sort of a man, for he watched the displacement through a period of nineteen years, and thus found it to be periodic. Of course, this could not be a movement of the stars themselves. His discovery was that, superimposed upon the conical motion was a secondary motion or inclination ; it caused the line marked out by the extension of the earth's axis upon the heavens to pursue a wavy and scollopy sort or motion instead of being a perfect circle. This motion, like the other, is the result of the varying pull of the moon upon the oblate spheroid of the earth. It was predictable from Newton's theory; he even suggested that it might exist, though it was a solar rather than a lunar disturbance which he had in mind.

These discoveries of Bradley were, as we see, made quite by the way. What he set out for he never found. Not even with his wonderful zenith sextant, which could enable him to plot stellar changes whose maximum was but $20^{\prime \prime}$ of arc, 


\section{THE PROOF OF THE EARTH'S MOTION 289}

could he detect any shift of position which he could regard as certainly due to stellar parallax. His discovery of the cause of aberration was announced in 1729. They did him due honour, and made him Astronomer Royal. There, by the minute precision and wide range of his observations, he laid the foundations from which in after centuries the theory of the universe will be builded, and of which some beginnings have been made in our own time. He was the founder of modern stellar astronomy; but it was not until a century after him that the invention of the heliometer made possible the discovery which had been the real quest of his quiet, fruitful life.

Meantime there were problems of nearer import to dwellers within our little solar world. 



\section{CHAPTER XXIII}

\section{LAPLACE “AND THE STABILITY OF THE}

SOLAR SYSTEM 
Physico-mechanical laws are, as it were, the telescope of our spiritual eye, which can penetrate into the deepest night of times past and to come.

HeLmholtz, On the Interaction of Natural Forces. 


\section{CHAPTER XXIII}

\section{LAPLACE AND THE STABILITY OF THE SOLAR SYSTEM}

IN the history of intellectual development, more especially in the development of science, precedence among the nations seems to flit about in a lawless way. In the workaday world in which we live, one of the strongest forces is that of heredity; its workings are revealed not merely among families, but in the larger forms which we may call social, the inheritance from one generation to another of ideas, customs, beliefs. The fact is one of the foundation-stones of the growing science of sociology.

But genius for discovery, for invention, for the grouping and generalisation of phenomena into broad and simple laws, seems to escape the force of heredity entirely. One would readily think that the career of a great man would mean the impregnation of a generation and a people with his ways of thinking and ways of doing, and that when he had gone there would arise a distinct progeny to carry on his work. But it does not seem to be so. Poland did not become the leader of the intellectual world because of Coppernicus, nor Germany because of Kepler, nor Italy because of Galileo. Newton had no successors among his own people nor in the generation that followed. It was the mathematicians of France who were destined in the obscure order of events to take up his work.

There remained when he died a number of minor but none the less important problems; subsequent facts, as they came to light, suggested several more. There was one of extreme intricacy which Newton may have pondered but which he never ventured to solve.

The slow sway of the earth's axis, pointed out by Coppernicus and explained by Newton, was clearly a periodical disturbance. So was the secondary nodding or nutation of the axis discovered by Bradley. Their effects might be momentous-they might 
determine changes of climate, for example-and so men came afterwards to perceive. But they were not permanent. It was clear that some time or other the earth would return to precisely the same conditions as that which had once prevailed; it was merely making a round.

But the fact that there could be any such deviation from seeming regularity must have very soon suggested that there might be other changes whose effect was progressive and cumulative. Men came to wonder whether the seeming permanent arrangement of the planets formed a stable system, or whether it might one day go all awry. Has this little patch of the universe which we call the solar system always existed more or less in its present form? Were the planets always arranged in the same order and same distance and with the same speeds as we perceive them now, or is there underneath all this apparent regularity, this machine-like motion, a subtle deviation which in the course of uncounted ages will change it utterly.

There was a curious fact turned up by Halley. Studying the records of some of the old eclipses, he found that the calculation, so far as he could perceive, of the times in which they should have occurred did not agree with the records at all. In the pages of Ptolemy and others he found accurate descriptions of eclipses which had taken place far back in the old Babylonian and Chaldean days. They did not tally with his computations by nearly two hours. This in a period of twentyfour hundred years is not a great variation; there was always a chance, of course, that his calculations, or the ideas upon which he based them, were wrong. But the new methods brought in by Newton had reduced planetary motion to a science of marvellous accuracy. So, when the estimates had been carefully checked up and found flawless, astronomers were able to lay hold of any such discrepancy as a distinct and significant fact; they could go hunting for the reason, rather than put the matter aside as something inexplicable or the mere product of error.

Halley did not find the solution of the problem he had posed. Before it could come it was needful to clear up a difficult and highly recondite problem, the pull of the planets on each other, their mutual perturbations, as it is known-in more technical phrase, the problem of three bodies. For this, in turn, mathe- 
matical analysis had to grow to new powers. Newton had lent a powerful aid with his invention of fluxions. The philosopher Leibnitz had made very near the same discovery. Together they had produced the new calculus. It was the new weapon of analysis which, when the "Mathematical Principles," the Principia, finally had taken hold, gave such a tremendous impetus to the mathematical treatment of scientific problems, and especially those of astronomy. There seemed to spring up a whole school of calculating geniuses to whom an unsolved problem was as meat and drink.

The foremost of the earlier ones was Euler, a Swiss. It is related of him that when in middle life he lost one of his eyes, he remarked that henceforth he would have less to distract him from mathematics. Later on he lost the use of the other ; but it seemed to make no difference in his astonishing activity. Princes of the mind were then high in the favour of princes of the land. Euler roamed about the courts of Europe, joining first in the organisation of the newly created Academy of Sciences in St. Petersburg, then in Frederick's reorganisation of the Academy at Berlin, then back again. All the while he was turning out with an incredible rapidity papers upon new methods of analysis, abstract dynamics, optics, the motion of fluids, the movement of the planets ; every branch of physical investigation seemed grist for his mill. Altogether he left some eight hundred memoirs, besides several respectable volumes, and a charming series of letters on the study of nature, addressed to a princess friend. His versatility was amazing. It may be noted in passing that this seems a characteristic of minds of the highest order. It was particularly true in the first two centuries after Galileo, before the sciences had become so intricate and highly specialised that mastery in more than one narrow field should make a Helmholtz a marvel to his kind.

Euler's association with the Bernouillis was so close that he might almost be regarded as a member of that famous family of mathematicians, two of whom were rivals of Newton, and one of whom, Daniel Bernouilli, was the first important Newtonian among mathematicians outside of Great Britain. Euler and the latter found a keen competitor in the precocious genius of Clairaut. He is remembered now, if he is remembered at all, chiefly for his classical investigations into the figure of the earth; but in his own time his celebrity was considerable. 
He had the gift of great personal charm; he liked to use it, and he formed one of those distinguished and supple-minded figures which graced the salons of the period, and lent solidity as well as brilliancy to a mode of human congregation whose disappearance from present-day society, lovers of the varied life may scarce view without regret.

Clairaut found a rival as aggressive as he was polished and suave in the foundling, Jean-le-Rond d'Alembert. Left as an infant on the steps of a church in Paris, and growing up to a gloomy view of the world, d'Alembert lives for us now chiefly as the collaborator, with Diderot and Voltaire, in the production of the famous Encyclopédie, and as the luckless victim of the versatile affections of another waif of fortune, Julie de l'Espinasse. He undoubtedly exercised a very considerable influence upon the political and philosophical thought of the time; but he was primarily a mathematician, and worthy of rank with the highest.

It was a rather curious coincidence that three of this group, Euler, Clairaut, and d'Alembert, all succeeded in obtaining independently, and very nearly simultaneously, the solution of the problem of three bodies-the means of calculating the mutual share of three planets, for example, acting one upon another by the force of gravitation.

They did not reach the larger problem : whether or no our system will endure. That was the work of their successors-in foremost line Lagrange and yet another mathematical genius whom the French are proud to class with Newton himself. This was that Baron Laplace who, through all the stormy times of the downfall of the ancient régime, the Revolution, the Empire, the Restoration, managed to balance himself with such dexterity as always to keep a comfortable berth and retain the favour of the whilom reigning powers.

Laplace had come up from the soil like all the rest; he was merely a peasant lad in the fields of Normandy, the son of a poor farmer. Some of the neighbours, or perhaps the parish curé, discovered his amazing genius for calculation, and gave him a start. After that his own abilities, alike as a politician, which were unsurpassed, and as a mathematician, which were of the highest order, were sufficient.

There is a story of how, at eighteen, he came up to Paris with a letter to the then reigning mathematician, d'Alembert, 
but gained no audience. Then he sent to the savant a letter on the principles of mechanics. It brought him a post at the military school, and a courtly word from d'Alembert that such a letter would be an introduction anywhere in Europe. Therewith his successful way began.

In taking up the "acceleration of the moon's mean motion," this steady shortening of the month which Halley had disclosed, Laplace was led to a still more important discovery; that was the changing eccentricity of the earth's orbit. The elliptical form of the earth's path about the sun, he found, was steadily growing less and less. This was the cause of the quickening of the moon's motion. Laplace calculated it all out, figured that the real amount of quickening was ten seconds in a century -instead of twelve, as Halley had estimated-and that this was precisely what the theory of attraction required.

But immediately came the question: How long had this decrease in the eccentricity of the earth's orbit been going on ? Was the eccentricity once immensely greater than it is now; did the path of the earth once resemble that of a comet; in times gone by, did it shoot down close to the sun into regions of blazing heat, then whirl about and rush away again into distant spaces of chilling cold, as the comets do ? It was a tremendously interesting problem, for it might give a clue to the whole past history of the earth-perhaps a hint as to its future as well.

The memoir which Laplace at length presented to the French Academy dealing with this question was of profound philosophic significance. His answer was: The variation of eccentricity is not cumulative; it is, like the precession of the equinoxes, like nutation, a periodic variation, requiring for its completion a long period of time. The latter Laplace estimated at eightysix thousand years. It was a glowing triumph of the calculating faculty, and it was the foundation of a wonderful work. This was that great Mécanique Céleste-the Mechanics of the Heavens-to which Laplace owes, largely, his fame. Its central idea is the perfect balance revealed in every motion of the planetary system. It seemed to rule out all change as Newton had excluded chance; it presented the solar machine as a vast engine, subject to slight variations in the motions of its parts, but whirling on without substantial deviations throughout infinity. We now know that there was in Laplace's calculations 
a seemingly infinitesimal error-that the solar system is not absolutely stable--and in our own day this has given us just that far glimpse backward which the results of the French mathematician seem to refuse.

But in his own day theory and computation seemed to unite in exhibiting a celestial mechanism so perfect as to be selfsufficient. So Laplace regarded it. There had grown up in France in the eighteenth century a school of philosophers who had undertaken to explain the universe without the aid or intervention of the antique hypotheses as to the origin of the world. They had swept far beyond Voltaire. The apostle of Newtonianism in France is often thought of nowadays as a very godless man; as a matter of fact he was a sincere deist, and even whilst he lived he had grown to the generation round him very much out of date.

When the Scotch philosopher Hume visited France a little while before the outbreak of the Revolution, he chanced to remark one evening at dinner that he had never known an atheist-hinted even that he regarded such a class as a myth.

" Monsieur," replied his host, the amiable Baron d'Holbach, " you are at table with seventeen."

The ideas of Laplace partook of the spirit of the time. There is a famous old anecdote, oft repeated, of his encounter one day with Napoleon. Laplace seems to us at this distance very much of a time-server, very ready to crook the pregnant hinges; he changed the dedication of his work from king to consul, from consul back again to king, as the times changed, with a complacency that was admirably serene. But for once his courage, or his fondness for saying smart things, got the better of his smug compliance. As the anecdote goes, he had presented Napoleon with a copy of his latest work. The Corsican parvenu bore a deal of resemblance to the gallery-playing potentates of a later-day, and loved, like these, to disclose the variety of his aptitudes and interests. He said to Laplace :

"Monsieur, I have examined your work, and I find therein no room for the existence of God."

" Sire," replied Laplace, "I find no need for such an hypothesis."

The work of Laplace was largely done in close association with another great French mathematician, a quiet and simple 
man, who lived chiefly upon nuts and fruits, planned methodically each day what he should do the next, who cared nothing for place nor the glitter of the court like Laplace, who lived to calculate, to meditate, incidentally to render into very admirable prose the famous poem, On Nature, of Lucretius. This was Lagrange. He was thirteen years the elder of Laplace, and is often thought to have been the more solid, as he was certainly the less showy man.

It is an idle speculation; both were men of prodigious power in analysis ; their peculiar abilities seemed to be a kind of complement one to the other. It was Lagrange who worked out the problem of the changing shape of the earth's orbit, discovered by Laplace. It was Lagrange who showed why it is that the moon turns towards us always the same face; he figured out that the moon must bulge a little, just as the earth does, and that this would act as a sort of a brake on the revolution of the moon, so that it would eventually come to a standstill. It was Lagrange who worked out the general method connecting the rate of change in the variations of planetary orbits with the disturbing forces. But in general they worked so closely together, the one taking up the problems of the other, and vice $v e r s \hat{a}$, that their names are usually linked in any account of the achievements of the period.

This peculiar relationship was in no wise disturbed by the translation of Lagrange to Berlin in I766. Students of the period-and it was a heyday time for philosophers and men of science in general-will recall that the fat Frederick, surnamed The Great, was then doing what he could to Parisianise the German capital. He had established an Academy like unto that which has rendered such signal services to France, and as there was a dearth at that time of native material, he imported half the great figures of France-Voltaire, Maupertuis, Lamettrie, d'Argens, and many another.

There came a vacancy in the mathematical section. Frederick had a taste for fine phrases as well as an excellent opinion of himself; he even wrote verses, whose halting metre a wit of the time remarked would limp after him in history. In his invitation to Lagrange to come and fill the vacant post, he explained that the greatest king of Europe wished to have the greatest mathematician in Europe at his court. It was a fine place to go; an invitation couched in such language was hardly to be 
refused. Lagrange went, and there he remained for twentyone years. It was at Berlin that he completed his great Mécanique Analytique, a superb work, practically the foundation of that especial science; it would have given him an enviable fame had he done nothing more.

These two giants, Laplace and Lagrange, so largely monopolised the stage as to dwarf into a minor place an excellent mathematician, a dreaming genius, Johann Heinrich Lambert, tailor's apprentice of Mühlhausen, of whose majestic reveries we shall hear hereafter. It was a discovery by Lambert-one that he did not live to solve himself - that gave to Laplace and Lagrange one of their most celebrated problems.

Halley, who pointed out so much for others to think about, had noted that the motion of Saturn was swifter than it ought to be, according to the Newtonian theory, while that of Jupiter was slower. Lambert found that Saturn in his day was moving faster than in Halley's time. There was evidently a fluctuation or disturbance of some sort at work. The situation was pretty obviously the result of the pull of one planet on the other, acting with or against the steady pull of the sun. But it was a mathematical puzzle of a very intricate order-the problem of three bodies over again. In many doubting, hesitating minds it was a stumbling-block to the acceptance of the theory of gravitation. In that day, just as in our own, there were, in abundance, types of minds which clung tenaciously to everything which seemed a difficulty or an obstacle in the path of any new idea. No doubt this type is of use, always; it forms a kind of check upon over-enthusiastic spirits, refuses to accept any new result until it has been proven up to the hilt; it is of undoubted value in sifting out fact from hasty theory, and in giving us a solid sense that what knowledge we may put by when the opposition has been cleared away is of real and lasting worth.

The solution of the special case of Jupiter and Saturn proved a clue to other and less important planetary perturbations. It naturally was received with great acclaim by astronomers, since it seemed to sweep away the last hindrance to the full acceptance of the idea of attraction. This idea was no longer an hypothesis. After the demonstrations of Lagrange and Laplace, it would take rank as a theory beyond all cavil or doubt. Fifty 
years later, utilising these same methods, the theory was to receive at the hands of Leverrier and Adams a brilliant and clinching verification in the discovery of a new and unsuspected member of the solar system.

This tacit partnership, undisturbed by the pitiful jealousies which disfigure so many pages of scientific history, closed with the death of Lagrange in I8I3. He was almost wholly a mathematician. The range of Laplace was larger. He extended and, through wider applications, gave almost new life to the Theory of Chance-that is, the calculus of probabilities. He was associated with the chemist Lavoisier in many of the latter's investigations. Together they produced an important memoir, which is one of the foundations of the modern theory of heat. Lagrange speculated little; the mind of Laplace was sometimes given to wider flights. It was in one of these that he divined and sketched the grandiose conception which endeavours to account not merely for the present motions and actions, but the origin of worlds as well. He was not alone in working out this theory ; though he did not know it, he had a precursor in a near contemporary. Moreover, he threw it out as little more than a suggestion, at the close of the theoretical portion of his more popular Exposition du Systeme du Monde. The evidence which has given weight and prevalence to the Nebular Hypothesis has largely come since his day; with it some diffculties which he could in no wise foresee. This, assuredly one of the profoundest flights of the human imagination, may well form matter of a later discussion.

Thanks to Newton, we know what makes the world go. Thanks to Laplace, we know with precision how it goes. How large is this machine? 



\section{CHAPTER XXIV}

FIXING THE BOUNDARIES OF OUR SOLAR WORLD 
E però, prima che tu più $t^{\prime}$ inlei,

Rimira in giuso, e vedi quanto mondo

Sotto li piedi già esser ti fèi ;

Col viso ritornai per tutte quante

Le sette spere, e vidi questo globo

Tal, ch' io sorrisi del suo vil sembiante.

$\mathrm{E}$ quel consiglio per miglior approbo

Che l' ha per meno; e chi ad altro pensa,

Chiamar si puote veramente probo.

Vidi la figlia di Latona incensa

Senza quell' ombra, che mi fu cagione

Per che già la credetta rara e densa.

L' aspetto del tuo nato, Iperione,

Quivi sostenni ; e vidi com'si muove

Circa e vicino a lui Maia e Dïone.

Quindi $\mathrm{m}^{\prime}$ apparve il temperar di Giove

Tra 'l padre e 'l figlio; e quindi mi fu chiaro

Il variar che fanno di lor dove:

E tutti e sette mi si dimostraro

Quanto son grandi, e quanto son veloci,

$\mathrm{E}$ come sono in distante riparo.

$L^{\prime}$ aiuola, che fa tanto feroci,

Volgendom'io con gli eterni Gemelli,

Tutta m' apparve da' colli alle foci.

Paradiso, Canto xxii., I27. 


\section{CHAPTER XXIV}

\section{FIXING THE BOUNDARIES OF OUR SOLAR WORLD}

$\mathrm{By}$ an instinct inborn to the mind, man is for ever seeking limits and confines. The progress of astronomy brought a natural desire to know the shape and the dimensions of the planetary system to which we belong. Is Saturn at the edge ? Out beyond it, amid the seeming chaos of the stars, are there other "wanderers," turning and turning, like our own, about the sun, but in the distance lost to view ? For more than a century and a half the telescope added no new planet. Their number remained at that which had been known to the ancients. The optic tube had almost infinitely broadened man's ideas of the extent of the system itself, and of the stars beyond; yet Saturn remained to Newton, as it was perhaps to the Chaldeans, the outer rim.

In I78I the news slipped across Europe that the limits of the solar system had suddenly been doubled. An obscure musician of Bath, in England, turned amateur astronomer, was sweeping the heavens with a small telescope, and was struck by a curious appearance in the constellation of the Twins. It was very much larger than any of the surrounding stars; he therefore suspected it to be a comet, and the attention of astronomers was drawn thereto. The close study of the comets was in the order of the day; many attempts were made to compute its path. At last it became clear that it was no comet, but that it moved in a circle, nearly. It was a new planet, revolving about the sun at a distance of close to twenty times that of the earth.

The discovery made a tremendous sensation, and it made fame for the man whose view had held it first. For our earthly concerns the later event was undoubtedly of more importance than the discovery itself. It was not a wonderful discovery, either in the instruments employed or in the sense of having 
been predicted and calculated as the consequence of some law, or a long series of observations. It was purely an accident, made, moreover, by means of a relatively small telescope. It undoubtedly would have been made by some other observer, probably within a few years, since star maps were coming into fashion more and more; the changing position of the planet must have soon been noted.

But what the discovery did was to lift from poverty and obscurity one of the most wonderful observing geniuses known in the history of astronomy. This was Herschel; his larger deeds were in the realms of stellar research, and they will fill a sequent chapter. Simple and loyal subject that he was, Herschel claimed the right of discovery, and wished to name the planet after his king, George III. The continentals did not take to the suggestion; some of them wished to name it after Herschel himself, and so for a time it was known. Finally it was agreed to draw a name from the ancient myths, like those of the other planets, and deeming that Uranus may have been the earliest of the astronomers, it perpetuates his twilight fame.

The new planet was in no wise remarkable, save as to its distance. It was only about half the diameter of its neighbour Saturn, though seventy or eighty times the volume of our pigmy earth. One peculiarity of its distance was promptly noted; just as with most of the planets, its orbit lay at about twice the distance from the sun as that of its next nearest neighbour. Saturn is at ten times the distance of the earth; Uranus was found to be very closely twenty times. Promptly the astronomers began to search for yet further outlying members of the system.

The probable existence of at least one more planet was borne in by the curious discrepancies observed in the orbit of Uranus. The discovery of this conjectured planet was one of the greatest triumphs, though not the final, of Newton's ideas. Before it could be made there was another, or rather a series, of not less interest.

Even in the solar system as it was known before Herschel, there was a curious gap. If the distance of Mercury from the sun be taken as unity, it was noted that Venus was very nearly twice this distance, and that each successive planet was something like double that of the next. The relationship is not 
exact ; the distance grows less and less as you journey outwards. Thus, the earth is only two and a half times the distance of Mercury; Mars is only about one and a half times the distance of the earth. But Jupiter is five times. Between Mars and the great planet there is a broad space that, even for Herschel's wonderful telescopes, seemed empty. Kepler had speculated upon this gap, had dreamed of a missing planet. There was no mistaking the fact that there was some sort of order in the distribution of distances. Saturn was very closely twice the distance of Jupiter. All sorts of ratios were tried in the endeavour to find an exact law.

Finally, taking a hint from Titius, in 1772 the astronomer Bode of Berlin noted that if by taking a little different geometrical progression than that of simple doubling, and by adding a constant each time, a very close approximation could be found. Thus, if the series be taken as $0,3,6,12,24$, and so on, and the number 4 be added at each step, the result is a series which expresses fairly well the relative distances. This is what is known as Bode's law. The discovery of Uranus, twice the distance of Saturn, a short time after, seemed to indicate that it was a veritable law. It deepened the mystery of the extra-Martian gap.

The upshot of it was that a little committee of astronomers was formed to search for Kepler's hypothetical planet. The zodiac and its adjacent regions was divided into twenty-four parts; each was portioned off to an observer. Undoubtedly the discovery that followed would have been made very shortly; as a matter of fact, it was an accident. Quite unknown to this special committee, Piazzi in Sicily, engaged in making a catalogue of the stars, noted one evening a small object which had no place on his map. It was the first night of the nineteenth century. The next evening it had shifted a little; so on through a fortnight or more, until he was convinced that it could not be a star. Like Herschel with Uranus, he thought it might be a comet. It was quite invisible to the eye; if it were a star it could not be above the eighth magnitude. In his puzzlement he wrote to two of his friends; one of these was Bode.

The supreme test of any natural law is the element of predictability. If after some striking relationship, some succession in the order of events, some apparently methodical arrangement, 
has been observed, new facts come to light, our instant question is : Do fact and theory hang together ? If not, then, as it were, the theory hangs alone. But if they do-if, moreover, the new facts be such that they might have been more or less calculated or divined from the previous arrangement-we have a feeling of certitude which nothing else can bring. When Bode opened Piazzi's letter his mind instantly leaped to the idea that here was the missing link of his system.

But by that time the object, whatever it was, had disappeared from view; he could not find it. Could its position be calculated ? Mathematicians tried hard; but the observations which Piazzi had been able to make were few in number, and very close one to the other. The difficulty resulted in the discovery of a mathematician of the first order, one of the greatest since Laplace.

There was at that time in Germany a young private tutor who had invented several new methods of analysis, among others that which now bears the name of the "method of least squares." By the aid of the latter he was able not merely to construct the orbit of the new planet, for such he found it to be, but to indicate to the astronomers the point where later on it would be found. Just a year after Piazzi first had sight of it, it was sighted again, close by where the young Gauss had predicted. It was Piazzi's obvious right to name it, and he called it after Sicily's protecting goddess, Ceres.

What Bode had surmised turned out to be true; it lay between Mars and Jupiter. As calculated by Gauss, its distance from the sun was 2.7 times. that of the earth. In the system of Bode it should have been 2.8. The agreement was remarkable, but the planet was disappointing. As best it was clearly only a few hundred miles in diameter; it was smaller than any heavenly body known at that time. It revolved like the other planets; but its orbit was extremely eccentric, and it was tipped up ten degrees to the ecliptic, a greater amount than that of any other planet then known. Altogether it was a puzzle.

The puzzle deepened when, a few months after, another German astronomer, Olbers, found a second. Gauss again calculated its path. It was found to be at almost the same distance from the sun as Ceres, revolving in a yet more eccentric orbit and tilted to the ecliptic at thirty-four degrees. Its bulk was 
about the same as Ceres. Here was a mystery. Two planets, evidently true planets, had been found; but they were more like fragments than the respectable bodies they should have been. The fact that their orbits were so close to each otherroughly speaking, identical-heightened the impression. It was surmised by Olbers that they were in reality bits of a larger planet, and he set about a systematic search for the missing pieces.

Seven years of patient observation brought from the depths a third. Again the observations were turned over to Gauss, to map its path in space. It closely resembled the others. To the second he had given the name of Pallas; the third he called Vesta. It was as absurdly small as the others. It is just visible to the unaided eye. Olbers kept up his hunt for other fragments, as he deemed them, for thirty years more: he had no further reward. Soon after he died a fourth was found; then a fifth; then they came tumbling in so fast that it takes a long catalogue - to number them. Up to the present time near five hundred have been found.

The largest was the third in order of discovery-Vesta. We now know that it is about five hundred miles in diameter. They range from that down to ten or twenty. But still they remain a puzzle. Even five hundred of them tossed together into a mould would not make a planet very much larger than the moon. Leverrier calculated from the observed disturbances in the orbital course of Mars that their combined pull was not equal to that of a planet one-quarter as large as the earth: it is known now that it is a great deal less. What is the explanation?

We do not know, for we have not as yet a theory of planetary evolution sufficiently complete to give a satisfactory account of this flying swarm. The idea of a "shattered planet" is attractive; it was the most obvious, and it was the first that was suggested. It is conceivable that a planet might go to pieces in a terrific explosion. The craters of volcanoes long ago revealed to man the fact that the earth has a molten interior. Doubtless this is true of all planets. Veritable explosions like that of Krakatoa a few years ago, are sufficient indication of the violence with which such a cataclysm might take place. If it ever did, the disrupted fragments would tend to go on circling the sun in something of the same sort of orbit. 
And this is a good deal the appearance which the asteroids, as Herschel named them, present.

The evidence in favour of this theory would be a great deal stronger if it were found that the asteroids pass successively through some common point in their closely associated orbits; but that is what they do not seem to do. The zone in which they swing, this cinder-path of the solar system, is as broad as the distance from the earth to the sun; their orbits are tilted to the ecliptic at all sorts of angles; they are the most eccentric of planetary bodies. One of them comes nearer to the earth at times than any other body but the moon.

It seems likely that there was no "shattered planet," and that these small shot of the system are more probably a kind of sputter in the moulding of our solar world. If our system was formed through the coalescence of a succession of rings like those of Saturn, sloughed off successively from a great revolving pre-solar nebula, the formation of the vast mass of Jupiter might explain the asteroids. Its enormous bulk would exercise a disrupting influence, perhaps, upon a neighbouring planetary fœtus, if we may conceive that such ever existed, and little by little what might have grown into an adult planet was pulled apart to form a crowd of dwarfs.

However this may be, the Keplerian gap was in a measure filled; the law of Bode seemed established. There did seem a discernible order in the arrangement of the planets. The new evidence in its favour was hardly more than presented than yet another discovery came which brought more of difficulty than the previous one had brought of aid.

Interesting and even exciting as was the discovery of the first new planet, that of Uranus, it none the less brought trouble. For a time it seemed as if it could not be brought into agreement with the hard-won laws of planetary motion. It was very soon found that the planet had evidently been observed, though not recognised, nearly a century before; the more carefully its motions were followed, and plotted, the more clear did it become that it did not fit with exactitude into the KeplerianNewtonian scheme. The types of minds which discover a curious delight whenever the marching intellect of the race strikes a stumbling-block were offered a temporary joy. Perhaps the laws of gravitation were not universally true, and there might still be room in the world for that hodge-podge caprice which 
had been the essence of the old order of thought. Not long.

As the wobbling path of the tipsy planet became more and more accentuated, here and there were found minds to throw out a suggestion that the distortions indicated an extra-Uranian. body. It was the most obvious explanation, and it presented a beautiful problem. The five or six heavy volumes of the Mécanique Céleste in which Laplace had embalmed the solar system in unchanging stability, were filled with the reverse problem here presented : his task had been to measure the mass of the component members, determine what disturbance each of them would exercise upon the other, then to find if observation agreed with the result. It was by this means that he detected the changing eccentricity of the orbit of the earth. Here the matter was : given a carefully observed disturbance, what and where is the planet, or the planets which cause it ?

By 1840 the materials were sufficient. Some observers had already thought of a search, in a purely empirical way, for the disturbers. Meanwhile the problem had been independently attacked by two young mathematicians. One was an undergraduate at Cambridge University in England, John Couch Adams; the other was Urbain Leverrier, in France, friend of the fiery and stimulating Arago. By October I845, Adams had worked out his results and announced them in a letter to the English Astronomer Royal. The actions of Uranus could be explained by assuming an outer planet which, according to his reckoning, was then moving along at such and such a point in the heavens. So important a post as that of Astronomer Royal must, to be sure, be filled by a personage of distinction. This has its disadvantages. It was Huxley who remarked that the moment a man acquires a great reputation in science he becomes a nuisance. The remark found here an exemplification.

If the Astronomer Royal had pointed his telescope towards the spot indicated by Adams he would have found the new planet within less than a couple of degrees of its calculated location. Instead of that he wrote back a letter with some foolish, vapid questions, quite in the spirit and quite on the customary mental level of official science and official investigation of any character whatever. Meanwhile Leverrier was ready with his results; they were published in June 1846 . The 
distinguished Astronomer Royal received a copy of this paper as well; he was astonished to find that the theoretical place of the planet, as calculated by the French mathematician, was within a degree of the point fixed by Adams. It is amazing to think that he could not be stirred to turn his telescope around and hunt, instead of writing another letter with the same questions. But another letter he wrote. Adams meanwhile had been perfecting his calculations; finally, the big telescope at Cambridge was brought into action. It must likewise have been in charge of a fat-wit, for the new planet was actually seen but not recognised; his method, Newcomb says, was like that of a man who, knowing that a diamond had been dropped near a certain spot on the sea-beach, should remove all the sand in the neighbourhood to a convenient place where he might sift it at his leisure.

No doubt others had tried; it was a difficult quest. But in methodical, painstaking Germany they were making splendid star-maps. To the head of the Berlin Observatory Leverrier wrote a careful letter, fixing with very confident precision the point where the new planet could be found. The head of the institution, Galle, received the letter on an afternoon; that night he swung his telescope round and the discovery was made. The planet was found exactly where these two mathematicians had reckoned it should be. In neither of the countries to which they belonged could the astronomers in charge of the great telescopes be roused to give heed to these unhonoured prophets. Thankfully there are not many similar instances in the history of the science, in which such extremes- of brilliant investigation and official stupidity have come together with such luckless result.

It was assuredly an amazing result, one of the spectacular triumphs of the calculating mind. There is scarce need to add that when it had come there could no longer be any doubt as to the universal application of Newton's law. By the aid of that law the hand of the astronomer had dipped into the distant waters of space and brought from its invisible depths a new world. Even while they hovered on the edge of the discovery, Sir John Herschel, in an address before the British Association, had very beautifully observed :-

"The past year has given to us a new asteroid; it has done more-it has given us the prospect of another planet. We see 
it as Columbus saw America from the shores of Spain. Its movements have been felt, trembling along the far-reaching line of our analysis with a certainty hardly inferior to ocular demonstration."

The discovery is often cited as one of the great feats of calculation; it was hardly less a witness to the marvellous accuracy which astronomy had attained. The deviation of Uranus from its appointed path, set by Kepler's law, never exceeded two astronomical minutes - that is, the thirtieth part of a degree. It lies just on the fringe of visibility; Neptune far beyond. The one would probably never have been recognised as a planet but for the invention of the telescope; without its present-day perfection, the second would never have been known.

The last of the planets possessed, like its immediate forerunner, but few conspicuous traits. It is a little larger than Uranus; like the latter, it rotates in an opposite direction to that of all the other planets. But its distance was a complete anomaly. If the law of Bode held good, it would have been found at something like twice the distance of Neptune-that is, at nearly forty times the distance of the earth from the sun. Instead of that, it is something less than thirty times. It had been difficult enough before to reconcile the observed distances of the planets with any absolute order of arrangement. With the discovery of Neptune's orbit, the idea of a simple "law" of distance was given up. Until we know more of planetary evolution than we do, it will be quite impossible to say why it is that the planets are spaced as they are.

It remained a natural question as to whether the new planet was in reality the outermost member of the system, or whether others lay yet beyond. Sixty years and more of observation, scrupulous in its method, and with an ever-increasing delicacy of observing instruments, has failed to present even a suspicion of an ultra-Neptune. The orbit of the new planet showed no such wobbling as that which, in the motion of Uranus, had pointed to the existence of the other. We may conclude, therefore, not absolutely, but with a considerable degree of probability, that we now know the shape and size of our planetary world, and practically all that is worth knowing of its contents.

Our planetary system consists, then, of eight large bodies, 
circled by twenty odd moons or satellites; of a swarm of asteroids ; a number of more or less prominent comets. These revolve within a very thin, very broad zone, that we might picture as like a cart-wheel cheese, or a very thin grindstone; or if you like, a very thick penny. In order of size or arrangement there seems no fixed relation; the mass of a single planet is greater than that of all the rest of the satellites of the sun put together. Yet even with Jupiter added, they form but an infinitesimal portion of the sun itself-grains of small shot beside a cannonball.

What lies beyond? The answer, so far as we may gather, is simply : space-space and space, and, for all we shall ever care, never an end. Neptune is distant from us thirty times farther than we are distant from the sun; so far as we know, for a thousand times this distance there is nothing, save, it may be, swarms of meteorites, speeding comets, and fragments of exploded worlds. There is certainly no star, no sun, within this distance; if there were any dark body at all comparable with the grandeur of the sun, its existence would be disclosed by the disturbing influence it would exercise on the outer planets.

Not in a thousand times the distance of Neptune,- - not, in so far as we know, in nearly ten thousand times. Were we to picture the whole solar system as a huge vessel, perhaps the size of the Lusitania, anchored or slowly floating in the midst of the lone wastes of the Atlantic, unvisited and uncompanioned by any other craft, large or small, we should have some sense of our isolation in the cosmos.

Are we anchored, or do we drift? Our sun is obviously one of the stars. Is it, and are they, fixed and immutable within the eternity of space and time? Was this universe of flaming suns cast, as it were, in a solid mould? If there be motion, do we merely drift, or are we speeding the stellar ways at velocities compared with which the flash of the cannon-ball would seem like the leisurely meandering of a sluggish stream ?

If we move, where, in distant æons, shall we bring up ? 
CHAPTER XXV

HERSCHEL AND THE HELTER-SKELTER FLIGHT OF THE STARS 
A moody child and wildly wise

Pursued the game with joyful eyes

Which chose, like meteors, their way,

And rived the dark with private ray:

They overleapt the horizon's edge,

Searched with Apollo's privilege;

Through man, and woman, and sea, and star,

Saw the dance of nature forward far ;

Through worlds, and races, and terms and times,

Saw musical order, and pairing rhymes.

EMERSON.

How can Dryasdust interpret such things, the dark, chaotic dullard, who knows the meaning of nothing cosmic or noble, nor ever will know?

CARlyle, Sartor. 


\section{CHAPTER XXV}

\section{HERSCHEL AND THE HELTER-SKELTER FLIGHT OF THE STARS}

THE surface velocity of the earth, especially between the tropics, is high-seventeen miles per minute, fifty times swifter than the swiftest cannon-ball. Seen from the centre of the earth, it would appear very slow; the hands of a clock turn twentyfour times while the earth turns once. Relatively, a huge Ferris wheel, revolving once in a few minutes, goes hundreds of times as fast. The whole great earth booms through space at nearly sixty times the speed of its surface in revolution, nineteen miles per second, two thousand times the cannon-ball. Yet from the sun, this dizzy flight would be imperceptible save to repeated observation; the earth would pass over only one degree of a circle in a day. We could think of it as fixed at the end of a spoke in a wheel ; the earth turns about this solar axis once in a year.

For us the crystal sphere of the stars is a globe, our earth its centre. Does it too revolve? Should we ever know if it did ?

When measurements of the telescope had reached an accuracy of a second of arc and the stars revealed no parallax, it was clear they were beyond two hundred thousand times the distance of the sun. Conceive that they are all turning about our sun, like the planets. The length, the circumference, of circles are to each other as their radii. If the stars moved as swiftly as the earth, then at this distance their "year" would be two hundred thousand of ours. They would require six hundred of our years to cover a degree. Their apparent annual motion then would be about six seconds of arc.

No such motion as this could be perceived; for a long time no motion at all. Yet, here and there, it did seem that, in very long periods, some of the stars had shifted place slightly.

Early in the century Halley, the sower of much seed, the harvest from which others would reap, had pointed out that 
at least three of the best-known stars of the heavens, Sirius, Arcturus, and Procyon, had certainly changed in their inclination to the ecliptic since Greek days, if the star maps of the Alexandrian astronomers could be relied upon. His view was strengthened by the fact that the brightest of all, the Dogstar, had perceptibly altered its position since the days of Tycho Brahé. Comparison of the ancient records of other stars indicated other probable deviations; but the motion, the change, was so minute that it might readily be an illusion or an error.

So far as the most careful observer gazing up at the sky could see, it has in no wise changed from the times of the earliest Greeks. Probably they had records now lost to us. Doubtless they made comparisons as did Halley, with all the care and accuracy at their command. Their idea was that the stars were fixed. So, for aught that the sceptic Halley could demonstrate, they remained.

Then came Bradley's discoveries showing how a considerable degree of apparent motion could be accounted for, simply from the annual motion of the earth, and the swaying of its axis. When, half a century later, Herschel began his investigations, the question was still open. The proof that they do move and much more beside, was his.

The attribute of genius is flung about rather carelessly at times; such a quality alone can account for such a career as that of this poor German musician, who became the greatest observing astronomer of his age. Kepler, we recall, came up from a pot-boy; the origins of Galileo and Newton were quite as humble; but all of them had a university career. Herschel had none. He was thirty-five before he had ever looked through a telescope. His father was an oboe player in a German regiment. It was not an intelligent pursuit; it is not ordinarily a stimulus to high deeds. The boy was brought up to the same task. His coming to England was through the removal of the Hanoverian guards to that country while he was playing in the regimental band. He was soon out of it; shortly afterwards he becomes an organist and music teacher in Bath. So his life runs along tranquilly for ten or twelve years, years in which the bent of a man is usually revealed and developed. Herschel was studying ; the long day over, he was deep in mathematics, optics, languages, trying to make good the education which he had lacked. In the end he comes across a work in 
astronomy. For the rest of his life in every spare moment he will think of nothing else. He determines to buy a telescope ; it is beyond his means; he makes one of his own; then another and another, until he has at last an excellent ten-foot reflector, and the real work of his life is begun.

His industry must have been something prodigious. By day, in the intervals of teaching, he is grinding lenses for larger and larger telescopes. In the evenings he is conducting concerts and oratorios; then sweeping the heavens for the rest of the night. He must have been of tough fibre to stand such a strain.

After five or six years of it his reward comes. He discovers the comet-like star which turns out to be the new planet which they will call Uranus. In a spectacular way it is the biggest thing since the discovery of the telescope itself. Like Byron, he finds himself famous in a night. The Royal Society makes him a Fellow; the King sends for him. He may now give up his concerts and music classes; he has a workshop and an observatory of his own, with the princely salary of $£ 200$ a year. Astronomy becomes the fashionable fad of the time, and telescopes are in demand. He makes them by the score. But soon, from a friendly word, the King realises how absurd it is to have this wonderful man grinding lenses, and he is given money to build a great forty-foot instrument, which is the dearest dream of his days. It is a magnificent affair ; compare it for an instant with the resources of Galileo. His crude tubes would enlarge only thirty-two times, Herschel's several thousand-six thousand, one may read, but the figure is somewhat misleading. How the noble Florentine would have stared could he have seen it ; would he ever have left off observing if it could have been his!

But its creator is worthy of the instrument. What he did with it forms a good share of modern stellar astronomy. $\mathrm{He}$ maps and catalogues the stars, the nebulæ as well. He discovers eight hundred double stars-stars which to the eye had seemed single. He passes in review the whole firmament open to his gaze, not a single time but four times, with a minute scrutiny as if he were searching for gold. He counts the number of stars in each of more than three thousand divisions which he makes of the firmament.

From all this he rises to a yet greater discovery or, if any prefer, demonstration - that of the proper or straight-line motion 
of the stars themselves. What many another astronomer, seeking as ardently as he, had failed to find, he made clear. Outside of any effect due to the refraction of the earth's atmosphere, to the motion of the earth about the sun, to the aberration of light, to the nodding of the earth's axis, he reveals, proves, that the stars move. Not to him will it be given to find their parallax, to compute their actual distance ; that must be the work of instruments yet more delicate than any he can contrive. But their relative motion at least he can disclose.

It is no revolving heaven that he finds, no fixed order; it seems all a random, mindless, helter-skelter flight. A swarm of bees, a cloud of fire-flies, reveals as little purpose. Sometimes it seems that there are real clusters; almost all of the Pleiades appear to move in a common direction-so do five of the seven stars of the Dipper. But, for the most part, it is chaotic enough ; side by side, one star is falling ever downwards, another rushing toward the zenith, two others speeding away in opposite level flight for the poles of the universe. Some may be describing orbits; it seems fairly certain that others are not. Some are flashing across the abyss of space at such tremendous speed that the combined mass of a hundred million suns could not hold them in leash.

Picturing it all, it seems like nothing so much as a wild dance, a mad Sir Roger de Coverley of suns, in a line that knows no end. Even now the mind cannot grasp it; a poet perhaps, not we of common clay! Yet, could our human kind wake to the full consciousness, the true significance, of this weird and seeming insensate riot of the stars, should it be happier, stronger, then than now?

"All a wonder and a wild surprise." And still, amid the confused movement of the heavens, there did seem, slowly emergent, one general fact. From it Herschel rises to that discovery of his which for us was of largest import.

Of course, if sun and planets are swung free in space, an apparent motion of the stars may be illusory; it might be due to our own motion instead. It might be the case of the Hipparchan-Ptolemaic and the Aristarchan-Coppernican conceptions over again. Just as our earth turns about the sun, so our sun may be circling some central luminary lost for us in the depths of space, compared with which our sun may be but a minor 
satellite, as our earth is a minor satellite to the sun. Our little system, this microcosm, may be the type, the image of the macrocosm; or, more simply, we may quite leave on one side any question of system or solar orbits. If we conceive the stars, these other suns, in motion, why regard our own as fixed ? It may be moving too-not perhaps in an orbit, but yet some whither.

It is hard most times to track out the history of an idea; that of a translatory motion of our system in space can hardly have been very remote, at least as a scientific inference. Exist it might in the teeming imaginations of Bruno or Democritus ; it could be but a guess. It might readily have reached its first distinct presentation in the mind of the man who had discovered the periodical aberration of the stars, and therewith made clear the almost fathomless distances at which they must lie. It is to Bradley, in fact, that Humboldt accredits it. In the work in which Bradley announced his second discovery, that on nutation ( $(\mathrm{I} 748)$; there is a remarkable passage :-

"For if our own solar system be conceived to change its place with respect to absolute space, this might, in process of time, occasion an apparent change in the angular distances of the fixed stars; and in such a case, the places of the nearest stars being more affected than of those that are very remote, their relative positions might seem to alter, though the stars themselves were really immovable. And on the other hand, if our own system be at rest, and any of the stars really in motion, this might likewise vary their apparent positions, and the more so the nearer they are to us, or the swifter their motions are, or the more proper the direction of the motion is, to be rendered perceptible by us. Since, then, the relative places of the stars may be changed from such a variety of causes, considering the amazing distance at which it is certain some of them are placed, it may require the observations of many ages to determine the laws of the apparent changes even of a single star; much more difficult, therefore, it must be to settle the laws relating to all the most remarkable stars."

But "the many ages" of observation were not needed. Time was going more swiftly now. It was scarce forty years, and not long after Bradley's death, before his ideas were put 
to the solid test. Mapping, plotting, comparing the bizarre and bewildering movements of translation, which with his great reflector he can demonstrate to exist, Herschel comes at last to perceive or imagine that in one direction of the heavens the stars are slowly separating, while in the opposite direction they are surely coming together. You watch a herd of sheep upon a hillside, or a multitude of men at a distance; they form a kind of blot or blur. A little nearer you begin to distinguish their heads; finally you perceive that they may be all standing or moving about at some distance apart. As you draw away, the process of separation is reversed-the single units again become a blur. There was hardly any mistaking the meaning of Herschel's observation. It was that we are drawing nearer - to the stars in one direction, flying farther and farther from them in another. The differences were almost inscrutably minute; the detection of each single motion had been in itself a long and painful task.

Moreover, the number of firmly established proper motions which he had to go on was very small. In his first paper on the subject he can use only fourteen. He did not reach his conclusion from the mere weight of his evidence; the evidence was slight. You review the prodigious industry of Herschel, and you gain the impression that he may have been one of those tireless and unflagging investigators who lay bare the truth simply by grubbing. Before his journals were published a great many people thought this of Darwin. We forget that the number of grubbers is not small. That Herschel's determination of the direction of solar motion was something more is evident from the fact that it was entirely distrusted by almost all the astronomers of his generation.

Curiously enough, only a few months after his results were published, a French observer, Prévost, reached a similar deduction from another series of observations than those which Herschel had employed. Their results were in quite striking agreement; they pointed to the idea that our system is moving, rather slowly as cosmic motions go, towards the constellation of Hercules. This point may readily be fixed by extending a line drawn through the three stars in the handle of the Dipper which lie in a straight line, to a distance about twice the extreme length of the Dipper itself, that is to say, to a point about equally distant from the Pole-star and from Arcturus. 
Twenty years later Herschel made another attempt, with seemingly more reliable data. It is evidence of the somewhat speculative character of his ideas, that in his second trial he seems to have gone wider than in the first. The exact point can hardly be said to have been established even yet. We have now clearly determined proper motions of hundreds of stars, where Herschel had less than a score. A century or more of observation, comparing, trying out, has served only to confirm, broadly, Herschel's earlier results. It may be that the stellar apex, as he called it, towards which we are moving, lies in the adjacent constellation of the Lyre rather than in the outstretched arm of the Greek god. It is a question of but a few degrees; either way the vital fact is that our solar system does move. The proof of this was Herschel's work.

The direction of this translatory motion appears to be at an angle of about sixty degrees to the plane of the ecliptic, in which we move about the sun. The result of this is to cause the earth to describe in the heavens, a spiral path. It might crudely be illustrated by a bed-spring leaning over to one side. It is perhaps worth noting that this corkscrew flight of the earth does not produce a motion tending progressively to turn the heavens upside down as some muddled minds have conceived.

Herschel made more than one attempt to determine the velocity of solar motion; obviously the available data were scant. It is of some interest that his conclusion was that "we may in a general way estimate that the solar motion can certainly not be less than that which the earth has in her annual orbit." This is nineteen miles a second. The latest calculations do not vary greatly from this figure. For a time it was supposed that the sun was careening through space with a rush ; some estimates put it as high as a hundred and fifty miles per second. It now seems likely that it is not much more than ten or fifteen miles, somewhere probably between these two. In this view the annual displacement of the solar system is a little more than double the diameter of the earth's orbit, or only about a tenth or fifteenth part of the diameter of the system itself.

Obviously if the stars were "fixed" it would require an enormous range of time before this displacement would be sufficient to cause any appreciable difference in the appearance of the firmament. So, too, it will be a long time before we shall be able to determine the larger question as to whether the motion of the 
sun is a mere aimless flight, no whither and no whence, or whether it be describing a curve about some central point.

The surmise of a circular motion was natural. The revolution of the planets, the quantity of satellites which in turn revolve about them-possibly, for aught we know, the satellites themselves may have their little moons-obviously suggested that this wheel-within-a-wheel arrangement is characteristic of the whole cosmic order. As yet there is no evidence pointing towards a central sun, but the idea that such a sun exists was considerably strengthened by another of the long list of discoveries made by this same wonderful man.

As Bradley's hunt for minute movements of parallax had led him to the discovery of aberration, so Herschel's researches in the same field led him to the discovery of the double stars.

Galileo had long before pointed out that the stars most advantageous for the discovery of a possible parallactic shift are those which lie in almost identically the same line of sight. The swing of the earth in its orbit would certainly produce a larger and more easily detected change of position in such a pair of stars than those more widely separated. Following this hint, Herschel set about making a catalogue of such doublets. One day the idea came that this closeness of position was not a mere accident resulting from the especial angle under which we see them, not a mere coincidence, as, for example, when a pair of mountain peaks happen to lie in the same line of view from where we are standing. The number of these coincidences was far too great. Laplace and others were then engaged in making the calculus of probabilities a fashionable study. The simplest computation from the laws of chance sufficed to show that alike the nearness and frequence of these pairs of stars was far greater than would occur from any random distribution.

So absorbing was their study that, as the difficulties of establishing any angle of parallax became more and more clear, Herschel gave over his attention to these perplexing appearances. Finally his reward came. It had been for some time known that the bright star which we call Castor, of the constellation of the Twins, is in point of fact two stars, so nearly in the line of sight that they appear to the eye single. From a long series of observations, supplemented by another by Bradley of many years before, Herschel was able to perceive a minute change in the position of the two stars, such as to leave little 
doubt that they were in reality revolving, one around the other. With this clue he set about searching for others: he found half-a-dozen. His observations enabled him to attempt a rough guess at the periods of their revolution; that of Castor and its twin he put at three hundred years. It has slowed down since; the present estimate is about a thousand years.

From this small beginning the number of double stars, or Binary Systems, as they have come to be called, has grown until they are now numbered by the hundreds. Their discovery naturally led to a search for triple and multiple systems. The probable existence of such multiples is no longer a matter of much question. So it was that Herschel's studies opened the way for some insight as to the structure of the universe. It was this latter which eventually became the especial predilection of his life.

But the heavens show something more than stars. Just as here and there-appear little clumps and clusters, so even to the unaided eye there are here and there faint blurs which do not seem to be made up of distinct stars. The old-time observers had given to these the name of nebulæ or clouds. The first effect of the introduction of the telescope was to resolve these star clouds in part into star clusters; naturally it was supposed that telescopes of higher power would resolve them all. Even before Herschel's time, such a view was found to be erroneous. Several astronomers just preceding him had begun to catalogue the nebulæ, with the idea of eventuaily determining their density and the changes that might take place in them. One of these observers was Messier, whose specialty was hunting comets. It was often very difficult to distinguish a comet from a nebula, so he made a record of over a hundred of these puzzling apparitions. This was where the matter stood when Herschel took it up.

Before he had done he had catalogued twenty-five hundred - disclosed, as well, their extraordinary variety. What was still more of interest was that he came to conceive them as the stuff from which suns and stars are made. He found them of all shapes and sizes, some bright and some dull, some with a seeming nucleus in the centre, some like cloudy stars surrounded by a nebulous atmosphere. As he phrased it, he found that they could be selected "so that an insensible gradation shall 
take place from a coarse cluster like the Pleiades down to a milky nebulosity like that of Orion, every intermediate step being represented." At first this led him to the idea that eventually they might all be dissolved into stars. Later on, as we shall find, he put aside this view, to regard them as floating islands of starry mist.

Herschel did not exhaust the possibilities of stellar research, though so it must have seemed when he died. He lived to a splendid age; he left a son nobly to carry on his work. The life with which his own may best be likened is Galileo's. $\mathrm{He}$ did for the larger universe of the stars what the Tuscan had done for the immediate portion in which we dwell. Theirs undoubtedly was a wonderful opportunity. But it was open to others. That is why in the records of this world the account of genius-the departure from the normal, essentially imitating, uninnovating mind-must always be large.

Our debt to them is great. Consider how vast a revolution had been wrought in the thoughts of mankind within the brief span of the life and death of these two men and we shall hardly begrudge their fame. It was a period of but little more than two centuries. Within these two centuries the race had gained a larger, more precise, more vivid idea of the realities of creation than, let us say, in the two hundred centuries or more that we may consider civilisation - a relatively high civilisation, in point of speech and manners and the conveniences and trappings of life-to have endured.

Yet in a larger sense it was not their work. It was the work of an instrument-in rounder phrase, of a machine. Without the telescope, Galileo and Herschel-yes, and Newton and Laplace and all their kind-were as babes on a deserted barque drifting the ways of the sea. Think of what were our ideas without it; consider what an utter havoc it wrought in all man's primitive impressions and ideas. When Galileo lifted his first telescope to the sky, there was naught save the geometrical constructions of a priest to disturb the repose of the earth. Men trod upon a globe solid and unmoving, and beneath the unhasting heavens. "Unchanging as the stars" was a synonym of the time. When Herschel died, men lived upon a whirling earth, shooting incredibly through space; this earth but a point turning round about one of fifty million suns. The optic tube had confirmed wild conjecture, had reached far beyond 
conjecture into the realms of dream. Neither earth nor sky nor suns stand still. There is nothing fixed, nothing at rest. The suns are tumbling headlong, shooting each whither, upwards, downwards, in every direction, dragging with them their progeny of helpless satellites.

Could Lucretius return, could his intellectual godfather, Democritus, come again among men, how marvellously they would find their previsions fulfilled; for, seen through the eye of the telescope, is it not, as their vast imaginations conceived, less a cosmos than a chaos into which we are born, wherein there seems nothing but blind confusion, a hopeless disorder, a wildly scattered rout, a drunken revelry of dancing suns ? 


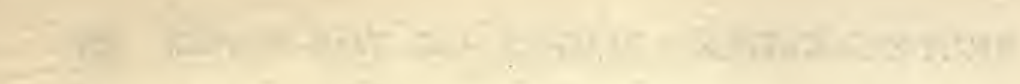

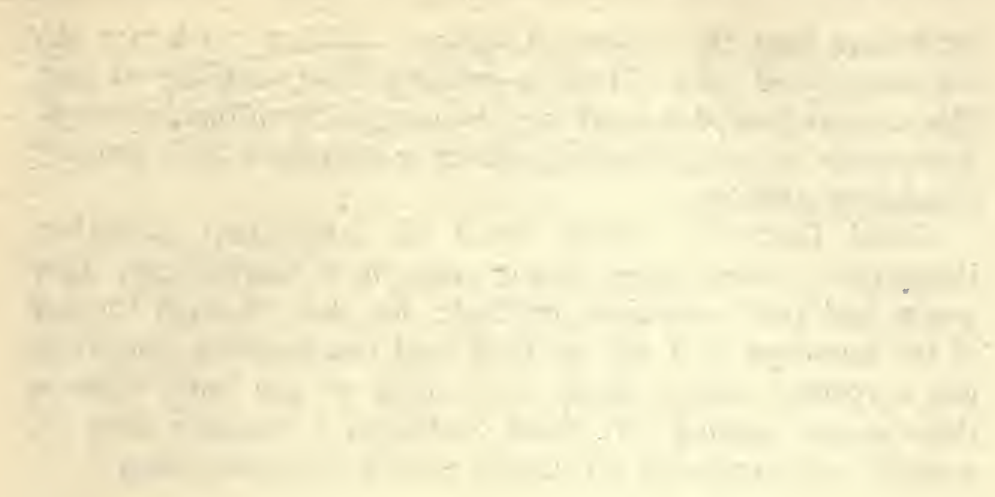


CHAPTER XXVI

THE MEASURE OF STELLAR SPACES 
Præterea, si jam finitum constituatur

Omne quod est spatium, si quis procurrat ad oras

Ultimus extremas, jaciatque volatile telum,

Id validis utrum contortum viribus ire,

Quo fuerit missum, mavis, longeque volare,

An prohibere aliquid censes obstareque posse?

Alterutrum fatearis enim sumasque necesse est ;

Quorum utrumque tibi effugium præcludit, et omne

Cogit ut exempta concedas fine patere.

Nam sive est aliquid, quod probeat efficiatque

Quo minu' quo missum est veniat, finique locet se,

Sive foras fertur, non est a fine profectum.

Hoc pacto sequar atque, oras ubicumque locaris

Extremas, quæram, quid telo denique fiat.

Fiet uti nusquam possit consistere finis,

Effugiumque fugæ prolatet copia semper. . . .

LuCRETIUs, De Rerum Naturâ, I. 967.

S'il est une limite à cette immensité,

Imagine un archer, qui de l'extremité

Decroche avec vigueur une fleche rapide ;

Admets-tu que le trait parte en l'espace vide.

Qu'il vole sans que rien soit la pour l'arrêter,

Ou bien à quelque obstacle ira-t-il se heurter ?

Il faut faire ton choix, et ta raison captive

Ne pouvant s'échapper de cette alternative

Sera, tu vas le voir, contrainte d'effacer

La borne qu'd̀ l'espace elle pretend fixer

Car soit que quelque chose interrcepte à distance

Le fleche, soit que libre au loin elle s'élance,

Tu vois bien, en prenant l'un ou l'autre parti,

Que le bord n'etait pas d'ou le trait est parti.

Avance, si tu veux, avance ta limite,

Tu ne peux m'eluder; de poursuite en poursuite

Je t'arrête et je dis : que devient notre trait?

Ainsi toujours, toujours ta borne avancerait,

Et partout à l'archer, n'importe ou tu le places,

L'immensite sans fin ouvre d'autres espaces.

Traduction de M. Martha. 


\section{CHAPTER XXVI}

\section{THE MEASURE OF STELLAR SPACES}

IF the truth be the highest thing for which man may strive, it surely seems to follow that we should award to seekers for the truth a special place. So, in a way, mankind has always done, first among savage tribes, to the medicine man ; in later days, when his view widened to the inclusion of moral problems, to the priest; later still, when he had begun to reflect upon the larger enigmas of existence, to the philosopher; in our own day, when the thing of utmost worth seems the reality, to the magi of science:- But if the things revealed by these later-day workers of magic be worth while, if humanity has been broadened, its aims exalted, if its primitive savage instincts to hurt and to kill, to maim and destroy, have been repressed or diverted, then surely we owe a debt to those who have supplied the means by which the miracle has been wrought.

It is a commonplace that all our knowledge of the world in which we live, its surroundings, its nature, its extent, has been derived from mechanical appliances. Then it is not to Galileo, the user of the telescope, but to Galileo the deviser, and to his obscure forerunners in Holland, that the greater debt is due. Insufficiently do we do honour unto him who contrives, who constructs, who invents, who improves. In the instance immediately at hand it was the instrument-maker who made it possible to work out the ranges of the stars. Scores and even hundreds of assiduous astronomers had tried it, but to no end. They had conceived many ingenious and roundabout ways ; perhaps two of these are worthy of record.

The new star that roused Galileo to his first great battle for the Coppernican system-the new star of I604-had likewise deeply engaged the attention of Kepler. He saw it first in October. By January it had begun to wane. When October came again it had disappeared from view. It was certainly a star. This Kepler could be sure of, because within this year 
his point of view had been shifted from one side of the earth's orbit to the other and back again, and still he could observe no change of position in the star, relative to its neighbours.

If yet unable to fix its distance, Kepler bethought himself of a method that might at least determine the lower limit. His idea was simply this: The outermost of the planets then known completes its orbit in a little less than thirty years. In a year, then, Saturn passes through an arc of about twelve degrees of its circle; in six months, half this. The position which it should occupy against the bank of stars may then be determined accurately for any desired moment. But if Saturn be observed from the earth at intervals of six months-that is to say, from one side of the sun to the other-its apparent shift of position averages about six degrees. And its distance from the earth is known.

Kepler estimated that the limits of error in observation attained in his time certainly did not surpass two minutes of arc. If, therefore, no shift like that of Saturn could be discovered for the new star, it follows that it must be as much more distant as six degrees are greater than two minutes. This was I80 times. Saturn being ten times the distance of the earth to the sun, it was clear that the new star was at least I80o times this distance. The same method was, of course, applicable to any star, and as the limits of possible error were steadily reduced, this lower limit of distance was steadily raised.

It had reached at least ten times I80o earth-distances when, fifty or sixty years later, the fertile mind of Huyghens caught up the problem from quite another point of view. By that time the ancient plan of classifying the stars according to their relative brightness had been taken up anew. Through the aid of the telescope they were able to fix this relationship with a far greater accuracy than anything hitherto known. Accustomed to such minuteness of observation, Huyghens conceived the idea of comparing the brightest of the stars with the sun. To effect this comparison he placed across the end of his telescope an opaque disk, which he pierced with a pin-point. Turning his tube now towards the sun, he found that its brightness, shining even through this minute aperture, vastly exceeded that of Sirius. Decreasing the aperture yet further by means of a small objective, Huyghens calculated that he must reduce the diameter of the sun 27,000 times in order to bring it down to the brightness 
of Sirius. It followed from this that if they are the same in size or light-giving power, Sirius is at least 27,000 times the distance of the sun.

The computation was vague; it was, after all, an estimate and not an exact measure, and it was an exact measure which, with the splendid advance of the science in other fields, now became the goal of stellar observers.

About the time that Bradley, despairing of any direct determination, had turned his attention from questions of parallax to that of the proper motion of the stars, an idea occurred apparently to several minds which was to bring the solution of the problem. One of these was a young Englishman named Savery, fated, like Gascoigne, his predecessor in this immediate work, like Fraunhofer, who was to follow him, to show a brilliant promise, to do a brilliant work, then to be cut off before he could enjoy its fruits. He had suggested a recondite method of working out stellar paraflax from observations of the aberration and velocity of light; in practice it failed, from the extreme complexity of the problem.

He turned from methods to instruments; the device he imagined - it seems independently to have occurred to a French contemporary, Bouguer-was not less ingenious and of far greater value. It was simply the notion of having a sort of binocular telescope with a single tube, showing two distinct images; it was so constructed that the images could be separated or superimposed at the will of the observer. From this it was possible to measure exceedingly minute angles. Perfected in the hands of the famous instrument-maker Dollond, the object-glass was simply cut in twain and mounted so that one half might be made to slide past the other. As imagined by Bouguer, the device was intended for the measure of the horizontal diameter of the sun; it thence derived its name of the heliometer, or sun-measurer.

So it remained, with but little wider application, until it was taken up by a young German optician, Fraunhofer. He had started out as an apprentice for a looking-glass maker, deadly poor, with no parents and no one to help. He revealed a genius for grinding and polishing mirrors and glasses; eventually he rose to be the head of the optical department of a great Munich firm. His name is more familiar as it is attached to 
the well-known Fraunhofer lines in the spectral image; it was his careful maps which first gave them prominence. But his greatest deeds were his instruments. Two of his most beautiful constructions were the famous Dorpat refractor and the Königsberg heliometer, set up in I829. The latter was essentially an equatorial telescope, designed on the Dollond plan of a divided object-glass, and provided with micrometer screws, permitting of angular measurements of an unheard-of accuracy.

At this time the head of the Königsberg Observatory was the celebrated Bessel, with a brilliant record as an observing astronomer, author of a vast work of tabulation, the Fundamenta Astronomice, and keen to prove the powers of his new instrument. As far back as I8I2 he had made an especial study of a double star in the constellation of the Swan, known in the catalogues as 6r Cygni. It was not a brilliant star-it is invisible to the human eye-but it had been found to have a relatively rapid motion across the line of sight. It had been studied by other astronomers after Bessel. Arago had spent a great deal of time upon it, with the merely negative result of determining that its parallax must be less than half a second. This meant that it must be more than four hundred thousand times the distance of the sun; how much farther no one could say. At the Cape of Good Hope, Henderson, with a fine instrument, was taking observations upon a great double star of the southern hemisphere, the alpha star of the Centaur; Struve was busy at Dorpat. It seemed certain that some sort of a result would be reached soon; as yet they were little further advanced than Hooke in the seventeenth century or Herschel or Bradley in the eighteenth.

When Bessel turned his great new heliometer on the swiftflying star of the Swan again, he must have felt that the goal was very near. He says himself that he did not know whether the measurements of its angle would turn out to be tenths or thousandths of a second of arc! Consider for a moment what this means. The dial of your watch is divided into sixty spaces, each representing a minute. Cut each of these into six and you have the three hundred and sixty degrees which make up the astronomical circle. Division of each degree by sixty gives astronomical minutes; by a sixty again gives astronomical seconds. A tenth of such a "second," then, is not a twohundred-thousandth part of the space crossed by the watch 
hands each minute of time; a thousandth of a "second" is less than a twenty-millionth part.

One has perhaps a little better idea of the accuracy attained when he thinks of looking through a slit at the far end of a tube, the slit the breadth of a thin knife-blade-say, the hundredth of an inch-the tube more than half a mile long. The slit would represent a tenth of a second of arc, of which one degree would cover thirty feet. These are the units, the subdivisions of the gauge, with which Bessel and his successors worked.

Observations taken from August I837 to October I838 led him to a parallax for 6I Cygni of $\frac{34}{100}$ of a second. This meant nearly six hundred thousand mean distances of earth to sun. It meant that light, travelling six hundred and sixty million miles per hour, would require nine and a half years to cover the intervening space. The distance has since been slightly reduced. But nearly seventy years of minute observation, by many different astronomers in different parts of the earth, have changed Bessel's result but little. He had at least reached a figure which could stand. The long puzzle was at an end. Here at last was a star whose distance was known.

Curiously enough, as so often happens, the solution would have come from other hands within not more than a year. Combining the observations of Henderson in 1832 with others made in 1839 , it was found that there was a star much nearer than this No. $6 \mathrm{r}$ of the Swan. This was the now familiar alpha Centauri, the third brightest star in the heavens, but unseen by our northern eyes. Its parallax was originally calculated at $0^{\prime \prime} .9 \mathrm{I}$, or nearly a second. Subsequent reckonings have reduced this somewhat; it is now set down at $0^{\prime \prime} .75$. This indicates a distance of 4.4 light-years. Seventy years of observation, again, have failed to disclose any more proximate sun.

About at the same time, Struve at Dorpat announced a parallax of a quarter of a second for Vega. Somewhat earlier he had estimated that of the alpha star in the Lyre at between 0 ".I and $0^{\prime \prime} .2$ of a second. After two years of observation, Peters, at Pulkowa, gave $0^{\prime \prime} . \mathrm{I}$ as the parallax of Polaris. This figure is slightly too great; it is probably not more than $0^{\prime \prime} .06$, answering to a distance of forty-four light-years. This is still about at the limit of certain parallactic measure. It is painful work; less than a hundred are yet known with sufficient precision to permit of any confidence in the results. This is 
hardly more than an average of one a year since Bessel's day.

Still, it is a beginning-enough to make certain that a true parallactic shift of the stars may be found, has been found. What Aristarchus, what Tycho, what Galileo, what Hooke, Halley, Bradley, Herschel, and a long line of investigators could not discover, Struve, Bessel, and Henderson had attained. They swept away the last objection that might lie against the Aristarchan-Coppernican scheme. For all thinking minds Bradley's discovery of aberration, the queer little annual shift of the stars in their places, had been definite proof. In no other way than by supposing the annual motion of the earth could this indubitable shift be explained. There could, indeed, be little doubt in an intelligent mind after Cassini's demonstration of the true distance and grandeur of the sun. It was wholly inconceivable that a body a million times the bulk of the earth should revolve about our midget planet.

After I840 or I850, when the results of Bessel and the others had been fully confirmed, doubt became mere obtusity. Human certitude can never be absolute; it can only approach infinite probability. It is practically infinite probability that the truth of the Coppernican theory will never be seriously questioned again so long as the world shall last.

The discovery of stellar parallax brought more than simple proof of theory ; it gave us our first insight into the true grandeur of the stars.

So long as man had no means of knowing their distance, it was open to suppose that the brighter stars are the nearer stars, that they are all more or less of a size. It was equally open to suppose that they were all at the same distance-a very great distance, no doubt-and that they vary in size as they vary in brightness to our eyes. Neither supposition in any wise represented the fact.

The nearest star, alpha Centauri, as convergent lines of study make clear, is something very close to a duplicate of our own sun. It is about the same in size, temperature, and brightness. We may therefore suppose that its evolution has been very nearly parallel to our own. It is not very fanciful to think that the discovery of the nearness of our sun was made upon one of the planets of alpha Centauri at about the same period 
as the determinations of Henderson and Bessel. We should allow always for a possible error of a few million years. Our sun would appear a star of the first magnitude to them, as does alpha Centauri to us.

At about twice the distance of alpha Centauri is No. 6I Cygni. It is of the fifth magnitude. Clearly, then, unless it be of an utterly different constitution, it is very much smaller than alpha Centauri or our sun. Its actual brilliancy appears to be not more than one-tenth that of the sun; it may not be one-third the latter's diameter.

At about the same distance, between eight and nine lightyears, is the great Dog-star. Sirius is nearly three times as bright as alpha Centauri, ten times as bright as 6r Cygni. The light it gives is perhaps thirty times that of our sun. Its bulk, if its temperature were the same, would therefore be more than a hundred times the bulk of our sun or of our nearest neighbour star.

Again, outshining any other star in the northern heavens, is huge Arcturus. It is fifteen or twenty times more distant than the Dog-star, and still more vast. The light it sheds would be equal to that of perhaps one thousand three hundred of our suns. It is apparently a solar type of star; its bulk, therefore, must be three or four thousand times the volume of Sirius, perhaps forty or fifty thousand times the volume of our luminary.

Apparent magnitude is therefore but little index of the reality. This conclusion is still further borne out by the amazing example of Canopus, the great star of prehistoric Egypt. It is the brightest of the southern heavens, second only to Sirius. Recent careful determination reveals the fact that it has no appreciable parallax, as it has no appreciable proper motion. The present limits of error are in the neighbourhood of a few hundredths of a second. Sir David Gill sets the distance of Canopus at a minimum of two hundred and ninety-six light-years. It is apparently situated among stars of the eighth magnitude, if not farther. In order to shine at its present brilliancy from this distance, it must have ten or fifteen thousand times the luminosity of our sun. At this distance our sun would long have ceased to be visible to the naked eye.

Canopus is, again, a solar type of star; its density and temperature is, then, somewhere near the sun's. Consider the inference. At the same temperature the amount of light shed 
by a star is dependent simply upon its surface. Surfaces are in turn proportionate to the square of the diameter, volumes to the cube. If Canopus gives out more than ten thousand times the light of our sun, it follows that its diameter is more than a hundred times that of our sun; that is, perhaps more than a hundred million miles in diameter. This would mean a sun, a body, the distance from whose centre to circumference would be four hundred times the distance from the earth to the moon; it would be greater than the distance from the earth to the sun. It would be so vast that within its almost unimaginable shell the earth and all the inferior planets might, in the absence of a deterrent medium, pursue their orbital ways. On present reckonings, its volume is perhaps a million and a half times that of our central orb.

Reflect that the sphere of the sun would contain a million of our little earths; then that, on the estimates given, the sphere of Canopus would hold more than a million suns, more than a million million earths.

All this, it is to be remembered, is simply the apparent lower limit. How much more vast it may be we have no means of knowing. Already the mind reels in its endeavour to comprehend a body, a single mass, of such stupendous dimensions. Even the greatest of the telescopes probably do not reveal more than a hundred million stars. If we were to suppose that they were of something the average size of our sun, then Canopus would swallow a million of them. And, for aught we now know, Canopus may be a hundred, a thousand, a million times vaster still. It seems probable that some of the stars are distant more than thirty thousand light-years. If the great sun of Argo be as far away, its bulk would necessarily be that of a million million suns to give us the light it does.

Nor have we any reason to suppose that this colossus is the greatest object in the universe. There are at least two other stars known, which may be as large, or larger, than Canopus. One of these is Rigel, the second brightest star in the constellation of Orion; the other Deneb, the brightest star of the constellation of the Swan. Like Canopus they yield no appreciable parallax, yet their luminosity is so great that it must be thousands of times that of the sun.

Consider now that these estimates of actual brilliancy, that is to say, of the true grandeur of the stars, is dependent upon 
their supposed distance. Consider that the parallax is known of sixty stars out of perhaps a hundred million revealed by the photographic plates. Consider that merely a beginning has been made, and it is easy to see that any endeavour to fix an upper limit is simply absurd. It is conceivable that gigantic suns may exist, compared with which even huge Canopus would seem a pigmy, and compared with which our solar deity would be as insignificant as one of the five hundred asteroids which circle out beyond the path of Mars, to us. There may be not merely one, there may be many.

We have no distinction as to vastness, we have none of littleness, even. Just as it is clear that there are suns hundreds, perhaps millions of times the bulk of : our sun, so it appears that there are others, probably, beside which we might seem very huge and very important. The universe, then, is not made up of units of a regular pattern, of much the same grandeur; there is no evidence of set design, no evidence of the existence of a mould for suns and worlds. The stars differ among themselves in size as much, perhaps, as the components of our solar system, the individual planets and their satellites, even, differ among themselves.

The moral is not distant; it is not flattering. What is demonstrated beyond a doubt is that in the firmament of stars our solar system is of no especial consequence. It is not unique, it is one of hundreds of millions. It is not enormously vast; it is merely mediocre. It seems to have absolutely nothing about it that is distinctive. It is one of a crowd, a mob, a multitude, an infinite swarm. This is the social, the moral, the anthropological lesson of the measures of stellar distance.

If you wish to picture it, you may conceive it in the simile already adduced, that of one of a cloud of dancing fire-fliesa cloud hundreds of miles in extent. If it will be a better help to the mind, we may think of a huge mountain, streaming with millions and billions of ants. One of these ants, one of these fire-flies, would be our sun. It is in some such way, perhaps, that we may estimate the importance, not of the little life of man, not of the minor planet that we call the earth; but of the whole solar system and all that it contains.

The stars move; that Herschel had made clear. Like the 
earth, like the sun, they are flying, flying, flying. Is there any way that we can compute their speeds?

In front of the window near where I write, lies the Golden Gate of the Pacific, famed in the legends of the newer Argonauts. Across it, as I write, a ship sails slowly. Its distance, the width of the Gate, are known. It is needful only to time its passage to know how fast the ship is sailing. It is the same with the stars whose distance we know.

Bessel had chosen the star numbered 6I Cygni, for measure of its parallax, because of its relative rapid motion across the line of sight. When he had computed its distance it was not difficult to reckon its speed. It came out at nearly forty miles per second. As cosmic motions go, it was not great. Some of the planets, some of the comets, move as swiftly. But consider that this star is not a planet, not a tenuous comet. It is a sun ; it is doubtless carrying in its train a company of satellites like unto our own system.

It taxes the imagination to conceive even the rate of motion of our own earth. One can count five, at the utmost ten in a second. In each of these counts our earth has flashed on several miles along its pathway around the sun. The star in the Swan that we number 6I is moving twice as fast. You may multiply the speed of the earth by ten; and there are stars moving more swiftly still, one of them the greatest star of the northern firmament.

The first of these terrific speeds to be discovered was the celebrated "run-away" star known as I830 Groombridge-that is, a star otherwise so insignificant that it has merely a number in the Groombridge catalogue. It is apparently moving at somewhere near two hundred miles per second, perhaps more. The vast sun of Arcturus is moving more swiftly still. Some recent estimates set its speed at between four and five hundred kilometres, possibly three hundred miles or more per second. So far as we know, there is nothing like it in the universe. Of the stars whose speeds may be reckoned there is nothing approaching it save in the instance named. Most of those that are known move at comparatively moderate speeds like our own sun. But our knowledge of the stellar universe as yet is slight. For aught we know, there may be others whose rate of translation is vastly beyond that of Arcturus itself.

Three hundred miles per second! Let us try a minute to 
conceive it. Here is a body, possibly three or four thousand times the diameter of the earth. If its density be somewhat similar to that of our sun, its mass then is perhaps a hundred or two hundred million times that of the earth. The energy of a moving body is proportionate to its mass first, and secondly, to the square of its speed. A rifle-bullet moving at less than half a mile per second, and striking a steel target, becomes very hot. At a dozen times this speed it would develop enough heat to melt itself.

Arcturus is moving six hundred times as fast. Were it to collide with a stationary object, it would develop then thirtysix thousand times as much heat per unit of mass as the riflebullet. We have then an idea of what stellar collisions may mean. Arcturus has, let us say, forty to fifty thousand times the attractive force of our sun. It would draw another sun or planet towards it with proportional speed.

There is some evidence that such collisions take place. It is doubtful if the nearness of our nearest star is exceptional. Were Arcturus at the distance of alpha Centauri, and coming towards us, it would need but two or three thousand years to cross the intervening space-a fraction of a second in the lifehistory of the stars. Assuming that the average spacing of the suns is not much greater-it may be much less-it is evident, with many hundreds of millions of them flying each whither at tremendous speeds, such collisions might be frequent. As we shall see upon a later page, it is probable that they are.

Estimates of such unthinkable motions of colossal masses might well raise a doubt as to their reality. At three hundred miles per second, a body several miles in diameter flashing across the line of sight a few feet before our eyes, would move so swiftly that it would not be perceived. In our endeavour to obtain a mental presentation of the motion of such a mass as Arcturus, we might well believe that the observations were an error, or the whole idea an illusion. Happily there came a discovery which was not only to confirm the fact of stellar motion; but to disclose that motion, when it lay directly in and not across the line of sight. It was to do much besides. It came within a few years of the disclosures of Bessel and Struve, though it was not put into effect for many years thereafter. It was from such a strange quarter of the sky that men could scarcely then believe, and the wonder has not yet ceased. 


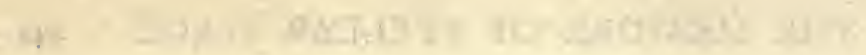

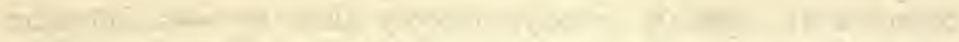

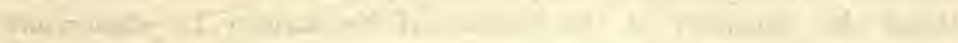

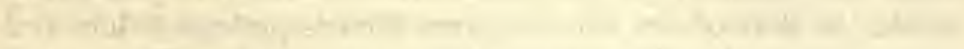

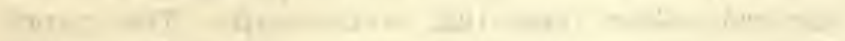

$+2=$

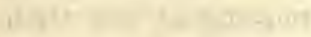

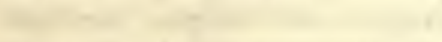

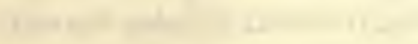

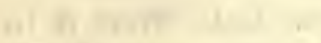

(1)

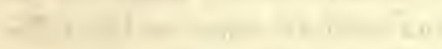

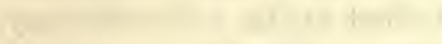

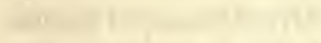

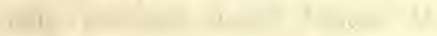

i

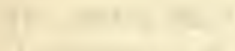

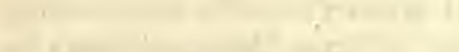

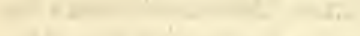

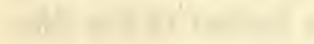

n)

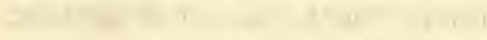

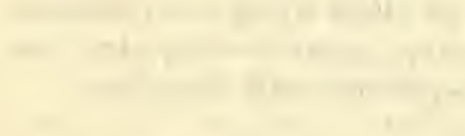

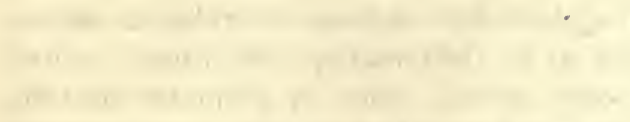

in

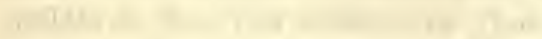

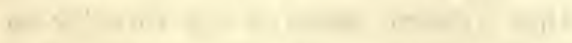

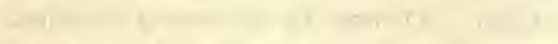

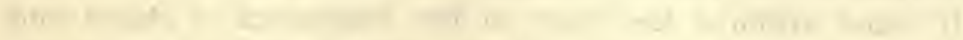

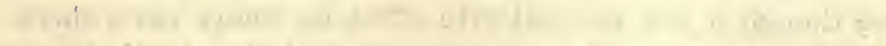
Wh

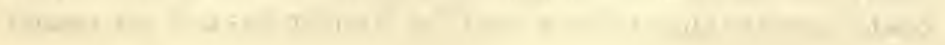




\section{CHAPTER XXVII}

THE SPECTROSCOPE AND THE STUFF OF COSMOS 
Was hier im Raume spukt!

ERMAN. 


\section{CHAPTER XXVII}

\section{THE SPECTROSCOPE AND THE STUFF OF COSMOS}

IF we look back upon the gradual advance of human knowledge, we might almost be led to conceive physical investigation as a kind of game of Hare and Hounds. The hand of nature, as it were, scatters the bits of paper which have enabled her followers to pursue her track. But sometimes the scent has been so thinly sown, the gaps so far between, that baffled man might have felt as though nature had not very fairly played the game. Perhaps it has added a certain zest; it has certainly demanded a sharpness of observation, a patience, and a genius of intuition, compared with which the interesting problems of Mr. Sherlock Holmes seem elementary.

Certainly no puzzle was ever set the mind of man to solve seemingly more elusive than the lines which cross the coloured band formed when a thin beam of sunlight is turned through a prism. As the band is spread wider and wider, the number of these dark lines runs up into thousands; they seem distributed in no regular order, they appear and disappear under different physical conditions, in seeming hopeless confusion.

Surely no phenomenon was ever better named than when Newton spoke of this prismatic band as a spectrum -a spectral apparition. Could Newton have been told that out from all this tangle we should one day learn the constitution of the sun, of the stars as well-their temperature, their motions, their physical states, even that dreamer of wonderful dreams would have sagely shaken his head. How has all this marvellous accession of knowledge come?

In Newton's time men had settled down to think of light as a substance, that it was due to the emission of infinitesimal particles, which bombard the eye with incredible speed. Newton's contemporary, Huyghens, had a different idea, that light was not material at all, but, like sound, a form of wave 
motion. Though Newton gave his adhesion, finally, to the "emission" theory, the pages of his Opticks are full of evidence to show how often he inclined to the alternative view.

The theory held its ground, though with increasing difficulty, as one new observation after another was made, for a century or more, and until it came under the keen scrutiny of an English physician, Dr. Thomas Young. The latter showed that by pricking a pair of pin-holes, close together, in a piece of paper, the two little pencils of light which come through, when spread out upon a screen, appear coloured in the interval in which the rays from the two openings cross each other. Very much the same appearance may be noted on very thin soap-bubbles. Black spots appear which, from having been studied by old Sir Isaac, are known as Newton's rings. The fact could only be explained by the idea that the rays in part mutually extinguish each other. Further experiments with very thin plates left no doubt as to the interpretation.

Evidently, then, light was not a material substance; it was inconceivable that one little shower of particles could abolish the other in this curious way. If light were immaterial it must be then some form of motion, since there was no other way by which the transmission or propagation of light could be explained. Huyghens, it seemed, had the right of it all along. It was some little time, however, before the conclusions of Young, independently reached a few years later by a young French physicist, Fresnel, could penetrate the understanding of the academic authorities; it is generally so. This was in the first ten or fifteen years of the new century. A generation later, and in a new generation with fresh eyes to see, a second crucial test, by Foucault, brought conviction.

Then it was that the investigators began to consider with a larger insight the dark lines which cross the spectral band of sunlight. They had been roughly mapped by Wollaston, a co-worker with Young; with more care by Fraunhofer, the celebrated telescope-maker of Munich. It had been noted very early that the spectrum of ordinary gaslight, for example, does not show these dark lines; the gradations of one rainbow colour into another are not interrupted; the spectrum is continuous. Again, it was found that if some of the elementary gases, like those which compose water-for example, oxygen or hydrogen -were illuminated by an electric spark, their spectral bands 
showed only a series of bright lines, and not the whole rainbow spectrum, like the sunlight. Moreover, these bright bands seem to vary with the different substances employed. Finally, solid substances, rendered incandescent, gave varying dark-line spectrums. It seemed as if each substance produced its own characteristic apparition.

Evidently here was a capital discovery. The light of the spectrum comes from a distance. That distance may be half a foot, a few feet, a few miles, it may be millions of miles. So long as the light passes through no absorbing medium the spectrum remains the same. What if this were true even of the light of the sun! It was first needful, of course, to sift out all the disturbances due to purely earthly conditions, to atmospheric absorption, and the like. If this could be done, then it might be possible to compare the spectrum of the sun with the spectrum of the various elements, and so determine the materials which make up that glowing disk of light.

Such a possibility floated before more than one mind, notably Sir John Herschel's, but the solution came from a German physicist, Kirchhoff, working in conjunction with the celebrated Bunsen. One day, passing a ray of sunlight through vaporised sodium, one of the constituents of common salt, he noted that the characteristic bright lines of the spectrum of sodium had disappeared. He saw in a trice that he had made an observation of profound import. Following it up, he was able to show that when a gas grows cold it will absorb the same rays of light which it emits when it is incandescent.

The dark lines of the solar spectrum mean, therefore, that in the sun are many of the earthly elements sending us their characteristic light, but sending it through an atmosphere of cooler gas, which absorbs these rays, and produces the dark lines we see.

This was the essence of Kirchhoff's discovery. The broad facts were simple enough; the details were infinitely puzzling. Of a truth, spectrum analysis, as this study has come to be called, has developed a wondrous and ofttimes precarious delicacy. Sometimes it has seemed as if the apparent contradictions, the inexplicable anomalies that have appeared as the study developed, were likely quite to vitiate any certainty of inference. Patience and persistence, however, have told, and the typical German textbook on the subject now comprises three huge volumes. It is to-day a special science. 
Latterly the camera has proved a wonderful aid. Instead of trusting merely to the momentary impressions of the eye, it is possible to photograph the varying spectra with accuracy; moreover, to follow the spectrum out beyond the range of the eye into the so-called ultra-violet portions, whose rays affect only photographic plates. These spectrograms make possible measures and comparisons which would be quite impossible to the unaided eye. Likewise they may be copied and sent about from one worker to another, so that results may be discussed at first-hand by various minds.

The fact of largest philosophic interest which we owe to the spectroscope is the demonstration that the material of the solar system and of the universe as well is all the same. This had been long surmised; obviously it could be only a conjecture. Of the seventy odd elements known upon the earth, many show their characteristic lines in the spectrum of the sun. Not all; and this has led to the idea that perhaps in the enormous temperatures of the sun our so-called elementary atoms are decomposed, disassociated into a comparatively few simpler forms.

On the other hand, practically all of the solar lines could be accounted for. There were a few outstanding. They seemed unmistakably to indicate the existence of substances which no terrestrial chemist had ever seen. It is the essence of true theory that it shall, if need be, afford the basis of prediction. Spite of all the bizarre tracings with which he had to deal, the spectroscopist did not hesitate. He announced new elements, gave them a name; he even hazarded a guess at their nature and their place in the chemic scale.

So commonplace has all this become that it does not now seem bold; quite the contrary. So closely interlinked are the physical investigations of to-day that what once seemed daring now appears merely a necessary consequence. It is the difference of the times. The predictions of the spectroscopist, it hardly needs be said, were subsequently verified, most notably by the discovery of the hypothetical element, helium, which does not belong to the sun alone, but to the earth as well.

As the study advanced it became further evident that the spacing of the spectral lines is influenced by the temperature of the body from which the light comes; if it be a gas, it is influenced by the pressure. In following out these and similar 
clues, a new study came into being, that of solar physics. To-day we know more of the constitution, the temperature, and physical characteristics of a body ninety millions of miles away, and for ever inaccessible to man, than our forefathers three or four generations ago knew of the earth itself. Not merely this, but the spectroscope has reached out to tell the same story of the stars; to-day the stellar bodies are divided according to their apparent temperature into different types-solar or yellow stars like our sun; white or bluish stars like the great Dog-star, Vega, and others; red suns like the bright star of the constellation of Hercules; the subdivision is often carried much further.

From out of solar physics has grown a yet broader study, that of stellar, or, if one prefers, of cosmic physics. Amid the multiplied interests of man there are surely none more distantly removed from his primitive pre-occupations for food and shelter than this.

But the revelations of the spectroscope were not to stop with chemical and physical conditions. By an extraordinary circumstance, grounded in the very nature of light itself, it was to do more; it was to prove an independent method of determining solar motion.

There is much in the economy of science that resembles that of our workaday and business life. Very often it has happened that a loan of fact or theory from one branch of scientific investigation has later been returned with heavy interest. This was true in the present instance. It was the motion of the earth which first revealed the finite velocity of light. Later, as we have seen, this was turned about in explanation of the annual aberration of the stars. The return went further.

If light be a form of wave motion, it follows that if the body which sets up these light waves be itself in motion, in sufficient velocity, this would occasion some disturbance in the behaviour of the light it transmits. You find a familiar analogy in sound. If while an express train is travelling at a high rate of speed the engineer blows his whistle continuously, this will seem to cause a change of pitch in the sound, accordingly as the train is travelling towards or away from a bystander. The fact is one of everyday experience.

The case with light is a little different. Not only does it 
travel at nearly a thousand times the velocity of sound, but its vibrations are crosswise to the line in which it travels. The motion of the source of light does not occasion a change of pitch-that is to say, of the light colour-but this movement is disclosed by a slight displacement in the position of the lines of the spectrum.

The placing of the lines is determined by the wave-lengths of the different rays. If the source of light be approaching, the waves will be crowded a little closer together, with the result that the lines will be pushed up a little farther towards the violet end of the spectrum. Conversely, if the source of light is flying away from us, with sufficient speed, the wave-lengths will be drawn out a little, the spectral lines will be displaced slightly towards the red end. By a marvellous refinement of measurement, this displacement can be utilised to reckon the speeds of stars moving directly in the line of sight-that is to say, which have a motion radial to that of the earth and the sun.

This is accomplished by means of photography. If the spectrum of a moving star be registered upon a photographic plate, side by side with that of some source of light within the laboratory, whose lines exactly correspond with those of the star, the minute change of position due to the star's motion may be observed.

By this means it has been possible, to some extent, to check the calculations as to the speed of the stars reckoned from the measures of parallax and of proper motion across the line of sight, or at least to render these calculations probable. If, for example, the speed of a number of stars of about equal magnitude, and therefore probably of about the same distance from the earth, be computed first by the earlier method, then as many more by the spectral method, we may compare the averages. If they roughly agree, it is evident that in neither the one instance nor the other are we dealing with optical illusions. The chances against this concurrence being the result of a mere hazard has enormously increased as the number of motions thus reckoned increases, and with this increase the concurrence grows closer. Were it possible only to reckon the speed of the stars by means of their parallax, it might still be open to supposition that these computations were grounded upon some periodic disturbance like that of stellar aberration and nutation. Were the estimates grounded only upon the 
displacement of the lines of the spectrum, the difficulties which the latter involves, the extraordinary delicacy of observation required, might equally leave the results open to doubt. Their substantial concurrence-that is, that the average speed of a hundred stars reckoned by the one method and a hundred more by the other, is not vastly different-brings a high degree of assurance.

Some day or other the concurrence of these two methods may result in a reckoning yet more sublime-that is, the orbits of the stars. It is obvious at a glance that the spectrograph registers only the part of stellar motion that lies directly in the line of sight; while, on the other hand, of proper motions we can know nothing, save that part of the motion which lies at right angles to the line of sight. If stars could be found having both a large radial motion and a large proper motion, likewise a measurable parallax, it would then be possible to estimate their actual speed, and to plot their paths as well.

Obviously, however, such a condition could not obtain. If the apparent motion were large, the spectral displacement would be small, and vice versâ, so the one or the other would be too minute for registry, unless perchance the speed were prodigious and the placing of the star just right for such observation. This is a problem of the future. It is clear that if a long series of observations could show, for example, that either the apparent or radial motion was growing greater or growing less, here at least would be a slender basis from which some sort of inference might be made.

In following the disclosures of the spectroscope, especially in its amazing invasion of the invisible, we shall see that some stellar orbits have been found, not of the sort we have been considering, but quite another. Meanwhile, we are now in a position to sum up man's long endeavours to orient himself and his world amid the cloud of stars. The effort is considerable. The mind grasps with ineffectual fingers a vivid realisation of the teachings of the new time. Distances, figures, lose all meaning in their vastness. They leave only a blur.

Let us try a little to sharpen the image. 


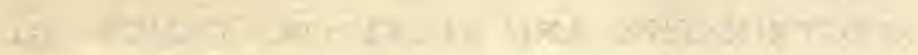

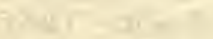

1

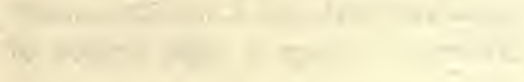

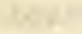

r.

in

$+n$

tran

(1)

(1) then

4.

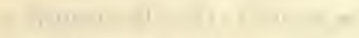

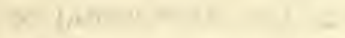

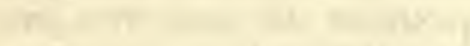

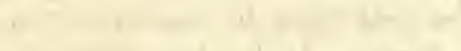

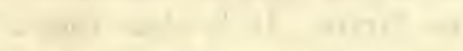

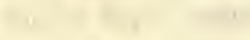

$+1$

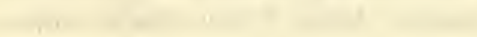

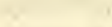

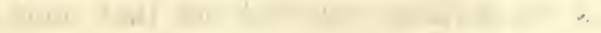

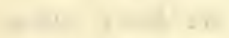

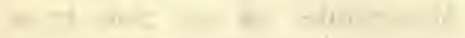

$1+x^{1}+2+1+1$

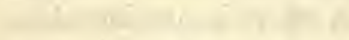

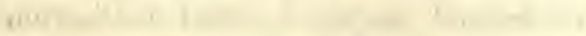

11

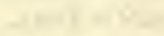

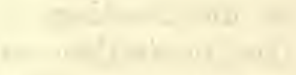

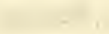




\section{CHAPTER XXVIII}

OUR PLACE IN SPACE: THE PLURALITY OF WORLDS 
You tell us that Democritus says that there are a countless number of worlds, and that there are some which are not only so like one another, but so completely and absolutely equal in every point, that there is no difference whatever between them, and that they are quite innumerable; and so also are men.

Cicero, Academic Questions.

The idea that there is but a single world in all infinitude would be as absurd as to suppose that a vast field had been formed to produce a single blade of wheat.

Metrodorus, 3rd C. B.c. (De Placitis). 


\section{CHAPTER XXVIII}

\section{OUR PLACE IN SPACE: THE PLURALITY OF WORLDS}

Blown about for days upon the tempest waters of the ocean, the first instinct of the mariner upon gaining some haven is to know; if he may, whither he has been tossed by the sport of the elements. If it be an unknown, uninhabited land, he will endeavour by the aid of the stars to fix its point upon the map. If it have there no place and its contours reach beyond the eye, his unconquerable ambition will be to know what is its extentwhat is its shape."

The position of man, tossed by the sport of chance upon our little earth, is much the same. From the earliest period he has sought-for a long time vainly-to gain some clue as to his latitude and longitude in space; let us say, also, the extent of space itself. The ideas of the ancients could necessarily have been but of the crudest. Their whole knowledge of the earth, as we have seen, extended not much beyond the confines of a territory about the length and breadth of the United States.

Within four hundred years we know how vastly this has changed, but the extent of the change is less easy to realise. Save for a few who interest themselves with the problems and the reports of the astronomers, not many, perhaps, have any vivid presentation of the reality. Perhaps we may reach this by a process of summation. Starting from familiar facts, from familiar distances, we may rise step by step, perhaps, to some vague conception of the cosmos in which we move.

The longest voyage ever taken by the ancients was probably the circumnavigation of Africa, five or six hundred years before our era. It was rarely repeated. In general, the extreme extent of the Mediterranean and the Black Sea and along the western coast as far as Ultima Thule, was the utmost reach 
of their more than ordinary voyages; let us say, twenty-five hundred miles.

When Sebastian de Elcano entered the harbour of San Lucar, in the month of September I522, with the ships of the ill-fated Magalhaens, he had accomplished a voyage of between 30,000 and 40,000 miles; his armorial bearings carried a globe with the inscription, "Primus circum dedisti me." The ranges of the earth which men would now undertake to span had been multiplied ten or a dozen times.

The circumference of the earth is roughly 25,000 miles. Could we leave the earth and voyage in space, the first object with which we might meet, barring a chance swarm of whizzing meteorites, would be the moon. It lies at very near ten girdles of the earth-that is to say, 240,000 miles. He who first measured the distance to the moon covered a space, then, something like a hundred times the longest voyage which had yet been made by man.

After that, space is a blank for a long way. Could we journey on from the moon, the first foothold we might gain, the hundreds of little asteroids disregarded, would be, were its position right, the planet Venus. The most brilliant object of the moonless night is, as we know now, about the same dimensions as the earth, surrounded doubtless with a dense atmosphere, and perchance as likely to be peopled with intelligent beings as any other of the planets. Its distance from the earth at its nearest approach is about one hundred times the distance of the moon-that is to say, about twenty-five million miles. A spin to Hesperus, therefore, would, under the most favourable circumstances, involve a journey a thousand times longer than a trip around the globe. A voyage to Mars would, at the nearest, be one-third farther.

The sun is at about four times the distance of Venus at its nearest approach-that is to say, roughly, four hundred times the distance of the moon; roughly, four thousand circumferences of the earth. This is about ninety-three million miles. In the antique illustration of the railway train, a flying express which would carry the traveller from New York to San Francisco in two days would bring him to the sun in two hundred years. Were some solar Krakatoa to explode, we might see the effects eight minutes after; but the report, did sound carry so far, would not be heard until fourteen years later. 
Our little earth turns, of course, very near the sun; it is one of the innermost of the planets. Jupiter is five times as far. Within the planetary scheme the remotest object which we may see with the naked eye is Saturn with his rings; he is distant about ten times the way of the sun. The telescope brings within our view Neptune three times farther still. This, the outermost reach of the system, so far as we know it, lies at considerably more than a hundred thousand times a girdle of the earth, considerably more than a million times the width of the Atlantic, a little under twenty-eight hundred million miles. To skirt the rim of this system, Neptune, travelling at 200 miles per minute, requires 165 of our earthly years.

Could we set out from this rim for a journey through space, so far as we know the first stopping-place which we might gain would be the alpha star of the constellation of the Centaur. It is something like nine thousand times the distance of Neptune - that is to say, about two hundred and seventy-seven thousand times the distance of the sun. To cross the intervening emptiness, could we travel at the speed of light, would require close to four and a half years; at the speed of an express train, one million two hundred and fifty thousand years.

The brilliant Dog-star lies apparently twice farther stillthat is to say, at eight or nine light-years from our solar system. The Pole-star is something like forty light-years. These are among the nearest of the suns.

With present-day micrometric methods, and still more by means of the photographic plate, it is possible to reduce the limits of error in measures of parallax to between o.or and 0.02 of a second of arc. As the accepted parallax of alpha Centauri is about $\frac{3}{4}$, or 0.75 of a second, it will be seen that there is little likelihood that further advances will seriously change our ideas as to the distance of the nearer stars.

In all, measures of parallax have been effected with reasonable accuracy upon sixty to a hundred suns, and the number is growing steadily. But this, in the face of fifty millions or more which the gigantic telescopes of the present day will disclose, seems an absurdly small number; it might readily yield the inference that their distance is for the most part so great that it would be hopeless ever to dream of trying to fix our place in cosmos. The easy conclusion would be that, so far as any human means of observation will ever 
reach, the extent of the starry universe is an impenetrable enigma.

This may well be; but restless minds have not hesitated to attempt a guess. One is based upon the fact that we cannot as yet be certain that light is in any way absorbed in passing through empty space. It is an old remark that if it is not, and the number of stars is infinite, the heavens would be ablaze with light night and day, with a marvellous white light at that ; it would give to the disk of our sun the appearance of a sickly yellow.

Nothing of the sort exists, and one inference we might draw would be that the number of the stars is finite. The explanation may be quite otherwise. Space, as we shall see, holds more things than was imagined. The light of the stars may be cut off or dimmed in several ways. If it should turn out that it is not, in a vague way the number of the suns would be measurable; and there has been more than one attempt in this way to indicate the limits within which their number must lie. One of these is based upon the amount of star-light which reaches us.

Even in the old Alexandrian days, Hipparchus had adopted a method of classifying the stars according to their apparent brightness. Thus the Dog-star, Arcturus, Vega, and their like, were said to be of the first "magnitude"; those a little fainter, like the Pole-star, the "pointers" of the Dipper, of the second; and so on. All that are visible to the naked eye were classed in six such divisions; the faintest of them were broadly grouped in the sixth magnitude. With the invention of the telescope this method of classification has been carried out to the seventeenth and eighteenth magnitude. It was noted that, roughly speaking, the number of stars catalogued in each order of magnitude was about three times that of the next. Calculating as nearly as he might the total intensity of star-light, the French astronomer l'Hermite endeavoured to estimate the number of suns which would be required to shed the light they do. He fixed the outside limit of the possible number at 66,000 millions. If star-light reaches us integrally and undimmed, this limit is certainly far outside of the reality.

A very ingenious method of attacking the problem in another way was worked out by the distinguished American astronomer, 
Simon Newcomb. His idea in brief was this : within a radius of 400,000 times the distance of the sun from the earth there seems to be but one sun outside our own, the alpha Centauri noted above. If the stars were sown with some evenness in space, it would follow that the number of stars within a shell of twice this radius would be the cube of this number-that is to say, eight. In a shell three times this unit of diameter there would be twenty-seven, and so on, the number increasing always with the cube of the diameter. The data at present available for such a calculation are as yet meagre enough; nevertheless, in a way, the number observed agrees surprisingly with the number calculated. Moreover, it is possible to check the figures, in a way, from the measures of the proper motion of the stars. It is obvious that on the average the stars nearest to us will show the greatest annual change of position, and this gives a second but very crude method of calculating their number and distance.

Putting these results together, Newcomb comes to the conclusion that five hundred such concentric shells would include all of the stars visible to us by telescopic or photographic means. This would give, on the supposition of a perfectly even distribution, something like $125,000,000$ suns. It would mean a stellar universe thirty-three hundred light-years from one boundary to the other. But even conceiving that result is too small, merely doubling this diameter would give a total of eight times as many stars-that is to say, rooo millions in all. The number is vast, but there is little or nothing to make it improbable. We may go further yet; we may take the outside limit set by l'Hermite-that is to say, 66,000 millions. This, on the same theory of even distribution, would require a universe five to six thousand times the space to the nearest sun-let us say, roundly, a universe with a diameter of around 25,000 lightyears.

Picture it, see it, realise it, who can!

It might seem as if we had here reached out far beyond the powers of the telescope, and yet this is in no wise certain. It was the calculation of Herschel that his twenty-foot reflector would penetrate-that is, reveal the existence of a star-nine hundred times the distance of Sirius, and that his forty-foot reflector would penetrate twenty-eight hundred times the dis- 
tance. The actual ranges of the stars were, of course, not known to him; but he seems to have made a splendid guess. According to present-day photometric methods, a star of the first magnitude sheds about a hundred times the light of a sixth magnitude, and so on, so that a star of the sixteenth magnitude sends only one-millionth as much light. So far as we now know, the brilliancy of a star varies evenly and inversely as the square of the distance. If this were strictly true, on the average, therefore, a sixteenth magnitude star would be about a thousand times as far away as one of the first.

Herschel's forty-foot reflector, with an aperture of four feet, showed stars up to the seventeenth or eighteenth magnitude of our present-day classifications.

There are twenty or twenty-one stars in the heavens accounted of the first " magnitude." The parallax of three-fourths of these has been fairly determined. With one exception, they are all under fifty light-years. Arcturus comes out at between two and three times this distance. The average of these known stars would fix the mean distance of first magnitude luminaries at about twenty-two light-years, or very evenly five times the distance of the nearest one we know of. This is more than one million times the space between the earth and the sun---that is, ninety-three million million miles.

But there are at least three of the first magnitude stars whose parallax evades our present resources. Present methods would certainly disclose the shift of a star thirty or forty times the nearest, so that each of these three-Canopus, Rigel, and Deneb-must be considerably more than this. Sir David Gill considers that present limits of error will not permit us to suppose that Canopus is nearer than two hundred and ninety-six lightyears. The fact that Rigel has practically no apparent motion seems to fix it at a still greater distance, and Deneb may not be much less. If we set the average of these three at three hundred light-years, this would raise the average for all of the first magnitude stars to above sixty light-years. We may conclude that the mean distance is somewhere between these upper and lower limits. It cannot be less, and it is probably not much more.

Merely to fix our ideas of this distance, it may be noted that our shining sun would be of the first magnitude only within five or six light-years, and it would quite cease to be visible to the naked eye at much beyond thirty light-years. 
All this would seem to indicate an average distance for sixteenth and seventeenth magnitude stars as somewhere from twenty to sixty thousand light-years; the number is purposely stated very vaguely, because of a possible absorption of light through very long spaces. This appears to be the present limit of telescopic visibility.

The present calculated distance of Sirius is somewhat under ten light-years ( 8.6 is the latest estimate). Herschel's figure, therefore, was not far out of the way if we set this distance at ten light-years. It is possible, though by no means certain, that we can see somewhat farther even than he supposed.

If the solar system were situated anywhere near the centre of the stellar universe, as some recent fanciful philosophies of creation suppose, then of course our telescopes would be able to sweep across a cosmos of twice these computed dimensions, or of from fifty to a hundred thousand light-years. There is little reason to suppose, however, that we are at the centre of any system or anywhere near it. But even thirty thousand or fifty thousand light-years would mean a universe several times more vast than the utmost limit conjectured by l'Hermite. And the figure of l'Hermite was based upon the idea that the total light of the stars was equal to about one-tenth full moonlight. More recent and more accurate calculations seem to indicate that it is not much more than one-sixtieth full moonlight. In a word, l'Hermite's estimate may have been five or six times too high. So, if we could rely in any way upon our present assumptions, we might infer that the present powers of the telescope would reveal the existence of a universe perhaps a hundred times more vast than any which can be accounted for now from measures of light, or than Newcomb deems probable from the methods employed by him.

It is obvious that we can know nothing of the real distance of the farther stars until the question of the absorption of light is settled. Of course, if there is the slightest dimming of the light, the boundaries of the universe will be to us forever unknown. Presumptuous in the last degree is it, therefore, to attempt to fix the position of the solar system in space. A microbe upon the surface of a microscopic drop of mist in a fog covering the Atlantic Ocean would not be more hopelessly situated in his endeavours to discover his whereabouts.

In the days to come, when the parallaxes of some thousands 
of stars are known, we shall be a little better off. Then it will be possible to gain some idea of average star spacing, and we shall be able to fix the position of the sun, probably, with reference to the brighter and nearer stars. It is quite possible that we have much nearer neighbours, for example, than alpha Centauri. The analogy of the planets points to such a conclusion. Uranus was discovered before any of the five hundred asteroids, and even Neptune before the most of them; and the asteroids are on the average ten or twelve times nearer than the outer planet.

Following the same analogy, it is likely that these more neighbourly suns or sunlets would be very much smaller than the star of the Centaur-that is, smaller than our own sun. For anything we now know, there is no reason to suppose that they may not vary as greatly in size as, let us say, the asteroids from Jupiter. There may be blazing suns no larger than the earth. On the other hand, between our own system and the Centaur there may be dark bodies vastly larger than our sun. They could scarcely be known to us save by their gravitational pull. For aught we now know, some of these dark bodies might be our nearest neighbours. If they had not been extinct too long, it would be very curious to visit them and examine, so far as we might, the ruins of extinct civilisations on their planets. Of course, the present chances of escape from our own system are exceedingly slight. But the advance in our physical knowledge within the last two or three hundred years is probably but the merest beginning. He would be a blind man who would assert that such an escape is forever an impossibility.

The conclusion of present-day computation is that the suns are numbered by the thousands of millions; planets and dark stars probably by hundreds of thousands of millions. The distribution would involve a corresponding vastity of space.

There is no great interest in mere numbers, however prodigious they may be; but from out this computation of a seeming endless welter of blazing suns, at least one curious inference may be drawn-that is, the probably colossal number of inhabitable worlds. Our solar system contains at least nine bodies, ranging in size from Jupiter to the moon, which at some stage or other of their evolution might present a theatre for life. It now seems indubitable that the stuff of the universe is all the 
same. If it had not been so in the beginning, we shall see that there is reason to believe it would become so in the course of any extended period of existence. If the stuff is the same, doubtless the properties inherent to matter are the same. We may scarcely regard our solar system as unique. We are led almost irresistibly to conclude that we may have many similars throughout the concourse of worlds.

Let us conceive for a moment that there are in the sky no more, or that we shall never know of any more, than say a billion suns-a thousand millions. If our solar system be anything of an average type, this would mean five or ten billion planets that might be, at some period or other of their cooling-off, the seat of an animal population, perhaps of a civilisation and an intellectual development something akin to our own. The number is large. It can hardly excite in the mind more than a vacant mental stare. But consider the further inference. We have as yet, of course, only the vaguest estimates of the age of our planetary system, in the sense that it comprised definitely defined bodies. Present-day estimates range from twenty-five or fifty millions of years, up to several hundred. Let us take a figure far outside, and call it a thousand millions.

Again, we may conceive that at some point or other over the earth our human civilisation has held at about its present level for ten or twenty thousand years. So far as primitive intellectual power is concerned, or in social organisation, in his pomps and ceremonies, his dress and his ways, man has probably varied but little within this period. The time may be much longer. It is now clear that it was not less.

Such minds as love to follow out calculations of probability will not fail to run forward to the conclusion. Let us say that the civilised life of mankind represents a hundredthousandth part of the conceivably habitable period of our solar system, in any portion of it, and assume this system to be a universal type. It follows that it would need but a universe of a hundred thousand suns to conceive that there is at least one other existing planet which has reached a stage of evolution almost identically parallel to our own. If we may reckon with a thousand million suns, the chances are there may be ten thousand such parallel worlds.

Even this number is still enormous. It is quite beyond the powers of the human mind vividly to picture the existence 
of ten thousand vast globes like the earth, each with its many continents, its white and black and yellow races, its Seven Wonders, and a wearisome line of Alexanders and Cæsars, of Tamerlanes and Kubla Khans. Let us then come a little closer, pursue our fancy further.

Conceiving our civilisation as dating back ten thousand years, if there be ten thousand planets of about the same degree of mental development as earth's humankind, it follows that there is at least one wherein the concourse of human history might be exactly parallel to our own. Somewhere in the distant ways, we might imagine a planet which, like our own, has just attained to a knowledge and use of electricity, just found the means of lightening its burdens by the employment of steam, just developed the art of painting, just found its Beethoven and its Wagner, just begun to agree to settle the differences among peoples by compromise or by arbitration, instead of by appeal to the bludgeon or to the largest number of bullets and bombs and fools to shoot them.

For that matter, the fanciful mind might even reflect upon an even closer possible parallelism, upon some planet distant so far that even the light of its central sun is shut from our eyes-a parallelism of each of our human lives. Even upon our own earth, it is only our lack of imagination, conditioned in the very narrow limits of human intercourse, that hinders us from realising that, among the billion or billion and a half of folk who tread this ancient earth, each one of us must have hundreds, and perhaps thousands, of alter egos.

The human pattern is not so diverse. There are few among us who have known a hundred persons so closely and intimately as to penetrate the inner working of their lives. Even in a hundred we discover innumerable traits and actions close akin to our own. In a hundred thousand the parallelism would become closer. In fifteen hundred millions undoubtedly it would coincide in multiplied instances. Our human pride bids each of us deem that he is in some sense unique, and that he orders his life after an especial fashion of his own. Could we visualise the reality, we should discover that we are, each one of us, but one of a thousand or one of ten thousand whose ideas, ambitions, dreams, and daily lives are, in all essential ways, identical. 
This evident parallelism of our earthly existence seems the counterpart of the larger parallelism of the cosmic organism. Imaginative minds have not hesitated to conceive of other inhabited planets within our solar system. Mars has been a favourite field of operations for novelists with ultramundane fancies; Venus may possess physical conditions much closer to those which obtain upon the earth. It may be that both of them, possibly others still, possess life in some form. Circling the infinitude of suns there may be an infinitude of others.

All the advance of physical knowledge has been, as it were, convergent rather than dispersive-that is, it tends always to reveal a single operative cause at work through a variety of phenomena. The analogy irresistibly suggests that if we ever attain to an extended knowledge of cosmos, it will be found to be relatively simple, following much the same course of development, and built on much the same pattern.

The quantitive measure may vary vastly. There is nothing, for example, to forbid our believing that each of the five hundred asteroids known to us may not have been one day, or may not one day be, the theatre of life in some degree. There is nothing to forbid our believing that the sun itself may one day become habitable. We do not as yet know what are the relative probabilities in the approach of the suns-as to whether they shall collide or go spinning one about the other as a binary system, like unto those with which the heavens seem filled. The latter might be the fate of our sun, or it might become satellite to some vast luminary like Canopus. If in either instance it were supplied with an exterior source of heat and light, life would undoubtedly develop at some stage or other of its cooling.

If the density of the asteroids be something the same as that of the earth, it is evident that the pull of gravity at their surfaces would be twenty or thirty times less, even among the largest of them. If the sun in cooling reaches the same density - that is to say, is reduced to one-fourth its present volumethe pull of gravity at its surface would be fifty times or more that upon the earth. It is evident that within our own system the physical conditions for the development of life would be extremely diverse. A being the size of an average man set upon an asteroid might "weigh" six or eight pounds. This same body set upon the sun grown cold might weigh four tons. 
It is evident that the jelly-like substance of which our bodies are composed would, under such pressures as this, be simply squashed. To sustain such a weight, beings would have to have bones and muscles of the tensile strength of steel.

It is difficult to conceive of a colloidal aggregation with such powers as this. Hence it is difficult to imagine the forms which life would take on upon a planet of the dimensions of the sun. It is quite inconceivable when we think of a planet of the possible size of Canopus. Were it of equal density with the earth, the pull of gravitation would be I0,000 times that of terrestrial conditions. Under such a force, a bar of steel upon a support would bend like so much putty. But, however it might be, if life were possible at all, probably it would differ in no general way, would involve no radically diverse order of sensations, and hence intelligence, than that with which we are acquainted.

Speculative minds which love large deductions will scarcely self-withhold from a fairly obvious inference. Life, sensations, passions, intelligence, are an evident condition or result of material organisation. Not unique upon our own planet, they are probably part of the universal order, if a universal order exists. This being so, it follows that the activities of life, the reflexes of our sensations, the impulses of our passions, the leadings of our intelligence, are all a part of the cosmic orderthat is to say, if it exist, of the cosmic machine. The supple movements of our bodies, the lifting of a hand, the turn of an eye, a given pain or pleasure, the sensations of a hurt, the joy of a lover's return, the promptings of avarice, the thirst for power, the passion of beauty, the visions of the prophets, the inductions of a Newton, the generalisations of a Spencer-all are a part of cosmic phenomena, and doubtlessly distributed with cosmic prodigality. Every thought, every idea, every rush of emotion, every flame of anger, every hidden wish, every heart-sickness, every little joy that we experience, we may conceive has its counterpart in hundreds, perhaps thousands, possibly millions, of similar beings with identical sensations and emotions, some separated from us by the width of a street, some by the distance of Cathay, some by spaces millions of times the distance of the sun.

Phenomena so widespread can hardly be the result of individual and diverse causes. We can only infer that our lives 


\section{OUR PLACE IN SPACE}

are as strictly conditioned and as strictly ordered as the march of the planets or the flash of a shooting-star in the skies.

Let him who revels in the sense of his importance, or him who believes that in the face of the larger concourse of nature our human efforts are more potent than Joshua before the sun as it rose over Gibeon, observe a little the slow turning of the cosmic wheel. Let him learn that his delusions, like those of Joshua, are conditioned in his darkling ignorance and the childish simplicity of his mind.

Mention has been frequent of the cosmic order and the cosmic structure-always, be it understood, with due recognition of the present limitations of our knowledge. Within a few decades a new and larger chapter of astronomy has been opening that may wholly transform our ideas. Its very name is half a paradox; it deals with worlds unseen, perhaps never to be known to us save as an inference.

The wonder of the starry realms is not yet dead. 
,

1.

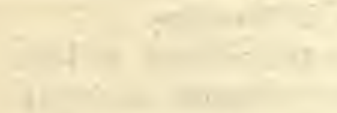

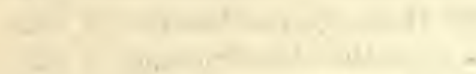

4.

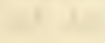

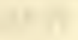

1

1

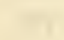

$\left(\frac{10}{2}\right.$

-

. 


\section{- CHAPTER XXIX}

\section{THE ASTRONOMY OF THE INVISIBLE}


THE world in which we live and move Outlasts aversion, outlasts love, Outlasts each effort, interest, hope, Remorse, grief, joy ; - and were the scope Of these affections wider made, Man still would see, and see dismay'd, Beyond his passion's widest range, Far regions of eternal change.

Nay, and since death, which wipes out man, Finds him with many an unsolved plan, With much unknown, and much untried, Wonder not dead, and thirst not dried, Still gazing on the ever full Eternal mundane spectacleThis world in which we draw our breath, In some sense, Fausta, outlasts death.

MattheW ARNold, Resignation. 


\section{CHAPTER XXIX}

\section{THE ASTRONOMY OF THE INVISIBLE}

WHEN the pattern of our solar system has been made out, it was the most natural thing in the world to suppose that countless other systems were cut out more or less in the same fashion. The scheme was engagingly simple-a giant sun at the centre, with a gay retinue of little planets skimming round about his worshipful majesty and deriving from him their sustenance and the order of their lives.

There came a-rude jostle when the astronomers discovered that there might be systems with two huge suns. With minds attuned to a sense of unitary dominance, the "star" system, let us say, the idea of divided primacy seemed as incongruous as would a performance of Hamlet with two counterfeits of the melancholy Dane. But the fact could not be denied.

Herschel had demonstrated that double-star systems actually exist. But little progress was made until the subject was taken up by the two great parallax hunters, Struve at Dorpat and Bessel at Königsberg. It followed very naturally from their study of stellar distance, wherein the accurate determination of the position of a star was of fundamental importance. If through a period of years two carefully located stars were found to separate slightly, then draw together again, it was a fair inference that they were in reality revolving one around the other. It seems a slender thread to build upon. But such a quantity of evidence has come subsequently as to permit no question.

Some of these double-star orbits, especially those surmised by Herschel, are so vast, they can as yet only be guessed at vaguely. Some twenty-eight or thirty are known with periods of less than a hundred years, and therefore with more or less certitude.

It is a matter of very curious interest to note that in two of the best known of these revolving pairs the companion sun 
was long invisible to the eye. In each case its presence had been divined, its position predicted, estimations of its mass been made, before actual visual observations had confirmed the fact.

The earliest of these predictions was that of Bessel regarding the companion of great Sirius. It could have been only a keen, and in some sense poetic, imagination which inspired this great astronomer to his daring prophecy.

"The astronomy of the future," he said, "will be the astronomy of the invisible." The embracing mind of Laplace had caught an inkling of the same truth. Bessel was bolder. It was he who first determined absolutely the monstrous distance of the stars, the first who showed that Huyghens' estimate, vast as it was, might be multiplied ten and twenty times before we approach reality. For aught that any human eye could see, the space between was void.

But in I844 his observations of Sirius led him to announce the probable existence of a dark companion. He came to the same conclusion regarding the very brilliant star Procyon, in the neighbouring constellation of the Little Dog. Their times of revolution he set at about half a century. Twenty years after, his predictions were verified in a curious way.

The American firm of telescope builders, Alvan Clark \& Sons, were finishing a wonderful new refractor, and the younger member of the firm turned it upon Sirius to test its powers. He exclaimed to his father that the star appeared to have a companion. He knew nothing then of Bessel's work, nor the later and more precise calculations of other investigators, who had to all intents demonstrated that the companion must be there. But repeated observation left no doubt.

The companion was most remarkable for its dimness; its giant partner gives perhaps ten thousand times as much light. It appears to be about half as big as Sirius-that is, perhaps twelve or fifteen times the bulk of our sun. It is evident, then, that the companion does not shine merely by the reflected light of the glowing Dog-star, for they appear to be separated as widely as Uranus and our sun. The diameter of the companion, therefore, would have to be something enormous, approaching the size of Canopus perhaps, did it possess no luminosity of its own. The inference, therefore, is that it is a dark sun, one of the dying embers of the flaming universe. 
Of especial interest to us is the fact that the nearest of the stars likewise forms one of these binary systems. Alpha Centauri has a double; their period of revolution, as estimated by See, is eighty-nine years. They are separated apparently about as widely as Sirius and its companion, and their combined mass is computed at about double that of our sun's. When we put with this Sir David Gill's conclusions, on other grounds, that alpha Centauri is almost the duplicate of our sun in temperature, density, and the like, we may conclude that the companion is of about the same density and only a little less luminous.

Of the six binary systems of which both the orbit and parallax are known, and from which therefore their mutual distances may be estimated, there is only one in which the space of separation seems greater than the distance of Neptune from the sun. In one of the nearest, and therefore most certainly observable, of the six, that of Procyon, the distance of its companion is apparently not more than ten times the earth's distance from the sun-that is, about the distance of Saturn.

When now we compare these apparently well-fixed distances with the periods of their revolution, we gain some idea of their speed. It is not very different from that of the planets. The period of Saturn is twenty-nine and a half years; that of the companion of Procyon is forty years. The companion of Sirius, at about the distance of Uranus, completes its circuit in fiftytwo years, where Uranus takes over eighty. It is therefore moving about twice as fast. The companion of alpha Centauri, at about the same distance, moves at nearly the same speed as the planet.

But it is from the spectroscope that the most interesting discoveries of binary systems have come. It is easy to perceive the mode. If the spectroscope can disclose the radial motions of the stars, it would follow that it ought equally to disclose the periods of revolution of a binary system, provided their motion is sufficiently rapid. If the system were at rest, compared with our own, or moving more or less at right angles to the line of sight, the backward and forward motion the two stars present to an observer would be represented in their spectra by a backward and forward motion of the bright and dark lines. If the system were moving within the line of sight, the mutual revolutions of its suns would be revealed by a constant 
alteration in the apparent speed, and by a definite periodicity of that alteration. For example, if such a binary were approaching or receding from our sun at, say, a speed of a hundred kilometres per second, and at the same time were whirling about a centre in an orbital velocity of about the same rate, the lines of the spectrum would shift according as the one star or the other was coming towards us or receding from us in its owr orbit, with a regularly varying rate, at one time standing still, then moving at a rate indicating twice the speed of the actual translatory motion of the double system.

Precisely these conditions were disclosed in the same year of I889, by Vogel of Berlin and Pickering of Harvard. Since this time the number of these "spectroscopic binaries" has grown rapidly. At the present time more than sixty such systems are listed, and their periods fixed. It is easy to see that it would be difficult, if not impossible, to discover by means of the shifting of the spectral lines a system of long period. It follows, therefore, that there is a very marked contrast in the period of the spectroscopic binaries and those observed by means of actual change of position. With possibly a single exception, no double system has been revealed by means of actual shift of position of less period than eleven years. On the other hand, no spectroscopic binary has been noted with a longer period than about three years. They range from this down to about a single earthly day.

We cannot imagine the arrangement of these short-period binaries save in one of two ways: either that their orbital velocity is enormous, or else that they are relatively very close together. But their orbital velocity is known by the same means which disclosed the fact that they are binaries. The greatest speeds computed for any of the short-period systems is from 250 to 300 kilometres per second. This is eight or ten times the speed of any planet in our system. It is still quite insufficient to explain the extreme rapidity of their revolutions. Moreover, the most of them are very much less than this. The Pole-star, for example, is a double star, with a period of four days, and the computed orbital velocity of its components is only three kilometres per second. This is very slow.

We are forced to conclude, therefore, that in many, if not in most, of these double systems, the two suns are very much closer to each other than any of the planets to our sun. For 
example, the period of Mercury is eighty-eight days, and its orbital motion is nearly thirty miles a second. It is the fastest member of our system. If the twin stars of Polaris are travelling at an average speed of only a mile or two per second and encompass their mutual revolutions in four days, they cannot be separated by more than a small fraction of the distance of Mercury from the sun.

These revelations bear with them many interesting implications. The detection of a binary system either by means of the spectroscope or by measures of actual displacement, is a matter of the most delicate observation. The shifting of the lines in the spectral image is exceedingly minute; the inferences one may draw are complicated by many physical problems, each of which may introduce a possible error. It is obvious that each system must be treated by itself-one does not lead to another. All this takes time.

On the other hand, the actual displacement of the double stars from their observed positions is measured for the most part by hundreds of seconds of arc, and we have already seen what accuracy these micrometric measures involve. Sometimes the series of observations must extend over half a century or more before any reasonable inference may be drawn. Here again the chances of error are great, and progress is necessarily slow.

If, in spite of all this, a little more than a dozen years has sufficed to reveal more than sixty spectroscopic binaries, the obvious inference is that their number is enormous. Let us supplement this with the fact that out of the comparatively small number of stars whose positions have been determined with very great accuracy, at least two hundred and fifty are known to be double systems, with fifty or sixty of their orbits measured from their displacements. Add to this that perhaps ten thousand stars are known, situated so nearly together that for the most part they can only be resolved into two by means of telescopes of the highest powers of magnificationdouble stars in the Herschelian sense. One might almost conclude from this that the double-star system was the general pattern of the universal arrangement, and that our solar system, so far from being the type, was relatively unique. One might go further, and conclude that a companion of our sun 
would eventually be found. This is always possible; but as we have seen, it is highly improbable.

So perhaps is the other inference that the universe is made up mainly of double suns. The marvellous progress in late years in photography of the nebulæ seems to have spread before our eyes the general course of stellar evolution. The images which have been obtained of revolving nebulæ present neither the general type of a disk with a single centre of condensation nor that of a double centre, such as the binary arrangement would suggest. Rather we find all types; sometimes a single central nucleus, sometimes a pair of nuclei, sometimes three or four.

For a long time we have known of stars that seem to be triple, or even multiple. The larger part of these doubtless are merely optically triple or multiple, and have no physical connection. But we may infer that some of them do constitute a system, and the photographic plate seems to reveal a quantity of these triple and multiple systems in the actual process of their evolution. This suggests readily enough that there is no single type, no common mould, but that could we journey through the stars, we should find a considerable variety, some of them alone in solitary grandeur like our sun, some of them sharing their thrones with a companion sun, others with dark companions. There may be triumvirates and decemvirs, and, for aught that we now know, conceivably centos and cinquecentos -that is to say, twins and triads and clusters and swarms.

Of course, if there be aught in the idea of stellar evolution and the nebular theory, and we have no other theory of creation worth considering, there may have been a time when our own system presented the appearance of a cluster of suns. The companions of the central mass, however, are so insignificant, even the greatest of them, Jupiter and Saturn, that they would be all but invisible at the distance of the nearest known star. But the telescope has revealed, as the photographs of nebulæ have suggested, that this partition of the mass of matter within a system is not always so dismeasured. The separating masses may be more nearly equal.

We meet here with a perplexing problem. The fact that our own system is made up of more than five hundred individual bodies, the most of them, so far as we can see, in stable motion, readily suggests that other flaming suns are likewise companioned, 
perhaps not always so numerously, perhaps sometimes more so. But with two central masses, each of the proportions, let us say, of our sun to the rest of the planets, it is difficult to conceive how such a system could long subsist. If they were spaced as closely as the two components of the Pole-star appear to be, for example, the problem would be relatively simple. Then their satellites might revolve around the common centre of gravity; but obviously with a somewhat perturbed motion.

But if they were as widely separated as Neptune and the sun, as some of the binaries appear to be, probably each of the pair would have its satellites. If these latter were at any considerable distance, like Jupiter, they would be most curiously pulled about in their orbits when they came in conjunction between the pair of suns. Life on such planets, if they exist, would be a topsy-turvy affair. When in conjunction, day would be of course continuous, ocean tides would probably be enormous, the course of the seasons would doubtless be quite broken up-certainly if the axes of the planets were inclined to the plane of the ecliptic like our own. Their inhabitants would experience the most violent changes of temperature, with consequent storms and a general derangement of physical conditions.

Altogether, when we try to project our own little scheme of things into the general order of the universe, we are hopelessly estopped by the very beginnings of our knowledge of stellar arrangements. In another two or three centuries, doubtless, the case will be different and our knowledge considerable.

In a general way, our representation of our immediate planetary system is complete. We cannot conceive it as very materially altered by any subsequent discovery. We know the distance and size of the sun, the planets, their satellites, and this so accurately and surely that "astronomical knowledge" has become the synonym for fixity and certitude.

Our knowledge of the solar system represents an effort of the human mind extending through several thousand years. The larger and more definite part of this knowledge has all come within three centuries, the last details within fifty or sixty years.

Accurate star-knowledge dates from Bradley and Herschelthat is to say, from a little more than a century and a halfand it is concerned with motions for the most part less per- 
ceptible in a year than planetary motions in a day, with distances in which the prodigious remoteness of the sun becomes a unit of measure. The perfected telescope is not a century old, the spectroscope is not a half-century, and the application of photography is hardly a quarter of a century. In another three hundred years we may know a thousand or perhaps ten thousand times as much about the stars and the universe they compose as we do now.

The spectral image and the subtle movement of its cryptic lines have revealed to our wondering ken a considerable number of the stars as tumbling about each other in a sort of rollicking kirmess, furious as the wild romp portrayed by Rubens' ebullient sketch in the Louvre. It would be curious if it should stop here ; it does not.

The development of our knowledge of binary systems has obviously lent a powerful support to the theory of stellar collisions; and the importance of this is great. We shall see hereafter that our conceptions and theories of stellar evolution and devolution are pivoted upon the reality of this fact.

It is in no wise probable that the generality of the binary systems came from any binary matrix. We need not conceive them as necessarily evolved from the same nebular mass. Possibly much the larger part of them were as purely the result of chance, let us say, as the appearance of a shooting-star in our atmosphere. In the larger sense there is, to be sure, no chance anywhere. To the infinite eye, did any such exist, the flash of the shooting-star, the collision of suns, would all seem as definitely fixed and predictable as the rambles of a roulette ball. We can conceive of no such infinite eye. But in so far as our knowledge is real knowledge, the human mind approaches, though at vast distance, to this infinite intelligence. It may be some hundreds of years, possibly a million, before the human mind attains such heights. Conceivably our orderly little system of planets might be disrupted, or life upon the earth become for one reason and another physically insupportable, before the mental evolution of the race had proceeded so far.

In our present ignorance we can only conceive the approach of suns, like that of the molecules of water vapour in the steam chest, as to all intents fortuitous. In the one instance as in 
the other there is a chance formation of a double system, whose existence may be relatively that of a moment, or of an æon. The conception of the helter-skelter flight of the stars, combined with the extension of the law of attraction, long ago suggested that the number of such binary and multiple systems must be very great. This involved a corresponding, though lesser, number of actual collisions. In a very striking way has the spectroscope confirmed these conclusions.

Long ago the sudden appearance of a very bright star in the skies obtained its due meed of wonder and surmise. The Star of Bethlehem may have been more or less of a myth. One of the best known was the famous star of Tycho. It was first seen on 7 th November I572. Four days later it had grown to the first magnitude. It continued to increase in brilliancy, finally rivalling Venus at its brightest, and becoming visible in full daylight. A month later it had begun gradually to fade, and in the following May it had disappeared from view. The telescope was thèn, of course, unknown.

This is the type of these apparitions. Formerly they were supposed to be very rare. Miss Clerke, in her System of the Stars, was able to list only ten which were known up to the end of the fifteenth century-that is, until the coming of the telescope. Not many more have been found since; but it is notable that ten or twelve of these have come within the last century. One observer, Mrs. Fleming, has made the subject her speciality, and she already has eight to her credit.

There is, of course, no reason to suppose that they have been any more frequent within the last twelve or fifteen years since Mrs. Fleming began, than in the twelve or fifteen years preceding, or than in thousands or millions of years. The difference is simply due to perfected methods of observation. Doubtless if these methods could be still further refined, these conflagrations would be found to be daily and conceivably hourly happenings. We do not observe them simply because they are for the most part so remote that they do not strike the attention even of observers with telescopes of enormous power. For the most part actual visual observation is quite unable to cope with the problem, and resort is had, therefore, to star photographs and spectrographs.

These new stars or nove, as they have come to be called, seem to have a rather characteristic spectrum, so that when an 
observer has become familiar with this especial spectral arrangement, he may be led to suspect the existence of a nova when it appears in his spectrographs. If then he possesses a series of photographs of the region, he may readily observe whether or no there be any star at this point which had been increasing in brilliancy. All this, it will be seen, is quite outside of the usual work of the observatory. It may be pursued as readily in the library, or floating around on a duck-pond, as on the top of Mount Hamilton, and resembles very much the ingenious method by which Mr. Berenson digs from obscurity unknown painters by means of the tell-tale eyes and ears which they have drawn.

Could they be close regarded, the blazing up of these nove would doubtless be, in mere extent, the most impressive spectacle which the realms of nature afford. The most notable recorded since the days of Kepler was that observed by Dr. Anderson in February of Igor, flashing out from amidst the constellation Perseus. It chanced that this very region had been photographed by the Harvard Observatory several times during the month of February, and up to two days before the star was noted by Dr. Anderson. So we happen to know that it must have risen from a star of below the twelfth magnitude to a star of the first within about three days. It became the brightest star in the heavens, Sirius alone excepted. The difference of its light within these three days corresponded to an increase of twenty-five thousand fold.

The apparition faded rapidly but fitfully, until it has become visible only as a little star of the twelfth or thirteenth magnitude. The most careful observations have failed to detect for it any parallax or proper motion, so that it is certainly not nearer than a hundred light-years-that is, ten times the distance of Sirius-and probably very much more.

After the outbreak the star was found surrounded by a striking nebulosity. This it was possible to photograph, and likewise to make a measure of its apparent diameter. If it be distant no more than a hundred light-years, the extent of the nebula must be at least fourteen hundred times the diameter of the earth's orbit. Professor Young accounts this an underestimate.

Repeated photographing of the star brought to light an astounding and almost inexplicable phenomenon. It was ob- 
served that there were in the nebula well-defined knots and streaks of condensation. These were estimated to be moving away from the star at such a speed that, if it were as near as alpha Centauri, would mean a velocity of more than two thousand miles per second. If the distance is fifty or a hundred times as great, the speed becomes comparable with that of light itself. The most plausible explanation of the phenomenon offered was that suggested by Kapteyn, that this motion of the knots and streaks was merely apparent and not an actual rush of masses of star matter. It represented simply a progressive illumination of spiral streams of nebulosity, advancing outwards with the speed of light. If this explanation is correct, the distance of the star would be about three hundred light-years, and its actual outburst occurred about the time that Columbus was discovering America. It follows from this estimate that the diameter of the resulting nebula was perhaps two or three hundred times that of the distance of Neptune from the sun.

If our sun had been the body or one of the bodies involved, our earth would have been enveloped in a vast mass of nebulous matter, probably hot, irradiating the entire sky and abolishing night and day. Probably the heat would have been so great that every vestige of life would have been instantly shrivelled at the first onset of this flaming deluge; the crust of the globe itself might have been melted, and the earth have returned to the primitive condition from which it sprang.

It is by no means certain as yet that these stupendous outbursts really represent starry collisions. For a little time the behaviour of their spectra seemed to negative this view. But the researches of Ebert of Munich made clear that the perplexing contrariety of apparent motions was readily explicable on the theory of anomalous refraction. On the other hand, it is evident that the swift rush of a sun or dark body through a dense mass of nebula would produce the same spectacle. The number of nebulæ we now know to be enormous. They may be counted by the hundreds of thousands, and their extent, even measured by sidereal standards, can only be regarded as something monstrous.

Both explanations may turn out to be true. A variety of circumstances make it probable that actual collisions do take place, and with such frequency as to be quite unaccountable from any calculus of probability based upon our present ideas 
of the spacing of the luminous suns. These probable collisions, combined with the evident number of binary systems, tend to confirm the conclusion we have reached upon other grounds, as to the enormous number of dark bodies. More than thirty years ago, and before the variety of evidence now at hand had been accumulated, Professor Johnstone Stoney, from a profound study of stellar phenomena, was led to say :-

"If what I here venture as a surmise with respect to the cause of stellar heat and the origin of double stars, is what really takes place, we must conclude the sky to be peopled with countless hosts of dark bodies, so enormous that those which have met with such collisions as to render them now visibly incandescent must be comparatively few indeed."'1

The astronomy of the invisible, it will be perceived, is as yet in its infancy. There is already sufficient to indicate that its field is immense-that is to say, that the number of dark bodies probably far transcends the number of those which the telescope brings in view. In a sense this is yet a surmise. It is obvious that until the matter can be cleared up our knowledge of the cosmos can at best be incomplete, our conjectures as to its form and structure but provisional.

It is only very recently that this fact has become clear. In ignorance of it, the astronomers did not hesitate to build up vast systems which had little larger foundation perhaps than their own imaginations. It will perhaps be of interest, nevertheless, to pass them in review, and endeavour to sift out any elements of truth they may contain. Possibly from the wreck of them we may gather some ideas.

1 Proc. Royal Society, I86I-69. 


\section{- CHAPTER XXX}

THE STRUCTURE OF THE UNIVERSE 
LoNG before the discovery of the New World, it was believed that new lands in the far West might be seen from the shores of the Canaries and the Azores. These illusive images were owing not to any extraordinary refraction of the rays of light, but produced by an eager longing for the distant and the unattained. The philosophy of the Greeks, the physical views of the Middle Ages, and even those of a more recent period have been eminently imbued with the charm springing from similar illusive phantoms of the imagination. At the limits of circumscribed knowledge, as from some lofty island shore, the eye endeavours to penetrate to distant regions. The belief in the uncommon and the wonderful lends a definite outline to every manifestation of ideal creation; and the realm of fancy-a fairyland of cosmological, geological and magnetic visions-becomes thus involuntarily blended with the domain of reality.

Humbold', Cosmos. 


\section{CHAPTER XXX}

\section{THE STRUCTURE OF THE UNIVERSE}

LOokING up of a summer's night into the firmament with its countless silvered points of light, there seems little enough to suggest any idea of arrangement or order. For aught that the unaided eye might know, they might be merely incandescent bulbs stuck at random in the ceiling of the sky. For all we can see, they wheel together about the pivot star.

In the beginnings of astronomy there seemed as little order or arrangement in the movements of the errant stars, the wanderers, the planets. They went in a zigzag aimlessness across the heavens, marching forwards and backwards in a bizarre fashion that was at first unaccountable enough. It was long centuries before men were able, from this apparent tangle, to reach the idea that the planets move in circles. When at last it was made clear that they do, the simplest arrangement that could be imagined for the unmoving stars was to suppose they were attached to a crystal sphere which enclosed space. This, as we know, is what the ancients did.

Among the ancients there were a few, like Democritus, who could rise to more sublime conceptions; there were very few. But when in our modern time the planetary arrangement had at last been solidly grounded, the question of the spacing of the stars came back again.

Our human knowledge has often advanced through recourse to analogy. Vaguely we have come to perceive that the order of phenomena is relatively simple. In our ignorance we imagine more than is needful. The explanation of one narrow group of facts leads often to the enchainment of many. When, in the seventeenth century, the remoteness of the stars, or, in other words, the detachment of the solar system, had become clear, it was natural to think of our planetary arrangement as a microcosm which might be the mirror of the macrocosm.

It is hard to say to whom the idea came first. The imper- 
severant Kepler speculated about it, as he did upon nearly everything else under the sun. Bruno, as we have seen, had revived the Democritan idea that the stars are blazing suns; it lay but little further to suppose, as he did, that they have planets revolving in their train as does our own. It was this thought which inspired Fontenelle's brilliant volume on the Pluralité des Mondes. Before the century had ended, and when the grandeur of our orb had been established beyond all cavil, Huyghens had boldly announced the possibility that there might be other suns as vast. Yet for his heresy he did not hang or burn.

The same thought had come to Newton; it is reflected in the pages of Milton too. But the first definite presentation of the idea that the stars might be arranged upon some definite system like unto our own, seems to have come from an obscure English schoolmaster, some time after all of these had passed to earth. This was Thomas Wright of Durham. His volume appeared in I750, with a long-train title, as was the habit of the day: "An original Theory or New Hypothesis of the Universe, founded upon the Laws of Nature and solving by Mechanical Principles the General Phenomena of Visible Creation; and particularly the Via Lactea." It was a godly book, and the author felt properly constrained, after the fashion of the time, to show that it tended towards the promotion of virtue and piety. He says :-

"In a system naturally tending to propagate the Principles of Virtue, and vindicate the Laws of Providence, we may indeed say too little, but cannot surely say too much; and to make any apology for a work of such nature, where the Glory of the Divine Being of course must be the principal object in view, would be too like rendering virtue accountable to vice for any author to expect to benefit by such an excuse."

Thomas Wright was the author of the Grindstone Theory, which, amid many vicissitudes, has more or less held the field to the present time. His ideas were comprehensive. He computed that the Milky Way must contain at the very least three or four million stars, and he adds :-

"When we consider them all as flaming suns, progenitors and primum mobiles of a still much greater number of peopled worlds, what less than Infinity can circumscribe them, less than an Eternity comprehend them, or less than Omniscience produce and support them, and where can our wonder cease?" 
None the less he conceives the sidereal creation as finite, and he invites the reader to imagine a vast gulf or medium everywhere extended like a plane, and enclosed between two surfaces, the whole of it spaced with stars. To an eye situated anywhere near the middle point of this plane, it is evident that towards the poles there would be an apparent promiscuity; but that looking across the plane in either direction the stars would seem crowded together, and thus might readily produce the appearance of the Milky Way. In other words, he conceived that the arrangement of the stars may be that of a huge heavily flattened globe, or, as we have since come to think of it, in the shape of a grindstone. $\mathrm{He}$, of course, regarded the sun as the centre of this system; from it proceeds " that mystic and paternal power productive of all life, light, and the infinity of things."

These ideas of Wright were caught up by the young Kant, to form, as we shall trace hereafter, the basis of his cosmical theory. A few years later, and quite independently of either Wright or Kant, came the Cosmological Letters on the Arrangement of the World-Structure, from the pen of Johann Heinrich Lambert, contemporary worker in the fields of Laplace and Lagrange. It was beyond doubt a remarkable book. Lambert was at once a mathematician and a poet, with an imagination which outran that of all his predecessors. Even yet our knowledge is quite insufficient to estimate the value of his grandiose conception. It was that of a universe made up of wheels within wheels. His ideas might readily have been suggested by an attentive study of the arrangements of our system. He simply conceived it as the image of the whole. The beginning, that is, the first order, would be that of the planets with their satellites or moons. Next after this would be the sun with its planets. Our sun, with others like it, he imagined as turning about another centre, this in its turn, with others, around yet another; and so on until the mind, reeling beneath the immensity of such conceptions, will no further go.

Just as in each of the smaller systems there is a central body grander far than all the rest, so Lambert believed that for all of the larger orders there exists a central orb of corresponding magnitude. No such central point, no such massy sun, about which our sun may be turning, was at hand. Lambert 
therefore imagined one; and since it would needs be very large and on this account conspicuous, if it were aglow like the rest, he conceived that these vast central suns were opaque and dark.

It was a pure conceit. There was simply nothing save a shadowy analogy upon which the imagination of Lambert had to build. His ideas were generally forgotten, or remembered only to be flouted. Simon Newcomb, in his Popular Astronomy, has this rather tart word :-

"As not the slightest evidence favouring the existence of these opaque centres has ever been found, we are bound to say that this sublime idea of Lambert's has no scientific foundation. Astronomers have handed it over without reservation to lecturers and essayists."

In a way this rebuke is still justified. Still, it is curious to note how, within a very few years, discoveries have come which lend a hint that such opaque centres may exist. These might be the dark suns which the spectroscope has revealed.. Their number, we know already, is great. Whether they be companions of glowing suns or not, there seems little reason to doubt that eventually the number of dark bodies will be found vastly to outnumber those which are ablaze. A sun of the probable grandeur of Canopus would have a mass more than sufficient to form such a centre of the third order; and on the reasoning indicated, it is much more likely to be dark than luminous.

Perhaps in another half-century or so, we may have some basis upon which to estimate the validity of Lambert's conceptions. At the present time speculative minds may still let their fancy rove. The most vital objection which may be urged against this view, at least so far as our own solar system is concerned, is the apparent absence of any considerable perturbation of the planets. The motion of the moon, we know, is very sensibly affected by the sun. If we are revolving about some greater sun; it might readily be supposed that it would exercise some gravitational pull upon the larger planets in a similar way. No equivalent deviation from their orbits can be found. It seems fairly certain that there is no body in any wise comparable with the mass of the sun within at least a thousand times the earth's distance. Between this and 277,000 times--the estimated distance of the nearest sun-is, of course, 
a long way. Some millions of dark bodies might lie within this vast abyss. One of these might be huge enough to be a centre of revolution for our system; we have no present evidence of its existence.

So much for fancy. Scientific method has not been more successful.

The first to attempt a conception of the structure of the universe by induction from observed facts was William Herschel. It was, indeed, the great problem of his life. To gain some sort of an idea, he set about systematically counting the number of stars in different telescopic fields to determine whether there is any wide variation in their apparent number. This process he called "star gauging."

The actual count of the whole heavens was, of course, a physical impossibility with such telescopes as he employed. These were, for this purpose, not greatly inferior to the best which we now have. He therefore counted selected portions of the field, and made his estimates accordingly. His industry was amazing. Before he was through he had actually made computations for 3400 telescopic divisions of the sky. What he found was that the stars seemed very much more numerous in the direction, or as we may say, the plane, of the Milky Way than in the heavens at right angles to this. He therefore conjectured that there might be some definite distribution-in a word that the universe, at least such of it as the telescope may disclose, does possess a definite shape.

If it may be supposed that the stars lie at something like a general average distance one from the other, the result of Herschel's investigations was to confirm in a measure the ideas of Wright and Kant. He thought that, looking in the direction of the Milky Way, the stellar universe might extend perhaps five times as far as in the direction perpendicular to this. He did not conceive, however, that this arrangement was perfectly uniform, but that in one direction there is an immense bifurcation. The figure which he drew was bizarre enough. It resembled a two-legged body with no head.

Herschel did not himself hold by his two-legged universe. Further consideration revealed to him that the assumption of equal spacing, or, as we may say, equal star density, might be wholly erroneous. His discovery of binary systems and the 
apparent existence of distinct star clusters like the Pleiades and others, rendered it highly possible that there are, as it were, clumps of stars. This might be true over vast areas.

It was evident that a mere count of the stars could not settle the question. It was needful to gain some idea of their distance. This alone might give some clue as to their relative spacing. But in Herschel's time no reliable measures of parallax could be made. He therefore conceived a simple method of determining relative, if not actual distance. This lay in comparisons of brightness or magnitude.

If the radiance of the suns be equal, it is obvious that the light that comes to us from them will be in proportion to their distance, more precisely in inverse proportion to the square of the distance. A star twice as far as another will send onefourth the light-it will seem just one-fourth as bright. Then, to determine their relative distance, all that remained then was to find some method of accurately determining the light of the stars.

Herschel found this in a fairly satisfactory way in the use of telescopes of different powers. In reflecting telescopes at least, the amount of light transmitted to the eye of an observer is in proportion to the square of the diameter of the reflecting mirror. It follows that, on the average, a star four times the distance of another will appear of equal brightness with the other viewed through a telescope four times as large. This, of course, assumes that the stars are of equal size and emit light with equal intensity. We know now, of course, that the stars vary in size as greatly as the members of the solar system - that is to say, in proportions all the way from the sun itself down to the minor satellites of a minor planet. We know, too, that their light-giving power varies as widely, let us say, as from an incandescent electric lamp to an arc light. Nevertheless, bunching them by the millions, it is probable that the assumption of an equal average size for each "magnitude" is fairly justified, and Herschel's larger telescopes easily showed twenty or thirty millions of suns.

It was on this basis that Herschel estimated that, on the average, a star is distant in proportion to its magnitude, and that his forty-foot reflector therefore revealed the existence of stars 2800 .times the distance of Sirius, the brightest of the heavens. He assumed, of course, that there is no extinction of light across this distance. 
When now he compared the number of stars of average equal brightness with the estimates of their relative distance, it was found that there was no correspondence. If we were to conceive the stars distributed in a series of spheres, or spherical shells, one enclosing the other after the manner of a Chinese egg, the earth or the sun being supposed at the centre, it would follow from the supposition of even spacing that the number of stars in each shell would increase in the proportion of the cube of the distance. The figures did not correspond. The actual number increased much more rapidly in the lesser magnitudes than the theory would suppose.

Towards the end of his life, therefore, Herschel seems to have concluded that it was impossible to set any definite bounds to the stellar system; but he appears more or less to have retained the belief that its general shape answered somewhat to the conclusions of his earlier research.

The subject appears to be one of endless fascination to the astronomer, and since the time of Herschel a considerable number of minds have attempted the problem. One of the most notable was the elder Struve, long the director of the Pulkowa Observatory. He combined the result of a count of the stars of several magnitudes made by Bessel in a wide zone, with the gauges of Herschel. He adopted the same theory as the latter, supposing that the brightness of the stars supplies, on the average, a measure of their relative distance. His conclusions were that the stellar system might be made up of a series of layers of varying density, lying parallel to the plane of the Milky Way. In the via lactea the stars would be densest; he would conceive that in this layer they are spread out as in a wide, thin sheet, with our sun situated somewhere near the middle of the layer. Were we to journey outwards in a direction perpendicular to this plane, we should find the stars growing thinner and thinner without perhaps ever reaching a boundary.

Against the hypothesis of Herschel, Struve, and all their like, the late Richard A. Proctor, well known as a writer on the more popular side of astronomy, brought forward objections that seem decisive, at least so far as our present knowledge extends. One was as to the assumption that the stars are more or less alike in their actual light-giving power. Stars that we now know to be of very nearly equal distance may vary 
in their apparent brightness by hundreds and perhaps thousands of times. Such is the case, for example, of Sirius and 6r Cygni. This difference may be due to a vast disparity in size; it may be due to an equally wide disparity in their temperature or light-giving power. The apparent brightness, therefore, is only the vaguest sort of a clue to the distance. It is actual measures of parallax alone which could ever afford a sure basis for safe induction.

Proctor likewise brought forward the argument from the apparent drift of the stars. Here and there over the heavens the stars of certain regions, at least such as disclose an apparent motion, seem moving in a common way. Their motions may not be at all equal, but have the same general direction. It is just as if throughout the spaces of the sky there were currents and eddies as in a stream of water. This Proctor aptly described as "star drift." It may be entirely an illusion, a happen-chance, depending on our point of view; but if it have any underlying reality, it is evident that this would result in agglomerations of stars in one region with relative emptiness in another. If such systems exist, it is clearly hopeless to suppose that our present means are sufficient to attain any definite ideas as to universal structure.

Carrying out his conception of star drift, Proctor was led to conceive the Milky Way as an irregular spiral stream of minute stars lying in and among the larger stars of the system. That all this could be little more than guess-work is evident from the conclusions of Mädler. Drawing naturally upon much the same material, Mädler conceived the stars of the Milky Way as entirely separated from the rest of the stellar system and as belonging to an outlying ring or system of rings. In order to account for the gaps in the Milky Way, this ring was supposed to be cleft on one side. It is on this account often referred to as the "cloven ring" theory. In this view the stellar system, viewed from without, might present some such an appearance as a split key-ring, spread out a bit. The outer ring, cleft on one of its sides, would represent the system of the Milky Way, while the luminous mass in the centre would include the remainder of our stellar universe. Mädler likewise entertained the idea of a central sun.

It cannot be said that we are any further advanced at the 
present day. It is evident that the data which we have to go on is as yet insufficient. In a recent volume, ${ }^{1}$ and in a later monograph, Simon Newcomb, himself the foremost living student of this especial subject, sums up the slender conclusions which seem warranted thus far. He believes that the collection of the stars which we call the universe is limited in extent. The smallest stars that we see with the most powerful telescopes are not necessarily more distant than those of a grade brighter, but are rather smaller or less luminous stars. This does not preclude the possibility that far outside of our universe there may be other collections of stars of which we know nothing.

The boundary of this especial universe is apparently somewhat indefinite and irregular. As we go outwards towards the boundaries, the stars may thin out gradually. It does not seem possible to decide whether the agglomerations of the Milky Way lie on this.boundary or not.

Seeliger of Munich would go a little further. This astronomer made an exhaustive study of the distribution of the great mass of stars relative to the so-called Galactic Plane. But the inquiry extended only to stars of the ninth magnitude-that is to say, to a few hundred thousand out of, possibly, hundreds of millions. Within these limits there does seem an unmistakable increase of star density in the region of the Milky Way, and a progressive decrease in either direction perpendicular to this plane. In other words, these hundreds of thousands of brighter suns seem collected into some such a mass as that imagined by Herschel and Struve. In Seeliger's view, "the Milky Way is no merely local phenomenon (local to us), but is closely connected with the entire constitution of our stellar system."

This idea is somewhat strengthened by the researches of Celoria, the successor of Schiaparelli, at Milan. Celoria utilised a very much larger number of stars; his results were much the same. But one circumstance is to be noted. From the star gauges made by the Herschels, father and son, the crowding of the stars in the Galactic Plane appeared to be perhaps twenty times more intense than towards the Galactic Polesthat is to say, in the regions at right angles to this plane.

From the later studies of Celoria and others, it does not appear that this Galactic star density is more than two or three

1 Newcomb, The Stars, 1902. 
times that of the poles. The studies of Pickering of Harvard would reduce this to certainly not more than two times. The discrepancy is due simply to the fact that the later counts go further, the averages involve enormously greater numbers. The inference is that if the investigation were carried very much further-if it were possible, to stars of the fifteenth magnitude or beyond-this difference of star crowding would quite disappear.

It will be seen, therefore, that as yet the problem is unsolvable. It may be that the appearance of a grindstone stellar aggregation is simply an illusion. It may, of course, always be that it has no boundary, or, possessing a boundary, this may lie for ever beyond our means of discovery. Before we can form any idea of shape or of finitude, there is a fundamental question which must be solved. This is the extinction or absorption of light.

Our present theory of light was suggested and is to some extent based upon the analogy of sound. We know that sound is a wave process. In conceiving of light as of a similar nature, the most, though not all, of the observed facts may be quite satisfactorily accounted for. We know that the vibrations of sound are progressively damped down by the medium in which they are propagated-in other words, that they eventually wear out against the friction of the medium. The conception of a light-carrying medium involves the idea that the ether is to all intents frictionless. This is, of course, a philosophic absurdity, if we conceive the ether to be of a material nature. The inference, therefore, is that sooner or later the vibrations of light would be extinguished by the medium through which they travel. It may be, of course, that the whole ether theory will later be discarded, and that there is no necessity for this conclusion.

Be that as it may, we now know that space is nothing like so empty as was formerly supposed. It is booming with suns and probably a vastly greater number of dark bodies. If our planetary system, with five or six hundred permanent members, is an image or type of solar arrangements in general, the number of planets, satellites, asteroids, and comets may be hundreds or thousands of times the total number of central masses, glowing or dark, just as the number of dark suns may be hundreds or thousands of times those of the visible suns. 
This is a first fact. The swarms of meteors is a second. Space is teeming with them; they may be the fundamentals of the universe. Their number is vast beyond all computation. Seen through a section hundreds of thousands of millions of miles thick, they could hardly be perfectly translucid.

And besides all this there is cosmic dust. It is microscopic in dimensions, possibly less than a thousandth of a millimetre in average diameter. However, the stars are very far. Arrhenius has computed that no more than one hundred such minute particles, distributed evenly through every cubic kilometre of space, would, at the distance of the farther stars, suffice to block their light from our view.

In view of all this, it becomes highly improbable that the light of all the stars reaches our eyes undimmed. It is possible that this accounts for the fact that the heavens are not eternally ablaze, and why a billion of blazing suns in no wise affects the temperature of the earth. It may be that we see the stars as through a veil, and that the more distant of them are nothing like so far away as our present estimates suppose. This, of course, in no wise touches the distance of those whose parallax has actually been determined; but these are hundreds against many millions. It may well be that the stars of the eighteenth magnitude are nothing like a thousand times as far away as the average of the first magnitude stars, as the present theory supposes.

The question will probably find decisive answer from investigations that are now being carried out. Professor Comstock of Washburn Observatory has recently brought forward the evidence to show that either the more distant stars have individually less light-giving power, are actually smaller or fainter, or else that at great distances their light does suffer some diminution, some absorption. There seems, of course, no reason to suppose that the actual size or luminosity of the stars is any less in one particular region than in another. The conclusion, therefore, is for absorption, and Professor Comstock endeavours to find what factor of absorption, mathematically expressed, would account for the facts he has brought out.

If such an absorption takes place, it is obvious that we shall never know much about the farther reaches of the stellar system, and nothing at all of its possible boundaries or shape. We shall, to be sure, steadily advance in our knowledge of 
regions less remote. It may be that with this steady advance the nearer of the stars will be found aggregated into systems as orderly and as simple as that of our planetary arrangement. It may be that from this we shall attain to some more or less definite conceptions of the rest. They would never be more than the fancies of Lambert-inferences from analogy.

Of more proximate interest is the question as to whether our own sun is a member of any immediate system of stars. Already there is a slight suggestion that it may be. A very ambitious attempt at an orderly arrangement of the nearer stars was made some years ago by Maxwell Hall.

His reasoning was simple. If the sun is revolving about any central point, it is obvious that this point will be more or less at right angles to the line of its present motion. From the known proper motions of the nearer stars, Hall endeavoured to fix such a point and to bring these known motions into agreement with this idea. His results did not tally with the observations. His work remains, therefore, merely a magnificent attempt. It may be that in later days it will be possible to take up the problem with more hopes of success. It is, however, based upon the idea that the force of gravitation is sufficient to hold the suns to such an orbit. At the present time, as we shall see, this is doubtful.

It follows, therefore, that the conceptions we may make of stellar arrangement are yet of the vaguest. It may be that no such arrangement in the sense 'of definite systems exists. We might here have recourse to the analogy of molecular and molar motions, such as they are known to us.

If there were aught in Lambert's vast ideas of systems within systems, we might readily suppose that the succession of " orders" which he imagined might extend inwards towards the infinitely little as well as outwards towards the infinitely vast. We might discover a like order in the structure of matter. We might find, for example, that the atoms and molecules of the chemist likewise possess a planetary arrangement. It is curious to note that this is precisely the drift of present-day conceptions of atomic structure.

In the light of recent research, especially of Professor J. J. Thomson of Cambridge University and his school, we may conceive the atom as made up of a relatively large number 
of ultimate units-ultimate so far as our present knowledge extends-and there seems reason to suppose that these ultimate units comprise more or less of a planetary system. It seems even as if we should be able to compute the times of revolution of these ultra-atomic satellites, though it is not yet clear as to whether there exists a central and attracting mass.

The atoms themselves may constitute minute systems; they may in their turn be arranged into what we might term molecular systems. A noteworthy attempt in this direction was made some years ago by the distinguished Russian chemist, Mendeléeff. He endeavoured to represent the arrangement of the atoms within the molecule as following a Newtonian order, and perhaps ruled by Newtonian law. Neither of these conceptions represents as yet anything more than ingenious conjecture. But even if they should be confirmed, it is noteworthy that in the next step higher we may be certain that any planetary scheme of arrangement distinctly ceases.

The motions of the molecules in a free or vaporous state are known with a high degree of probability. For definite temperatures the motions of the molecules of the air and of other gases may be computed with considerable accuracy, at least as to their average speeds. This constitutes our modern, or, as it is termed "kinetic," theory of gases. It regards the pressure which a gas exerts upon the walls of a bounding vessel as determined by the number and force of the molecular particles bombarding the walls of the vessel. But within the gas itself no order or systematic arrangement obtains. The molecules are conceived as flying about in every direction at a tremendous rate of speed, coming into collision one with another, and rebounding without loss of energy.

So far as our present knowledge goes, the myriads of the stars present, in their motions, rather the image of the molecules of a gas than any arrangement of suns and planets and satellites such as was pictured in the dreams of Lambert. To the eye of the universal mind, the suns may be as the ultramicroscopic particles of the air sporting hither and thither in confused and incessant flight. The dance of the motes in a sunbeam penetrating the shutters of a dark room may be, for aught we know, the mirror of cosmos. Perhaps the picture will be more vivid if we were to recur to the simile already employed, that of a school of dancing fireflies, flashing out their light 
through a moment of cosmic time, then to go dark until through a process of fertilisation and rebirth they blink and gleam again in unending cycles. The suggestion is but a fancy. The problem is transcendent. We do not know; it is possible that we never shall.

Probably it is among the naïvetés of our intellectual childhood to suppose that the pursuit of the scientific method will ever bring us any nearer to the ultimate mystery of creation than were the favoured children of Hebraic tradition. Doubtless, no more complete illusion ever possessed the human mind than that through its operations we may penetrate the origin of things. So far from reading any Reason or Intelligence into this strange wentle-trap of a world, the amazing insight into its more concrete processes, its mechanical device, which the last few centuries have brought, leads to utter bewilderment; it seems to the initiate eye yet stranger, yet more mystic, more unthinkable, more unbelievable, than ever.

The conception of a creative Being was simple-perhaps, in the mists of primitive ignorance, imaginable. This is true no longer. Our modern knowledge has pushed back immeasurably the limits of the world; it has disclosed the immeasurable duration of time. It has given us a rational account of the planet on which we live, the system of which we form a part. It has indicated a probable origin and a probable end. In some relative sense we know where we are; in some relative sense we know how we came to be here; in some sense we know less than ever why. What is still more, we know now that we do not know, and that in all finite probability we never can.

The cosmic structure may be for ever beyond our human ken, alike with cosmic ends and cosmic aims. There may be limits beyond which we cannot pass. But the area within these limits is vast-field enough for a splendid human work. We have learned to know the processes of human birth, the course of human evolution. We have learned to know in its larger outlines of the evolution of worlds. If the grandeur of our thoughts be measured by the immensities of space and time which they cover, surely no human thought has ever reached nearer to the essence of sublimity than this. We have cast aside the heavy trammels of our daily cares and daily needs to search for cosmic order; let us turn to view the ways of cosmic time. 


\section{"CHAPTER XXXI}

THE BIRTH AND DEATH OF WORLDS 
Or old hast thou laid the foundation of the earth: and the heavens are the work of thy hands.

They shall perish, but thou shalt endure : yea, all of them shall wax old like a garment; as a vesture shalt thou change them, and they shall be changed.

Psalm cii. 25, 26.

\section{MUTABILITY}

From low to high doth dissolution climb, And sink from high to low, along a scale Of awful notes, whose concord shall not fail :

A musical but melancholy chime, Which they can hear who meddle not with crime, Nor avarice, nor over-anxious care.

Truth fails not; but her outward forms that bear The longest date do melt like frosty rime, That in the morning whitened hill and plain And is no more; drop like the tower sublime Of yesterday, which royally did wear His crown of weeds, but could not even sustain Some casual shout that broke the silent air, Or the unimaginable touch of Time.

WORDSWORTH. 


\section{CHAPTER XXXI}

\section{THE BIRTH AND DEATH OF WORLDS}

IN the sixty or eighty years intervening between the discovery of the telescope and the publication of Newton's Principia, mankind penetrated more deeply into the mystery of his surroundings than in all the previous years of his intellectual life. These sixty or eighty years saw the establishment of the Coppernican system, of the science of mechanics, of the law of gravitation, of the true dimensions of the solar system; with it the littleness of the earth, the grandeur of the sun, the almost infinite distance of the stars. It was within this period that man learned to know at last his true place in creation.

When this vast work was complete it would seem as if natural investigation could no further go. But the inherent impulse of the mind forbids a stop. Coppernicus had shown the true system of planetary orbits, Kepler had established the laws of planetary motion, Newton had revealed the cause and binding force. There still remained the profound question which had agitated the mind of man from the earliest time in which he had begun to reflect upon existence. This was the origin of the world. In so far as they were not simply systems of conduct and morality, or mere rescripts of the history of an especial people, what we call religions represent mainly an endeavour to solve this profound problem. Practically all of the various faiths of the various peoples included some essay in cosmogony.

These early endeavours were naturally crude. Few of them had any material basis either in fact or in observation. They were for the most part merely like the extraordinary stories which spring up in the minds of highly imaginative children; they represent in truth simply the intellectual childhood of the race. Brahma in meditation on the lotus leaf through long ages, producing at length a golden egg as large as the universe, out of which the latter was slowly evolved, is a type. The 
Chaldean tradition of a Garden of Eden, the Deluge and the rest, the basis of the Mosaic system, is another. It was the latter which survived among the peoples of Europe when Hellenic science had gone down, and until the later years of the seventeenth century. After the generation of Cassini and Newton it could no longer satisfy any rational mind.

The telescope had cast the world adrift; cosmos seemed to have no whence and no whither. It produced a sort of an intellectual simoon. When the tumult had somewhat subsided, when it finally became clear that the facts were impassable rocks, speculative minds began to cast for an anchorage. If the Chaldean tradition was no longer tenable, still was there never a creation at all ? Did the universe, and especially that little part which is ours, for ever exist as it is ?

We know that the speculative brain of Newton sought vainly in the phenomena which he had investigated so deeply, for some sort of a clue. Too heavily weighted by prevailing dogma, too deeply occupied perhaps during the period in which his mind was really active-that is to say, before his mental illness - with the immediate mechanical theory of planetary movement, he could discover no opening. The problem passed to a newer generation, upon whom tradition had less weight.

Almost contemporaneously with the Principia, Fontenelle had rescued from oblivion the glowing fancies of Bruno, and speculated delightfully upon the plurality of systems and worlds. Huyghens' reveries upon the same subject, published posthumously, came ten or twelve years later. Leibnitz about the same time had conjectured that the planets are extinct suns; he had seen that the flattened shape of the earth indicated beyond peradventure that it had once been in a fluid condition. $\mathrm{He}$ divined that it had once been a molten mass. In $\mathbf{7 3 4}$ Daniel Bernouilli had undertaken some remarkable calculations, demonstrating on the calculus of probabilities that the solar system could not have been the product of chance. This was the state of speculation when the subject was taken up by Buffon.

It is to this great naturalist that we owe the first attempt upon thoroughly scientific principles to conceive the origin of the globe on which we dwell. His ideas were contained in a volume on the Theory of the Earth, first published it 1745 . Four years after it was incorporated as the first volume of his 


\section{THE BIRTH AND DEATH OF WORLDS}

celebrated Natural History, cherished companion of the mind of youth. Let us take note of the facts upon which he had to build.

The earliest observers, to whom the truth had become clear that the planets travel in circles, must have likewise noted that they all travel the same way. Some among them may have noted that the circling path of the moon is in the same direction. When the heliocentric ideas of Aristarchus had been established, it was found that the earth was journeying the way of the rest. All this could hardly be mere coincidence.

Then came the discovery of the various satellites-first of Jupiter, then of Saturn. All of these revolve about their central orbs in the same manner as the moon. Finally, it was observed that the earth's revolution upon its own axis was in the same direction. So it was found were the revolutions of all the other planets, and finally that of the sun, as one by one they were revealed by the telescope.

Putting all these motions together, Bernouilli had calculated that, in the theory of chance, it was millions to one that this could not be due to mere hazard. Whatever force, whatever power, had impressed this especial direction of motion upon one had evidently acted in the same way upon all.

Moreover, there was another curious fact. If one could take up a point of observation somewhat distant from the outermost rim of the solar system, he would observe that the whole of the planetary motions take place within a thin plane. If we project through the intervening spaces the disk which the ancients had named the ecliptic, or plane of eclipses, it is noted that none of the planetary orbits are inclined very much above or below this median line. Altogether, the steepest of the inclinations, at least in Buffon's time, did not exceed one-seventeenth part of the sphere of the heavens. This could be as little the outcome of chance as the common direction of movement. What was the determining cause of this striking uniformity?

The mind of Buffon found a hint in the calculations of Newton as to the relative mass of the planets and the sun. Newton had computed that the mass of the known planets and satellites put together would not equal the 650th part of the mass of the sun; we know now, of course, that even with 
500 satellites and two new planets added, it is still less than a 750th. The quantity is very small. If a 750 th part were chipped off a cannon-ball or a melon, neither would greatly suffer. The trained imagination of the investigator of nature swept swiftly to the thought-perhaps here is the explanation.

Buffon put with this Newtonian computation another of his own. Knowing the distance of the planets and their apparent diameters, it is a simple enough matter to calculate their volume; that of the sun as well. The volume divided by the mass is the measure of density - that is to say, the unit quantity of matter in a chosen unit of space. According to Buffon's calculation the average density of the planets is to that of the sun as 640 to 650 ; in a word, the relation was very near to unity. But if the stuff of the planets is of the same density as that of the sun, then it is next to certain that it is the same stuff. The figures were in error; but the conclusion was true. Remember that this was more than I50 years ago, a long time before the development of chemistry, a century almost before the use of the spectroscope; it was an intuition of genius.

With this discovery there seemed little question, then, that our little earth and all its kind were once a part of the sun. Somewise or other these planetary bits had been thrown off, brushed off, from the glowing mass, had cooled down into solid orbs and taken up their common way around the parent sun. It was a splendid guess-but how had it come ?

There were dozens of ways, of course. There might be vast eruptions upon the sun like those upon the earth which had destroyed Pompeii. There might be colossal explosions like that which in our own time blew away the island of Krakatoa. Buffon thought of another. Up to this time he had been following the firm path of induction, now he struck off into analogy and guesswork. The study of comets, the plotting of their orbits, the prediction of their return, was the order of the day. Some of them were very vast-they moved at frightful speed. Newton had shown that some of them smash into the sun, some just graze its edge. It was known that some of them at least come probably from beyond the confines of our planetary system. Was it not conceivable that from somewhere in the distant ways there had come one of especial power and great bulk, rushing along with such impetus as to cut 


\section{THE BIRTH AND DEATH OF WORLDS 405}

straight through the limb of the sun and carry away a bit of its flesh? It was a tempting hypothesis, not in the least unscientific, easily possible in the existing state of knowledge.

Buffon argues for his theory with tenacity and conviction, and with all that grace of style which made him one of the most widely known of writers upon natural science. But after all it was only a guess; it had no facts to go on. Nothing in the way of subsequent discovery ever came to its support. But it laid a solid foundation whereon others might rear a more enduring fabric. The central fact which Buffon had laid bare, not indeed with firm proof but with a high degree of probability, was that the matter of our solar world at least is of the same piece. It was a hundred years before it could be proved; but his surmise set men thinking, and led others to happier results.

A few years before Buffon, the mathematician Maupertuis had drawn attention to the curious shape of some of the vague nebulous masses which no telescope of the period could resolve into separate stars. Some of them appeared to have a figure like that of an oval or ellipse. If Buffon had not been so hot upon the trail of his sun-scraping comet, he might have seen that here was a hint of value. He let it go by. In the far away little university town of Königsberg, on the upper edge of Germany, there was a young philosopher with a teeming brain to read after him with better eyes.

The early years of the century had seen a lively polemic among the mathematicians over what the French call forces vives - that is, the energy contained in a body in motion. It really bore on the ground principles of a rational dynamics. Galileo had laid the foundations; Huyghens, Leibnitz, and Bernouilli had made important contributions; the matter was finally planted on a firm basis, not subsequently to be disturbed, by Euler in 1736 and d'Alembert in I743.

But the old Cartesian ideas were still floating about, ghosts from a once splendid fabrication which the Newtonian philosophy had woefully undone. A few years after d'Alembert, a young man fresh from his university studies dashed into the arena with an effort to bring back life to the ghosts. One does not readily recognise under this guise the familiar figure of the metaphysician, Immanuel Kant. He was born in Königsberg, the son of a saddler; as his name indicates, of Scottish descent. 
He had studied theology and the sciences in the university of his native place, become first a private tutor, then a privat docent in the university. Years afterwards he was given a professorship. This he held to the end of his lengthened days, never venturing, so the story runs, beyond ten miles outside the place of his birth.

He had a devouring mind; his mathematical studies had given him a lively interest in scientific problems. Five or six years after the appearance of Buffon's Theory of the Earth he came across a copy of the Hamburg Free Opinion, which contained a summary of the contents of Thomas Wright's remarkable volume, wherein the grindstone theory had been announced. Wright was not content to figure out the shape of the stellar universe, but indulged in some interesting speculations as to its history as well. It was stimulating. Kant was then twenty-seven, the age at which Darwin reached his conception of natural selection. Four years after he appeared with the vigorous essay in which the nebular hypothesis was for the first time laid down.

The slender volume bore the title of "General Natural History and Theory of the Heavens; or, a Research in the Construction and Mathematical Origin of the Entire Universe on Newtonian Principles." It contained a fulsome dedication to the "Very Enlightened and Very Mighty King and Sire," Frederick II. of Prussia. Neither the sounding title nor spreading dedication saved it from a dismal fate. The publisher of it straight away went into bankruptcy. It never really saw the light of publicity until long years thereafter. Moreover, it was published anonymously, and in the years that followed this promising student of the attainable had gone wandering in the desolate bogs of philosophic speculation, the undoing of so many brilliant minds. In a characteristic essay on The Only Possible Argument for the Existence of God, published in 1763 , he gave a summary of his theory. But it did not really come before the public until I79I, then only as an appendix to a German edition of Herschel's Structure of the Heavens. Though the fame of Kant by that time was great, it seems to have attracted little notice even then.

It was in many ways an amazing book. Its central idea is a paraphrase from Descartes, of more than a century before : "Give me matter and I will build a world " But he will build, 
not out of the cobwebs of his mind as did Descartes, but from the newest and solidest knowledge of the day. You will often read that this effort of Kant's was a mere speculation. Such a remark could come only from ignorance of the work itself. Kant had deeply studied Newton; he had studied Buffon; he was abreast with the scientific progress of his time. He sought a mechanical explanation of cosmos, and he found it in the law of gravitation. With the aid of this he endeavoured to group the known facts of cosmogony into a working theory. How well did he succeed?

Wright of Durham had pictured the Milky Way as an especial system of stars. With this thought Kant links the observation of Maupertuis as to the nebular patches in the sky. The latter can be, he says, nothing else than similar heaps of stars. Since they appear to have an ellipsoid form, they probably possess the same shape as the galactic system to which we belong. More or less after the fashion of Lambert, Kant saw the universe as made up of endless systems, of which our own is but a part, and of which in turn our solar system is more or less a model. The universe is for him infinite and endless; we rise from system to system until the mind is lost in a confused effort to comprehend infinitude.

$\mathrm{He}$ considers that gravitation is universal, estimates that if any of the fixed stars belong to our system they may be so distant that it would require a century of observation to disclose their apparent motion. But if the universe be made up of similar systems, it is evident that wie have but to study the one nearest at hand to understand the formation of them all. If now we examine our especial planetary arrangement, we find six considerable bodies-the number then known-revolving in a common direction; between them space is empty. There seems only one way that this common motion could have been impressed upon these widely separated bodies : they must once have been all of one piece. In a word, these empty spaces were once filled with a diffused material which, under the influence of gravitational attraction, would have steadily drawn together. He says :-

"I assume that all the material now contained in the various globes which belong to our solar world, in the beginning of things was resolved into an elementary ground-substance occupying the entire extent of the world in which the planets and 
comets now circulate. This condition of nature, regarded simply by itself, appears to be the simplest which can follow upon nothing. But this condition of general quiescence could last but a moment. The elements have within themselves the essential forces needful to set them in motion, and have in themselves a source of life. This matter at once reveals an effort to take on form. The scattered elements of like density come together by virtue of the force of attraction to form a sphere, around which will gather the substances of less specific gravity."

It is in such wise that he conceives the beginnings of the world, and this hypothesis he endeavours to firm ground through a hundred and fifty closely reasoned pages. He brings to bear the density and comparative mass of the different planets, their spacing one from another, the eccentricity of their orbits, endeavouring everywhere to find sequence and law. Having shown that the theory will, as he believes, satisfy existing conditions, he turns to the recently discovered rings of Saturn as proof that the mode of planetary formation which he has conceived is the actual mode through which all of the planets have passed, and of which Saturn, the outermost, represents the last stage.

It is in his endeavours to show that the contraction of a vast nebular mass would result in the formation of a series of planets such as our system presents, that Kant's reasoning is the least satisfactory. He supposes that the coalescing mass would acquire a rotatory motion, and that this motion would survive in the successive clumps into which the mass would condense. It is not at all clear that this would be the case. Moreover, on Kant's own theory the apparent result of the contraction of a vast mass would not be a planetary system at all, but that it would all draw towards a common centrethat is to say, the sun.

The available facts which Kant had to build on were inadequate, and some of the inferences which he drew have been discredited by subsequent discovery. The young Königsberg philosopher failed in his ambitious attempt to provide a satisfactory mechanical explanation of the origin of worlds; he did not become a greater Newton. It may be remarked that no one has succeeded since. The precise process eludes us still. That our solar system and all its kind grew out of 


\section{THE BIRTH AND DEATH OF WORLDS}

more or less nebulous masses there are few now to doubt, though we may not yet know how. The recognition of this probable origin we owe to Immanuel Kant.

It is not without interest nor without significance that while Kant's ill-fated little work was lying upon the musty shelves of the booksellers, unnoticed and unread, the splendid mind of Herschel should have been travelling towards much the same conception by an entirely different route. Herschel had a boundless curiosity to know of everything which the heavens contained; the nebulous patches of the sky, as we have seen, interested him deeply. When he began, the number known was not large. His first catalogue offered to the Royal Society a thousand. He made two more. These wisps of light fascinated him as they baffled him; he hardly left off thinking about them to the end of his life.

The most interesting discovery that Herschel made about them was a seeming gradation in what might be termed the degree of nebulosity. Some of them seemed clearly nothing but cloud, some seemed mottled as though they contained denser masses. These denser masses graduated into clusters of stars. From the milky nebulosity seen in Orion, up to a coarse cluster like that of the Pleiades, there was no line of demarcation. At first Herschel was inclined to think that with a sufficiently powerful telescope all the nebulæ might be resolved into star-heaps. Conceiving that each of these assemblages might be in grandeur and structure something like unto our own Milky Way, he made a little jest one day to the effect that he had discovered fifteen hundred new universes.

Later on his views changed. He came to see that there were apparently nebulous stars, twinkling points surrounded by a sort of halo. He came to the conclusion that the nebulosity about the star is not of a starry nature. It was in thus wise that he came to the view that some of the nebulæ at least might be "a shining fluid" of a nature wholly unknown to us.

From this came a vast conception, engaging in its simplicity, immense in its embrace. It was that the gradations he had noted in the appearance of these clusters in reality represented epochs of development, stages of world growth. He conceived that some "clustering power" might be at work converting these diffused and milky masses into brighter and more con- 
densed objects which would one day result in suns and systems. There was a vein of the poet in his nature; he must, too, have been a lover of flowers, for this is the analogy which comes to his mind. To such as imagine that scientific papers are always arid productions, unrelieved by the touch of fancy, a paragraph from his paper may be of interest :-

"This method of viewing the heavens seems to throw them into a new kind of light. They are now seen to resemble a luxuriant garden, which contains the greatest variety of productions, in different flourishing beds; and one advantage we may at least reap from it is, that we can, as it were, extend the range of our experience to an immense duration. For, to continue the simile I have borrowed from the vegetable kingdom, is it not almost the same thing, whether we live successively to witness the germination, blooming, foliage, fecundity, fading, withering, and corruption of a plant, or whether a vast number of specimens, selected from every stage through which the plant passes in the course of its existence, be brought at once to our view ?"

Herschel had reached this view in the years from $I 789$ to I79I. It was in the latter year that Kant's tract upon the nebular theory was reprinted as a tailpiece to a German edition of Herschel's Structure of the Heavens. The one was at the time the most celebrated observing astronomer, the other the most widely read philosopher, in Europe. The book could hardly have failed to attract widespread attention, particularly from the astronomers themselves.

It was five years after this that Laplace produced his popular Exposition du Système du Monde. At the close of this work Laplace devotes three or four pages to a criticism of Buffon's cometary-impact theory of planetary origins, then adds a brief three paragraphs sketching a theory which he presents as his own. That Laplace had read Herschel is evident from his own pages; whether he had read Kant is not so clear. He mentions neither the one nor the other. It may be noted that in this same section of his work he had borrowed from Bailly's Histoire an extended argument as to the probable agreement of ancient measures of the earth; he gave it with an air of novelty, but without a line or a word of credit.

The theory of Laplace differed in some essential ways from. 


\section{THE BIRTH AND DEATH OF WORLDS 4II}

that of Kant; in the main it was broadly the same. In the third edition of the Exposition, published twelve years later, he made some slight additions, and it is on the basis of these rather than his first sketch that it has become customary to speak of him as the author of the Nebular Hypothesis. Its originator he certainly was not. By that time (I808) the idea of nebular origins was common property.

What there was in Laplace's exposition of the theory original to him is so brief that it may be stated in his own words. He reviews the calculations of Daniel Bernouilli, without, however, any reference to the latter or to his papers. The number of planetary motions had been somewhat increased by the discovery of Uranus and numerous satellites; he concludes that the chances then are 137,000 millions to one that the system did not arise in any fortuitous way. He dismisses the conjectures of Buffon as unable to explain four out of five of the principal planetary phenomena, then proceeds :-

"This hypothesis, being very far from satisfying the required conditions, let us see if it is possible to rise to their true cause. Whatever be its nature, since it has produced or impressed the movements of the planets and the satellites, it must have once embraced all of these bodies; and considering the prodigious distance which separates them, it can only have been a fluid of immense extent. In order to have given them a movement almost circular around the sun, and in the same direction, it is necessary that this fluid must have once surrounded the sun like an atmosphere. Consideration of the planetary movements leads us to believe that, by virtue of an excessive heat, the atmosphere of the sun once extended beyond the orbits of all the planets, and that it has successively contracted up to its present limits; this might have taken place by reason of causes similar to those which occasioned the brilliant luminescence through several months of the famous star that was seen of a sudden in 1572 , in the constellation of Cassiopeia.

"The great excentricity of the orbits of the comets leads to the same result. It indicates evidently the disappearance of a large number of orbits less excentric. This in turn supposes an atmosphere around the sun which extended beyond the perihelion of observable comets, and which in destroying the 
movements of those which have traversed it during the period of its vast extent, ended by uniting them with the sun. It will be seen, then, that only such comets now exist as lay outside of this area during this interval. As we can only observe those which approach rather rear to the sun in their perihelion, their orbits must be very excentric. But at the same time it is seen that their inclination must offer like irregularities as if these bodies had been projected at hazard, since the solar atmosphere in no wise influenced their movements. Thus, the long period of the revolutions of the comets, the great excentricity of their orbits and the variety of their inclinations, is explained very naturally by means of this atmosphere.

"But how has the latter determined the movements of revolution and of rotation of the planets themselves? If these bodies had penetrated into this fluid mass (from the exterior), its resistance would have caused them to fall into the sun. One may surmise, therefore, that they have been formed out of successive limits of this atmosphere, by the condensation of zones which it has abandoned in the plane of its equator, in the cooling and condensing of the surface of this star, as we have seen in the preceding pages. One may conjecture further that the satellites have been formed in a similar manner from the atmosphere of the planets. The five phenomena already alluded to (similarity of movement, slight excentricity, \&c.) follows naturally from this hypothesis, to which the rings of Saturn give an added degree of probability. Finally, if in the zones successively abandoned by the solar atmosphere there were molecules too volatile to unite among themselves ${ }_{i}$ or to the celestial bodies, these latter would, in continuing to circulate around the sun, produce all the appearances of the zodiacal light, without opposing any sensible resistance to the movement of the planets."

To this slight sketch Laplace afterwards added some speculations as to the mechanical cause of the rotation of this nebulous mass, and the immediate cause of the splitting off of successive zones. This heated mass would in cooling contract towards the centre. As it contracted its velocity of rotation would, in consequence of one of the laws of mechanics, constantly increase. The time would come then when in the outer portions of the mass the centrifugal force would exceed the attractive power of the central portion. These outlying zones 
would then be thrown off as a revolving ring. This process would be repeated as the contraction continued, with the result of forming a series of such rings. The formerly continuous mass would then present some such an appearance as Saturn does now.

In each of these zones the denser materials, if they existed, would in cooling condense first; the zone would then be composed of mixed elements, partly solid, partly nebulous. If a sufficient nucleus were formed, this would gradually gather together unto itself all the materials of the ring, resulting in the formation of a fiery globe. This in further cooling would present us with the planets which we see and upon one of which we live.

It needs be said that in the theory of Laplace, as in the ideas of Kant, there was much that was purely speculative. Moreover, the hypothesis as framed by Laplace is open to as serious objections as was that of Kant. It is not at all clear that this cooling and contraction of the nebulous mass would produce such zones as Laplace supposed. It was pointed out that with increasing rotation the mass was just as likely to throw off little wisps of vapour as a vast zone. Moreover, as Newcomb has pointed out, in this theory the outer planets would have been formed first. There seems to be no evidence that such was the case. It is likely that the outermost planets are still in a much more fluid condition than some of the inner bodies like the earth. Finally, the discovery of the rotation of the satellites of Uranus, in opposite direction to that of the other planets and satellites, quite disrupted the idea of perfect uniformity of motion. These and perhaps other considerations, pointed out by various writers, forbade acceptance of the hypothesis in its primitive form.

It needs be said, too, that the theory was never presented by Laplace as a finality. He gives it, he says, "with that distrust with which we must regard all that is not the result of observation and of calculation." It was a conception of grandeur ; it had a very considerable degree of probability in spite of its difficulties; it was, moreover, in its broader outlines the only thinkable process by which our system could have arisen. But had no new evidence been adduced in its favour, it would probably have remained an interesting, not to say fascinating, speculation and nothing more. 
A few years after the last essays of Laplace at an explanation, twenty years after the earliest of his own, Herschel returned to the subject with fresh material for consideration. In two important papers he presented an elaborate theory showing how the "shining fluid" of a broadly diffused nebula might gradually condense under the force of attraction, with the denser portions as nuclei or centres of attraction. The first stage would be a dense nebula or compressed star cluster; from this would evolve one or more nebulous stars surrounded by an atmosphere. Finally, there would appear a single sun or a series of them. Leaning not upon theory but upon fact, he backed up his conjectures by abundant illustrations from the nebulæ and clusters actually observable by the telescope. In a word, he adduced evidence to show that the process of sun formation is open to the actual observation of man. It is quite true that the researches of Herschel did not establish the Nebular Hypothesis; it did not, moreover, attempt to account for planetary formation at all; but it did lend to the theory an element of objective confirmation which it had hitherto entirely lacked.

But Herschel, whose genius shines increasingly with the years, and who seems so great to us now, must have seemed otherwise to his contemporaries. His daring and vivid imagination must have excited in them some degree of distrust. Looked at even now, many of the results he attained seem rather the product of an amazing intuition than of a carefully wrought out induction. He had a mind which seemed to leap swiftly forwards to the truth. There are few of his conjectures -and their number was extraordinary-which have not been more or less completely verified by subsequent research. In his time he must have seemed like a prophet upon Pisgah.

It was half a century before anything was added to the nebular theory as it was left by Herschel and Laplace. Then came considerations of an utterly different nature-indeed, from wholly outside the domain of astronomy. It is curious to reflect that it was of such a nature and such force that it would independently have given rise to some such a theory, had there been nothing else to suggest it.

The eighteenth century was par excellence the mechanical century. It was the century that perfected the science of 
dynamics, that produced the steam-engine, the marvellous contrivances of Vaucanson, of Droz, and many another.

This wonderful advance inspired astonishing dreams. Inventive geniuses, some of them of the highest order, laboured to produce mechanisms which should imitate and do the work of man. Some of them succeeded so well that they were haled before the Inquisition-not merely the makers, but the mechanisms-as products of the black art. A vaster and wilder dream was that of perpetual motion, some device which should give out more power than it consumed, some contrivance by which the work of the world might be largely lifted from human shoulders. It seems fantastic to us now ; throughout a long period it was the constant preoccupation of many sane and resourceful minds. The prevailing ideas of force were vague; of the present-day conceptions there were but adumbrations. It seemed reserved for the nineteenth century to clarify these ideas and to set the limits of mechanical possibility.

The foundations were laid by an American. In the years that immediately followed the close of the Colonial Rebellion, a refugee from the revolted colonies, Benjamin Thompson (created Count Rumford) had instituted a remarkable series of experiments upon the nature of heat. Laplace and Lavoisier the chemist had jointly made an important contribution. Some time after, another Frenchman, a young engineer named Carnot, laid the foundation of the modern science of thermo-dynamics - that is to say, of the energy of heat. It appeared in a brief but very remarkable memoir, no sooner printed than straight away forgotten.

It was not until the early forties of the last century that this solution of ideas, as it were, crystallised out. This came in the expression of a law something akin to that which Lavoisier had established as to the indestructibility of matter-the indestructibility of energy -in Spencerian phrase, the persistence of force. It embodied the idea that the powers of nature, the forces of heat, of light, of electricity-broadly, the ability to perform work-represented a sum total of potential in the universe which remained unchanged. These forces may be converted one into the other: from light may come heat; from heat may come the energy of steam; from steam may come the motive-power to drive mills or dynamos. These 
forces may vary in their manifestations ; no whit of their energy is ever lost.

This vast idea of the correlation of forces-or, as we say now, of the conservation of energy-came as a veritable discovery. Like many a discovery-like, it might be said, nearly all great discoveries-it was reached independently and simultaneously by several different minds. One of these was a rich brewer's son in England, James Prescott Joule; a second was Colding, a Dane; a third was Julius Robert Mayer, an obscure physician of Heilbronn in Germany; a fourth was a young military physician of Berlin, Hermann von Helmholtz. The formulation of this law was in many ways the highest flight of the nineteenth-century mind.

The papers in which this discovery was enunciated were published, each in unconsciousness of any other, between the years 1842 and 1847 . The force of their tremendous import was not immediately felt. It was fifteen or twenty years before it seemed of enough consequence to squabble about who reached the idea first. But in the meantime one of its discoverers had seen its bearing upon the most important outlying problem in physical astronomy, and turned his attention thereto. This was the source of the sun's heat. It had long been a puzzle. Sir John Herschel styled it " the great secret."

Long before this time the development of geology, the revelations of the rocks, had made it.clear that our earth had existed for æons of time. Compared with it, the hypothetical date of the creation of the world did not represent the stroke of a second in the movements of a clock. Throughout millions upon millions of years the sun had been pouring downwards upon this ancient earth, and outwards through space, its floods of light and heat. Whence came this colossal store; how could it thus seemingly go on for ever without diminution? This was the problem, and no one could answer.

The first to make any rational attempt was the obscure Heilbronn physician. Convinced by his studies that some sort of source must be found, unable to discover it in the sun itself, he thought to find it in the incessant rain of meteors upon the sun's face. Simple observation of the heavens had shown him that the number of meteorites pouring nightly and daily into the atmosphere of the earth was enormous. In the deep cold 
of space they are doubtless cold. In their terrific rush through the atmosphere they become incandescent. The amount of heat they develop is proportional to their speed, squared. Their speed is proportional to the attractive force of the earth. The attractive force of the sun, at its surface, is twenty-eight times greater than that of the earth; the speed of the meteorites through the atmosphere of the sun would correspond. The surface of the sun is ten thousand of times that of the earth. The quantity of meteorites swept up by this vast body would be in proportion to its surface and to the force of solar gravity. Mayer made some rough calculations, and in 1848 , in a memorable paper, announced his Meteoritic Hypothesis.

It was a noble effort; but it did not hold. It was not long before it became possible to make some calculations as to the daily loss of the sun's energy by radiation. It is unthinkable. You get a glimpse of the amount from an ingenious comparison of Professor Langley's. He computed that if all the coal contained in the earth could be burned in an instant, it would not maintain the energy of the sun for one-tenth of a second. A similar series of calculations made it clear that a quantity of meteorites moving in space sufficient to keep up the sun's outpour of heat, would mean such a bombardment of the earth as to render the earth's surface red-hot. Obviously the meteoritic explanation was insufficient. The mystery remained.

Five or six years later, Mayer's compatriot, von Helmholtz, came forward with another explanation. By this time the once fluid condition of the earth, suspected by Leibnitz and Buffon, had been seemingly established. If the earth once existed as a diffused fiery mass, it would, under the influence of gravity, contract, just as Kant had supposed. In contracting it would develop heat. This heat would be radiated away into space. In the mind of von Helmholtz, here was the clue of the sun's energy : contraction.

The mass of the sun must once have occupied millions of times its present volume. It must have been diffused throughout a space extending perhaps thousands of times beyond the present outermost limits of the solar system. By contraction it has shrunk to its present proportions; by contraction is its energy maintained. This process is still going on. But it is evident that it has finite limitations in time. The mass of the sun is known; the amount of contraction 
needful to develop its annual expenditure of heat can be calculated. Relative to its mass this amount is small; two or three hundred feet per year, a few miles per century, would suffice. It would be long before such a contraction would be evident to any human measures. In six thousand years it would lessen the apparent size of the sun to us by less than a second of arc-that is to say, by less than an I8ooth part of its present angular size.

This is slow; but it is unceasing. Upon the calculations of von Helmholtz and others who followed him, it could scarce have been going on, at its present intensity, for more than eighteen or twenty millions of years. Moreover-and this was the startling feature-the process is nearing an end. If the total available supply which the contraction of the sun's mass could produce were divided into 454 parts, Helmholtz calculated that 453 of these parts had been spent. He pictured the solar mechanism as a kind of clock which was run down. Some day or other it would cease-on present-day calculations, within a period of something like seven millions of years.

It is needless to say that these estimates excited the liveliest interest, even among the laity. By some twist of chance, von Helmholtz's conclusions were made public in a popular lecture delivered at Königsberg, the home of Kant, whither he had gone to occupy a chair of physiology. They were presented as an incident in an exposition of the new theories of energy; the lecture was entitled " On the Interaction of Natural Forces."

Von Helmholtz's ideas were vehemently attacked. The conclusions of the geologists demanded, even for the events upon our little earth, a bank account of time compared with which seventeen million years was a bagatelle. The intrusion of the physicist was hotly resented. The new ideas found a valiant exponent in the sturdy figure of young William Thomson, now our distinguished Lord Kelvin. He has done many a battle in their defence. In later years Lord Kelvin has shown an inclination to modify-that is to say, enlarge-the estimated allowance. Even stretching it to the utmost, it still seems insufficient. The explanation of one mystery seemed only to substitute another hardly less acute. It is possible that, within the last year or two, the faint beginnings of our knowledge of radium and radio-activity offer a gleam of explanation and perhaps conciliation. It is too soon to be sure. 
In their main features, after half a century, von Helmholtz's conclusions remain unshaken. They do not exclude the contribution of the meteorites. If radio-active bodies exist in the sun, they too may share in the sun's support. But the main source of its vast wealth of heat and light is the contraction of its own mass. The power to which Kant and Laplace had attributed the origin of the solar system has likewise dowered it with warmth, with light, with life.

But the matter of especial interest here is the support which the theories of solar energy have given to the Nebular Hypothesis. Newcomb has pointed out that Kant and Laplace reached their conceptions in some sense by reasoning forwards - that is to say, they assumed that a nebulous mass once existed. There was no proof of this. They reasoned by a process of deduction. The path followed by Helmholtz was the reverse-he reasoned backwards. His results were attained by an induction from observed facts. He showed that, working back from present conditions, we should inevitably reach precisely such a condition as his forerunners had assumed. That two opposite modes of reasoning from utterly different sets of facts should have thus led to an identical result, gave to the hypothesis a solidity of foundation from which it can in no probability be shaken. Whatever may be the details of planetary evolution, the main fact was now clear.

Something like finality and, with it, some highly suggestive indications were brought by the camera. When the eager, searching eyes of Herschel had closed their long scrutiny, the number of known nebulæ had reached 2500. With the aid of the camera, the number estimated as presently known is above I20,000. Utilising the great Crossley reflector at the Lick Observatory, the late Professor Keeler, whose researches in this field disclosed so much that was new, was able to calculate that the total number which the camera might eventually record would reach several hundred thousand. In a word, the universe is teeming with them, and their extent is beyond conception. They are for the most part so distant that they have no observable parallax. Yet some of them range across several minutes of arc in the telescopic field. It follows, therefore, that some of the nebulæ must be thousands of times in extent the diameter of the earth's orbit. Probably a great number 
of them are thousands of times the dimensions of the whole solar system. In other words, present-day telescopes, in combination with the photographic plate, reveal the objective existence of precisely such masses as the hypothesis had required. Let us clinch the point.

In some of the older works at least, the ideas of Kant and Laplace are rather scantily dismissed as a mere hypothesis, " interesting if true." We now know that diffused masses of unthinkable extent do exist. The theory of solar energy and of a once molten earth show that such masses must have existed. The especial characteristics of our solar system indicated the same thing, and pointed out the probable course of planetary evolution. It would seem as if no further proof were needed; yet further proof exists. The camera has seemed to reveal that some such a process as Kant and Laplace supposed is actually taking place; not in a single instance nor as an isolated phenomenon, but throughout the whole course of the heavens.

Herschel's reflector was four feet in diameter. When it was first built it seemed little less than a miracle of ingenuity. It was hardly less a miracle of human patience. A quarter of a century after Herschel's death, and after many unsuccessful experiments, Lord Rosse succeeded in constructing, at Parsonstown in Ireland, a reflecting telescope with a six-foot mirror and nearly sixty feet in length. Its "light grasp" was more than double that of Herschel's. It was with the aid of this beautiful instrument that Lord Rosse disclosed for the first time the existence of spiral nebulæ-that is, nebulæ showing some such a spiral disk that is seen in the little St. Catherine's wheels. Some of his drawings were of exceeding beauty. It was a discovery of the first significance; but he was an amateur and a lord. It is to the discredit of academic astronomy that for a long time Lord Rosse's observations were ignored. Later on, out of an estimated I20,000 nebulæ, Professor Keeler could calculate that more than half, possibly nearly all, show this spiral shape.

It is in the highest degree improbable that this appearance is a mere chance. There seems no escaping the conclusion that these spiral nebulæ are in rotation, just as the nebular theory requires.

There are other appearances which at least suggest a way by 
which this rotatory motion might have been acquired, and perhaps shed some light upon the modes of planetary formation. Some of the more distinct nebulæ appear to show knots or clumps of denser formation, as though they in no wise possess a uniform constitution, but that within the mass several centres of condensation have begun to appear.

We have just a hint as to how these centres or nuclei might be formed. We know on the one hand that the number of nebulæ is enormous; on the other hand, that space is simply teeming with meteoritic or cometary swarms. These range in size all the way from grains of sand and brickbats up to bodies of considerable magnitude. When after uncounted æons a nebula had become somewhat thickened, if it were then to encounter a meteoritic swarm, it might readily arrest the motion of the latter and imprison it within its meshes. The motion of the meteorites would be partly dissipated in heat, partly in imparting motion to the nebula itself. It is conceivable that if such a swarm were very great, and the nebula already of some density, this might give rise in time to just the appearances which we perceive.

It may be that this imprisonment of meteorites within the spider-web of the nebulæ is no isolated event, but that it is a continuous process, like unto the sweeping up of the meteorites by the earth, the sun, and other large bodies. We know that some of the nebulæ at least are in very rapid motion, at speeds quite comparable to that of the stars themselves. It is very easy to suppose that they would of necessity encounter vast quantities of meteors.

Occasionally they would encounter a sun. It may be that this explains the blazing up of "new" stars, now a wellrecognised fact of stellar observation. In whatever way these centres of condensation may form, it is easy to see that by further condensation, they might readily result in the ringlike or Saturn-like appearances which some of the nebulæ present. If this were true the difficulty of understanding how these zones or rings were formed by the condensation of a nebular mass would be dissipated.

Moreover, it may be that the mode of evolution is not single, but that the process varies considerably under varying physical conditions. Still there is unmistakably in nature a certain unity. The modes of reproduction of life, whether of 
plant or animal, are at basis the same, though they differ widely in their details. A certain general analogy leads us to suppose that a like basic unity, with no doubt the same incidental variety, obtains in the reproduction of worlds. There seems no reason now to doubt but that the general features of the life-history of suns and systems is known.

When we consider the ineffable littleness of man and his world, this is a prodigious step. That he should be able to gain a sweep through such ranges of cosmic space and time seems almost weirdly incredible. Yet is he not satisfied, yet will he still go on. The earth was once a part of the sun, the sun was once a diffused fire-mist. It is thus that systems are born. But whence comes the fire-mist-what are these nebulæ?

Until very recently the general supposition was that these nebulæ represented a primal matter, the urstoff of the elements, and that perhaps by a process of condensation the various elementary substances which are found upon the earth were formed. The revelations of the spectroscope seem to negative this view. It is not impossible that the analogy noted above may be carried yet further. Through a series of hesitating approximations, biology reached at last the conception that the round of the matter of life is eternal and unceasing. The fact was expressed in the dictum, omne vivum $e$ vivo. It is possible that much the same is true of the universe. Moreover, throughout cosmos we may discover the same process of dissolution and death that we find in the world of life.

Shortly after the doctrine of the conservation of energy had been established, Lord Kelvin filed notice that account must be made of its dissipation as well. For example, so far as our little solar system is concerned, the idea of conservation would be a monstrous joke. The colossal energy of the sun is not conserved at all. It is wasted with a prodigality compared with which the most riotous spendthrift would seem a miser. If Mr. Rockefeller or Mr. Carnegie were to melt up their gold into bullets to shoot rabbits with, if they were to make bonfires of their bonds, they could not throw away their wealth more recklessly than does our central solar magnate. The quantity of warmth and light taken up by the planets is of course not a billionth part of that which is radiated away into space.

In the course of time, then, the sun will grow dark and 
cold, life upon the planets will no longer be possible; our system will be simply a series of revolving icicles. This probable fate seems already that of millions of others. It is a disclosure of recent years that the universe is full of dark suns. Half a century ago we knew of none at all. Now we must believe with Arrhenius that the number of dark suns far exceeds the number of those that blaze.

It follows from this fact of dissipation that in the course of time all the suns now lighting the heavens will one day go out. So we might picture the universe, originally dispersed in nebulæ, gradually gathering itself together into clumpy aggregations, these in turn condensing into suns and glowing planets, eventually to sputter and go out, then whirl on in icy immobility throughout the endless years. The picture is not inviting. To most minds it is dispiriting. We have no need to suppose it is true.

In any account of creation we must take note of the new stars that blaze out into the heavens and show for a little, then disappear or sink back into obscurity. Originally it was supposed that these apparitions were rare; we have seen that they are probably of frequent occurrence, and that in some instances at least they result from the collision of two suns. Their motions accelerated by their mutual attraction, they would approach each other with frightful velocities. If they struck the crash would be terrific. The amount and the degree of heat generated by the impact of two vast bodies would be such as utterly to dissipate them into vapour. They would be diffused again into the primal fire-mist from which they sprung, slowly to cool through the ages, slowly to grow hot again through their contraction and coalescence.

It is from the crash of suns, then, that the nebulæ may come. This is their origin, and this is the round of cosmic life. So at least, so far as our present knowledge extends, must we conceive it. It is thus that the cosmic process is sketched in the brilliant pages of Arrhenius. ${ }^{1}$

In this view the basis of the elements, the substance of the universe, is eternal, likewise the process which it pursues. A new Moleschott might now write a Kreislaut der Materie, a Circulation of Matter. Devolution follows evolution, regeneration follows degeneration, world without end.

1 Lehrbuch der Kosmischen Physik, Leipzig, 1902. 
The process has obviously three stages-the nebular period, the star period, the dark sun period. The duration of these is not coequal. In the estimation of Arrhenius, the nebulous stage is vastly the longest. Next after that would come the dark sun stage; conceivably this might last for a time which, so far as our human imagination could compass it, would seem infinite. A rushing star might pursue its path through the heavens for ages without meeting with another, in the union with which it might be again scattered to fertilise the ways of space. Yet it is evident that with anything like an average distribution of stars through space, there would be an average chance of impact. Therefore there would be a general average for the period of darkness, as there would be a like average term for the period of nebulous diffusion.

The period of solar activity, of what we might term solar life, is comparatively easy of computation. In a rough way we already know this period for our own sun. It is easy to see that this period is but an incident, a few seconds, or at most minutes, perhaps, in the arc of this unceasing circle. Just as life appears an inconsequent moment in the evolution of the stellar system, so the term of solar brilliancy, which alone makes this moment of human being possible, is itself but a slender fraction of the larger life of the stars.

It seems as if we may at last make answer to the inquiry of Epicurus: "And whence came chaos?" Apparently chaos comes from the cosmos, as the cosmos in its turn comes again from chaos. In this view there was no chaos, no beginning, and there may never be an end. It is conceivable that the universe-that is to say, the universe of suns and worlds to which we belong-has a finite limit in space, though to space itself the mind may set no bounds. But limits in time for the vast swarm of systems which the telescope brings in view are difficult to perceive. It seems to be a ceaseless turning of a wheel.

But there remains always the unceasing dissipation of energy. It may be as Arrhenius pictures it, that when a sun has cooled sufficiently to form a crust, it will conserve practically the whole of its heat through a vast period; it would dissipate less in hundreds of thousands of years then than in a single year now. It may be, too, that the energy radiated away into space from 
a billion suns is eventually absorbed by billions of nebulæ. But in the end, if the universe is finite, some loss must take place. Even though its clock hands move so slowly that the duration of our whole solar system might represent the flash of a falling meteor, still in the ultimate view it is difficult to conceive the round of cosmic life as a perfect circle, without a diminution and without a break.

Sometimes among scientific workers one perceives a certain arrogance, as though the great problems of existence had been quite disposed of. Doubtless it is a consequence of that foolish academic spirit engendered by long contact with only young and immature minds. It is hard to realise that the development of the mind under rigorous methods of proof is only just begun. Few of the larger problems have yet been touched. Of the fate of cosmos we can know little until we know more of what cosmos is composed.

The spectroscope has told us much. What must we infer from the newer knowledge that has come within a few years ? 


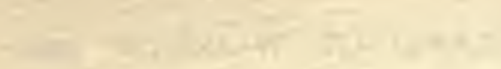

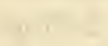

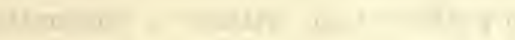

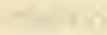

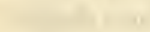

$+$

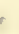


CHAPTER XXXII

THE COSMIC EXCHANGE OF MATTER AND LIFE 
Worlds on worlds are rolling ever From creation to decay, Like the bubbles on a river, Sparkling, bursting, borne away.

Shelley, Hellas.

Our little systems have their day, They have their day and cease to be.

In Memoriam. 


\section{CHAPTER XXXII}

\section{THE COSMIC EXCHANGE OF MATTER AND LIFE}

WhEN, after so many centuries of prediction and expectation, the New World was actually found, Europe could not rest for thinking its full of wonders, as men had dreamed so long. The persistence of this belief seems curious now. Nowadays the trained imagination of the scientific adventurer has no such expectations of the unknown. There may be some: witless folk left still to believe that if we could reach the North Pole we should find griffins and goblins and giants and genii. What the four hundred intervening years since Columbus have taught us mainly is the art of accurate inference and prediction. We can foretell what the polar regions are like, and we know them to be destitute of any sane man's interest. Can we form any idea of worlds outside our own ?

If it should turn out that the stellar universe has no more real "structure" than that of a gas-if the resemblance to the kinetic theory of gases which I have suggested should be verified, the fact would carry with it many interesting implications. One of these would be the incessant exchange-incessant at least in the sense of cosmic time-of the material and of the units of which this universe is composed, perhaps of life as well. This could but mean the ultimate identity of the world scheme throughout the farthest reaches of space.

If we follow the analogy of the kinetic theory, we must either conceive of the number of dark suns or dark bodies as very great, or else picture the universe as a gas which is very thin. The molecules of the air which we breathe, for example, are not spaced at anything like the distances which we at present regard as the average spacing of the suns. When the air is reduced to a liquid or frozen solid, or what is very nearly the same thing, when water goes over into vapour or steam, the difference of the volume occupied is not enormous. A cubic 
inch of water produces only about 1800 cubic inches of steam at ordinary pressures.

Water is practically incompressible, and we must therefore conceive the molecules of which it is composed as in practical contact. In a state of vapour, then, according to the kinetic theory, the molecules are distant one from the other on the average about 1800 times their own diameters.

With the perfected air-pump it is possible to reduce the rarefaction of a gas to less than a millionth of its density at ordinary pressures. By means of liquid air this may be carried somewhat farther. In a gas at this density we may conceive the molecules then as eighteen million times and more their own diameters apart. If the distance between alpha Centauri and our sun represents anything like an average spacing of the stars, then, pursuing our conception of the universe as a stellar gas with the molecules as suns, its density would be something like air or water vapour at less than one-millionth atmospheric pressure.

If we conceived of a thousand dark suns for one blazing star, this stellar gas would still be highly rarefied as compared with ordinary air. It would still be exceedingly tenuous if we conceived of a million dark bodies for every luminous sun. It is almost impossible for balloonists to survive when the barometer has dropped two-thirds. If, then, the imaginative Mr. Wells were to write a story whose characters were vast beings breathing this stellar air, he would have to picture them as able to exist in a much more ethereal medium than those which live and move about at the bottom of our sea of earthly atmosphere.

But if the stars were spaced on the average of thirty million times their own diameters, the chances of collisions between suns would be almost infinitely small. It would probably not begin to account for the number of new stars which blaze forth in the sky. It is possible, of course, that a simple rush through a relatively dense nebula might account for many of these; probably not all. The number of dark bodies must therefore be considerable. Analogy with known suns like Sirius, Arcturus, and Canopus would suggest many of them are of colossal size. Even when they are cooled down to the crust-forming stage the energy they contain is still prodigious. We conceive the interior of the earth as a glowing gas practically rigid under the enormous pressure which it sustains. We may believe this true of all dark bodies, large and small. 
It follows that even a relatively small body crashing through the enclosing crust would produce a terrific eruption. When a pair of bodies comparable in grandeur with the sun came together, the effect of course would be tremendous. It would resemble an explosion, and the matter they contained would be blown about over an area that would be considerable, measured even by stellar spaces. If this process were continued over extended periods of cosmic time, the result would be a more or less even distribution of the different materials or elements of which the suns are composed. It would produce precisely the condition of more or less kinship of constitution which the spectroscope has revealed.

It is evident that the number of relatively near approaches of the suns would be immensely greater than the number of actual collisions.. If we conceive the suns in general as provided with satellites like our own, the effect of this nearing of the suns would be a constant planetary exchange. Thus, for example, suppose that our sun and alpha Centauri should come rather closely together, they might not collide; they might be moving too swiftly to form a binary system. They still might approach near enough so that our sun would rob alpha Centauri of an outer planet or so, or alpha Centauri might rob our system of Neptune or Uranus.

Lively minds may, if they like, picture the stellar dance as a sort of endless Virginia Reel, with the suns flinging off their partners and taking new suns in a continual round. Just as we conceive the particles of musk or the particles of smoke diffusing through the air of a room perforce of the incessant movement, collision, and rebound of the particles of air, so we might in imagination portray the planets as diffusing through space, going on from one sun to another, to the end of the world. The cosmic processes are leisurely; but time is long.

In yet another way the binary systems might easily lose their satellites simply by means of their mutual attraction one upon the other. It is easy to see that when a planet or satellite swept between a pair of suns, its orbit would be straightened out more or less, with the result that the planet would pursue a path extremely elliptical, or else go shooting away into space. With a speed sufficient, they would of course go travelling on until they came within the sphere of influence of another system. ${ }^{1}$

1 T. J. J. See, The Evolution of Stellar Systems. 
We have never run across as yet such a runaway planet, nor have we any actual evidence that they exist. But the possibility is one of the plain implications from our recently acquired knowledge of twin suns. For aught we know this may be the origin of one or more of the planets of our own system, though the striking uniformity in all the motions of our system makes the chances against this perhaps millions to one. It is difficult to understand how a planet coming, on the theory of chance, from any one of the possible directions of space could be swung into line into the general plane of planetary motion and set marching with the rest, all by the sheer power of gravitation.

Be this as it may, the apparent conclusion which we may draw regarding the stability of our planetary system is precisely the opposite from the conclusions of Laplace and Lagrange. So far as the motions and forces inherent to it are concerned, our system would apparently be stable throughout infinite ranges of time. For anything that we can now perceive this is the case. But the probability that the vast majority of heavenly bodies are not luminous but dark, the consequent implication of great number and increased possibility of approaches and collisions, gives the matter quite another aspect. In another two or three hundred years perhaps we shall know something of the actual number of bodies in space, perhaps of their relative separation as well. Then it would be possible to compute, on the theory of probability, the average chance which every system has of surviving amid the constant clash of the suns as they pursue their interweaving ways.

How many of the meteoric swarms through which the earth sweeps are of origin foreign to the solar system we do not know. Quite possibly all of them are; it is fairly certain that some of them are. We have seen our globe and all of the other planets sweeping up hundreds of tons of them per day, the sun possibly thousands of tons. We have, then, in the meteoric showers a steady cosmic contribution to the mass of our system. On the other hand, the far larger part our system may act simply as a temporary carrier; we may be steadily picking up swarms as we push through space. These swarms take on highly elliptical orbits; in nearing another system these might be much more readily shed than a planet. In the same fashion we might lift a few swarms from some neighbourly sun. 
It goes without saying that what is true of the meteors is equally true of comets, since, as we have seen, they are probably one and the same thing. By whatever name we know them, the result is a constant addition to every considerable body of our own system, a steady taking up of cosmic material, accompanied doubtless by a constant levy upon our system as, through the long ranges of time, we come within the attractive sphere of some dark or luminous sun.

This unending exchange of matter and its larger aggregations which we thus may picture, is not the sole way that the materials of the universe might be equalised. There is another that is probably going on under our eyes. It involves the infinitely little as the other may engage the almost infinitely large. This is the incessant radiation of particles from all incandescent bodies.

A candle, the arc of the electric-light, the sun too, probably -in brief, everything which glows is sending into the space about it a shower of minute corpuscles of ultra-atomic dimensions. Moreover, and quite independent of this, all highly luminous bodies, and in especial the sun, are constantly driving from them minute particles of matter under the'pressure of light.

Nothing at first seems stranger than that the immaterial sunlight might exert a propulsive force. It is hard to think that as it drives against the earth and other bodies it bears down upon them with a certain energy. It was indeed a logical inference from the ether-wave theory of radiation. Professor Clerk Maxwell, who pointed out this necessity, mathematically developed what this light pressure or force must be. He had a rare combination of the mathematical-that is, the essentially analytic-and the constructive or synthetic mind. In this problem and in another he illustrated one of the astonishingly rare instances in which mathematics has ever pointed the way to scientific discovery.

It is only two or three years ago that a Russian physicist, Lebedeff, and almost simultaneously Nichols and Hull, in America, by experiments of exceeding ingenuity, demonstrated the existence of this pressure. It is extremely slight ; but it is to be noted that the force it exerts will be in proportion to the surface of the body upon which it acts. On the other hand, it is evident that the powers of gravitation are in proportion to 
the mass of bodies. This has a curious consequence. The mass of a body decreases in proportion to the cube of its diameter; but the surface decreases only in proportion to the square. It follows, therefore, that with smaller and smaller bodies the relations between the force of attraction and of light pressure progressively alter; gravitation decreases much more rapidly than the force of light. It is evident, then, that there will come a point where the pressure of light is actually greater than the pull of attraction. At this point the particle has become exceeding small; but it will then be shot away from a highly luminous body, even against the tremendous gravitational pull of the sun itself.

This critical diameter, as it is termed, is reached with particles less than a micron and a half thick, supposing them to have the same density or specific gravity as water. A micron is the $\frac{1}{25000}$ th part of an inch. The speeds which may be thus imparted to these particles are something enormous. A microscopic body of matter of half the dimensions indicated will dash from the sun at a rate of 500 kilometres per second. One might imagine that with a constant decrease of the size of the particle this speed might become practically infinite. As a matter of fact it has a limit, which is perhaps eighteen times 500 kilometres; that would be 9000 kilometres, or upwards of 5000 miles, per second. At such velocities a particle shot from the sun would reach the earth after a few hours.

The consequence of this pressure of light we are only just beginning to perceive. To be sure, the quantity of matter involved is extraordinarily slight. On the other hand, the outpour is enormous. Und die Zeit ist unendlich lang. It is an ingenious suggestion of Arrhenius, from whose paper these interesting details are drawn, that we may have here the solution of one of the outstanding riddles of cosmical physics. Perhaps this is the origin of the meteorites.

It is very striking that the meteorites seem to consist of minute particles in relatively loose combination. They are rather porous, and seem to be built up particle by particle. When they are melted down the result is a solid and vitreous mass, a very different substance from the pumice-like meteorite which reaches the earth. In their wanderings through space we may conceive these particles coming into collisions sufficient lightly to fuse them together. Once such a nucleus was formed 
it would possibly continue to grow and grow. Large bodies might thus be built up.

If this be the secret of the meteorites, and the meteorites in their turn are the nuclei of planets and suns, we possess then a complete picture of the round of the cosmic exchange. We perceive that there is in the universe nothing constant, nothing stable. There is incessant motion, incessant aggregation, incessant disaggregation. Conceivably in the coming years the advance of our ultra-physical knowledge will give us an insight into the creation and the concomitant annihilation of what in our present ignorance we term matter.

Not a little in the recent extensions of physical theory, at the hands of Professor J. J. Thompson, Sir William Ramsay, Rutherford, and their co-workers, suggests that the problem of the creation and annihilation of matter is not transcendent, as up to three or four years ago it was supposed to be. The paradoxical performances of radium, the general phenomena of radio-activity as well, indicate that the process may be incessant, and furthermore observable; what is still more, that its full delineation is at hand.

This conceivable creation and dissipation of matter would be then, in our present phraseology, a function of energy. The cosmic exchange of matter, alike in large masses and in very small, would be in larger view but a part of that cosmic exchange of energy which was a commonplace before more than the vaguest conceptions of energy had been framed. To the most primitive mind it was evident that every form of earthly life, vegetable alike as animal, was in some sense progeny of the sun. Possibly we may widen the conception to look upon the sun and all its myriad kind, as in some sense centres of projection of a creative energy whose evanescent manifestation is that material world in which we live and part of which we are.

Our account of the universe in terms of substance and force, the irreconcilable and unescapable antinomies of our human thought, would then be closed. Aside from the ever-interesting details of their interworkings, there would be nothing left for speculation save the everlasting and implacable inquiry of Voltaire-doubtless, too, of the Voltaires of thousands of years gone-his ironical and impertinent-

"Why is anything?" 
We may picture a cosmic interchange of the material of shattered suns, the stuff too of all the glowing suns; an interchange as well of planets, conceivably with their contents quite intact. May we go yet further and picture a cosmic interchange of life ?

The problem of vital origins has been coeval almost with that of the origin of the world. Considering the amount of acrid controversy, alike theological and scientific, which it has engendered, one might also say that it has been co-evil.

When the architectonic theory of creation was given up, the Chaldeans' entertaining tales of life's beginnings went with it. With the discoveries of the microscope it seemed possible to pursue forms of life almost to molecular dimensions, and from this it did not seem absurd to suppose that, under favouring conditions, the activities which we call vital might be spontaneously set in motion. It was the service of Pasteur and his kind to show that, whatever may have been true of the past, we have no evidence that spontaneous generation takes place now. As the chemist could get no further than the microscopist, speculative minds were not wanting to imagine the origin of life from ultramundane sources.

This suggestion came from two of the strongest heads anywhere to be found within the last half-century. One of them was the latter-day leader of English physicists whom we know as Lord Kelvin; the other was the multi-minded von Helmholtz, almost equally distinguished as physicist, mathematician, and physiologist. Independently, each of them conceived that life may have never originated upon this earth at all, but that it might have been brought to our planet through the agency of meteorites. They imagined that germs from distant worlds might have been tucked away in the interstices of meteoritic stones, and reaching the earth, have found here a favourable medium. From this might have come all the myriad wonders of life after the manner revealed in the latter-day Gospel According to Darwin.

It is curious that a speculation-it was never anything more -deriving from two minds so eminently sane and unfanciful, should have met with such a show of disaffection as this undoubtedly did. It was objected that in its rush through the atmosphere, as a shooting-star, the meteorite develops a temperature probably of several thousand degrees, and that all 
possible life would thus be simply annihilated. The objection was not in the least valid. It is now known that in the brief moment of its flash through the air only the surface of the meteorite is fused; when the interior temperature can be measured soon after its fall to the earth, it is found to be astonishingly cold, just as our supposition regarding the cold of space would require. A much more serious difficulty lay in our later-gained knowledge of the meteorites themselves. It is not at all clear that they are chips of shattered planets from far-off systems.

But in the suggestive paper already referred to, Die Verbreitung des Lebens in Weltenraum, ${ }^{1}$ Arrhenius has given this extramundane theory a new and very plausible form. The distinguished Swedish compeer of Kelvin and von Helmholtz points out that we already know of life-germs less than a quarter of a micron in diameter; and since there exist several bacterial diseases wherein the germ is apparently too small for microscopic detection, we may suppose other germ forms yet more minute. Smaller still must be their spores or seed-like granules, with resistant envelopes, which the bacteria throw off, and to which their continued existence is due.

Many of the bacteria we know float in the air; so much the more must the spore germs. It is easy to see how they might be carried up by air-currents into the higher levels of the atmosphere. It is Arrhenius' interesting suggestion that from there they might be driven off into space perforce of electrical repulsions.

It has been for a long time known that the earth possesses an electrical "charge," that bodies or particles will be attracted to or repelled from it just as, let us say, bodies of paper are caught up by a glass rod when the rod is rubbed up smartly. The globe is in a way a vast electrical "field," which by times -say, upon a clear, snappy winter morning-may attain considerable intensity.

We have come in later days to know that there is a unit of electrical charge, or, as we might say, an electrical atom. When a body is "electrified" it is, as it were, covered with these electrical atoms. This unit charge may be sustained by very minute bodies as well as by larger ones. It is not a function of surface or mass. It follows, therefore, that we may conceive of 1 Die Umschau, June 13, 1903. 
charged particles so small as to be repelled by the negatively charged earth with greater force than the pull of gravitation. Arrhenius computes that a particle one-seventh a micron in diameter, possessing a unit charge, might be driven off and out of the earth's atmosphere by this means.

A seventh of a micron is about the size of the smallest bacterium known. We have life particles, therefore, of the requisite minuteness. But how could they acquire an electrical "charge" ? Arrhenius answers : from the sun. The particles shot off from candescent bodies bear always a negative electrical charge. The sun, we know, is raining these cathode particles or corpuscles into space in every direction. The earth is rushing through a continuous if imperceptible hail of them. It is the beating in and union of these solar corpuscles with the particles of air in the upper strata of the atmosphere which probably explains the appearance of the polar light.

These corpuscles could just as well unite with a germ or a spore as with a particle of water or of air. They are of ultraatomic mass. They would add practically nothing, therefore, to the weight of the germ or spore, while they would impart to the latter their electrical charges. In the outermost strata of the atmosphere the free-path motion of the air molecules may be rods or even miles wide; the germs would encounter no retaining force to hold them in leash; they would go travelling out into the void, where they would come under the impulsion of the pressure of light. Arrhenius calculates that a germ of this size would be driven at a speed sufficient to carry it to the nearest of the fixed stars in three thousand years.

We may conceive of yet another rate of transport than that suggested by Arrhenius. We have seen that space is swarming with meteorites; the spores might readily be caught up in a meteoritic stream and be carried onward to far realms of stars. The germs might easily become embedded in the growing bodies of the meteors, and thus they might penetrate the atmosphere of another planet with the latter. We should have then a realisation of precisely the conditions imagined by Kelvin and von Helmholtz.

It might readily be objected that no germ or spore is known capable of retaining its vital energies for so long a period: But a germ or spore in its travels would be subjected to the temperature of space, and this we estimate at but a few degrees above 
absolute zero. The effect would be precisely the same as if they were frozen in solid hydrogen. The vital activities are simply a function of temperature, and at this intensity of cold they practically cease. Dr. Allen Macfadyen, of the Jenner Institute in London, has shown that germs and spores may be subjected to this infra-freezing process without being " killed." They resume their activities, pernicious or otherwise, when they are thawed out.

Let us conceive that these frozen germs or spores reach another planet whereon no life whatever exists. All of the same material, the planets probably all follow more or less the same course of evolution. So soon, then, as they have cooled off sufficiently from their glowing state to form a crust, they constitute a possible milien of life. It is reasonable to suppose that as soon as the heated vapour of these hot planets has condensed to water, and a-carbonic acid-laden atmosphere is formed, the lowest forms of plant life, the bacteria, may thrive and develop. It is known that some forms at least can sustain a temperature of $90^{\circ} \mathrm{C}$. or very near to the boiling-point.

This is the kernel. Once it is planted upon a cooling globe, we may readily conceive the latter to become the theatre of such a wondrous vital activity as that which in æons gone our earth has been the scene.

It is perhaps worthy of note that the idea of a cosmic distribution of the elementary forms of life adds nothing to, as it subtracts little from, the mystery of life itself. It in no wise precludes the possibility of spontaneous generation upon the earth or elsewhere, incessant or sporadic, now or at some distant anterior time. It in no wise precludes the possibility of the production of life in the laboratory. It may be a fact that no such thing as spontaneous generation has ever taken place upon the earth. It is even conceivable that it has never taken place historically within the cosmos. The peculiar molecular complication which displays the phenomena of life may be coexistent in time with the universe itself. Such seems more or less the view of Arrhenius.

Be this as it may, we have no more present reason to infer this than to suppose that sulphide of iron, or some other more or less complex inorganic compound, was never formed synthetically upon the earth. Sulphides and other compounds are 
found widely distributed over the earth; they likewise occur in meteorites, conceivably also in meteoritic dust. Some of these compounds may exist in the minute particles which reach the earth under the pressure of radiation. Probably it would be very difficult to find anywhere upon the earth an actual synthesis of these compounds now taking place. Yet there is no mystery about them. They are formed and unformed, daily and hourly, in the laboratory and in industrial processes. We have, moreover, excellent reason for supposing their natural production at some period or other of the earth's history. In brief, a given substance that one might pick up in the street might have been produced by a chemist; it might have been formed when the earth was at the temperature of a blast-furnace; it might have come from some celestial stithy at ten million times the distance of the sun.

So with life. Forms of life may reach us in one way and another from every part of the universe; but at the same time its spontaneous production from inorganic materials may be taking place on the earth without cease, let us say, under the tremendous pressures existent at the bottom of the sea, or in warm springs of peculiar chemical content. In forty or fifty years a Berthellot or a Fischer may be producing endless varieties as readily as they do new chemical varieties of sugar now.

It seemed worth while to be somewhat explicit upon the point in view of the extraordinary persistence of the idea that the chemical processes of life are any whit more mysterious than the chemical processes which produce salt or sugar or glass, or result in the burning of coal in the grate. The preferences of the atoms, their tendency to combination-what in vague phrase we call chemical affinity-is one of the three or four great world mysteries. The especial atomic association which displays the phenomena of life is not now a mystery save in the most restricted sense. It is no more of a mystery, let us say, than the laws of the weather.

The parallel is perhaps very close. The weather sharp now knows the most, though not all, of the physical conditions which produce the varieties and eccentricities of atmospheric phenomena. The bio-chemist understands the most, but not all, of the physical conditions which result in the display of life by " inert" matter. But he cannot, as yet, follow these conditions sufficiently close to produce life, just as the weather-prophet 
cannot yet predict earthly weather five hundred years hence, as he will be able not distantly to do. Probably the solution of the one problem will be reached almost as soon as the other.

But if the interesting speculation here detailed could be justified, we should then be in possession of a conceivable mechanism by which life is propagated and distributed throughout the universe. The implication of this will hardly escape. The cosmic exchange of matter means that the material of the universe is more or less alike. Not for the most distant planet of the most distant star can we conceive of any other forces in play than those which exist upon our earth and within our solar system. It follows that with the same forces, acting upon the same materials, the physical evolution of the suns and planets will be the same throughout. These are the conclusions to which every scrap of knowledge we possess unmistakably points.

If the course of stellar and planetary evolution is the same, it follows that vital evolution and the forms of life will differ little. This we should infer from whatever point of view we consider its origin. If it be an incident of planetary coolingthat is to say, spontaneous to each cooling planet-or if it be propagated from one world system to another, after the manner so daringly imagined by Arrhenius, the result would be the same.

We may go further. Intelligence-that is, our mental faculty - is simply a function of a definite physical organisation. Then just as it is impossible to conceive life qualitively different from that upon the earth, so nowhere in the universe can we conceive of forms of intelligence of a different order than our own. The development may be higher as we know that it may be lower. It may envisage more facts, its deductions may be swifter, its generalisations wider. Its limitations will remain more or less our limitations. The problems that are transcendent to us are, we may infer, transcendent throughout the universe, so far as that universe will ever be known to us.

Such at least seems the implication of that unending process of give and take which we now know to be at work throughout the last corners of the stellar scheme. If we could travel for a lifetime with a thousand times the swift rush of light, we should probably fail to discover any world, any race, any intelligence differing perhaps more widely from our own than 
Columbus and his followers found when the new Indias were unveiled. A universe that is to all our human intents immeasurably vast is likewise immeasurably old. The universal effect of commerce is to obliterate differences and establish a relative sameness, such as now obtains throughout our human trading world. It cannot be otherwise with the commerce of the stars. The cosmic exchange, operating through immeasurable time, must likewise have traded the universe into a more or less uniform mode.

Cosmos is wide, cosmos is old, cosmos is kin. What holds it together? 
CHAPTER XXXIII

THE LAST RIDDLE 
Ah, what a dusty answer gets the soul

When hot for certainties in this our life.

George Meredith. 


\section{CHAPTER XXXIII}

\section{THE LAST RIDDLE}

THERE can never be in human knowledge any such thing as finality. Always at the end there is a mystery ; it will always be there. Still in a relative way we do seem here and there to approach something like finality. We have reached something like finality in the explanation of the planetary mechanism. So far as we are now able to perceive the planets form a system that, internally at least, is stable. So far as we now know, if they were undisturbed by any exterior agency, they would pursue their orbital ways for ever. It may be that subtle causes are at work eventually to disturb this apparent equanimity. If there are, they are too minute in their action to be observed. For all of our human concerns the sun long since will have been snuffed out and life upon any of the planets become impossible before they would begin to have an appreciable effect.

The dominating, binding force of the system of the planets we call gravitation or attraction. When we endeavour to conceive of a similar system for the stars we are lost. We can imagine no such binding force. Considering their speed, the spaces that intervene between the stars seem insuperable. The force of gravity, the attraction of one particle of matter for another, is practically the weakest force we know. It requires the minutest measurements of which man is capable, to disclose the existence of this attraction between two earthly bodies.

Even the attracting force of such an enormous mass as the sun, exerted upon the huge bulk of the earth, is representable by very familiar strengths and strains. An ingenious comparison has been made by Professor Young. He pictures the earth as attached to the sun by means of telegraph wires. Their own weight of course disregarded, it would require a system of wires spaced a half-inch apart, and covering the whole of the surface presented to the sun, to hold the earth in leash. When we consider that each wire would hold a section 
of the earth on the average four thousand miles in length, and that the average density of the earth is five times that of water, it will be seen that this is a comparatively slight pull.

Even within our planetary system it becomes very much less. Neptune is thirty times more distant from the sun; the force of gravitation there is, then, nearly a thousand times slighter than upon the earth. A series of telegraph wires spaced forty feet apart would be strong enough to hold Neptune to its accustomed way. Consider, then, how feeble would be the force of gravity at the distance of the nearest star.

It is easy enough to compute the mutual attraction of alpha Centauri and the sun. They are distant 277,000 times the earth from the sun. The force of alpha Centauri's attraction upon the earth, then, is something like 75,000 million times less than that of the sun. The mutual attraction of our sun and the nearest neighbour sun, since they have apparently about the same mass, would only be twice this amount. It is inconceivably small. If we were to conceive these two suns as forming a binary system, the one determining the path of the other, it would require millions of times this attracting force to hold them in their orbits, with the suns moving at perhaps ten or fifteen miles per second.

It does not seem possible, from any conceptions which we can now frame, to think of the sun as a part of a system. If the spacing of the stars-that is to say, the suns which we are able to see-be at anything like this average distance, we are equally lost in our endeavours to conceive of any unitary stellar system as well. Whence, then, the force which moves the sun, and gives the stars their speed ? This is the celebrated problem proposed by Simon Newcomb, and computed by him for a special instance.

Since the days of Newton and Leibnitz, the mathematicians play with infinities as deftly as a Japanese juggler with plates and sharp knives. It is not difficult for a mathematician to reckon up what speed a body might attain in falling from infinity towards a known mass with a known attractive force. The case for the stars is stated thuswise by Professor Newcomb:

The telescope discloses something more than fifty million suns; suppose that we double this number, and give to each of these suns five times the mass of our own. In other words, let us conceive of a stellar universe equivalent in its mass to 
five hundred million suns like ours. The telescopes reveal the existence of stars distant possibly thirty thousand light-years or more. Let us conceive this mass distributed over an equivalent extent of space. Conceive that a star is drawn from an infinite distance towards the centre of this system: what is the utmost speed which it may acquire? The very surprising answer is twenty-five miles per second.

But we have seen that Arcturus and I830 Groombridge move at two or three hundred miles per second. Of course if one sun approached very close to another, the case would be quite different. For example, a body approaching the sun may acquire a velocity of nearly four hundred miles per second. For such a mass as that of Arcturus, still more of Canopus, this velocity would be very much greater. It may be that it is from their occasional approach one to another that the stars acquire some of the speeds that they are known to possess. This would obviate one difficulty; but not its correlative.

If such a stellar universe as Professor Newcomb imagines is incapable of generating a velocity like unto that of Arcturus or Groombridge, it is obvious that it could not hold a star or sun with such a speed in leash. If Arcturus is moving at three hundred miles or more per second, it would require a mass one hundred and forty-four times that of five hundred millions suns to keep this speeding sun from dashing away into the depths of space. If our stellar system were finite, and of less mass than this, Arcturus would be lost to it.

Arcturus is but probably one case in many. There may be hundreds and thousands of suns, for aught we know, moving very much more rapidly than this. If ever the stars formed a relatively compact system, they might, in this view, have been steadily losing one sun after another. In so doing the system would be steadily losing mass, with the result that it would progressively lose whatever power it may originally have possessed to hold together.

Of course all this is merely the vaguest conjecture. We know absolutely nothing about the mass of the universe save perchance one thing. Seeliger of Munich has pointed out that the idea of an infinite universe is incompatible with the notion that the law of gravity is absolute and invariable. Seeliger assumes that the law is not absolute, and that the force of gravitation does not increase or decrease in perfect conformity 
to the law of inverse squares. ${ }^{1}$ It may be remarked that such an assumption is required by the electro-dynamical theory of gravitation; but there is not the slightest evidence as yet that such a diminution takes place. If it does not, it would follow of course from an infinite universe that we should have stars and other bodies moving at infinite speeds.

We are undoubtedly obliged to make option between the two possibilities, and to the writer it has always seemed that the idea of a finite universe was preferable. Of course, either finite or infinite is in reality unthinkable; we can conceive the one as little as the other. But since the human mind is so constituted that it can frame no working conceptions of the universe which are not mechanical conceptions, it is a part of the economy of thought to believe that, for all our means of observation will ever tell us, the mass and number of the stars is a finite quantity.

If it be finite, it is possible that some other force, or forces, exist to determine stellar motions than those of gravitation. But the necessity for any such assumption may be dissipated with the increase of our knowledge. There is distinctly such a possibility in the probable number of dark bodies. Their number and mass might be sufficient to produce any stellar speeds with which we are at present acquainted.

Even conceding this, if gravitation be the only effectual inter-stellar force, we should probably have to give up the notion that there exists any stable arrangement of stellar systems. We should probably have to picture the starry scheme as we have done, in something after the same fashion as the kinetic theory of gases. The stars would simply be flying in every direction without any conceivable order whatever.

This is a part of the riddle. There still remains the larger one of the nature of gravitation itself.

When Newton revealed the presence of an attracting force between all masses of matter, it was objected by his contemporaries that such a force was unthinkable. It remains so still. Newton's theory (not Newton himself) conceived space as to all intents and purposes empty. But so constituted is the human mind that while we may picture-that is to say, understand-one body imparting motion to another by impact, we cannot picture an attraction or pull without an intervening medium.

1 Sitzungsberichte d. Münchener Akad., 1896. 
This was a great stumbling-block to the acceptance of the new gravitation theory. It involved the idea of action at a distance. This is one of the inconceivables. No one saw this more clearly than Newton himself. He had a highly speculative mind-that is to say, a very vivid imagination, scientifically trained. He tried to think out a method by which this apparent attraction could be accounted for. No abler head ever pondered the subject. It is of interest to know precisely how he conceived the problem.

To the end of his days Newton refused to consider gravitation as an inherent property of matter. So far as his physical speculations were concerned, he was a thorough materialist. But as late as $I 717$, in the second edition of his Opticks he wrote :-

"At the end of the Third Book I have added some Questions. And to shew that I do not take Gravity for an essential Property of Bodies, I have added one Question concerning its Cause, chusing to propose it by way of a Question, because I am not yet satisfied about it for want of Experiments."

This same thought pervades the Principia. At the very beginning of the work, as his eighth Definition, he says :-

"Wherefore the reader is not to imagine that by these words I anywhere take upon me to define the kind or the manner of any action, the causes or the physical reason thereof, or that I attribute forces, in a true and physical sense, to certain centres (which are only mathematical points) when at any time I happen to speak of centres as attracting or as endued with attractive powers."

As Newton was the first to grasp the idea of attraction, so was he the first to speculate upon its cause. At the end of the Principia we find this pregnant paragraph :-

"Hitherto we have explained the phænomena of the heavens and of our sea by the powers of gravity, but have not yet assigned the cause of this power. This is certain, that it must proceed from a cause that penetrates to the very centres of the sun and the planets, without suffering the least diminution of its force; that operates not according to the quantity of the surfaces of the particles upon which it acts (as mechanical causes used to do) but according to the quantity of the solid matter which they contain, and propagates its virtue on all sides to immense distances, decreasing always in the duplicate proportion of the distances. Gravitation towards the sun is made up out of the 
gravitations towards the several particles of which the body of the sun is composed; and in receding from the sun decreases accurately in the duplicate proportion of the distances as far as the orb of Saturn, as evidently appears from the quiescence of the aphelions of the planets; nay, and even to the remotest aphelions of the comets, if those aphelions are also quiescent. But hitherto I have not been able to discover the cause of those properties of gravity from phænomena, and I frame no hypotheses (hypotheses non fingo); for whatever is not deduced from the phænomena is to be called a hypothesis; and hypotheses, whether metaphysical or physical, whether of occult qualities or mechanical, have no place in experimental philosophy. In this philosophy, particular propositions are inferred from the phænomena and afterwards rendered general by induction. Thus it was that the impenetrability, the mobility and the impulsive force of bodies, and the laws of motion and of gravity were discovered. And to us it is enough that gravity does really exist, and act according to the laws which we have explained, and abundantly serves to account for all the motions of the celestial bodies and of our sea."

In a celebrated letter to Sir Robert Boyle on this subject, Newton gave freer range to his imaginative faculties, and endeavoured to show how the phenomena of gravitation might flow from the supposition of a very tenuous "æther"-something of the same sort of concept as physicists have since imagined to explain the phenomena of light. It is of interest as affording a glimpse at the workings of a great mind, as do the letters of Faraday and Darwin. Let the grubbing brain that never lifts its eyes into the speculative blue above, consider this curious passage :-

"I will suppose æther to consist of parts differing from one another in subtilty by infinite degrees . . . in such manner that from the top of the air to the surface of the earth, and again from the surface of the earth to the centre thereof, the rther is insensibly finer and finer. Imagine now any body suspended in the air or lying on the earth, and the xther being by the hypothesis grosser in the pores which are in the upper parts of the body than in those which are in the lower parts, and that grosser æther being less apt to be lodged in those pores than the finer $æ$ ther below, it will endeavour to get out and give way 
to the finer æther below, which cannot be without the bodies descending to make room above for it to go into."

In the 2Ist of his celebrated queries, in the Opticks, Newton elaborates his ideas still further, endeavouring even to conceive what the properties of the ather must be in order that it might serve as an explanation of this inexplicable power. It runs :-

"Is not this Medium much rarer within the dense Bodies of the Sun, Stars, Planets, and Comets, than in the empty celestial spaces between them? And in passing from them to great distances, doth it not grow denser and denser perpetually, and therefore cause the gravity of those great Bodies towards one another, and of their parts towards the Bodies; every Body endeavouring to go from the denser parts of the Medium towards the rarer? For if this Medium be rarer within the Sun's Body than at its Surface, and rarer there than at the hundredth part of an Inch from its Body, and rarer there than at the fiftieth part of an Inch from its Body, and rarer there than at the Orb of Saturn; I see no reason why the Increase of density should stop anywhere, and not rather be continued through all distances from the Sun to Saturn, and beyond. And though this Increase of density may at great distances be exceeding slow, yet if the elastick force of this Medium be exceeding great, it may suffice to impel Bodies from the denser parts of the Medium towards the rarer, with all that power which we call Gravity. And that the elastick force of this Medium is exceeding great, may be gather'd from the swiftness of its Vibrations. Sounds move about Ir40 English Feet in a second Minute of Time, and in seven or eight Minutes of Time they move about one hundred English Miles, Light moves from the Sun to us in about seven or eight Minutes of Time, which distance is about $70,000,000$ English Miles, supposing the horizontal Parallax of the Sun to be about I2". And the Vibrations or Pulses of this Medium, that they may cause the alternate Fits of easy Transmission and easy Reflexion, must be swifter than Light, and by consequence above 700,000 times swifter than Sounds. And therefore the elastick force of this Medium, in proportion to its density, must be above $700,000 \times 700,000$ (that is, above $490,000,000,000)$ times greater than the elastick force of the Air is in proportion to its density. For the Velocities of the Pulses of elastick Mediums are in subduplicate Ratio of the 
Elasticities and the Rarities of the Mediums taken together."

When some of Newton's followers proposed flatly to accept actio in distans Newton would have nothing whatever to do with it. In his well-known letter to Bentley he evidences his impatience. He says :-

"It is inconceivable that inanimate brute matter can, without the mediation of something else which is not material, operate upon and affect other matter, without mutual contact, as it must do if gravitation, in the sense of Epicurus, be essential and inherent to it. This is the reason why I desire that you would not ascribe an innate gravity to me. That gravity should be innate, inherent, and essential to matter, so that one body may act upon another at a distance, through a vacuum, without the mediation of anything else by and through which their action may be conveyed from one to another is to me so great an absurdity that I believe no man, who has in philosophical matters competent faculty of thinking, can ever fall into. Gravity must be caused by an agent acting constantly according to certain laws; but whether this agent be material or immaterial, I have left to the consideration of my readers."

The riddle of Newton's time remains a riddle to our own. In some regards the mystery has deepened rather than cleared. One of the greatest works of the last century was undoubtedly the establishment of the idea of the conservation of energy; but gravitation is a standing negation of such a concept. So far as we can see now, it represents an inexhaustible supply of energy with no corresponding dissipation. It is true that so far as our earthly concerns go we are not able to utilise gravitation for the establishment of perpetual motion; but possibly the universe does. According to our present ideas it is the impact of suns, ${ }^{1}$ doubtless for the most part cold suns, combined with the heat of attraction, which gives rise to the incandescence of the stars. When this initial store of energy has been dissipated and the suns become cold again, they have merely to come into a second collision that the cycle may be resumed. So far as we can now see this might go on for ever. The universe itself might realise that perpetuity of utilisable force or energy which is denied to man.

\section{James Croll, Stellar Evolution.}


This is part of the puzzle. Another is the apparently instantaneous propagation of gravitation. Attraction is a force, and every other force with which we are acquainted requires a finite time for its extension through space. Endless endeavours have been made to discover a rate of propagation. Laplace was among the many who tried it. He thought for a time that he had; latterly he gave it up. Very recently a German mathematician, Gerber, thought to deduce the rate from the motion of perihelion of Mercury. ${ }^{1}$ This is estimated at forty-one seconds in a century, and according to Gerber's computations this would indicate a rate of propagation for gravitation similar to that of light and electric waves. It remains as yet merely a plausible theory.

A further mystery of gravitation is that it cannot be screened. It acts apparently with the same force through a planet as through empty space. When the planetary bodies are in conjunctionthat is to say, in a straight line from the sun one with the otherthey swerve slightly perforce of their own mutual attractions; but not otherwise. It needs be said that in this regard gravitation does not stand absolutely alone. The same thing is true of magnetism. We are equally unable to devise a magnetic screen. If we could do either we should have perpetual motion, and, more than this, we should be able to navigate space.

It is obvious that so long as we know nothing of the theory or "cause" of the most familiar fact of our daily lives, we cannot advance very far. Countless efforts have been made to break through this impasse; none have succeeded-that is, if we bar the philosophers. Readers with a taste for such things will doubtless find interest in a recent volume of Professor Wilhelm Ostwald, ${ }^{2}$ wherein the difficulties which have beset a considerable line of hard-headed thinkers, from Newton to Kelvin, are lightly brushed away.

In a scientific sense, probably the most noteworthy attempt towards an explanation was the hypothesis proposed by Lesage, a modest physicist of Geneva, about a hundred and fifty years ago. Lesage, who is in no wise to be confounded with the author of Gil Blas, suggested that the facts of gravitation might be accounted for by conceiving of an infinite rain or hail of infinitesimal particles, driving about in every direction

1 Zeitschr. f. Math. u. Phys. 1898, II.

2 Vorlesungen über Naturphilosophie; Leipzig, 1902, p. 193. 
with an average equal motion, and so small that they would penetrate and flow through all forms of matter whatsoever. Because this rain must be incessant and to all intents infinite, Lesage conceived it to come from beyond the confines of the known universe; hence he called these flying bodies ultramundane particles.

It will be perceived that Lesage's idea of an eternal downpour of minute particles of matter does not differ very greatly from the ideas of Democritus and Epicurus. It is evident from his memoir that it was a reading of these which probably suggested the hypothesis he framed. It was, to be sure, a purely speculative conception. It was a kind of an explanation ad hoc. Before us is a fact-how might it be explained? We have of course not the slightest evidence that any such corpuscular downpour takes place.

Still, it is noteworthy that Lesage's hypothesis has been favourably entertained by more than one acute and penetrating mind, in especial, that of S. Tolver Preston, an English physical philosopher who gave high promise ere he died. It was Tolver Preston who pointed out that the scheme imagined by Lesage differed but little from our present-day theory of gases, of the cause of the pressure of air, \&c. His postulates were much the same. ${ }^{1}$ We should merely have to imagine an order of corpuscles as much smaller let us say, than the molecules or particles of air as the latter are smaller than small shot or sand.

Very recently in the emanations of radium we have learned to know of a corpuscular order perhaps a thousand times smaller than the smallest of the atoms, possibly hundreds of thousands of times smaller than the molecular aggregations of air or vapour. There is nothing a priori to forbid our imagining that a'yet more minute order exists, and sufficient in numbers to satisfy the assumptions of Lesage as they were modified in the mind of Preston. Probably we are as yet merely upon the rim of physical knowledge. Of what another two or three centuries like the last may bring forth we have of course not the remotest suspicion. But so far as our present-day knowledge extends, the theory is little more than a brilliant fancy.

Endeavours at an explanation of a hydro-dynamical sort have not been few. It has been known for a very long time that pulsating spheres, immersed in an incompressible medium like 
water, attract each other and tend to approach. In the supposition of a light-bearing ether we have something of such an incompressible medium, supra-sensible to our present methods of observation; if we could conceive of every ultimate particle of matter as a pulsating sphere, then we might have here an explanation of attraction. But it was pointed out by Arago, and doubtless by many another before him, that such pulsations would require a definite time for their propagation. The theory stumbles over the fact that no finite speed for gravitation can be detected.

This order of ideas has recently found an ingenious extension at the hands of two Swedish investigators, C. A. and Victor Bjerknes, father and son. Their work has given emphasis to the idea that it is to such a hypothetical ether that we must look for the ultimate explanation of the interaction of all forces. By means of such an assumption we may do away with the utterly unthinkeble notion of action at a distance; but it must be said that the various attributes framed for this highly useful ethereal medium are as absolutely incongruous as the incongruous conceptions it is designed to avoid. There never was folly more sheer than to suppose that we can think of continuous extended substance in which matter or material bodies may move. Perhaps this is no worse than our endeavours to conceive of an atom which cannot be divided. We have here passed the limit of experimental proof and stepped into a realm where we are offered the choice of fancy or metaphysics. The one is undoubtedly of as much value as the other, with the difference perhaps that where ingenious fancy has sometimes, if rarely, pointed to new paths of discovery, metaphysic has never. It is a fatal anodyne to physical inquiry, the relaxation, sometimes, in summer moods, for healthy minds; their staple diet never. It is the predilection, the writer has long been convinced, only of cobweb brains, lost in the phantasies of a mild distemper.

In such a summer mood, amid serene days when the mind refuses to be vexed with difficulties, even the most obvious and insuperable, let us turn the last page. Above me, as I look high over the hills, the azure is entrancing in its beauty, boundless, so far as I can ever know. For the spacious abstraction we call the universe we can imagine no end; its annihilation is unthink- 
able. Yet the irresistible bent of the mind which leads me to believe that I am I, and to lend to the exterior world an objective existence, illusory though it may be, determines that I shall also recognise in the concourse of phenomena a definitive tendency or direction. A machine that can go on for ever is no machine. The energy of the universe may be constant; but that part of it which is utilisable apparently tends to lower and lower levels; in a Clausian sense, the sum of entropy is increasing. This, in scholastic phrase, can only predicate final immobility. If, as all our reason peremptorily demands we believe, we are part and $\operatorname{cog}$ of a cosmic mechanism, we must look to its fate.

What will it be ? 
$\therefore$ CHAPTER XXXIV THE END OF THE MACHINE 
Now sit we close about the taper here, And call in question our necessities.

Julius Casar, iv. 3.

But, Socrates, the sun I think is still upon the mountains, and has' not yet gone down.

Plato, Crito. 


\section{CHAPTER XXXIV}

\section{THE END OF THE MACHINE}

AN impenetrable veil hides from us the beginning of things. So far as we can now see, it will never be lifted. Equally from our view is veiled the end. The forces with which physical investigations deal are finite; they are measurable, and, in a way, simple. The single exception to this-and that may be only an apparent exception, the outcome of our present ignorance -is gravitation. So long as that riddle is unexplained, it is idle to conjecture. Perhaps it would still be idle if it were solved.

So far as we can now perceive there appears to be, in Spencerian formula, an increasing aggregation of matter. If the matter of the universe is finite, and if this aggregation be pursued indefinitely, it could have but one result : that would be final congregation into a single mass. The universe of suns and planets would be tumbled into a single lump.

Whatever be the larger fact, it is not improbable that this may be the fate of that part of cosmos which it will ever be given to our human kind to know. There is much in recent stellar discovery to suggest such a conclusion. It is obvious, for example, that, if we do not mistake as to the vast size of Canopus, we should have here a relatively advanced stage of the process.

If the meteoritic idea of the origin of suns and planets hold aught of truth, the tendency is towards the formation of larger and larger bodies. Each of these would act in some sense as centres of aggregation. It is fairly clear that in the course of ages the earth has grown, all of the planets have grown, the sun itself has grown. The continuous sweeping of these large bodies would eventually empty space of all its minor contents.

If we prolong our vision we shall see that amid the alternate formation of systems, and their disintegration through stellar 
collisions, there would yet be a tendency towards the accumulation of matter into ever narrower areas. Presently this would produce one enormous body which no collision would shatter.

It is obvious, for example, that the collision of our sun and Canopus would not mean a dissipation. If the earth fell into the sun, even at enormous speed, its mass is yet too slight to cause the dissipation of the mass of the sun into primeval nebula. In the light of our present estimates, precisely the same thing would be true if our sun were drawn into Canopus. It would add something to the heat of that star; it would add something to its mass. Canopus would not be destroyed.

We know nothing of the motion of Canopus. If it were careering through space at the speed of Arcturus, it would be sweeping up suns at a relatively tremendous rate. Whether it be in motion or no, the result would be much the same. We might even conceive it as standing still, and since we know that the stars about it are moving rapidly in every direction, in the end they would one by one approach and be drawn within its gigantic spider's web.

We might, of course, conceive that a similar process was at work throughout other regions, with the resultant formation of other suns equal in grandeur to Canopus. If two such suns in their turn came in collision, the result would probably mean the dissipation of both into a primitive nebulous condition. But there would be this difference, that whereas the matter of which they were composed had originally extended over vast areas, that which would be occupied by the new nebula thus formed would probably cover but a small extent of the former. If contraction then took place, the resultant system would apparently have one vast sun at its centre instead of the original pair. The process which had been followed out by each of them would, after the elapse of an immense period of time, be resumed with double the energy - that is to say, with double the attracting force.

So far as we can now see, there is little to stay and nothing to limit such a process. The end might be delayed through æons of time, compared with which the life-history of our solar system would appear but seconds in a seeming eternity. It could have but the result which we have surmised. This central mass would dissipate its heat, it would cool just as our planet has cooled, just as the sun is cooling, just as great Canopus 
will cool. If there were planets revolving about it, a time would come when life upon them would be impossible. The image of the universe then would be that of an inert clod, mindless, helpless, motionless, and dumb.

All this, it scarce needs saying, is but the purest speculation. Arrhenius, for example, has quite another view, offering, in his textbook of cosmical physics, the idea that the matter of the universe follows a continual round of alternating aggregation and dispersion. The penetrating mind of this great Swedish investigator conceives that this knows no end. In a private note to the writer he very trenchantly observes:-

"Formerly we knew only of the Newtonian force of gravitation, and therefore cherished the idea that in the end everything would clump together. But we now know of the pressure of radiation which may balance the tendency of congregation. At the catastrophe of Nova Persei it was observed that hydrogen shot out from the star with a velocity of about 700 kilometres per second. If Nova Persei is of the same magnitude as our sun, this velocity is so great that it would drive the hydrogen out from the gravitational field of the star into infinite space. Many nebulæ-e.g. that of the Pleiades or Orion-indicate by their extraordinary dimensions such a diffusion into practically infinite distances.

"I therefore adhere to the idea of an oscillation of matter because it is impossible for me to understand a beginning or an end of the system of matter that we observe. If there were an end, with complete rest, the condition would have been reached in the infinity of time which lies behind us, and there would be nothing left in the world for us to observe. Therefore also the second law of thermo-dynamics cannot be perfectly true as it is formulated now."

The justice of these observations is evident. Yet it is difficult to understand how the balance could be maintained simply from the pressure of radiation without assumptions which as yet have but a slight foundation. We might conceive, of course, that the heat generated by the contraction of a nebulous mass increases with the mass, and we might therefore imagine that bodies enormously larger than our sun are likewise enormously hotter. There is little, however, as yet, to suggest that such is the case. The conclusions of Sir William Huggins, in fact, are directly the contrary. He supposes that the maximum of 
temperature is reached in bodies at the evolutionary stage of our own sun. If this were true, the pressure of radiation from a body of the conjectural dimensions of Canopus would be quite insufficient to counterbalance its gravitational pull. The process of aggregation might be delayed, but in the unthinkable reaches of time which we are considering it would still be consummated.

The very acute observation that if any such process were at work it would have been completed long ago, lays bare the real dilemma. It is evident enough that the problem is in reality transcendent.

Such gigantesque if somewhat tenuous speculations mark in some sense the highest attainments of the human mind. Reflecting upon its lowly origin-considering its stumbling, groping beginnings-comprehending in a single sweep the tremendous range of its activities-we shall not err, perhaps, if we consider that the true world-marvel is the mind itself. Reluctantly, and with the painful sense as of a hobble cast about the feet of some splendid courser, every fibre of his body trembling with the excitement of the chase, we recurrently awake to the realisation of its finite limitations.

From such heights we must descend at intervals to consider the rather slender foundations upon which it rests. It was Hume who pointed out that all we know of cause is reiterated sequence, the constant succession of events. It is this constant succession which we call law. It is upon this which rests the vast body of co-ordinated knowledge which we may regard as in some sense permanent, an inexpugnable fortress. It is with the aid of these same materials that speculatively we lift our kites and aëroplanes to tour the blue above.

But it is evident that we can have no idea as to the past, no surmise as to the future, save that which is based upon the supposition that this constant succession is never changed. Moreover, the facts which we have to go on are as yet slight. The law of gravitation is hardly more than two hundred years old. The idea of conservation of energy dates back little more than half a century, a couple of generations. It is only within forty or fifty years that man has had any reasonable basis upon which to speculate as to his origin or his future.

This fact bids us exercise a certain, if indulgent, scepticism towards any very rigid conclusions. We need not cast aside 
sense or science. We need not throw ourselves into the intellectual muck of astrology, spiritism, or degrading gullibility. But we may remember that time is long. To set out the matter well, Professor Langley has drawn the threads of his fancy into a graceful parable, whose import will ever be salutary :-

"We have read somewhere of a race of ephemeral insects who live but an hour. To those who are born in the early morning, the sunrise is the time of youth. They die of old age while its beams are yet gathering force, and only their descendants live on to mid-day; while it is another race which sees the sun's decline from that which saw it rise. Imagine the sun about to set; and the whole nation of mites gathered under the shadow of some mushroom (to them ancient as the sun itself) to hear what their wisest philosopher had to say of the gloomy prospect. If I remember aright, he first told them that, incredible as it might seem, there was not only a time in the world's youth when the mushroom itself was young, but that the sun in those early ages was in the eastern, not the western, sky. Since then, he explained, the eyes of scientific ephemera had followed it, and established by induction from vast experience the great 'Law of Nature' that it moved only westward; and he showed that since it was now nearing the western horizon, science herself pointed to the conclusion that it was about to disappear for ever, together with the great race of ephemera for whom it was created. What his hearers thought of this discussion I do not remember, but I have heard that the sun rose again the next morning." 1

This is excellent. Yet the codified experience of the human race is of worth. Reason, inference, induction, synthesis, will ever remain the only means of dispelling the environing ignorance into which we are born, or of effecting any amelioration of our human lot. For the here and now it is our sole guide. So far as it may surely lead, wide-eyed and fearless, we must follow.

For the rest it is not probable that the main results of the last two or three centuries will ever be materially impaired. Our ideas and our presentation of them will insensibly change. The facts undoubtedly will remain. What we have to consider is that perhaps a very slight modification of our present ideas

1 Langley, The New Astronomy. 
might suffice greatly to change our ideas of the future. The discovery of radium and the cathode radiations, emanations, of the pressure of radiation, and the like, to all of which reference has repeatedly been made, may very distinctly alter our ideas as to the age of the earth, of the sun as well. In the course of three or four centuries, three or four other discoveries may come of yet more vital import.

There is, however, one central fact which, for aught we may now see, may never be modified and from which we can never escape. The cosmic machine runs on. We die. La vie est brève, la vie est court. It seems fairly incontestable that life had a beginning upon the earth, and, what is of much deeper import, there was a time in the history of the earth when it bore no human race. So far as we can see, that which has a beginning must also have an end. When the candle of the sun has been burnt to its socket, the cycle of evolution which produced our race will have turned downwards and backwards, returning to the bathybii and lichens from which we sprang.

The history of the earth does not suggest a high importance for the individual human life. We may roughly estimate the period of man at from two to five hundred thousand years, perchance a million-let us say, roughly, ten to thirty thousand generations. It does not seem probable that the number of human beings on earth has varied very greatly in ten or twenty thousand years, perhaps not in fifty thousand. At present the number is about fifteen hundred millions-in American notation, a billion and a half. The personnel of this number is changed on the average once in twenty-five or thirty years.

It is easy to see that the aggregate number of human beings who have ever lived upon earth runs into hundreds, it may be thousands, of billions. The lives of the vast majority of these were of as much consequence to human history as the spawn of fishes or the larvæ of flies. It is considerations of this sort which make it difficult to understand at times the ardour with which men pursue the shows and baubles of this world.

The individual life is of little consequence to the race. The aggregate life of the race seems of little consequence to the earth. Billions upon billions of coral polyps may materially alter the surface of the globe. Probably their work will be of more consequence, will have effected greater changes in terrestrial conditions, than all that will ever be effected by man himself. 
It may be that the human race has yet a long time to run, compared with the relative brevity of its past. It may be that human achievement has hardly begun. Be that as it may, it will one day be finished.

So far as we can now perceive, human civilisation is but a flutter of consciousness amid the wide cycle of life that sweeps through from lichen-and bacterium to saurian monster and back again. And the cycle of life is but an evanescent moment in the history of the globe. The history of the globe is in its turn but an evanescent moment in the cycle of the stars; suns glow for a little time, and planets bear their fruitage of plants and animals and men, then turn for æons in a drear and icy lifelessness. We may change the moving lines of the poet stightly:-

"The earth hath bubbles as the water has, And life is of them."

Such is the cosmic order so far as the Book of Revelation is complete. That revelation has dissipated our childish dreams, it has shattered our childish faiths. So far as the outer world is intelligible to us, the immediate portion in which we live our lives is simply a machine, so orderly and compact, so simple in construction, that we may reckon its past and gauge something of its future with almost as much certitude as that of a dynamo or a water-wheel. In its motions there is no uncertainty, no mystery, save the eternal mystery which will for ever shroud the underlying reality. This is the first fact which modern science has to offer to the philosophic mind.

Accepting cosmos as a machine, dominated by simple mechanical laws, we still pursue our lives as if human destiny were the subject of human control. We may accept the mechanical necessity of day and night, the change of the seasons, the variations of climate throughout long periods. They are the inevitable results of the planetary mechanism. To this much of the idea of mechanism we are accustomed, and insensibly reconciled.

But the wind bloweth where it listeth, the rains cometh, tribes and kingdoms rise and fall. The perception of order in these more intimate phenomena is as yet incomplete. In a volume to follow, I purpose to review the advance of our insight 
into the terrestrial, the human, the social, and the economic mechanism, and to inquire whether in the sculpturing of the earth, in the course of the winds, in the fall of the rain, in the rise of kingdoms, in the appearance of great minds, great ideas or great discoveries, in the alternation of years of drouth and years of plenty, in dress or customs, or in the little happenings of our daily lives, there is any different order at work than that which we may observe in the cosmos at large.

LoNDON, June 1903;

Berkeley, California, April 1906. 
BENEDICITE.

\section{LA PAIX DES DIEUX}

Et l'homme dit: Démon! qui hantes mes ténèbres Mes rêves, mes regrets, mes terreurs, mes remords; O spectre! emporte-moi sur tes ailes funèbres Hors de ce monde, loin des vivants et des morts.

Loin des globes flottant dans l'Étendue immense Où le torrent sans fin des soleils furieux Roule ses tourbillons de flamme et de démence, Démon! emporte-moi jusqu'au Charnier des Dieux.

Oh, loin, loin de la Vie aveugle où l'esprit sombre Avec l'amas des jours sterile et des nuits, Ouvre-moi la cité du silence et de l'ombre, Le sépulcre muet des Dieux evanouis.

O démon! Mène-moi d'abîmes en abîmes Vers ces Proscrits en proie aux siècles oublieux, Qui se sont tus, scellant sur leurs lèvres sublimes Le Mot qui fait jailler l'Univers dans les cieux.

Alors le Compagnon vigilant sur ses rêves Lui dit: Reste, insensé! Tu plongerait en vain $\mathrm{Au}$ celeste ocean qui n'a ni fonds ni grèves. C'est dans ton propre cœur qu'est le Charnier divin.

La sont tous les Dieux morts, anciens songes de l'Homme, Qu'il a conçus, créés, adorés, et maudits, Evoqués tour à tour par ta voix qui les nomme Avec leur vieux enfers et leur vieux paradis.

Contemple-les au fond de ce cœur qui s'ignore, Chaud de mille désirs, glacé par mille hivers, Où dans l'ombre éternelle et l'éternelle aurore, Fermente, éclate et meurt l'illusoire univers.

Leconte DE Lisle, Dernières Poèmes. 

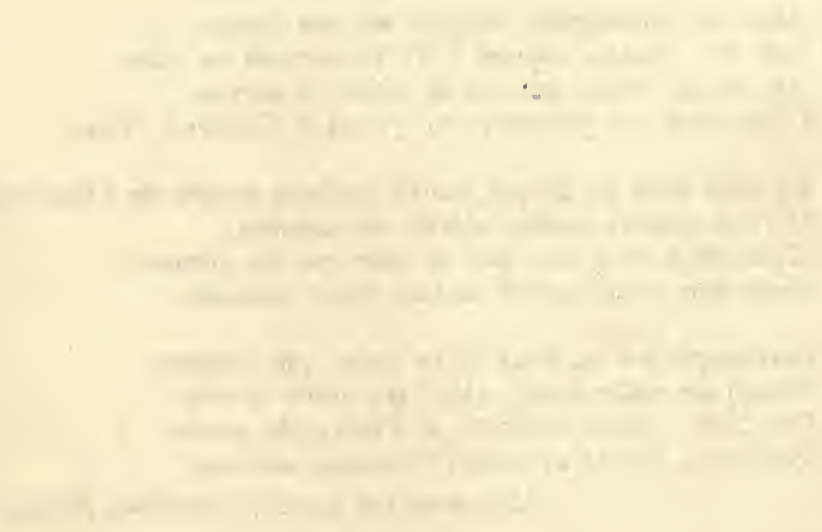


\section{BIBLIOGRAPHY}

Aside from the especial citations in the text, the materials for the present volume bave mainly been drawn from the following works :-

Cicero, Academics ; Nature of the Gods, ed. Bohn.

Diogenes Laertius, Lives, ed. Bohn.

Euvres de Lucrèce, Trad. Lagrange.

Martha, Le Poème de Lucrèce, 1896.

Apelt, Die Epochen der Geschichte des Menschheit, 1845.

Bailly, Histoire de l'Astronomie Ancienne et Moderne, 4 vols., 1779, et seq.

Delambre, Histoire de l'Astronomie Ancienne et Moderne, 6 vols., I 815 , et seq.

Whewell, History of the Inductive Sciences, 3 vols., I 847 .

Montucla, Histoire des Mathématiques, 4 vols., I758, et seq.

Libri, Histoire des Sciences Mathématiques, 3 vols., 1838.

Humboldt, Cosmos, 7 vols., I 845 , et seq.

Lange, Geschichte der Materialismus, 3 vols., 1873.

Buckle, History of Civilisation in England, 2 vols., 1859.

Lecky, History of the Rise and Influence of the Spirit of Rationalism in Europe, 2 vols., 1865.

Draper, History of the Intellectual Development of Europe, 2 vols., I 86I.

Merz, History of European Thought, 2 vols., 1900.

Schiaparelli, I Precursori di Copernico nell'Antichita, 1873.

Matter, Histoire de l'École d'Alexandrie, 3 vols., I 843.

Berti, Copernico, 1876 ; Bruno, 1889.

Martin, Galilèe, 1868.

Brewster, Memoirs of the Life of Newton, 2 vols., 1860.

Voltaire, Lettres Phil. sur les Anglais, 1734; Eléments de la Phil. de Newton, 1745 .

Rosenberger, Newton und Seine Physikalischen Principien, 1893.

Lewes, Aristotle, I864.

Galileo, Opere Complete, I7 vols., I 855.

Descartes, EEuvres Complètes, II vols., I 824.

Bertrand, Les Fondateurs de l'Astronomie, 1889.

Berthelot, La Révolution Chimique, 1890. 
Mach, Die Mechanik in ihrer Entwickelung, 1883. Die Principien der Warmelehre, 1900.

Duhem, L'Évolution des Théories Physiques, 1896.

Lodge, Pioneers of Science, I 893.

Berry, History of Astronomy, 1892.

Williams, A History of Science, I904.

Clerke, History of Astronomy in the Nineteenth Century, 1902. System of the Stars, 1905. Problems in Astrophysics, 1903.

Wolf, Les Hypothèses Cosmogoniques, 1886.

Helmholtz, Vorträge und Reden, 2 vols., 1903.

Kelvin, Lectures and Addresses, 3 vols., I 889.

Croll, Stellar Evolution, I889.

Tait, Recent Advances in Physical Science, I 885.

Ball, The Story of the Earth, 1904.

Arrhenius, Lehrbuch der Kosmischen Physik, 1903.

Newcomb, Popular Astronomy, 1886. The Stars, 1902.

Young, General Astronomy, 1904.

Langley, The New Astronomy, I 894.

See, T. J. J., Evolution of the Stellar Systems, I 896.

Faye, Sur l'Origine du Monde, I 896.

Lockyer, J. N., Meteoritic Hypothesis, I 890.

Thomson, J. J., Conduction of Electricity in Gases, 1903. Electricity and Matter, 1904.

Vogel-Newcomb, Populäre Astronomie, dritte Aufl., '1905.

Baur, Chemische Kosmographie, 1903.

Righi, La Moderna Teoria dei Fenomeni Fisici, 1904. 
I N D E X 



\section{N D E X}

ABACUs, calculating machine, 58

Abdera, Greek city in Thraké, I3I

Aberration of the stars, Bradley's discovery of, 286

Abjuration of Galileo, 196

Absorption of light, 395

Academy, French, its expedition to Cayenne, 230

Acceleration of falling bodies known to the ancients, 124

Acceleration of "falling bodies first measured by Galileo, 198

Accuracy, extraordinary, of modern observations, 232

Acoustics, studied by the Greeks, 147

Action at a distance, inconceivable, 449

Adams, J. C., predicts an extraUranian planet, 3 I I

Africa, circumnavigation of, 80 , I60

Ahmes, manuscript of, 56

d'Ailly, his Imago Mundi, ro

transmits Roger Bacon's ideas, 160

Air, ancient ideas of materiality of, I 38

weight of, demonstrated by Torricelli, 240

pump, invented by Guericke, 24I

Akosmism, Fichte's, as an alternative, 9

Alchemy, beginnings of, 5 I

d'Alembert, French mathematician, 296

Alexandria, its stirring life, 80

its decline, I46

Alexandrian school, its long survival, 126

Algebra, early use of, 58

Al-Hassan, founder of the Assassins, I 55

Al-Hazen calculates the height of the earth's atmosphere, $24 \mathrm{I}$
Almagest, Ptolemy's, Coppernicus' debt to, I64

Al-Maimum, measure of the earth, 78

collects a great library, I 53

Alpha Centauri, size of, 336

a double star, 373

distance from the earth, 357

Alphonso of Castile, his remark, I7

Amber, first manifests electrical properties, I 39

America, discovery of, its effect on Europe, 163

Anaxagoras, ideas of the sun, 22 ideas of attraction, 123

on homeomerice or similar parts, I 36

Andalusia, public libraries in, 154

Anderson, observation of new star, 380

Antony, Mark, presents a library to Cleopatra, I 52

Apelt, his history of ideas, Io

Apex, stellar, the direction of sun's movement, 323

Apollonius of Perga, introduced conic sections, 92

on Mercury and Venus as satellites of the sun, 169

Appearances, difficulty of overcoming, $2 \mathrm{I}$

Apple, Newton's, probably a myth, 257

Arabian culture, its character, 156

Arcetri, death-place of Galileo, 207

Archimedes, inscription on his tomb, 57

description of his planetariumfailure to adopt Aristarchus' ideas, I 16

his "Arenarius" or sand-reckoner, III

his greatness and limitations, I 25

Arcturus, vast size of, 337

its frightful speed, 340 
Arcturus, its unaccountable speed, 447

"Arenarius," a work of Archimedes, III

Aristarchus, of Alexandria, on motion of the earth, 22

anticipation of the Coppernican idea, I 2

measures distance of the sun, 89

on distance of the sun, 93

on the path of the moon, 169

Aristotle, on spontaneous generation, 5

copies much from Democritus, I 34

his doctrine of a fixed earth, 102

Middle Age deification of, 156 on size of the earth, 75

Armils, accuracy of Alexandrian, 95

Arnold, Sir Edwin, his poem, 155

Arnold, Matthew, quoted, 2, 370

Arrhenius, work on cosmical physics, I 2

ideas of cosmogony, 423

on origin of meteorites, 437

on the cycle of matter, $46 \mathrm{I}$

Assassins, Al-Hassan, founder of sect, I 55

Asteroids, discovery of, 307

Astronomical knowledge, synonym of certitude, 377

Atheism, periods of its recurrence, 159

Atheists, the first of, I4I

Athens, lateness of its intellectual awakening, I $3 \mathrm{I}$

Atmosphere, height of the earth's, 24 I

Atomic idea, early arguments for, 136

Atoms, early ideas of, 136 rain of, in space, Democritus' conception of, I 38

Attraction, early ideas of, 122

Coppernicus on, 170

Gilbert's ideas of, 190

insufficient to hold the stars in a system, 446

Kepler on, I 88

law of, Newton's account of its discovery, 255

Newton's discovery rejected by Huyghens, 246

true nature of Newton's discovery, 260

Augustine, St., his age, $15 \mathrm{I}$
Auzout, applies the micrometer to telescopes, 245

Averroes, his type of thought, 156 mistaken observation of Mercury, 221

Avicenna, his type of thought, I56

BAcIlli, structure and size of, 40

Bacon, Lord, quotation from Plato, 99

apology for, 203

estimate of his work, 213

ideas on attraction, 246

ignorant of Kepler's work, 192

on Coppernicus, 212

on Democritus, I 30

rejection of Coppernican theory, 177

Bacon, Roger, influence on Columbus, 159

describes the telescope, 200

Bacteria, obscure utility of, 16

Baer, von, stimulus to Spencer, I 36

Bailly, his History of Astronomy, i I on early measures of the earth, 77 on the parallax of the sun, 95 quotation from, on astronomy, i Io quotation from, 268

Balance, the, discovery of, 54

Bankruptcy of science, 39

Barometer, discovered by Torricelli, 240

Bel, servitors of, 68

Benn, on early mathematics, 57

Bentley, Newton's letter to, on gravitation, 452

Berenson, method of identifying painters, 380

Berkeley, Bishop, conceptions of a dream world, 31

Bernouillis, the, family of mathematicians, 295

calculus of the solar system, 402

Bessel, the first to determine stellar parallax, 334

on astronomy of the invisible, 372

Bethlehem, Star of, 379

Binary systems, Herschel's discovery of, 324

probable origin of, 378

spectroscopic, 374

Binomial theorem, invented by Newton, 255

Bion, his teachings, 64

Bjerknes, hydro-mechanical theory of gravitation, 455

Boccaccio, an evangel of the Renaissance, 159 
Bode, law of spacing of the planets, Body, human, regarded as a machine, 32

Boileau, Bishop, resists the effort to suppress new ideas, 220

du Bois-Reymond, quotation from, 253

Books, price of, in ancient times, I75

Borelli, ideas on gravitation, 246

Bouguer, invention of the heliometer, 333

Bouillaud, ideas on gravitation, 246

Boyle, and Marriot, on laws of pneumatics, $24^{2}$

likens universe to Strasburg clock, 247

Newton's letter to, on gravitation, 450

Bradley, discovers the aberration of the stars, 286

discovers nutation, 288

on movement of the solar system, 32 I

Brahma, hatching out the universe, 401

Brewster, Sir David, on Lord Bacon, 2 I 4

account of Newton's discoveries, 257

Brightness of the stars, measure of relative distance, 390

Browning quoted, 2

Bruno, on plurality of worlds, 30 his life and ideas, 177

Buckle, History of Civilisation, I I

Buffon, his good gorilla, 49

on origin of the solar system, 402

Burning glass, very old, 200

CASAR, his huge debts, I 49

death of, visited by heavenly portents, 269

Calculating spirit, its temperature, 87

Camera, used in photographing spectra, 348

Campo di Fiori, Bruno burned in, I 80

Canopus, its probable distance and grandeur, 337

evidences increasing congregation of matter, 459

lower limit of distance, 360

reflections on a planet as large as, 365

Carlyle, quotation from, 3 I 6
Carnot, founds thermo-dynamics, 4 I 5

Cassini, fixes the true distance of the sun, 229

Cause, Hume on idea of, 462

Cayenne, results of the expedition to, 230

Celestial mechanics, founded by Newton, 260

Celoria, distribution of the stars, 393

Cena de le Ceneri, La, a work by Bruno, I 79

Central sun, Lambert's idea of, 388

Centre of solar system, earth as, IO 4

Ceres, discovery of, 308

Certitude, beginnings of, 49

Chaldeans, their measure of the earth, 75

Chance, Democritus' conceptions of, I4I

solar system not due to, 402

Charles II., his reign the golden age of English science, $26_{3}$

Charles the Hammer-check of the Saracen, 157

Charles the Wise founds Royal Library of France, I 52

Charron, the sceptic, Gassendi's resemblance to, 22 I

Chatelet, Madame du, translates Newton's Principia, 265

Cheerfulness, Democritus' idea of the highest good, I 42

Cheops, orientation of his tomb, IOI

its geometrical construction, 68

Chinese, slight value of their contributions, I 57

Chronometer, perfected by Harrison, 244

Cicero, his Commonwealth, I 6

Academics, quoted, 354

belief in divination, 269

on gravitation, I2I

on the value of life, I 47

testimony to Democritus' style, 132

Circle, divisions of, 54

Civilisation, its former precariousness, I4

revelations of its antiquity, 25

ancient, its frail foundation, 127

Clairaut, mathematical investigations, 295

Clark, discovery of Sirius' companion, 372 
Cleomedes, on measure of the sun, 94

failure to accept Aristarchus' ideas, II 6

proof of littleness of the earth, II 2

Clerke, number of new stars, 379

Clocks, invention of, 243

Cogito ergo sum, keynote of Descartes' philosophy, 218

Colding, discovery of conservation of energy, 416

Collision of suns is incessant, 378 of nebulæ and suns, $42 \mathrm{I}$

Colonies, Greek, IO2

Columbus, his great project, 160 effect of his discoveries, $\mathrm{I}_{3}$

Cometary origin of the planets, Buffon's idea of, 404

Comets, the terror they once inspired-orbit of, first calculated by Newton, 270

tails, their enormous length, 273

their disintegration into meteoritic swarms, 276

Compass, introduction of, I 58

Comstock, on absorption of light, 395

Congregation of the Index, judgment against Galileo, 196

Conical shadow of the earth, its implications, 9 I

Conservation of energy, establishment of the idea of, 416

Constantinople, the fall of, 158

Constellations, fanciful names of, 99

Constructive impulse, I 8

Coppernican theory, injustice of the name, II4

its truth demonstrated by Galileo, 202

not put forward as a hypothesis, 166

system, perfected by Kepler, I9r

Coppernicus, quotation from, vii, 162

his argument against the revolution of the fixed stars, 102

his life and ideas, 164

proof of littleness of the earth, I I 2

Coral polyps, the changes they have wrought, 464

Cordova, Saracen capital, 154

Corpuscles, rain of, from candescent bodies, 433

enormous speed of, 434
Correlation of forces, a nineteenthcentury discovery, 416

Cosmic structure, Struve and Proctor on, 39I

dust, Arrhenius on, 395

exchange, the, of matter and life, 429

Cosmological letters, Lambert's, 387

Cosmos, likened to a gas, 397

eternity of, 424

Cosmotheoros, a work by Huyghens, 245

Crassus, source of his wealth, I 49

Creation, the increasing mystery of, 398

primitive ideas of, $40 \mathrm{O}$

Critical diameter of minute particles, 434

Crito, speech to Socrates, $45^{8}$

Croll, on stellar collisions, 452

Crusaders burn the Tripoli Library, 154

Curve of development, 36

Cycle of matter, Arrhenius on, $46 \mathrm{r}$

Cyril, Saint, the murder of Hypatia, I 53

DALToN, John, founder of modern chemistry, I 28

Dante, creates Italian poetry, I 59 quotation from Il Paradiso, 304

Dark stars, Stoney on number of, 382

Darwin, age of discovery of natural selection, 406

Decimal system, Hindu origin of, 58 .

Deer, methods of reasoning in, 9

Democritus, of Abdera, inscription to, $\mathrm{v}$

his Diakosmos, Io

his doctrines, 15

his life and ideas, I 3 I

Deneb, its enormous size, 338

Density of the sun and planets, Buffon's calculation, 404 of star spacing, 430

Descartes, his life and work, 216 anticipated by Democritus, I 34 ignorant of Kepler's work, 192 Kant's paraphrase of, 406

Design, in the cosmic order, I6

Diakosmos, chief work of Democritus, I 32

Dialogues, Galileo's, a brilliant work, 205

Dichotomy of the moon, 89 
Diogenes Laertius, list of Democritus' works, 132

Discours del la Methode, a work of Descartes, 217

Discoveries, growth of great, 106

Discovery, era of maritime, I60

Displacement of stellar spectra, 350

Dissipation of energy, Kelvin on, 422

Distance of the stars, Herschel's method of measure, 390

of the planets accurately determined, 232

Dollond, perfects the heliometer, 333

Dominis, Antonio de, his sentence and fate, 206

Double stars, Herschel's observation of, 324

growing knowledge of, $37 \mathrm{I}$

Doubt, Democritus on necessity of, I 34

Draper, History of Intellectual Development, I I

denunciation of Lord Bacon, 2 I 5

Dust, cosmic, Arrhenius on, 395

Dynamics, foundations laid by Galileo, 198

EARTH, speed of in space, 22 doctrine of a round, its antiquity -when introduced, 64

its littleness proved by bisection of the heavens, I I 2

pictured as an animal by Kepler, rgr

probable origin, 26

rate of revolution compared, 317 shadow of, a cone, 67

smoothness of, 4 I

third motion of, Coppernicus' discovery, 167

Ebert, explains perplexing appearances in stellar collisions, $38 \mathrm{I}$

Eclipse of the sun and moon, its implications, 9 I

Eclipses, early predictions, 64

Electricity, ancient ignorance of, I 39

Electro-dynamical theory of gravitation, 448

Elements, new, discovered by spectroscope, 348

Ellipses, Kepler's discovery of planetary motion in, I 87

Ellipticity of the earth's orbit decreasing, 297

Emerson, quotations from, 20, 316
Empedocles, anticipates Darwin, 63 loves and hates among the atoms, I 39

Energy, crudeness of ancient ideas of, I 39

of heat, new science of, 4I 5

supply of from the impact of suns, 452

England, still outside of European civilisation in Newton's day, 262

Ephemeræ, Langley's parable on a race, 463

Epicurus, idea of the sun, 5

borrows his philosophy from Democritus, I 34

his rule of life, 2 I 8

inscription over his garden, 155

life and death of, a work by Gassendi, 222

on chaos, 34

Epicycles, representation of planetary motion, I I 5

Eratosthenes, of Alexandria, his measure of the earth, 73

inconsistency of his ideas, I I 5

on different levels of the Mediterranean, $12 \mathrm{I}$

on distance of the sun, 93

prediction of a new continent, 78

Erman; Paul, quoted, 344

Error, ancient limits of, I 45

Ether, suppositions regarding it incongruous, 455

Euclid, permanence of his doctrines, 9

epigram on mathematics, 57

his geometry still taught, 146

his influence on Galileo, 198

Eudoxus, crystal sphere of the stars, 106

Euergetes, Ptolemy, his armils, 95

Euler, contributions to mathematics, 295

Eumenes, collects a vast library, I 52

Evolution, the scheme of, 12

Bruno's idea on, 182

idea of, how reached-as a world picture, 35

parallel, of other worlds to our own, 363

Explorers, scientific, as poets, 187

Exposition du Systeme du Monde, a work by Laplace, 30 I

FALL of bodies; Aristotle's ideas, I98

Faraday, ideas of matter, I 37

Fatimite Library, at Cairo, I 54 
Faust, quotation from, 38

Ferdinand and Isabella, court of, its enlightenment, 63

Fernel, his measure of the earth, I64

Fez, Saracen capital, I 54

Figure of the earth, established by Newton, 26I

Finality, impossible in human knowledge, 445

Fire, discovery of, 50

First magnitude stars, average distance, 360

FitzGerald, his translations of Omar, 155

Fixity in events, difficulty of recognising, 4

Fleming, Mrs., discovery of new stars, 379

Fluxions, invented by Newton, 255

Fontenelle, on the plurality of worlds, 233

Fools, Galileo on number of, 199

Foot, unit of length, 54

Force, clarifying conceptions of, 242 persistence of, Spencer's phrase, $4 \mathrm{I} 5$

Forefathers, savagery of our, 14

Foster, Sir Michael, quotation of, I 44

Foucault, on wave theory of light, 346

Fourth dimension, is improbable, 9

Foxes, methods of reasoning in, 9

Fraunhofer, perfects the heliometer, 333

maps spectrum lines, 346

Frederick the Great, invites Frenchmen to Berlin, 299

Kant's work dedicated to, 406

Freedom of the will, its denial by Democritus, I4I

Fresnel, wave theory of light, 346

Galileo, Kepler's tribute to, title page

an early Coppernican, 177

and Kepler, neither could make use of each other's work, 207

correspondence with Kepler, 199 estimate of his work, 208

his abjuration, his life and ideas, 197

on distribution of the stars, $28 \mathrm{I}$

on nature's horror of a vacuum, 240

on parallax of sun, 95

to Newton, amazing change of ideas from, 326
Galle, discovers Neptune, 312

Gascoigne, effect of his inventions, 95

invention of micrometer threads, 244

Gases, spectrum of, 346

kinetic theory of, 397

Gassendi, his life and ideas, 219

Gauss, his method of least squares, 308

General Natural History of the Heavens, a work by Kant, 406

Generation, spontaneous, no evidence for, 436

Genius, innateness of, I 85

Geometers, their modes of reasoning, 104

Geometry, antiquity of, 9 analytic, developed by Descartes, 217

rise of, 56

Gerber, on rate of propagation of gravitation, 453

Gibbon, :on Omar Khayyám's calendar, I 55

Gilbert of Colchester, advocate of Coppernican theory, I 76 compared with Lord Bacon, 2 I 5

his ideas on attraction, I90

Gill, Sir David, on distance of Canopus, 360

Gravitation, first ideas of, 23

influence on fauna of planets, 365 investigation of by Royal Society, 247

Kant on universality of, 407

Kepler on, 188

possible rate of propagation, 453

relative strength of, 445

Seeliger on difficulties in law of, 447

the riddle of-Newton on diffculties of conceiving, 449

Gravity, Coppernicus on, I70

Greek science, just misses modern world conception, I 28

Greeks, the legacy of, 145

Gregory the Great, mentioned, 152 Grindstone theory of stellar arrangement, 387

Guericke, Otto von, invents the airpump, 24I

Gunpowder, introduction of, $15^{8}$

HALl, Maxwell, his system of the stars, 396

Halley, on new method of fixing sun's distance, $23 \mathrm{I}$ 
Halley, discovers changes in the position of the stars, 3 I 8

discovers the acceleration of the planets, 294

first prediction of a comet's return, 272

has law of inverse squares, 249

responsible for Newton's Principia, 253

Harmonices Mundi, a work by Kepler, 187

Haroun al-Raschid, his present to Charlemagne, 243

Harpedonapte, early surveyors, 56

Hartley, ideas of mind, 140

Harvey's discovery of circulation, rejected by Bacon, 2 I 4

Heat, memoir by Lavoisier and Laplace, 30 I

development of new science of, 4 I 5

of the sun, mystery of, 416

Heliometer, invention by Savery and Bouguer, 333

Hellenism, a high stage of culture, I 50

Helmholtz, quotation from, 292

idea of conservation of energy, 4 I 6

on extramundane origin of life, 436

theory of sun's heat, 417

Henderson, discovers the parallax of the nearest star, 335

Henri III., creates a special chair for Bruno, I 78

Heraclides of Pontus, his ideas, 102

Hercules, sun moving towards constellation of, 323

Heredity, not evident in the appearance of genius, 293

Heretics, Europe a holocaust under the Inquisition, I64

l'Hermite, calculates the number of the stars, 359

Hero, or Heron, last of the great inventors, 127

Herschel, Sir John, on the anticipated discovery of Neptune, 3 I 2

Herschel, Sir William, discovers Uranus, 305

his humble origin-demonstrates the movement of the stars, 1318

ideas on world formation, 414 method of star gauging, 389 on the nature of the nebulæ, 409
Herschel, Sir William, penetration of his great reflector, 359

Hicetas of Syracuse, his ideas, 103

picture of the earth's motion, 106

Hindus, slight value of their contributions, 157

Hipparchus, method of measuring the sun, 92

failure to adopt Aristarchus' ideas, I 14

his greatness and his limitations, I 24

Hippocrates, his visit to Democritus, 132

History, the farce of, I 2

its slight present value, I $5^{8}$

Hobbes, defence of the new doctrines, 222

d'Holbach, remark to Hume, 298

Homeomerice, or similar parts, Anaxagoras on, 136

Honian, the bookseller, I 55

Hooke, controversies with Newton, 259

devises the escapement for clocks, 244

his anticipations of Newton, 247

Hull and Nichols, demonstrate pressure of light, 433

Humboldt, his Cosmos, Io

on the force of Galileo's discoveries, 204

quotation from his Cosmos, 384

Hume, anticipated by Democritus, I 34

his dinner with atheists, 298

on idea of cause, 462

Huxley, life as molecular mechanics, 36

on the value of Greek science, 145 opinion of Descartes, 2 I 6

Huyghens, perfects the clock, 244

comparative size of stars, 386

rejects Newton's discovery of attraction, 246

Hydro-dynamical theories of gravitation, 455

Hypatia, the murder of, I 53

Hypothesis, meteoritic, as to sun's heat, 4I 7

IBN-JUNIS, application of the pendulum, 243

Idealism, Berkeleyan, as an alternative, 9

its barrenness, 3 I

Illusions of sense, Democritus on, 138 
Indestructibility of matter, taught by Democritus, $13^{8}$

Index, Coppernicus' work placed on the, I I

India, new route to, 79

Inferences, validity of scientific, 9

Infinitude, Lucretius' ideas on, 330 of worlds, Democritus on, I 35

Inhabitable worlds, enormous number of, 362

Inquisition, its capture of Bruno, I 79

endeavours to suppress works of Coppernicus and Kepler, 192

its frightful persecutions, I64

Instauration. Great, quotation from Bacon's work, 2 I6

Interaction of natural forces, a lecture by Helmholtz, 418

Interference, phenomena of, in light, 346

Interregnum, accepted picture of, I 5 I

Inverse squares, law of, nearly reached by Kepler, I90

Invisible, astronomy of, 37 I

Ionian Greeks, their enterprise and culture, I 3 I

Isis, priests of, 68

Isochronism of the pendulum, Galileo's discovery, I98

JACOBI, on ideas of Anaxagoras, I23 Joule, establishes the idea of conservation of energy, 4 I 6

Julian Star, carries Cæsar to the skies, 270

Jupiter, acceleration of motion, 300

"Little world" of, presents an image of the solar systemsatellites of, obey Kepler's laws, 204

moons of, discovered by Galileo, 2OI

KANT, on moral sense of man, 39 criterion of knowledge, 146 founds the nebular hypothesis, 405

on cosmic structure, 387

on matter, 27

Kapila, his philosophic views, 9

Kapteyn, explanation of appearance of new star spectra, 38I

Keeler, on spiral nebulæ, 420

Kelvin, on age of the sun, 4 I 8 on dissipation of energy, 422 origin of life, 436
Kepler, his life and ideas, I 85 computes the distance of the sun, 228

eulogy of Galileo, 209

his great discoveries ignored, 192 his rebuke to Rome, 205

on path of comets, 27 I

quoted on Galileo, title page.

Kinetic theory of gases, 397

Kirchhoff, discovery of absorption spectra, 347

Kirmess, dance of the stars likened to $a, 378$

Knowledge, antiquity of, 9

astronomical, synonym of certitude, 377

LActantius, on globular form of earth, 62

derided by Coppernicus, I69

Lagrange, his co-operation with Laplace, 299

Lambert, acceleration of Saturn's motion, 300

on structure of the universe, 387

Lange, history of materialism, I I

on character of Gassendi, 22 I

Langley, illustration of the sun's heat, 417

parable on the end of the world, 463

Laplace, on early measures of the earth, 77

eulogy of astronomy, 226

his life and work, 296

on Aristarchus, 89

on astronomy of the invisible, 372

sketch of the nebular hypothesis, 410

Laughing Philosopher, Democritus called the, 142

Lavoisier, anticipations of his ideas by Democritus, I 38

memoir on heat, 301

Law, idea of natural, 4 scientific, Kepler a pioneer, I 88

Layard, finds a convex lens in Nineveh, 200

Leaning Tower of Pisa used in Galileo's experiment, 198

Lebedeff, demonstrates pressure of light, 433

Lecky, History of Rationalism, I I

Leibnitz, accusations against Newton, 263

idea of planets as extinct suns, 402

invention of the calculus, 295 
Lens, found in palace of Nimrud, 200

Leonardo da Vinci, his genius, I 59 not a Coppernican, I 77

Leonids, meteoritic swarm, 276

Lesage, of Geneva, his theory of gravitation, 453

Lettres Philosophique sur les Anglais, Voltaire's, 265

Leverrier, calculates the orbit of the November meteors, 277 predicts an extra-Uranian planet, 3 I I

Leviathan, a work by Hobbes, 223

Lewes, quotation from his Aristotle, 239

Libraries, a characteristic of civilisation, 152

Library of Alexandria, its extent, I I I

Royal, of France, founded, 152

Life, brevity of human, compared, 24

cosmic exchange of, 436

human, value of, 464

influence of gravitation on, 366

physical explanation of, 33

probable likeness of, throughout the universe, $44 \mathrm{I}$

Light, composition of, revealed by Newton, 257

factor of extinction of, 395

geometry of, 59

speed of, Bacon's ideas on-

Roemer's discovery of, 283

wave theory of, 346

" Little world, the," of Jupiter an image of the solar system, 204

Llorente, on victims of the Inquisition, 164

Locke, anticipated by Democritus, I 34

Logarithms, unknown to the Greeks, 146

Louis XV., his patronage of science, 230

Lowell, quotations from his Masaccio, 174, I 84

Lucretius, on the size of the sun, 22

on the struggle for existence, 148

quotation from his poem, 330

reports ideas of Democritus, I 37

Luther, his appearance shortly after

Columbus' discovery, I63

on the Coppernican theory, I 77
MACAULAY, laudation of Lord Bacon, 2 I 3

on history, 98

MacFadyen, experiments on life of germs, 439

Machine, cosmos as a, 465

Machinery, its wide influence, I 50

Mädler, on structure of the Milky Way, 392

Magalhaens, expedition of, 356

Magnet, The New Physiology of, a work by Gilbert, I90

Magnitudes, stellar, a classification, 358

Man, primitive, his ideas of the world, 49

size of, compared with the earth, 39

Marco Polo, reports of, I 59

Maria Theresa, remark to Maupertuis, 234

Marriot, and Boyle, on pneumatics, 242

Martha, translation of Lucretius, 330

tribute to Democritus, I 35

Martyrdom, a useless sacrifice, I 82

Mass action, law of, discovered by Newton, 259

of the planets, computed by Newton, 26I

of the solar system, 403

Material of the universe, all the same, 348

Materialism, Democritus as its grandsire, 140

and mechanism, not identical, 220

Mathematics, origin of the word, 52 pay of professors of, 197

Matter, disintegration of, how far it may be carried, I 36

gravitation not an inherent property of, 449

increasing aggregation of, 459

indestructibility of, taught by

Democritus, 138

new ideas on constitution of, 396 the unceasing circulation of, 424

Matterhorn, imaginary being on the, 85

Maupertuis, on shape of nebulæ, 405

reply to Maria Theresa, 234

Max, Gabriel, portrait of primitive man, 49

Maxwell, Clerk, on pressure of light, 433 
Mayer, discovery of conservation of energy, 4I6

Measures of the earth, difference in early, 77

Mécanique Céleste, a work by Laplace, 297

Mechanical appliances, the foundations of modern knowledge, 33 I contrivances, attributed to black art, 415

Mechanics, effect of new discoveries in, 24I

placed on a new footing by Galileo, 200

Mechanism, idea of the world as, first consistently expounded by Descartes, 2 I9

Medical schools, first in Europe, I 54

Mendeléeff, Newtonian scheme of molecular constitution, 397

Mercury, possibly indicates rate of propagation of gravitation, 453 transit of, observed by Gassendi, 221

Meredith, George, quotation from, 444

Merz, History of Nineteenth-Century Thought, I I

Metaphysics, its utter barrenness, 459

Meteoric swarms, extra-mundane origin of, 432

Meteorites, origin of, 434

Meteoritic origin of sun's heat, 416 swarms, their nature and extent, 275

Meteors, identity with comets, 275

Metrodorus, on plurality of worlds, 354

Microbes, conceived as human, 42 discovery of, 33

expulsion of, from the atmosphere, 437

Micro-man, idea of, 40

Micron, unit of measure, 40

Middle Ages, reaction in favour of, I 52

Midnight sun, land of, conjectured, I 47

Milky Way, Democritus' ideas on, I 35

ideas on, 386

structure of, 394

Milton, quotation from Paradise Lost, 280

visits the blind Galileo, 206

Mind, decline of the human, I 5 I
Modern ideas, permanence of, 8

Moestlin, teaches the Coppernican theory, I 76

the teacher of Kepler, 185

Molecules, spacing of, 430

Montaigne, writes on the speech of the people, 178

Moon, first measures of distance of, 87

Morin, mounted telescope on a bar; 244

Mosaic cosmogony destroyed by Galileo, 204

Motes in the sunbeam, suggest idea of atoms, I 37

Motion of the earth, absolute demonstration by Bradley, 288

objections to, 106

Multiple star systems, 376

Mystery, the increasing, of creation, 398

Mysticism of numbers, Kepler's adherence to, 186

NAPOLEON, reproach to Laplace, 298

Nature, religion of, a chimera, I7

the enigma of, 16

Nebulæ, Herschel's catalogues of, 325

origin of, 424

photography of, its revelations, 420

rapid motion of, $44 \mathrm{I}$

worlds in formation in, 30

Nebular hypothesis, history of, 401 nuclei, how formed, $42 \mathrm{I}$

Necessity, doctrine of, affirmed by Democritus, $\mathrm{I}_{42}$

Neptune, discovery of, a triumph of the law of gravitation, 3 I I distance from the earth, 357 its great distance, 28

Nero, precedes St. Augustine, I 5 I

New Astronomy, The, quotation from Professor Langley's, 463

Newcomb, objections to nebular hypothesis, 4I 3

on cosmic structure, 393

on count of the stars, 359

on history of nebular hypothesis, 419

on Lambert's cosmical theory, 388

problem of runaway stars, 445

New Hypothesis of the Universe, a work by Wright of Durham, 386 
New World, discovery of, a sort of laboratory experiment, 160

Newton, Prof. H. A., discovery of nature of meteorites, 275

Newton, Sir Isaac, character of, 258 discoveries, almost anticipated by Kepler, 190

his discoveries and ideas, 253

his process of discovery, 186

law of gravitation discovered, 255

letters to Bentley, 452

on atoms, 34

period of mental eclipse, 263

New star, Galileo's controversy regarding a, 199

New stars, spectroscopic detection of, 379

Nicholas of Cusa, observation of sun-spots, I 81

Nichols and Hull, demonstrate pressure of light, 433

Nietzsche, Fr., quotation from, viii

his " blonde beast," 49

Notations, primitive, 52

Nova Persei, its distance and grandeur, 380

Nova, origin of, 380

Novum Organum, a passage from, 246

Nutation, discovered by Bradley, 288

OBSERVATORY, astronomical, first in Europe, I 54

Olbers, finds new asteroids, 309

Omar Khayyám, his culture and character, I 55

myth of burning of the Alexandrian Library, I I I

Omens, ancient belief in, 4

belief in, 5 I

Opinions of Philosophers, a work attributed to Plutarch, 93

Optiks, quotation from Newton's, 449

Orbits of stars, 350

of double stars, 373

Order, perception of a fixed, 465

Orders in nature, conjectures on their existence, 396

Oscillatorium Horologium, a work by Huyghens, 245

Osiander, his forged preface to Coppernicus, 164

Ostwald, Wilh., on gravitation, 453
Oxford, Bruno's disputations at, I 78

Pacificus, his early clock, 244

Paley, his famous work, 263

Pantheism, Bruno its godfather, I 82

Papyri, number of, in Alexandrian Library, 152

Parallax, first measurements of, 86 of the sun, Galileo's search for, 202

of the sun, problem of, 227

stellar, first discoveries of, 334

Paris, in the thirteenth century, I 52

Parliament of Paris, its extraordinary decree, 220

Parthenon, golden image in, 69

Pascal, development of the barometer, 24I

fright before the infinite, 30

Pasteur, on spontaneous generation, 436

Pattern of worlds, probably not very diverse, 364

Pendulum, isochronism, discovery by Galileo, 198

Pentateuch, the, as a cosmogony, Io

Period, of double stars, 374

Persecution, religious, enormous number of its victims, 164

Petrarch, an evangel of the Renaissance, I 59

Philoläus, of Crotona, his ideas, IO3

Philosophy, its worthlessness, I 5

Physical sciences, little developed among the ancients, 148

Physics, cosmic, a new study, 349

Piazzi, discovery of the first asteroid, 307

Picard, new measures of the earth, 256

Pickering, discovery of spectroscopic binaries, 374

on distribution of the stars, 394

Pivot of the sky, Polaris, IOI

Planet, Kepler's hypothetical, 307

Planetarium, Archimedes' construc. tion of the, 116

Planetary motion, Kepler's laws of, I 88

system, shape and arrangement of, 314 
Planets, how fertilised with life, 7 motion of, difficult to map, 385 motor force of, 208

orbits of, first correctly arranged

by Coppernicus, 167

possible exchange of, 43 I

regarded as wandering stars, 27

Plato, and Aristotle, their credulity, I 45

his adherence to a fixed earth, $\mathrm{IO} 2$

inscription on his Academy, 57

on numbers, 52

on the Greeks, 98

quotation from his Crito, 458

wished to burn works of Democritus, I 34

Pliny, his Natural History, Io

on weather forecasting, I49

story of Democritus' power to raise the dead, I 32

Pluralite des Mondes, a work by Fontenelle, 386

Plurality of worlds, taught by Bruno, I 80

Plutarch, on cessation of rotary force, 123

Plutocracy, always a dominant power, I 49

Polaris, a double star, 375

Polemic, Gassendi as a model of, 222

Pole Star, distance from the earth, 357

Pons asinorum of intellectual development, 5

Pope, his epigram on Newton, 264

Populace, the mind of, 150

Porta, Della, on force of steam, 243

Poseidonius, failure to accept Aristarchus' ideas, I 6

measure of the earth, 76

on distance and diameter of the sun and moon, 94

on the tides, 122

Precession of the equinoxes, cause of, 167

Preston, S. Tolver, on Lesage's theory of gravitation, 454

Prévost, fixes direction of the sun's motion, 322

Priesthood, Egyptian, their learning, 56

Principia, Newton's, generally rejected by his contemporaries, 265
Principia, of Descartes, its profound influence, 239

of Newton, its origin and contents, 253

quotations from Newton's, 449

Printing-press, effect of its introduction, I 75

Proctor, on cosmic structure, 391

Procyon, companion sun of, 372 .

Proportion, development of idea of, 55

Protagoras, first of the atheists, I4 I

Protyl, 34

Psalm, quotation from $52 \mathrm{nd}, 400$

Ptolemaic system, Schiaparelli on, 165

Ptolemies, court of, no Columbus at, 80

found the Alexandrian Library, I 52

the, Greek kings, 57

Ptolemy, C., measure of the earth, 79

on measure of the sun, 92

on parallax of the moon, 87

Publishing, rapid growth of, in the fifteenth century, I75

Pulsilogy, an invention of Galileo's, 198

Pyramids, how measured, 55

Pythagoras, sacrifices a hecatomb in honour of his discovery, 57

taught revolution of the earth, IO2

QUERIES, quotation from one of Newton's, 45 I

RAMSAY, Sir William, on formation of matter, 435

Ranke, estimate of the number of victims of religious persecution, I64

Rationalism, its slight influence, I 50

Reflecting telescope, invented by Newton, 257

Reformation, early attempts before Luther, I 76

follows discovery of America, 163 the, might have been anticipated, I 57

Refraction, Ptolemy on, 200

Religion in the Middle Ages, 156

rational, first taught by Bruno, I 82 
Renaissance, the problem of, I 58

Renan, on curiosity, 5 quotation from Dialogues Philosophiques, $2 \mathrm{I} 2$

Revelation, quotation from Book of, 48

Revolution of the earth, difficulty of conceiving, $\mathrm{IO}_{3}$

Revolutionibus, De, Coppernicus' work, analysed, I64

Rheticus, disciple of Coppernicus, I76

Richelieu, Cardinal, procures an extraordinary decree from the Parliament at Paris, 220

Riehl, on Bruno, 18I

Rigel, its enormous size, 338

Roemer, discovers the speed of light, 284

Roman civilisation, exhaustion of, 15 I

Rome, its age of culture, I46

Rosenberger, account of Newton's discoveries, 257

Rosse, Lord, observations on spiral nebulæ, 420

Rotation of the sun affirmed by Bruno, I $8 \mathrm{I}$

Royal Society, its origin, 247

Rubens, his picture in the Louvre, 378

Rumford, on nature of heat, 4 I 5

"Run-away" star, 1830 Groombridge, 340

stars, Newcomb's problem of, 446

SaKya-Muni, mentioned, I 55

Salons, French, patronised by men of science, 233

Samarcand, Saracen capital, I 54

Sanctorius, invention of a pendulum clock, 244

Saracens, their great libraries, I 53

Saturn's rings, a picture of world formation, 408

demonstrated by Huyghens, 245

Savery, invention of the heliometer, 333

Scepticism, need of scientific, 462

Schiaparelli, on Ptolemaic and Coppernican systems, I65 on theory of epicycles, II 5

Schonberg, Cardinal, letter to Coppernicus, I 76

Science, ancient, sparseness of discovery in, 127

civilisation as the work of, 6
Science, value of Greek, I46

Sea, general level of, I 2 I

Sebastian d'Elcano, first circumnavigation of the earth, 356

See, T. J. J., Evolution of Stellar Systems, 43I

Seeliger, on distribution of the stars, 393

on the infinity of the universe, 447

Seleucus of Babylon, follower of Aristarchus, II 4

Seneca, inscription in Epicurus' garden, 155

Sensation, Democritus' ideas on, I 34

Serapis, library in the temple of, 152

Sexagesimal system, 53

Shakespeare, appropriates Bruno's comedies, 178

Shattered planet, theory of, 309

Shelley, his Hellas quoted, 428

Shooting-stars, degenerated comets, 275

Simplicius, ideas of attraction, I 24 on grandeur of the stars, 148

Sirian traveller, viewing the earth, 44

Sirius, distance from the earth, 357

its dark companion, 372

size of, 337

Sizzi, on Galileo's discoveries, 203

Skies, fascination of Mediterranean, 99

Slavery, in ancient society, 50

in England, lateness of, I4

Slaves, first men of science, 5 I

Socrates, contempt of astronomy, I 35

idea of the earth, 5

speech of Crito to, 458

Solar history, stages of, 424

Solar system, dimensions of the, 305

ideas on origin of, 402

motion of, 318

stability of, 446

Solomon, believed in a flat earth, 5 Somerset, Lord, his early steamengine, 243

Somnium Astronomicum, a work by Kepler, 245

Sorbonne, Bruno's letter to the, I 79

Space, demonstration that it is practically empty, 242 
Space, not so empty as was supposed, 395

Spacing of the planets, Bode's law, 306

Spectroscope, revelations of, 345

Spectroscopic binaries, discovery of, 374

Spectrum, named by Newton, 345

Speed of the sun's translatory motion, 323

Spencer, his doctrine compared to that of Democritus, I 40

on registered experience, 9

value of his philosophy, I 5

Sphericity of the earth, early arguments for, 63

Spinoza, Bruno his godfather, I 82

Spiral nebulæ, Lord Rosse's observations, 420

Spores, size and nature of, 437

Stability, of binary systems, 377

of the solar system, 293, 446

Stadia, varying lengths of, 77

Stadium, unit of distance, 54

Star gauging, Herschel's method of, 389

history, three stages of, 424

light, l'Hermite's calculation of, $36 \mathrm{I}$

streams, Proctor on, 392

Starry universe, extent of, 36 I

Stars, average distance of first magnitude, 360

nearest, their distance, 29

outside limit of number, 359

radial velocity of, 349

spectrum characteristics of, 349 speed of the, 340

Stellar system, possible loss of stars from, 447

Stoney, on number of dark stars, 382

Strabo, prediction of a new continent, 78

ridicules Eratosthenes' ideas-his notions of gravity, I 2 I

Structure of the heavens, a work by Herschel, 406

of the universe, theories of, 385

Struve, on cosmic structure, 39 I parallax of Vega, 335

Sun, absolute distance of, 23 I age of, 4 I 8

calculations as to visual diameter of, 147

comparative grandeur of, 337
Sun, evidently distant and large, 67 first measure of its distance, 89

fixity of, first imagined, 104

its position in space, 362

its shifting position, 65

Kepler likens to a great magnet, I90

mediocrity of our, 339

movement of translation, 320

origin of its heat, 416

spectrum of, 347

volume of the, 234

Sunlight, pressure of, 433

rays of, parallel, 59

Suns, collision of, is incessant, 378

Sun's motion in space, path of the, 323

Sun-spots, Galileo's demonstration of, 204

Super-men, Democritus' idea of, I4I

Swift, fanciful tale, 40

System of the universe, Lambert's, 387

solar, how it would look from the outside, 27

TAINE, on English slaves, I 2

on truth, I 88

Telescope, first described by Roger Bacon-history of its discovery, 200

penetration of Herschel's great reflecting, 359

Telescopes, colossal, of Auzout and others-accuracy of modern, $28 \mathrm{I}$

Tennyson, quotation from In Memoriam, 25, 428

Tetrad, grand, 52

Thales, measure of the Great Pyramid, 55

quotations from, 84

Theophilus, Bishop, destroys Alexandrian Library, I 53

Theory of the Earth, a work by Buffon, 402

Thermo-dynamics, founded by Carnot, 415

Thermoscope, Galileo's invention, 243

Thompson, Benjamin (see Count Rumford), 4I 5

Thomson, J. J., on constitution of matter, 396

Thomson, Sir Wm. (see Lord Kelvin), 4 I 8 


\section{INDEX}

Three bodies, problem of, 296

Tides, early observations of, 123

Kepler on, 189

Galileo on, I 89

theory of, established by Newton, 262

Time, ancient lack of an accurate measure of, 126

Torquemada, the number of his victims, I 64

Torricelli, discovery of the barometer, 240

Toscanelli, encourages Columbus, I60

ideas of, 79

Tourbillons, or vortices, imagined by Descartes, 219

Trigonometry, its late development, I 46

Triple star systems, 376

Tripoli, its library burnt, I 54

Twentieth century, attains to a true cosmic picture, 7

Tycho Brahé, famous star of, 379

his observations utilised by Kepler, 186

objections to Coppernican idea, 28

on origin of comets, $27 \mathrm{I}$

Tyndall, his conception of materialism, 140

littleness and greatness of man, 39

Types of stellar arrangement, 376

ULPIAN library, in Rome, I 53

Uniformity, remarkable, of planetary motions, 403

Universe, as a flower garden,

Herschel's idea of, 4 10

as a cyclic process, 7

binding force of, 445

end of, 459

extent of, Coppernicus' ideas of, I 66

Newcomb on limits of, 359

pictured as a gas, 429

Unthinkables, Democritus' choice of, I 37

Uranus, discovered by Herschel, 305

Urban VIII., inscription on his brother's tomb, I59

Urstoff, 34

Usher, Archbishop, date of creation, 24
VACUUM, limits of, obtainable, 429 nature's horror of, 240

Vanini, torture and fate, 206

Vaucanson, marvels of mechanics, 4 I 5

Vendelinus, estimate of the distance of the sun, 229

Venus, distance from the earth, 356

phases of, discovered by Galileo, 202

transit of, first observed by Horrox, 222

Velocity, surface, of the earth, 317

Vinci. See Leonardo da Vinci

Virgil, quoted, I05

Virginia Reel, cosmos likened to a, $43 \mathrm{I}$

Vives, Ludovicus, quotation, 72

Viviani, carries out Torricelli's experiment, 240

Vogel, discovery of spectroscopic binaries, 374

Voltaire, a sincere deist, 298

his ironical inquiry, 435

introduces Newton to France, 264

tale of Micromegas, 44

Vortex ring theory, 219

Vortices, the foundation of Descartes' system, 219

Voyages, extent of ancient, 355

WALLIS, his treatise on gravity, 254

Washington, George, mentioned, I 49

Weather predictions of Democritus, I 35

Wheel, bacillus on the, 39

Whewell, his History of Science, ro

Williams, on methods of animal reasoning, 9

Wittenberg, the Athens of Germany, I 79

Wollaston, maps, spectrum lines, 346

Wordsworth, his "Mutability" quoted, 400

World formation, a mechanical process, 7

image, difficulty of constructing a, 3

Worlds, the birth and death of, 401

Wren, Sir Christopher, law of inverse squares, 298 
Wright of Durham, author of the Grindstone Theory, 386

XERXES, entertained at Abdera, I 3 I Ximenes, Cardinal, destroys valuable manuscripts, I 54

YEAR, early measures of, 53

Young, Dr. Thomas, on interference, 346
Young, Prof. C. A., on strength of gravitation, 445

ZENOPHANES, early ideas of geology, I 48

Zero, introduction of, 58

Zodiac, circle of the animals, 104

Zone of no shadow around Syene, 59

Zones, first conceptions of, IOI

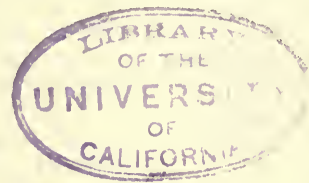

THE END

Printed by Ballantyne, Hanson \& Co.

Edinburgh \& London 





\section{RETURN TO: CIRCULATION DEPARTMENT}

\section{Main Stacks}

\begin{tabular}{cc|l|l}
\hline $\begin{array}{c}\text { LOAN PERIOD } \\
\text { Home Use }\end{array}$ & 1 & 2 & 3 \\
\hline & 4 & 5 & 6 \\
& & \\
\hline
\end{tabular}

\section{ALL BOOKS MAY BE RECALLED AFTER 7 DAYS.}

Renewals and Recharges may be made 4 days prior to the due date. Books may be renewed by calling 642-3405.

\section{DUE AS STAMPED BELOW.}

\begin{tabular}{l|l|l}
\hline FEB 1:0 2004 & \\
\hline & & \\
\hline & & \\
\hline & & \\
\hline & & \\
\hline & & \\
\hline & & \\
\hline
\end{tabular}


YO 22751

179769

$\begin{array}{ll}Q 125 \\ & 97\end{array}$

UNIVERSITY OF CALIFORNIA LIBRARY 
1II!

24

58

ins. 